\title{
ADVANCED COAL LIQUEFACTION RESEARCH AND DEVELOPMENT FACILITY Wilsonville, Alabama
}

Technical Progress Report

Run 260 with Black Thunder Mine Subbituminous Coal

January 1992

Work Performed Under Contract No. AC22-90PC90033

For

U.S. Department of Energy

Pittsburgh Energy Technology Center

Pittsburgh, Pennsylvania

and

Electric Power Research Institute

Palo Alto, California

By

Southern Electric International, Inc.

Wilsonville, Alabama

and

Southern Company Services, Inc.

Birmingham, Alabama 


\section{DISCLAIMER}

This report was prepared as an account of work sponsored by an agency of the United States Government. Neither the United States Government nor any agency thereof, nor any of their employees, makes any warranty, express or implied, or assumes any legal liability or responsibility for the accuracy, completeness, or usefulness of any information, apparatus, product, or process disclosed, or represents that its use would not infringe privately owned rights. Reference herein to any specific commercial product, process, or service by trade name, trademark, manufacturer, or otherwise does not necessarily constitute or imply its endorsernent, recommendation, or favoring by the United States Government or any agency thereof. The views and opinions of authors ex. pressed herein do not necessarily state or reflect those of the United States Government or any agency thereof.

This report has been reproduced directly from the best available copy.

Available to DOE and DOE contractors from the Office of Scientific and Technical Information, P.O. Box 62, Oak Ridge, TN 37831; prices available from (615)576-8401,

Available to the public from the National Technical Information Service, U.S. Department of Commerce, 5285 Port Royal Rd., Springfield, VA 22161. 


\author{
ADVANCED COAL LIQUEFACTION \\ RESEARCH AND DEVELOPMENT FACILITY \\ Wilsonville, Alabama
}

\begin{abstract}
TECHNICAL PROGRESS REPORT
Run 260 with Black Thunder Mine Subbituminous coal Published: January 1992
\end{abstract}

\author{
Prepared by \\ SOUTHERN ELECTRIC INTERNATIONAL, INC. \\ Wilsonville, Alabama 35186 \\ subcontractor to \\ SOUTHERN COMPANY SERVICES, INC. \\ Birmingham, Alabama 35202 \\ Contract No. 43850
}

Prepared for

THE UNITED STATES DEPARTMENT OF ENERGY

Contract NO. DE-AC22-90PC90033

and

ELECTRIC POWER RESEARCH INSTITUTE

Palo Alto, California 94303

Contract No. RP1234-1-2 


\section{PREFACE}

Operation of the Advanced Coal Liquefaction $R \& D$ Facility at the clean Coal Research Center in Wilsonville, Alabama, is funded by the U. S. Department of Energy (DOE), the Electric Power Research Institute (EPRI), and Amoco Corporation. Southern Company Services, Inc. (SCS) manages the wilsonville program on behalf of DOE, EPIRI and AmOCO.

The Wilsonville R \& D Facilit $\ddot{y}$ combines two process units: a Close-Coupled Reactors (CCR) unit and a Residuum Oil Supercritical Extraction-Solilis Rejection (ROSE-SR ${ }^{S M}$ ) unit. The CCR unit uses H-Oil technolocy, developed by Hydrocarbon Research, Inc. (HRI) and was constructed and modified by Catalytic, Inc. to allow close-coupled operation. The modification primarily consisted of adding a second reactor in close proximity to a pre-existing reactor. These close-coupled reactors can be used for both thermal/catalytic and catalytic/catalytic modes of operation. The ROSE-SR ${ }^{S M}$ unit uses a proprietary solid-liquid separation process developed by the Kerr-McGee Corporation. The process separates ash and unconverted coal (UC) from resid as a heavy fluid phase, termed solid product, using a deashing solvent near its critical point. The combined two-unit system is generally known as a Two-stage Liquefaction (TSL) process.

The TSL process is an advanced coal liquefaction concept, where the severities in the first and second stage can be independently varied, allowing for improvement in product slate flexibility. During Run 260 emphasis was placed on reducing solids buildup in a low-rank coal liquefaction. 
1.

2 .

$2 \cdot 1$

2.2

3.

$3 \cdot 1$

3.2

3.2 .1

TSI system stability

Feed Coal.

Conclusions...

Recommendations.

OPERATING DATA AND PROCESS PERFORMANCE.

slurry preparation

3.3

Closed-Coupled

4.

5.
$3.3 \cdot 1$

3.3 .2

$3 \cdot 3 \cdot 3$

3.4

4.1

4.2

5.1

5.2

$5 \cdot 2 \cdot 1$

5.2 .2

$5 \cdot 3$

Run 260 Catalyst Activity And Thermal

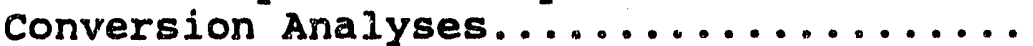

$5.3 \cdot 1$

5.3 .2

$5 \cdot 3 \cdot 3$

Unit operations

Solids Buildup.

Process Performance.

Residuum Oil Supercritical Extraction -

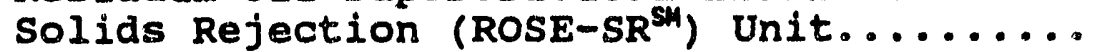

3.4 .1

Unit Operations and Process Performance

Distillation System.

OVERALL TWO-STAGE LIQUEFACTION YIELDS.

TSL Performance..................... 38

Process Solvent Quality and Hydrogenation... 40

CATALYST

Catalyst sulfiding procedure.

Analytical Results

and

Catalyst size and Recovery...........

Catalyst Elemental Analysis and

Naphthalene Activity.

34

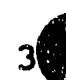

38

38
40

43

43

44

45

Overall Two-Stage Conversion Activity..

First Stage Conversion Activity....... 52

Second stage Conversion Activity...... 55

5.4

Catalyst Requirement and Performance Comparisons.

5.5 


\section{TABLE OF CONTENTS (continued)}

\section{Bection}

page

6.

DISTILLATE PRODUCT QUALITY AND UNIT SOLVENTS.... 62

$6.1 \quad$ Product Quality.................... 62

6.1.1 Blending and Process streams........ 62

$6.1 .2 \quad$ summary...................... 64

6.2 Unit solvents.................... 64

$6.2 .1 \quad$ CCR Unit Recycle Solvent...........664

6.2 .2 ROSE-SR ${ }^{S / 4}$ Unit Deashing Solvent....... 64

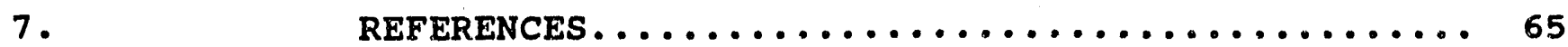

APPENDIX A - Nomenclature and Definitions...... 66

APPENDIX B - Material Balance Methodology....... 70

B.1 - Elemental Balancing Yields..... 70

B.2 - Material Balance Methodology.... 70

B.3 - Material. Balance Data Selection Criteria.......... 71

APPENDIX C - Microautoclave Activity Test

Descriptions.............. 72

c.1 - solvent Quality............... 72

C.2 - Catalyst Activity........... 72 
A. Summary of Runs Since $242 \ldots \ldots \ldots \ldots \ldots \ldots \ldots \ldots \ldots \ldots$

B. Summary of operating conditions and overall TSL Yields

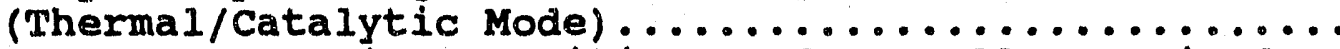

c. Summary of operating Conditions and overall TSL Yields

(Catalytic/Thermal Mode)..................... 10

D. Percentage of Pyridine Insolubles and Cresol Insolubles.

E. First Stage Coal Conversion Using $C I$ and PI...........

F. Cut points and overlaps in Each Period...............

G. Solvent Quality.............................

1. Typical Properties of Black Thunder Coal in Run 260....

2. Recycle Process Solvent Analytical Data..............

3. Post Run 260 Pluggage Samples.....................

4. Mineral Analysis of Solid Deposits.................

5. TSL Yields Before Elemental Balancing (Phase 2 Data)....

6. Close-Coupled Reactors operating Data..............

7. Process Conditions and TSL System Yields (Phase 2 Data).

8. Summary of ROSE-SR ${ }^{S M}$ Performance Parameters............

9. ROSE-SR Analytical Data......................

10. T102 Operating Conditions.....................

11. Analytical Data for the Interstage stream.............

12. Analytical Data of Streams Used in the Elemental

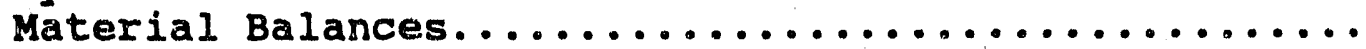

13. R1236 Catalyst Age and Analytical Data..............

14. Metal Analysis of Shell 324 Catalyst (Wt \& Metal Oxides)

15. TSL System Responses in Resid + UC Conversion and Excess Resid Run 260 with Black Thunder Coal,

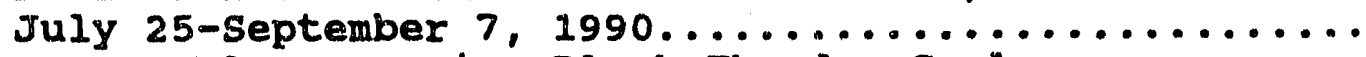

16. Run 260 Coal Conversion Black Thunder Coal,

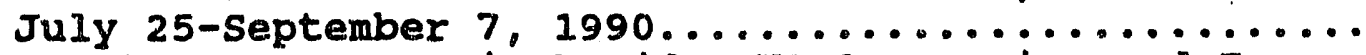

17. TSL System Responses in Resid + UC Conversion and Excess Resid Run 260 with Black Thunder Coal,

September $2 \%$-November $13,1990 \ldots \ldots \ldots \ldots \ldots \ldots \ldots \ldots$

18. Run 260 Coal Conversion Black Thunder Coal, Septer Ler 27 -November $13,1990 \ldots \ldots \ldots \ldots \ldots \ldots \ldots \ldots$

19. TSL System Responses in Resid + UC Conversion and Excess Resia Run 260 with Black Thunder Coal,

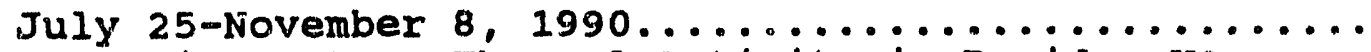

20. Run 260 First stage Thermal Activity in Resid + UC Conversion Black Thunder Coal,

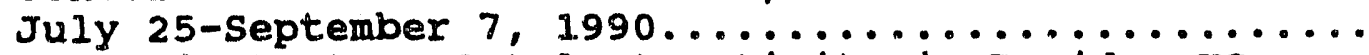

21. Run 260 First stage Catalyst activity in Resid + UC Conversion Shell 324 1/16", Black Thunder Coal Steady-state operation: September 27-

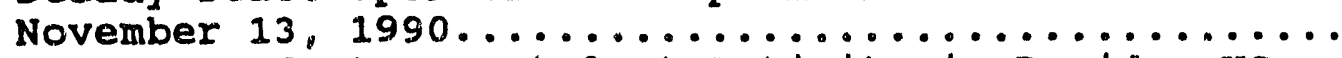

22. Run 260 Second stage Catalyst Activity in Resid + UC Conversion Sheli 324 1/16", Black Thunder Coal Batch Deactivation: July 25-August 3, 1990.......

23. Run 260 second stage Thermal Activity in Resid + UC Conversion Black Thunder Coal, September 7-

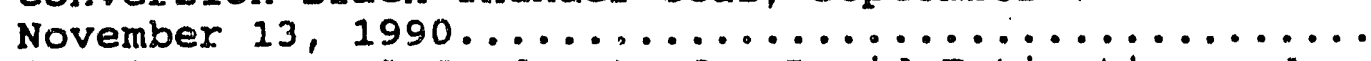

24. Projection of Coal Feed Rate for Resid Extinction and Calculation of steady-state Catalyst Replacement..... 


\section{LIBT OF TABLEB (continued)}

No.

Tables

Pacre

25. TSL Process Performance summary................... 108

26. Experimental and Model Predicted Coal Feed Rate

27. Percentages of Process streams Used to Prepare Product

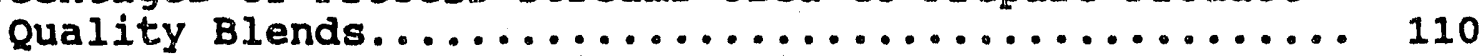

28. Properties of 260 Total oil Blends................. 111

29. Properties of Naphtha (IBP-350 $0^{\circ}$ ) ................ 112

30. Properties of Middle Distillate $\left(350-450^{\circ} \mathrm{F}\right) \ldots \ldots \ldots \ldots \ldots 113$

31. Properties of Middle Distillate $\left(450-650^{\circ} \mathrm{F}\right) \ldots \ldots \ldots \ldots \ldots 114$

32. Properties of Gas 011 (650 $\mathrm{F}-\mathrm{EP}) \ldots \ldots \ldots \ldots \ldots \ldots \ldots \ldots \ldots \ldots$

33. Phase 3-4 Criteria Unit and TSL Elemental Closure Errors

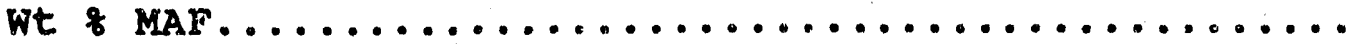


1. Simplified Flow Diagram of the Close-Coupled ITSL Coal

Liquefaction system with Interstage separation.......

2. Liquefaction Modes Tested since Run $242 \ldots \ldots \ldots \ldots \ldots \ldots$

3. Flow Diagram of Coal Slurry Preparation System........

4. H-Oil Ebullated Bed Reactor....................

5. Flow Diagram of the Residuum oil supercritical

Extraction - solids Rejection Unit.............. 121

6. Coal Conversion by Forced Ash Balance...............

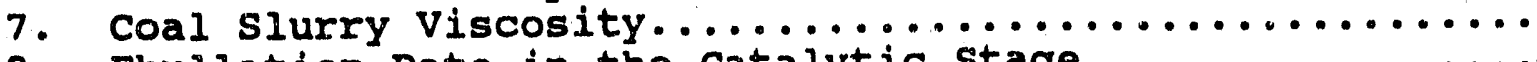

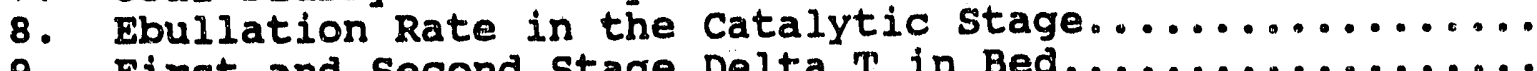

123

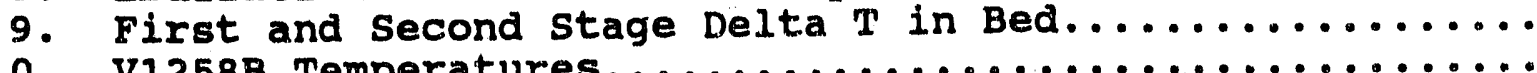

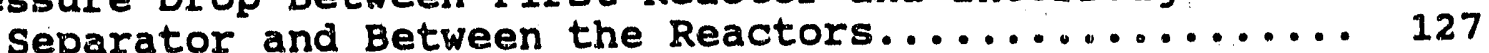

13. Location of solid Deposit Samples.................

R1235 overhead Resid Concentration...............

15 .

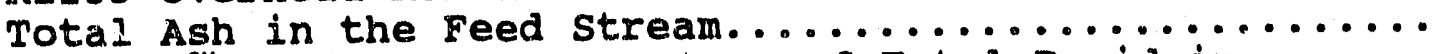

16.

ROSE-SR ${ }^{\text {SA }}$ Resid as a Percentage of Total Resid in

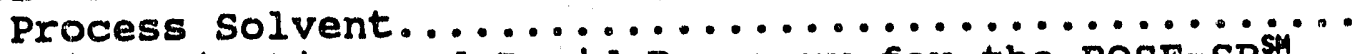

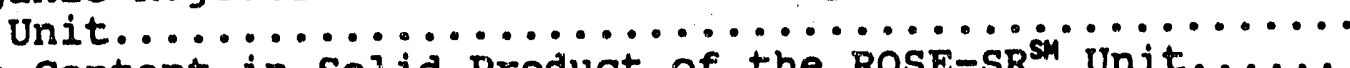
Ash Content in Solid Product of the ROSE-sR Unit......
sulfur content int he Bottoms Product and Resid Product

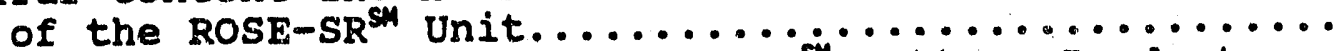

20 . organic-Free sulfur in the ROSE-SR Bottoms product....

Nitrogen Content in the Bottoms Product and Resid

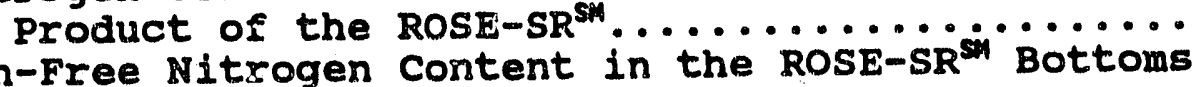

22.

Ash-Free $\mathrm{N}$
Product

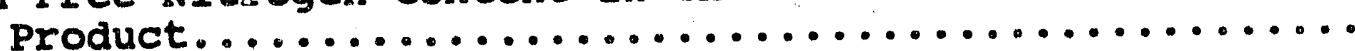

T102 Vacuum Column overlap Between overheads and Bottoms

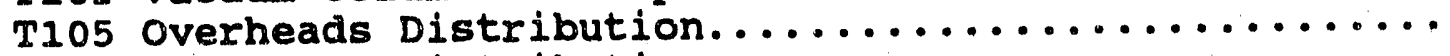

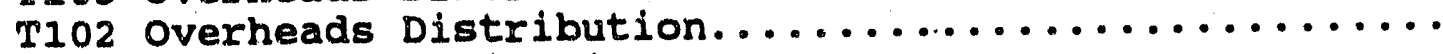

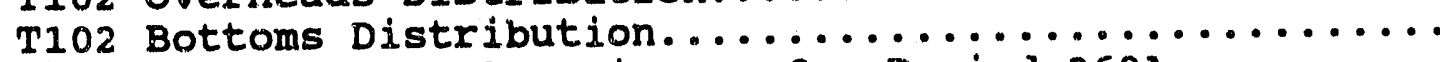

Material Balance Flow Diagram for Period 260A.........

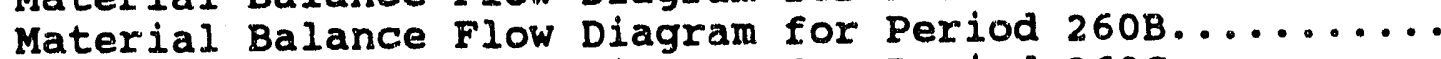

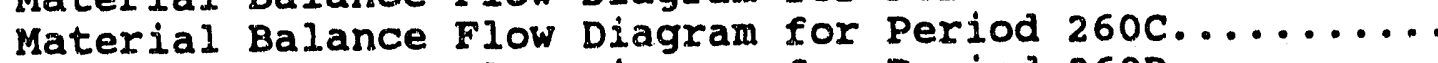

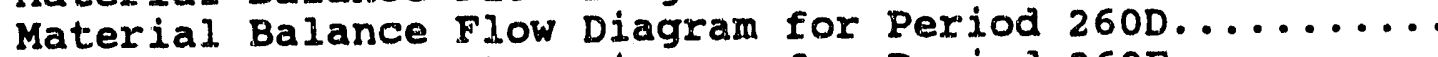

Material Balance Flow Diagram for Period 260E..........

Material Balance Flow Diagram for Period 260F..........

Hydrogen Content in the Process solvent and Interstage

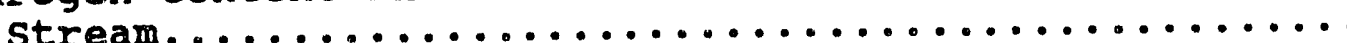

Hydrogen Content in the Distiliate and Resid Products

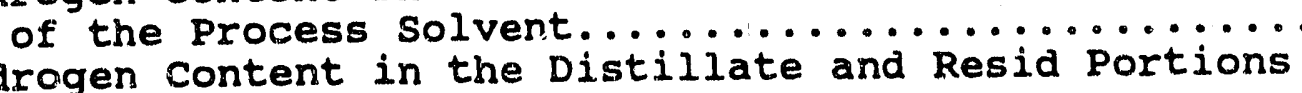

36. Hydrogen Content in the Distillate and Resid Portions

37. Comparison of Resid Hydrogen in the Process solvent and

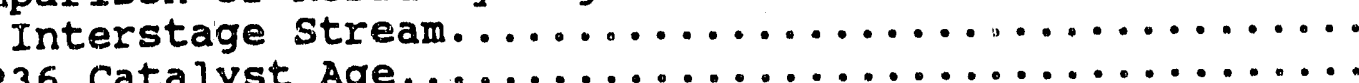

38. R1236 Catalyst Age...... THF Extracted Carbon and sulfur Deposits on Ri236 
40. THF Extracted Hydrogen and Nitrogen Deposits on R1236

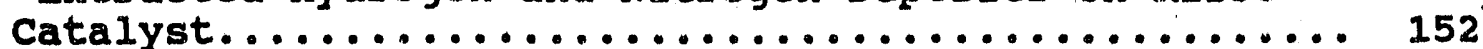

41. Carbon to Hydrogen Atomic Ratio on R1236 Catalyst.......

42. Naphthalene Activity of R1236 Catalyst..............

43. Trend Data of Overall Two-Stage Excess Resid Yield With Common organic Rejection (260A-C in

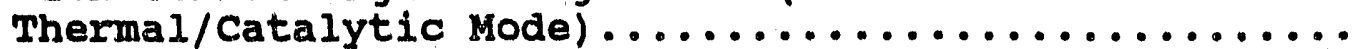

44. Trend Data of Overall Two-stage Resid + UC Conversion (260A-C in Thermal/Catalytic Mode) - Adjusted........

45. Trend Data of Overall Two-stage Resid + UC Conversion (260A-C in Thermal/Catalytic Mode) - Not Adjusted....

46. Trend Data of Overall Two-stage Excess Resid Yield With Common organic Rejection (260D-F in Catalytic/Thermal Mode).......................

47. Trend Data of First and Second Stage Coal Conversions

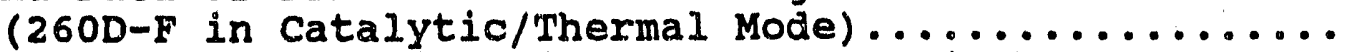

48. Trend Data of Organic Rejection (260D-F in

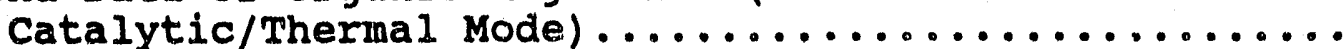

49. Trend Data of Overall Two-stage Pasid + UC Conversion (260D-F in Catalytic/Thermal Mode) - Adjusted........

50. Trend Data of overall Two-stage Resid + UC Conversion (260D-F in Catalytic/Thermal Mode) - Second stage by Difference............................

51. First Stage Thermal and Second stage Catalytic Conversion Activity Trend (260A-C in Thermal/Catalytic Mode) - Adjusted..............

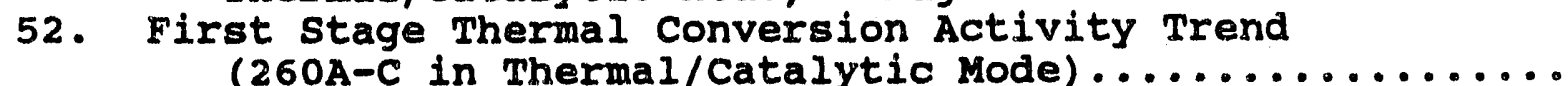

53. First Stage Arrhenius Plot for Thermal Activation Energy (260BC in Thermal/Catalytic Mode)...........

54. First Stage Thermal Activation Energy Comparison

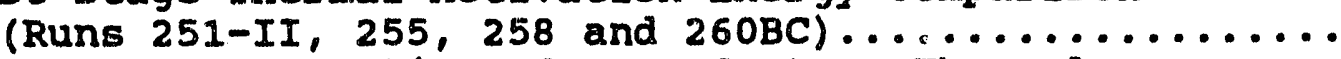

55. First stage catalytic and second stage Thermal Conversion Activity Trend (260D-F in (Catalytic/Thermal Mode) - Adjusted...............

56. First Stage Arrhenius Plot for Catalytic Activation

Energy (260D-F in Catalytic/Thermal Mode) - MB Periods
57. First Stage Arrhenius Plot for Catalytic Activation Energy (260D-F in Catalytic/Thermal Mode) -

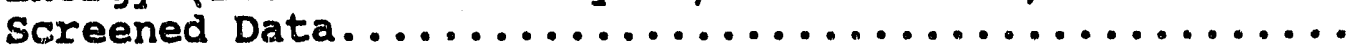

58. Second Stage Catalytic Conversion Activity Trend (260A-C

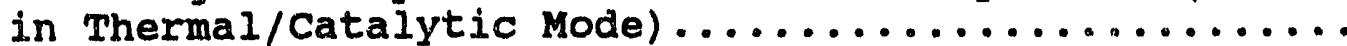

59. Second Stage Arrhenius Plot for Thermal Activation Energy (260D-F in Catalytic/Thermal Mode)-MB Periods.

60. Second Stage Arrhenius Plot for Thermal Activation
Energy (260D-F in Catalytic/Thermal Mode) -

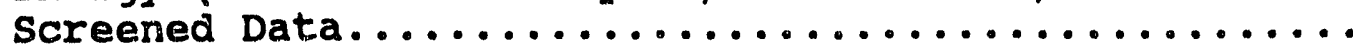

61. First Stage Temperature Effect Based on Projections by Using CSTR First Order Resid + UC Conversion Model (260B vs 260C) - Space Velocity Unit:

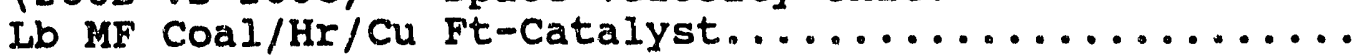




\section{IIBT OF FIGUREg (continued)}

No.

Iitles

Page

62. Projection Using CSTR First order Resid + UC Conversion Model (260B) - Space Velocity Unit:

Lb MF Coal/Hr/Cu Ft-Catalyst...................

63. Projection Using CSTR First order Resid + UC Conversion Model (260C) - Space Velocity Unit:

Lb MF Coal/Hr/Cu Ft-Catalyst....................

64. First Stage Temperature Effect Based on Projection By Using CSTR First order Resid + UC Conversion Model (260B vs 260C) - Space Velocity Unit:

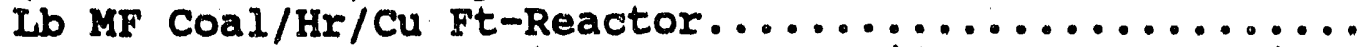

65. Projection Using CSTR First Order Resid + UC Conversion Model (260B) - Space Velocity Unit:

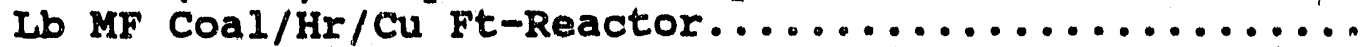

66. Projection Using CSTR First order Resid + UC Conversion Model (260c) - Space Velocity Unit:

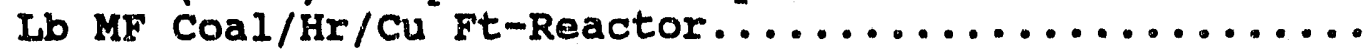

67. Parity Plot of Experimental Vs Predicted $c_{4}+$ Distillate

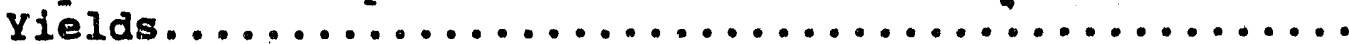

68. Parity Plot of Experimental Vs Predicted Coal Feed Rates

69. Overall Two-stage Resid + UC Conversion Comparison of Thermal/Catalytic Vs Catalytic/Thermal

(260C Vs 260D-F) - Space Velocity Unit:

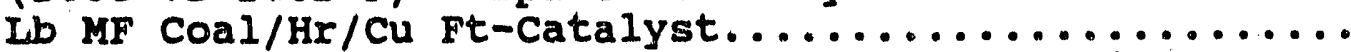

180

70. Overall Two-stage Resid + UC Conversion Comparison (Runs 260, 251-II and 251-III) - Space Velocity Unit:

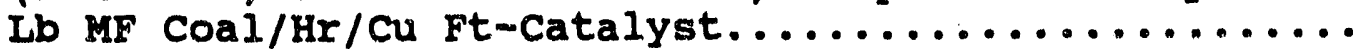

71. $C_{4}+$ Distillate Yield Comparison (Runs 260, 251-II and 251-III) - Space Velocity Unit: Lb MF Coal/Hr/Cu

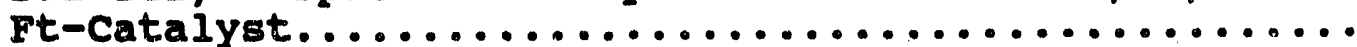

72. Overall Two-stage Resid + UC Conversion Comparison of Thermal/Catalytic Vs Catalytic/Thermal (260C Vs 260D-F) - Space Velocity Unit: Lb MF Coal/Hr/Cu

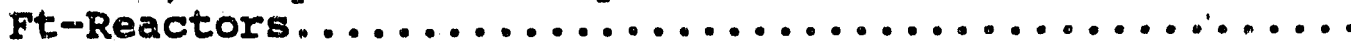

73. Overall Two-Stage Resid + UC Conversion Comparison
(Run $260,251-I I$ and $251-I I I)$ - Space Velocity Unit
Lb MF Coal/Hr/Cu Ft-Reactors......................

73. Overall Two-Stage Resid + UC Conversion Comparison
(Run 260, 251-II and 251-III) - Space Velocity Unit:
Lb MF Coal/Hr/Cu Ft-Reactors............................

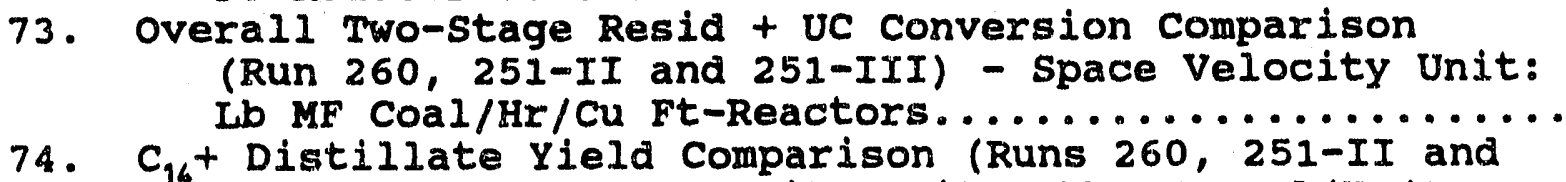
251-III) - Space velocity Unit: Lb MF Coal/Hr/Cu

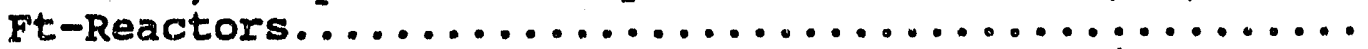

75. Overall Two-stage Resid + UC Conversion Comparison (Runs 260, 258, 255 and 251-II) - Space Velocity Unit:

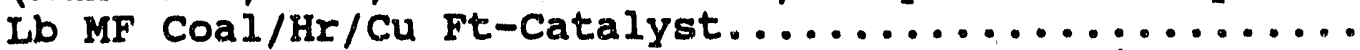

76. Overall Two-stage Resid + UC Conversion Comparison

(Runs 260,258, 255 and 251-II) - Space Velocity Unit: Lb MF Coal/Hr/Cu Ft-Reactors...................

77. Coal Conversion Comparisons (Runs 260, 258, 255 and 251-II) - Space Velocity Unit: Lb MF Coal/Hr/Cu

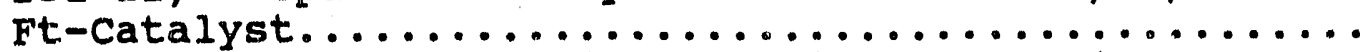
188

78. Boiling-Point Cut Conversion and Yield Comparisons
$(260 \mathrm{C}$ and $\mathrm{D}) \ldots \ldots \ldots \ldots \ldots \ldots \ldots \ldots \ldots \ldots \ldots \ldots \ldots \ldots \ldots \ldots$

79. Distillate End Point and Selectivity Comparisons (260C, 260D, 251-IIB and 251-IIIB).............. 
No.

80. Distillate Product Distribution Comparison (260C, 260D,

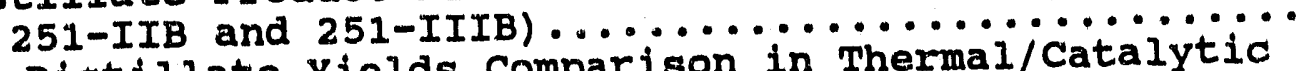

81. $C_{4}+$ Distillate Yields Comparison in Thermal/Catalytic: Mode (260C, 258B, and 258H) - Space Velocity Unit.

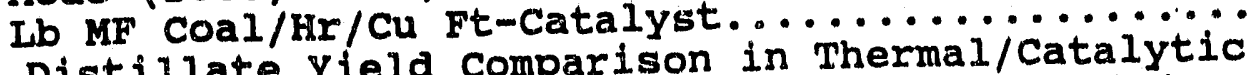

82. $C_{4}+$ Distillate Yield Comparison in Thermal/Catalytic

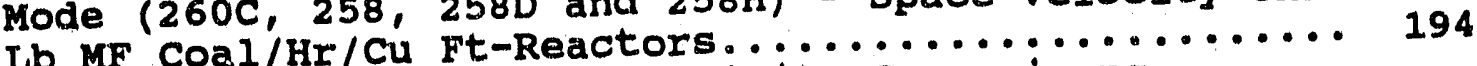

83. Distillate End Point and Selectivity Comparisons (260C $258 \mathrm{~B}, 258 \mathrm{D}, 258 \mathrm{H}, 255 \mathrm{C}$ and 251-IIB) ........ 195

84. Distillate Product Distribution Comparison (260C, 258B, $258 \mathrm{D}, 258 \mathrm{H}, 255 \mathrm{C}$ and $251-\mathrm{IIB}) \ldots \ldots \ldots \ldots \ldots \ldots \ldots \ldots \ldots \ldots \ldots \ldots$

85. Effect of Thermal Reaction Severity on Coal Conversion (Run 260) ...............

86. Effect of Thermal Reaction Severity on Resid + UC

87. Curve Fitting of Resid + UC Conversion vs Thermal Reaction Severity with Black Thunder Cual in Thermal/Catalytic Mode (260A-C, 258A-G and 258H).... 199

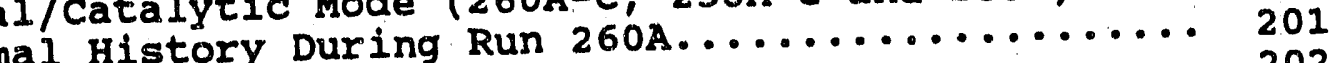

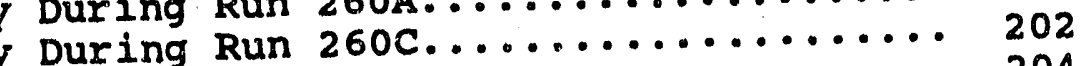

89. TSL Thermal History During Run $2600 \ldots \ldots \ldots \ldots$

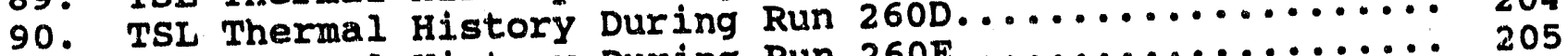

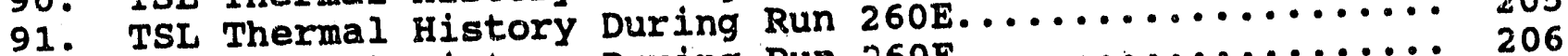

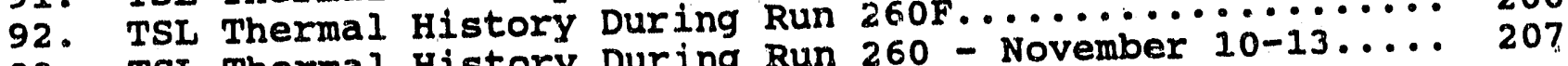

93. TSI Thermal History During Run 260 - Novemd (July 25-

94. Interstage Heater Outlet Temperature Trend (July 25 ... 208

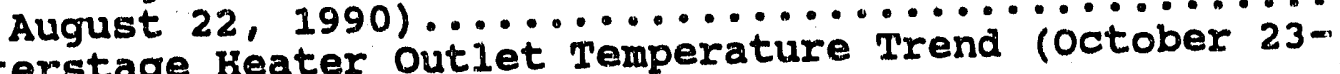

95. Interstage heater outlet Temperature Trend (october 23 ....

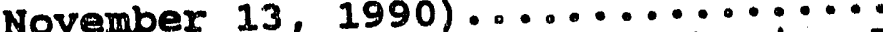

96. Partial Schematic of CC-ITSI Showing Product Separation. 210 
This report presents the results of Run 260 performed at the Advanced Coal Liquefaction $R \& D$ Facility in Wilsonville. The run was started on July 17,1990 and continued until November 14, 1990, operating in the ilose-Coupled Integrated Two-Stage Liquefaction mode processing Black Thunder mine subbituminous coal (Wyodak-Anderson seam from Wyoming Powder River Basin). Both thermal/catalytic and catalytic/thermal tests were performed to determine the methods for reducing solids buildup in a subbituminous coal operation, and to improve product yields. A new, smaller interstage separator was tested to reduce solids buildup by incroasing the slurry space velocity in the separator, In order to obtain improved coal and resid conversions (compared to Run 258) full-volume thermal reactor and 3/4-volume catalytic reactor were used. Shell 324 catalyst, 1/16" cylindrical extrudate, at a replacement rate of $3 \mathrm{ib} / \mathrm{ton}$ of $\mathrm{MF}$ coal was used in the catalytic stage. Iron oxide was used as slurry catalyst at a rate of 2 wt $\&$ MF coal throughout the run. (TNPS was the sulfiding agent.)

In the thermal/catalytic mode, the major tests were: effect of space velocity, effect of first stage (thermal) temperature, and effect of a new separator on solids buildup. In the catalytic/thermal mode, the major tests were: effect of space velocity, effect of first (catalytic) stage temperature and effect of second (thermal) stage temperature. The tests in the catalytic/thermal mode were made without the interstage separator. The close-coupled reactor unit was on-stream for 2253 hrs for an on-stream factor of $93.8 \%$ and the ROSE-SR ${ }^{S M}$ unit was on-feed for 2064 hrs for an on-stream factor of $99.0 \%$ for the entire run. 


\section{INTRODUCTION}

The Close-Coupled Integrated Two-stage Liquefaction (CC-ITSL) mode was used in Run 260 in thermal/catalytic as well as catalytic/thermal sequences. Prior runs in the CC-ITSL configuration include Runs 250-259 (Ref. 1-10).

In the CC-ITSI mode, the product from the first stage reactor is sent directly to the second stage reactor, without depressuring or deashing. In Run 260, in the first two test periods, an interstage separator was used to remove the recycle and vent gas, water, and light hydrocarbons produced in the first stage. The remainder of the first stage product was sent to the second stage. The vacuum flashed bottoms were recycled for coal slurry preparation instead of the atmospheric flashed bottoms allowing all the distillate to be sent to the distillation system. The third test period operated without interstage gas separation by blocking the vent stream of the interstage separator. In the remaining test periods, the interstage separator was bypassed.

The effluent from the second stage is separated using three flashes: a high pressure flash, an atmospheric flash, and a vacuum flash. Part of the bottoms from the vacuum flash, which contains resid, unconverted coal, and ash, is fed to the Residuum oil Supercritical Extraction-Solids Rejection (ROSE-SR ${ }^{\mathrm{SM}}$ ) unit. The remaining portion is recycled. The solids-free resid recovered in the $R O S E-S R^{S M}$ unit is recycled with second stage distillate and the vacuum flashed bottoms for coal slurry preparation. A simplified flow diagram of the CC-ITSL process is shown in Figure 1.

A brief summary of Integrated Two-stage Liquefaction (ITSI) runs at wilsonville follows: 
Table A. summary of Runs since 242

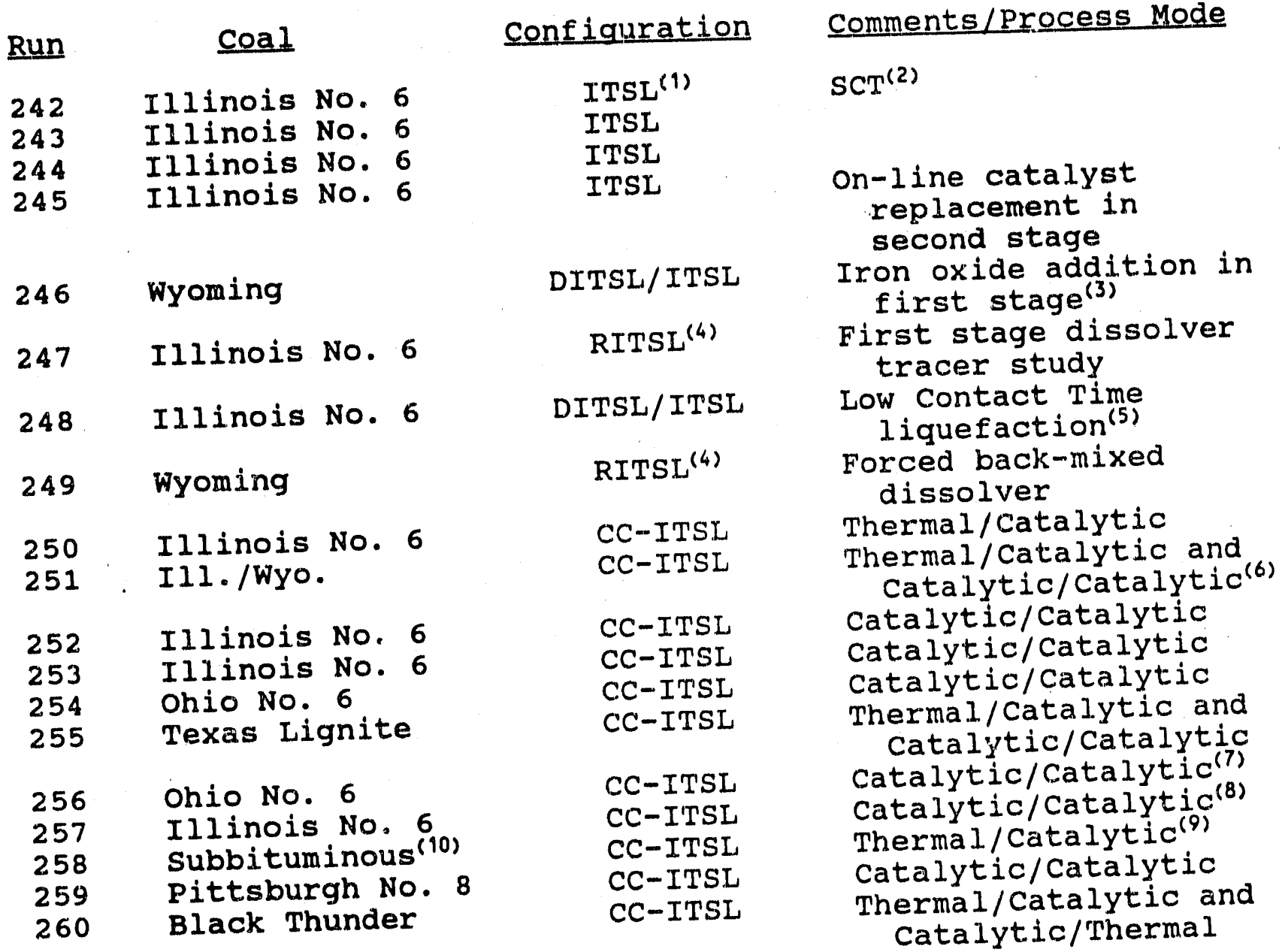

(1) In Runs 242-250, the first stage was a thermal liquefaction stage and the second stage was a catalytic stage.

(2) SCT denotes short Contact Time liquefaction. A dissolver was not used.

(3) Iron oxide and dimethyl disulfide added, which forms sulfided iron catalyst in TLU. that the reactor interstage stream is cooled and depressured.

(5) A 5.2" ID dissolver was used.

(6) Catalytic/catalytic mode denotes that a supported catalyst was present in both reactors.

on-line catalyst replacement capability added to second reactor.

Run tested half-volume reactors and low/high configuration.

(9) Spring Creek/Black Thunder Mine coals from Powder River Basin.

(10) Run operated completely with half-volume reactors.

Figure 2 shows, in a block diagram form, all of the operating modes tested at wilsonville since Run 242 . Figures 3,4 , and 5 are flow diagrams of the coal slurry preparation system, ebullated bed reactor, and the ROSE-SR unit, respectively. The nomenclature and definitions are given in Appendix A. 


\section{objectives}

The primary objectives of Run 260 were:

- (1) to reduce solids buildup in a low-rank coal operation,

(2) to obtain a better defined end-point for the distillate product with a low-rank coal, and

(3) to obtain improved product yields and quality with Black Thunder coal.

The secondary objectives to supplement the primary objectives were:

(1) to test a new, smaller interstage separator in the thermal/catalytic mode,

(2) to perform tests in the catalytic/thermal mode, and

(3) to study the effects of first and second stage reactor temperatures. 


\section{CONCLUSIONS AND RECOMEENDATIONS}

\subsection{Conclusions}

- A high coal conversion (about 96 wt $\%$ MAF coal) was obtained with Black Thunder coal at a first stage (thermal) temperature of $840^{\circ} \mathrm{F}$; however, $C_{4}-C_{3}$ gas make and heteroatom and gas yields were also high, 14.2 and 10.3 wt MAF coal, respectively.

- The new interstage separator did not perform satisfactorily due to its smaller size which did not provide enough residence time for separation. A. significant portion of the product and hydrogen gases from the first stage went to the second stage. This gas separation difficulty caused problems in calculations involving individual stage yields.

- In period $260 \mathrm{C}$ (thermal/catalytic mode) without interstage gas separation, the "all-distillate" product slate was not achieved. TSL excess resid yield was 8 wt \& MAF coal with 11 wt o organic rejection. $\mathrm{C}_{4}+$ distillate $y$ ield was 54 wt $\%$. Run 260 investigated lower coal space velocities than tested before in Run 258 by use of higher reactor volumes. However, the improvements in distillate yields (reduction in resid yields) projected from a first-order model were not realized probably due to differences in reactor operation parameters such as hydrogen partial pressures, thermal-to-catalytic volume ratios (temperature profile), operation with interstage separator, etc., which are not accounted for in the above model.

- In period 260D (catalytic/thermal mode) without an interstage separator, the second stage reaction temperature was $774^{\circ} \mathrm{F}$ (lower than the target $825^{\circ} \mathrm{F}$ ) which could not be increased due to the less process heat generated in the second stage. Thus, most of the conversion occurred in the first stage. Coal conversion was low ( 91 wt $\%$ MAF coal) and as a result organic rejection was high, (18 wt \& MAF coal). $\mathrm{C}_{4}+$ distillate yield was 60 wt $\%$ with zero excess resid make. The "all-distillate" product slate was achieved with a high distillate selectivity due to low reaction temperatures and feed rate. The performance of shell. 324 catalyst (in terms of resid + UC conversion) improved significantly when it was in the first stage vs being in the second stage. This observation suggests that the currently used method for evaluating catalyst pexformance is likely to give results dependent on the reactivity of the feedstock.

The new smaller diameter separator vessel and the 
shorter, heat traced transfer line did not prevent solids from depositing in the transfer line. However, the new separator vessel itself had no solid deposits. The catalytic/thermal mode of operation has shown promise so far in preventing or at least in arresting rapid buildup of deposits between the reactors.

Good process performance was observed in the catalytic stage in catalytic/thermal mode in 260D period, and operations were satisfactory in this first test at wilsonville with a low first stage temperature (and low preheater outlet temperature) while feeding a low-rank coal. However, later operations at higher coal feed rates were not smooth. Lower first stage coal conversion and higher viscosities $\left(800-1100 \mathrm{cps}\right.$ at $350^{\circ} \mathrm{F}$ and $8.4 \mathrm{sec}^{-1}$ ) were responsible for operations with the lowest possible ebullation rates in the catalytic reactor. The lower ebullation rates caused poor backmixing in the catalytic reactor which resulted in large temperature rises (30$50^{\circ} \mathrm{F}$ ) in the bed. At this coal feed rate in catalytic/thermal mode the TSL coal conversion was only about 86 wt $\%$ MAF coal.

significant solids buildup was observed in the second stage reactor in the catalytic/thermal mode. Although the exact reason for this buildup is not known, it may be related to the nature of the thermal stage products and high temperatures in the interstage preheater.

No significant differences were observed in the product quality despite operational changes in the six periods studied. Hydrogen content in the oil blend averaged 11.35 wt $\%$. Sulfur was the lowest heteroatom and averaged 0.05 wt $\%$. average end point for all blends in thermal/catalytic mode of operation was about $780^{\circ} \mathrm{F}$ and catalytic/thermal mode about $800^{\circ} \mathrm{F}$. The overall average overlap was about 10 wt $\%$.

\subsection{Recommendations}

- Heat losses from the reactor system must be minimized to obtain desired temperatures in both stages.

- Catalytic/thermal mode with higher second stage temperature should be studied to obtain process performance comparable or better than in thermal/catalytic mode.

High interstage preheater temperatures should be eliminated to obtain good second stage conversion data. 
- Pretreated coals should be tested to reduce heteroatom products and to improve hydrogen efficiency.

- Modifications may be made to the front end to increase allowable space velocity with full volume reactors.

- Catalytic/thermal and/or catalytic/catalytic modes must be further studied as a means to reduce solids buildup.

- Tests could be made to delineate the effects of lower temperature vs. presence of supported catalyst in the first stage on solids buildup.

- Pretreatment methods should be investigated as a means of preventing solid deposition problem with low rank coals. 


\section{OPERATING DATA AND PROCESS PERFORMANCE}

Reducing solids buildup, obtaining a better defined end point for the distillate product and obtaining improved product quality and yields with a low-rank coal were the main objectives of Run 260 . In order to achieve these objectives, tests were made in thermal/catalytic as well as catalytic/thermal modes. Also, a new interstage separator was tested. Catalyst replacement was performed in the catlytic stage to obtain steady-state catalyst activity. The tests were made with Black Thunder coal and ShelI 324 catalyst.

\subsection{TSL System Stability}

TSL system stability is judged by evaluating material balance closure errors, plant operation stability, and plant performance stability. Criteria for selection of stable days include:

- Mass balance closure errors for CCR unit (first and second stages), and ROSE-SR ${ }^{S M}$ must be less than 10 wt of MAF coal.

- The sum of absolute values of inventory changes including drumouts, must be less than 15 wt $\%$ MAF coal for the following locations

a) Between the second stage and ROSE-SR ${ }^{S M}$ unit,

b) Between the ROSE-SR ${ }^{S M}$ unit and the first stage.

A description of the elemental balancing procedure and a more detailed description of the selection criteria are given in Appendix B (Material. Balance Methodology).

Yields for stable days with similar operating conditions were averaged to obtain the final characteristic yields for each set of operating conditions. The operating conditions for each representative operating period are included in Tables $B$ and $C$. The first two periods, obtained in the thermal/catalytic mode with the new, smaller interstage separator, were unstable for the following reasons: the volume of the separator was too small to provide adequate vapor/slurry separation, and significant and unknown amounts of gaseous components went to the second stage. Thus, material balances could not be performed to determine individual stage contributions. The third period was operated without interstage gas separation by blocking the vent stream of the interstage separator. After the first three periods, the interstage separator was bypassed. After the third period, which was also performed in the thermal/catalytic mode, the reactor sequence was reversed for catalytic/thermal operation.

Between June 10 and July 9, 1990, plant maintenance and modifications were performed. The new interstage separator, V1258B was installed. V1258B has about one quarter of the volume of the previous separator. Also, the lines to and from the 
Toble 8. SImanaY OF OPERATIMG CONDITIONS AND OVERALL TSL YIELDS (THERMAL/CATALYTIC MOOE)

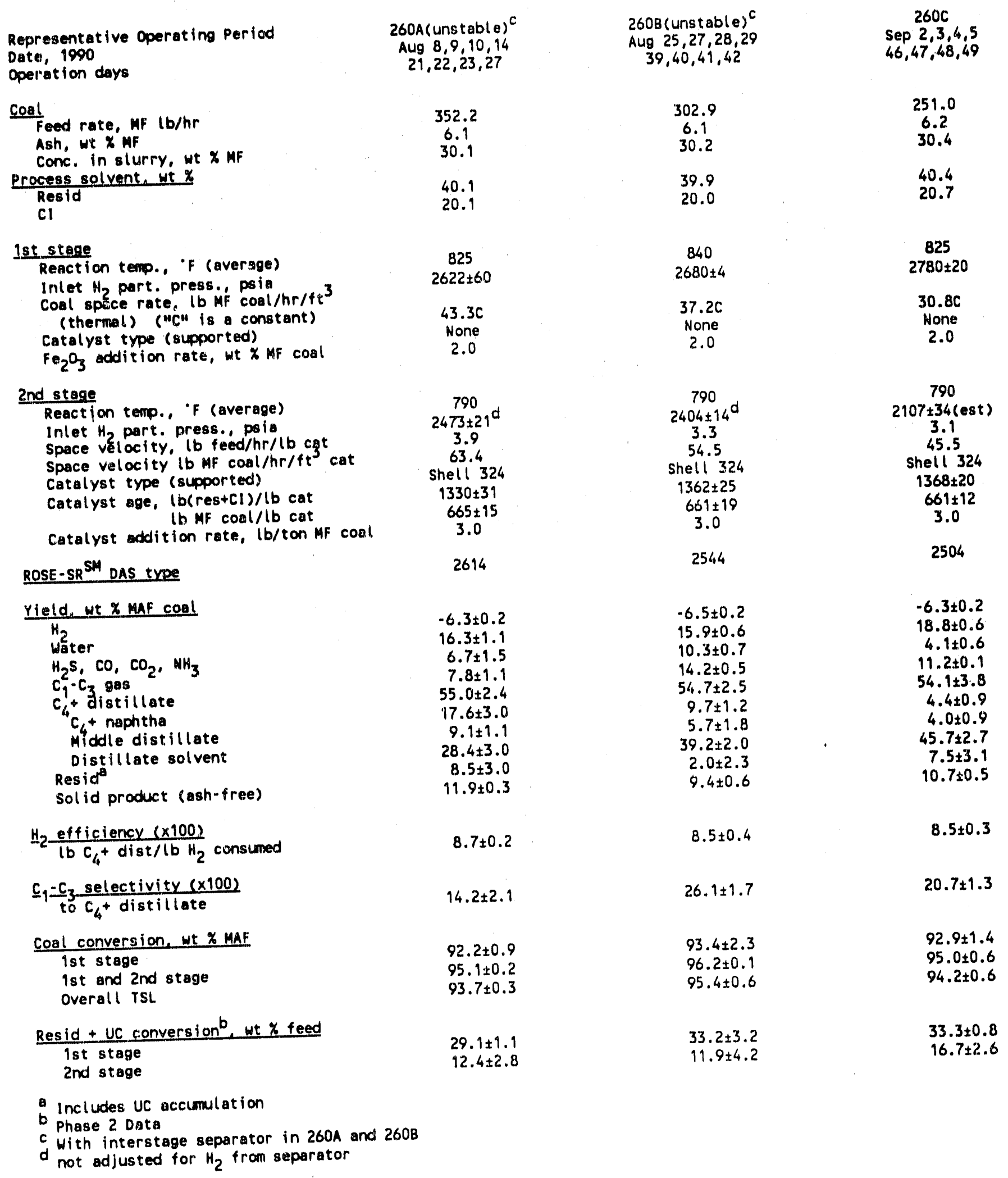


Toble C. SUMaRY OF OPERATING CONDITIONS AND OVERALL TSL YIELDS (CATALYTIC/THERMAL MODE)

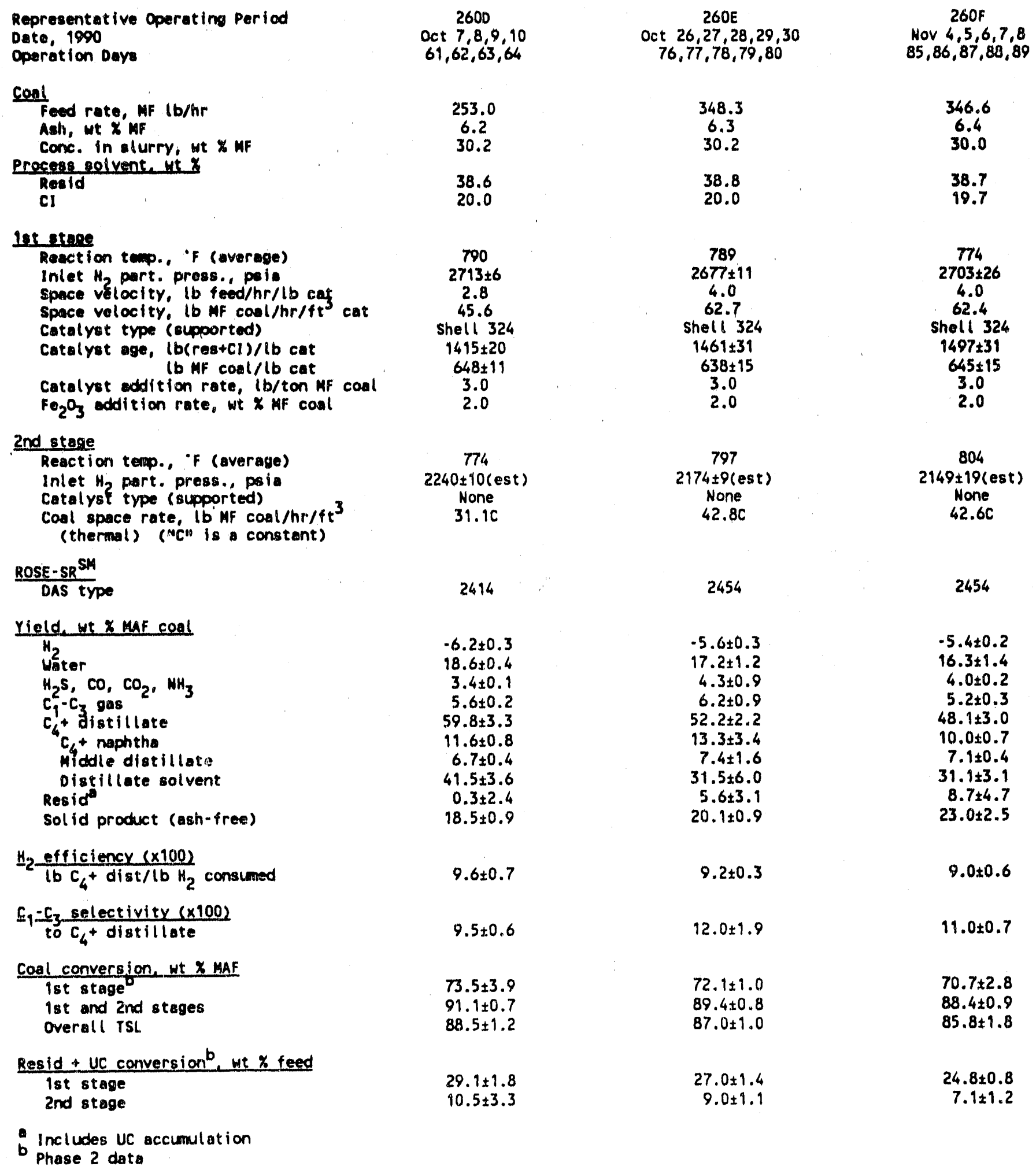


vessel are shorter. On inspection, the ebullating pump on R1235 was severely eroded, however, the pump on the second stage reactor was in good shape. The second stage reactor (R1236) piping was changed to operate at $3 / 4$ volume while the first stage reactor (R1235) remained at full volume.

From July 9 to July 16, 1480 pounds of catalyst was sulfided. on July 13, catalyst was carried over into the ebullating pump suction Iines of R1236 during bed expansion. The bed moved as a plug when there was an apparent flow surge. The ebullating pump lines were cleaned.

Run 260 started on July 17, 1990. With the new smaller interstage separator (V1258B), good control of the flow could not be established. The gas back pressure controller and level controller interacted with each other and with the level controller on the high pressure separator. To solve this problem, the pressure transmitter on the vent gas was set to a narrow pressure range and the pressure controller was tuned. The interstage separator could be operatad, without carryover into the vent line, however, it became apparent that the separator was not taking most of the gas out of the bottoms. There was little recycle gas coming from the interstage separator and additional. hydrogen had to be added to the preheater to maintain pressure. The controlled level was increased in the separator and total gas flow to the first reactor was decreased to reduce the flow of gas in the bottoms, but to no avail.

Due to the flow of gas to the second reactor, the individual reactor yields could not be obtained by mass balance.

During the latter part of August, the main problem was the increase in pressure drop across the line between the reactors and the lack of gas separation in the interstage separator. The line between the reactors had solid deposits. During the outage, September 8-25, the line was hydroblasted clean. The reactors were reversed with $\mathrm{R} 1236$ as the first stage reactor at $3 / 4$ volume and the interstage separator was bypassed.

coal feed resumed on september 26. In the catalytic/thermal mode, there was not enough reaction in the thermal reactor to overcome the heat losses resulting in a low thermal reactor temperature and lower coal conversion. Increasing the coal feed rate to 300 lb $\mathrm{MF}$ coal/hour increased the second stage temperature to about $795^{\circ} \mathrm{F}$. The first stage catalyst addition tube plugged with ammonium salts resulting in an outage during october 14-17.

The feed rate was further increased to 350 lb MF coal/hour on October 18 resulting in a higher second stage temperature with increased coal conversion at least temporarily. However, with cooler weather, the second stage could not be kept above $800^{\circ} \mathrm{F}$. Coal conversion declined with the decline in temperature (Figure 6). Also, at $350 \mathrm{lb} \mathrm{MF}$ coal/hour feed rate, the slurry viscosity increased substantially (from 400-600 cps to 800-1100 cps at $350^{\circ} \mathrm{F}$ and $8.4 \mathrm{sec}^{-1}$ ) (Figure 7 ), leading to operational 
difficulties. The ebullation rate in the catalytic reactor was very low in the catalytic/thermal mode and became lower with high temperature rises within the bed during the higher coal feed rate, higher slurry viscosity and lower coal conversion in period 260E (October 26-30). Operation in period 260E conditions was difficult. The separator after the thermal reactor began not to separate the gas from the bottoms liquid in a fashion similar to that of the interstage separator at the beginning of the run.

After the first stage reactor temperature was lowered to $775^{\circ} \mathrm{F}$, the ebullating pump speed on the catalytic reactor was reduced to as low as it could be. The catalyst bed height increased making the operators uncomfortable with an uncontrollable situation. The temperature rise within the bed did not increase until November 5 when there were problems adding the catalyst back to the reactor. This may have been the point at which a hole developed in the R1236 plenum chamber. The thermal reactor temperature increased above $800^{\circ} \mathrm{F}$, however, the coal conversion did not improve.

On November 9, the first stage temperature was increased to $805^{\circ} \mathrm{F}$ and the second stage was reduced to $750^{\circ} \mathrm{F}$. With the higher first stage temperature, the ebullation rate could be increased. With the lower second stage temperature, coal conversion decreased and the separator would not separate resulting in a carryover of ash and viscous material into the distillation towers - most of which was arummed. The october-November test period at a high coal feed rate was operationally unstable.

In summary, period 260A (August 8-14) was unstable due to incomplete gas separation in the interstage separator, low interstage overhead Iiquids due to low overhead gas rate, and elemental analysis adding to more than 100\%. Period 260B (August 25-29) was a.lso unstable due to incomplete interstage gas separation and pulsating gas flows. Period 260C (September 2-5) was obtained without interstage separation by blocking the vent stream of the separator. However, a high pressure drop developed across the piping between the reactors resulting in much lower pressures in the second stage reactor. The new interstage separator did not solve the subbituminous deposit problems.

During the catalytic/thermal operation, period 260D (October 7-10) was the most stable. Higher viscosities, low coal conversion, low thermal reactor temperature, and difficult operation were expeienced in period 260E (October 26-30) and period 260F (November 4-8). During the latter part of the run, boiler outages caused unstable distillate processing in T102 and V1082. Also, the water softener was not properly being regenerated causing calcium deposits in the deaerators.

\section{Equipment and piping inspections after Run 260}

R1235 - Bottom had 132 pounds of solids (62.1 wt $\%$ ash, and 72.3 wt $8 \mathrm{CI})$. The bottom head was jacked down which pulled the plenum chamber and suction pipe apart. 
Reactor wall was coated with about $5 / 16^{\prime \prime}$ thick solids (67.3 wt 8 ash, 76.7 wt 8 CI).

P1222 - Suction tube was about $50 \%$ full of solids, $61.2 \%$ ash, and 69.5 wt 8 CI. There was a layer of solids on thermocouple bundle and on catalyst addition tube in suction cup and inside of oup.

R12.36 - Reactor walls were essentialiy clean.

P1236 - Suction flange was half full of material that looked

like iron oxide (grainy: 67.6 wt \% ash, 75.4 wt \% C.I).

- The suction cup was full of soft flaky bulldup (56.7 wt o ash, 60.9 wt \& CI).

- The plenum chamber had a hole on top.

V1247 bottom outlet pipe had 1/8" layex (49.1 wt $\%$ ash, 57.9 wt $\%$ CI). V101.A - Normal subbituminous deposits on top of head.

Pipe between R1236 and R1235 had a small layer of solids where pipe goes down to interstage sampler.

\section{DIPEICULTY OR CHANGE}

Start of Run 260 , July 17.

V1258B level. and vent control problems, July 18 .

off feed, July 19.

Vent control problems. Problems with coal addition, recirculating pumps, July 20-23.

Tuned V1258B vent pressure controller, July 23.

Could not make up process solvent. Cooling tower fan failed. V1258B overthead oil-water separator plisgging.

Could not add coal due to recirculation pump problems.

Large hydrogen usage in first stage and high vent rate on second stage, July 27.

Main breakex in motor control center trippea out due to overheating.

Set some gas flow from second stage to first stage, August 2 .

\section{CONSEQUENCE OR REASON}

Carry over into vent line.

Clean out vent line and downstream separators.

operated with entire flow-through bottom of V1258B.

V1258B in service.

Off feed 0845 to 1750 hours on July 23 .

off feed 0845 to 1750 hours on July 24 .

Gas not being removed from liquid in V1258B separator.

off feed 1520 to 2005 hours on July 30 .

Reduce hydrogen usage. 
DIFEICULYY OR CHANGE

started catalyst addition and withdrawal in R1236, August 4.

Bypassed V1258B so as to change pressure control point to a pressure transmitter downstream of V1258B, August 7.

During a planned power failure, one of the emergency generators falled.

Variable speed belt on coal slurry feed pump broke, August 15.

First stage temperature increased to $840^{\circ} \mathrm{F}$, August 15 .

Power failure and one of the emergency generators failed.

Power failure, August 19.

Tested emergency generators. Had power failure during test, August 20.

Reduced coal feed rate from 350 to $300 \mathrm{MF} \mathrm{1b/hr,} \mathrm{August} 22$.

Steam boiler not staying on line, August 26-27.

Fan turned on for T105 OH, August 26.

Pressure drop across line between reactors progressively getting higher, August 23-September 7 .

stopped gas flow from overhead of the separator - all flow through bottom. Coal feed rate lowered to $250 \mathrm{lb} \mathrm{MF}$ coal/hr. Decreased first stage temperature to $825^{\circ} \mathrm{F}$, August 30 .

Source of light ends to V1074 found, September 7 .

Outage, September 8-25.

\section{CONGEOUENCE OR REASON}

Vent valve PIC would not control. Set valve back up the way it was.

Off feed at 1040 hours. Back on feed 1725 hour, August 11 .

Plant upset.

off feed 1530 to 1815 hours, August 18 . Computer down.

No equipment down but computer off for 2 hours.

General upset. Plant load is too much for emergency generators.

Interruption of $\mathrm{V} 1082$ and $\mathrm{T} 102$ vacuum.

To control loss of light ends from T105.

Pressure in second reactor getting progressively lower.
Light ends were in the gas vent, due to high ambient temperatures and level control malfunction. 
DIFFICULTY OR CHANGE

Lines between the reactors had solid deposits. Lines were hydroblasted clear. No deposits reported for separator.

Boiler deaerator taken apart to look for abnormal operations.

Reactors switched - R1236 first reactor.

on coal feed, september 26.

Target second stage reactor temperature could not be obtained due to lack of reaction and heat losses in second reactor, september 27 .

Boilers down several times, September 27-29.

Damperier fell into burner on Dowtherm heater.

Hydrogen flow to second stage set to $10 \mathrm{lb} / \mathrm{hr}$, october 1 , lowered to $8 \mathrm{lb} / \mathrm{hr}$, october 2 .

Valve worn out in vacuum flash recirculation line.

Lowest attainable pressure in T102 was 2.2 psia with $630^{\circ} \mathrm{F}$ bottoms temperature, October 4 .

Impulse leg on second stage reactor DP plugging. Second stage reactor temperature dropping, october 11.

Provlems in transferring heavy distillate to T102, october 11.

To 300 lb MF coal feed rate, october 12 .

Catalyst addition tube plugged. Dowtherm reported to be present in distillate samples.

\section{CONSEQUENCE OR REASON}

Found deposits in steam stripping section but not total cause of bojler problems.
Vacuum upsets. Low water flow due to high DP in water piping.

off coal feed from 0225 to 0900 hours, september 30 .

Attempt to improve $\mathrm{H}_{2}$ partial pressure in second stage.

off coal feed for 13.3 hours, october 5 and 6 .

Recirculation solvent not topped as desired.

DP in error. Steam tracing on line was repaired.

Condensate line plugging repaired.

Catalyst could not be added. T105 taken off line to check for Dowtherm leaks. 


\section{DIPEICULTY OR CMAYCE}

coal slurry recirculation pump stopped. Spare pump not hot.

catalyst addition tube still plugged. on inspection ammonium salts found in tube.

Outage october 14-18.

on coal feed, October 18 at 0430 hours, 350 lb MF coal/hr.

Delays in coal addition due to increased slurry viscosity, october 19-22.

Top thermocouple indication in R1235 thermocouple was in error, October 19-22.

Level transmitter on V1250 (after high pressure letdown) not functional, october 23.

Seat and trim replaced in v1250 control valve, october 26 and 27 .

V1247 carryover into V1249.

First stage temperature lowered to $775^{\circ} \mathrm{F}$, october 31 .

Dowtherm present in V1082 sample, November 2 .

Low steam pressure, November 3 .

\section{CONSEQUENCE OR REABON}

off coal feed for 25 minutes, october 13 .

off coal feed at 0845 , october 14 .

Heat leak on R1236 ebullating pump repaired. Catalyst addition valves were leaking - replaced with those on R1235. Vacuum jets on T102 repaired.

Second stage temperature could not be increased.

some vacuum bottoms were drummed.

Bed exotherm in error.

Operated with valve open.

Transmitter was relocated.

some light ends went to the vent.

Valve worn out.

Heavy resid and ash sent to distillate piping. start of problem with gas liquid separation in separator.

After Dowtherm was detected, steam was used in jacket.

Caused delay in processing bottoms. Feed rate lowered to $1000 \mathrm{lb} / \mathrm{hr}$ for 11.5 hours. operation becoming very rough.

After catalyst addition/withdrawal November 5 , there was a operation was difficult and unsteady. larger temperature spread in R1236. 
DIPEICULTY OR CEANGE

Feed pump stopped pumping when switched, November 8.

Raised temperature of first reactor to $805^{\circ} \mathrm{F}$ and lowered second reactor to $750^{\circ} \mathrm{F}$, November 9 .

V1247 carryover, November 9.

Second stage temperature lowered to $735^{\circ} \mathrm{F}$, November 12 .
CONSEQUENCE OR REASON

Loss of feed to reactors for a short period.

End of Run 260, November 14 .

\section{2 . Feed Coal}

Black Thunder coal from the Thunder Basin coal Company in Wright, Wyoming, served as the feed coal for Run 260 . It was last used in Run 258 along with Spring creek coal. of these two subbituminous coals, the Black Thunder mine coal became the preference coal for Run 260 mainly because of its lower sodium content. Ashed samples from spring creek coal contained about 10 wt of sodium oxide whereas Black Thunder samples contained about 2 wt if sodium oxide. It was felt that the high sodium content may harm catalyst activity.

The properties of the Black Thunder coal offer some insight as to how the feed coal may behave in liquefaction. Typical properties of the Black Thunder coal are summarized in Table 1. These properties came from analysis of actual feed coal samples during each of the material balance periods in Run 260. oxygen content, for example, averages 18 weight percent and is two to three times higher than in many of the bituminous coals. Much of this oxygen will end up as water and some will remain in the final distillate product. The hydrogen to carbon atomic ratio for the Black Thunder coal averages 0.86 which is slightly higher than ratios for bituminous coals. This indicates that the chemical makeup of the Black Thunder coal is going to be different from typical bituminous coals.

Sulfur and nitrogen heteroatoms are of significance in the Black Thunder coal. As shown in Table 1, this coal is almost devoid of pyritic sulfur, which is a natural catalyst found in many bituminous coals. For Run 260, the pyritic sulfur had to be generated by the addition of iron oxide and a sulfiding agent (TNPS: di-tertiary-nonyl-polysulfide). The nitrogen content of the Black Thunder coal is approximately $1.0 \mathrm{wt} \%$. In general nitrogen has always been more difficult to remove compared to sulfur and has shown up in the final distillate product at an 
undesirable level. overall, the Black Thunder coal properties from Run 260 did not
differ significantly from those observed for this coal in Run 258. Metals composition of the Black. Thunder coal is of significance and it differs from bituminous coals such as Iliinois and Ireland. oxides of silicon, iron, and aluminum comprise about 90 wt $\&$ of the ash from Ireland and Illinois coals (Ref. 8 and 10). Calcium and magnesium together comprise about 6 wt * The Black Thunder coal contains less iron and much more calcium and magnesium compared to bituminous coals. The high calcium level is undesirable since it may exhibit a tendency to deposit in vessels and pipes as calcite.

Table 1 contains coal conversion test data obtained from feed coal samples during the run. The test measures the tendency for the coal to convert to tetrahydrofuran soluble material under specified conditions. The coal conversion values were unusually low for the Black Thunder coal but were similar to the data observed from the Black Thunder coal in Run 258. Wyodak subbituminous coal, for example, used in runs prior to Run 258 gave coal conversion values in the 70 to 75 wt $\%$ range. However, the trend observed for the Black Thunder coal in Run 260 showed no decrease in coal conversion in regard to this independent laboratory test.

The Black Thunder coal contains about 20 wt $\%$ moisture. This high moisture level becomes a factor in achieving high coal feed rates since the coal is dried as a slurry before it enters the first reactor. Slurry drying requires a few hours residence time in the mix tank before it is pumped over to the feed tank. In Run 260, the feed slurry was prepared by mixing recycle solvent $\mathrm{V} 131 \mathrm{~B}$ and the feed coal in a specified proportion.

\subsubsection{Slurry Preparation}

The process solvent used for coal slurry blend preparation was a mixture of V1074 distillate, full range ROSE-SR ${ }^{5 M}$ resid and V1082 vacuum flash bottoms. The mixture was blended in V101A slurry blend tank with coal and was fed to the first stage reactor. Recycle process solvent analytical data is in Table 2 . In Run 260 , the target process solvent composition was: resid $=40 \mathrm{wt} \%$, distiliate $=40$ wt $\%$, and $C I=20$ wt $\%$ coal concentration in the slurry was about 30 wt $\%$.

\subsection{Close-Coupled Reactor (CCR) Unit}

The primary objectives for the CCR unit during Run 260 were:

Test the subbituminous coal from the Black Thunder Mine in the CC-ITSL process with thermal/catalytic and catalytic/thermal modes of operation,

2) Maintain steady-state operation with catalyst 
replacement (1/16" Shell 324) in the catalytic reactor

3)

study the effect of a new interstage separator, shorter transfer line, and process changes on solid deposition, and

4) Quantify yields by operating the interstage heater at low enough temperatures so that conversions in the heater will be negligible.

Feed slurry composition, coal feed rate, and reactor temperature were changed to maintain smooth operation and obtain high distillate yields. Coal conversion, hydrogen consumption, distillate and resid yields were monitored daily as performance indicators. Catalyst samples were analyzed routinely to evaluate catalyst activity and integrity.

\section{3 .1 Unit operations}

Prior to Run 260, the plant was off feed to perform routine maintenance, install the new interstage separator (V1258B), and complete all piping modifications. The new separator was about 4 times smaller in diameter compared to the old separator (V1258). The transfer line between the first stage reactor (R1235) and the new separator vessel was shortened considerably. The transfer line was heat traced in order to maintain high skin temperatures. Both the use of V1258B and transfer line modifications were aimed at preventing deposit formation.

Fresh Shell $3241 / 16^{\prime \prime}$ catalyst was sulfided in four batches between July 9 and 16 for use in the catalyst replacement program during the run. After sulfiding, the plant went on coal feed on July 17. The startup conditions were the following:

Coal Feed conditions: coal

MF coal feed rate slurry composition Process solvent

R1235 first stage conditions: Reaction temperature Inlet $\mathrm{H}_{2}$ partial pressure =

$=$ Black Thunder Mine

$=3501 \mathrm{~b} / \mathrm{hr}$

$=2.33$ solvent-to-coal ratio

$=40$ wt $\%$ resid, 20 wt $\% \mathrm{CI}$, and 40 wt $\%$ distillate

R1236 second stage conditions: Reaction temperature catalyst

Catalyst age

catalyst charge

$=825^{\circ} \mathrm{F}$

2600 psia

Catalyst replacement rate

$=790^{\circ} \mathrm{F}+$ aged Shell $3241 / 16^{\prime \prime}$

$=757 \mathrm{lb}$ (resid+CI)/1b catalyst

379 lb $\mathrm{MF}$ coal/lb catalyst

$=280 \mathrm{lbs}$

( 120 lbs fresh +160 lbs aged) batch

operational changes that were made since the start of the run in 
the thermal/catalytic mode of operation and the dates are indicated below:

July 17-25:

July 24:

August 2:

August 15:

August 22:

August 30 :

Level control problems in V1258B.

Catalyst charge increased to 300 ibs.

Catalyst replacement at $31 \mathrm{lb}$ cat/ton MF coal.

First stage temperature increased to $840^{\circ} \mathrm{F}$.

coal feed rate decreased to $300 \mathrm{lb} \mathrm{MF}$ coal/hr.

Blocked V1258B (interstage separator) overhead.

First stage temperature decreased to $825^{\circ} \mathrm{F}$.

coal feed rate decreased to $250 \mathrm{lb} / \mathrm{hr} \mathrm{MF}$ coal.

September 8-25: Scheduled shutdown to switch reactors.

At the start of the run, the two reactors were maintained at

$825^{\circ} \mathrm{F}$ and $790^{\circ} \mathrm{F}$ average temperatures, respectively. The first stage reactor was operated at full volume to promote coal convexsion, while the second stage reactor was operated at $75 \%$ capacity to maintain resid inventory. The first stage was operated thermally, and the second stage reactor was initially charged with 280 lbs (dry) of shell catalyst. The catalyst charge was a mixture of fresh sulfided catalyst and aged catalyst from Run 258. A mixture of fresh and aged catalyst was used to reduce the time required to reach an equilibrium age. Because the catalyst charge had a younger age than the age desired, the catalyst was batch aged from July 19 to August 5 .

The process solvent contained 40 wt $\%$ resid and 20 wt $\% \mathrm{CI}$. The process solvent was prepared by blending resid from the ROSE-SR ${ }^{\text {SM }}$ unit, heavy distillate from the T105/T102 distillation system, and a recycle stream containing solids (Cresol Insolubles, CI = ash + unconverted coal) from the V1.082 vacuum flash bottoms. The startup process solvent was derived from Run 259 Ireland mine (Pittsburgh seam *8) bituminous coal. The displacement of the Ireland derived process solvent took 10 to 12 days. As a result Ireland derived process solvent took the previous run, the coal
of the displacement of material from the UC (unconverted coal) to
conversion increased steadily and the UC ash ratio decreased steadily until about July 31 .

Solids were recycled using the V1082 vacuum flash bottoms stream (30-40 wt? CI, 60-70 wt? resid) which allowed for all the distillate to be sent to the T105/T102 distillation system. In Run 258, solids were recycled using the V1067 (atmospheric flash) stream. Also in Run 258, the distillate for the process solvent came from the V1072 (vacuum flash overhead) stream. However, since the T102 column was in use in Run 260, the T102 column bottoms was used for the distillate portion of the process solvent makeup. This resulted in recycling primarily all the material boiling above $850^{\circ} \mathrm{F}$.

since the new interstage separator (V1258B) was in place, there were initial problems controlling the level in the separator from July 17 to 25. Process stream carryover into V1258B overhead line and to V104 vessel was experienced on July 18 . The unit went off feed on July 19 for about 14 hours, so that the V104 and 
V1258B overhead lines could be cleaned.

When the unit came back on feed, the level in V1258B could not be controlled, and as a result, the V1258B overhead stream was blocked. All the effluent of the first stage reactor including the gases went to the second stage reactor. The pressure controller in the V1258B overhead Iine was tuned and the range on the controller was narrowed. This resulted in fairly good control of the level in V1258B, and further processing continued with the overhead stream line from V1258B unblocked.

The coal feed rate was lowered to about $200 \mathrm{MF} 1 \mathrm{~b} / \mathrm{hr}$ on July 20 due to problems with recirculation pumps on the v101A slurry tank and a plug in the V101A vent line. Because of these problems, coal could not be added into the slurry tank. Enough feed was not available for continued operation, and the unit went off feed intermittently on July 23 and 24.

The problem with the V101A recirculation pumps was traced to an air. leak, which was repaired. The unit came on feed on July 24, and the flow rates were raised to target levels on July 25. Because of numerous operational problems in the beginning of the run, Phase 2 material balances could not be performed until July 25.

Because of the small size of the new interstage separator, the vaporization rate as well as the disengagement of entrained hydrogen gas bubbles was inadequate. The V1.258B overhead stream flow rate was low and inorganic gases and light organics were flowing through the bottom of the separator and into the second stage. Since the flowrates and distribution of gases and light organics through V1258B bottoms could not be estimated, individual unit yields could not be determined. However, first. and second stage coal and resid+uc conversions could be determined by a forced ash balance.

The recycle gases from the first and second stages were mixed with fresh hydrogen and recycled back to the first and second stage reactors, respectively, in order to maintain desired hydrogen partial pressures. The recycle gas rate to the first stage was so low that essentially pure hydrogen was being fed to the first stage reactor. Since the underflow of gases through V1258B resulted in higher vent rates in the second stage, the second stage vent gas was recycled back to both the first and second stages beginning on August 2 .

The heavy distillate (V1074) from the T102 column bottoms usually costains 98 wt 8 material boiling above $650^{\circ} \mathrm{F}$. But starting August 13 , up to 8 wt of naphtha fraction was found in V1074. The source for this naphtha fraction in V1074 was not immediately clear. The higher than usual amounts of naphtha in V1074 caused considerable problems since this fraction was vented in the slurry tank along with moisture. On september 7 , the source for the higher naphtha fraction in V1074 was traced to the second 
stage gas vent. Because of highe ambient temperatures and poor level control, the light ends condensed in T1059 and flowed into v1.074.

on July 24, the catalyst charge was increased to the target amount of $300 \mathrm{lbs}$. On August 2, catalyst replacement at a rate of $31 \mathrm{~b}$ catalyst/ton MF coal began in the second stage catalytic reactor to maintain the catalyst at an equilibrium age. Catalyst replacement was scheduled for every other day.

Pluggage of the withdrawal tube on $\mathrm{R} 1236$ resulted in problems with catalyst withdrawal on August 2 . After several attempts the plug was dislodged, and the necessary amount of catalyst was finally withdrawn and fresh catalyst was added back on August 4. Because of the missed addition on August 2 , two replacements were done on August 4.

Once the initial operational problems with the run were resolved, and the level in V1258B could be controlled, fairly smooth operation prevailed. The temperature of the first stage reactor was increased to $840^{\circ} \mathrm{F}$ on August 15 to reduce the resid yield and increase the distillate yield. Phase 2 data indicated a resid yield of more than 5 wt : MAF coal following the first stage temperature increase. Therefore, the feed rate was decreased to $300 \mathrm{lb} / \mathrm{hr}$ on August 22 to achieve resid extinction. However, phase 2 data indicated that the hydrocarbon gas make increased from about 10.5 to 12.5 wto MAF due to the decrease in coal feed rate. Resid yield remained around 5 wt $\%$ MAF coal.

The pressure drops between the first stage reactor and the separator vessel and between the reactors gradually increased from the beginning of the run. The nuclear density gauge on V1258B also showed a gradual increase. On several occasions, difficulties in controlling v1258B level was experienced because of sluggish movement of the flow control valve located just below the separator vessel. All of these occurrences indicated gradual solids buildup somewhere between the reactors. A detailed discussion pertaining to the solid deposition problem is given at the end of this section.

on August 30 , the interstage overhead was blocked due to its poor performance, the first stage temperature was raduced to $825^{\circ} \mathrm{F}$, and the coal feed rate was reduced to $250 \mathrm{lb} \mathrm{MF} \mathrm{coal/hr}$. All the effluent of the first stage reactor including the gases went to the second stage reactor. This test served two purposes. The hydrogen partial pressure in the second stage reactor was much lower without the separation of gases from the process stream between the reactors. The lower hydrogen partial pressure can have a significant impact on hydrogenation and resid + UC conversion in the second stage. The second purpose of this test was to serve as a comparison for the following test with catalytic/thermal operation.

The thermal/catalytic mode of operation concluded on september 7 
and the plant was shut down. The lines between the reactors and the separator vessel were inspected for deposits. The transfer line pipe before and after the separator vessel had considerable amount of deposits, with only a pencll-sized hole available for the process stream to flow. The separator vessel itself was clean. The deposits in the lines were cleaned by hydroblasting.

During a scheduled shutdown (September 8 to 25), piping changes made the catalytic reactor (R1236) the first stage and the thermal reactor ( $R 1235)$ the second stage. In this catalytic/thermal mode of operation, the interstage separator was completely bypassed. The primary purpose of this test was to determine the effect of the catalytic/thermal. mode of operation on solids deposition.

In the catalytic/thermal mode of operation, the initial target conditions were the following: 
Coal feed conditions:

Coal

MF coal feed rate

slurry composition

Process solvent

First stage reactor (R1236) conditions:

Reaction temperature $=790^{\circ} \mathrm{F}$

Inlet $\mathrm{H}_{2}$ partial pressure $=$

catalyst

Catalyst age

2700 psia

Shell $3241 / 16 "$

$=14131 \mathrm{~b}$ (resid+CI)/1b catalyst

Catalyst charge $\quad=300 \mathrm{lbs}$

Catalyst replacement rate $=3 \mathrm{lb} \mathrm{cat} / \mathrm{ton} \mathrm{MF}$ coal

Second stage reactor (R1235) conditions:

Reaction temperature $=825^{\circ} \mathrm{F}$

Inlet $\mathrm{H}_{2}$ partial pressure $=2250$ psia (est.)

operational changes that were made since the start of the run in the catalytic/thermal mode of operation and the dates are indicated below:

September 26: Catalytic/thermal mode. Low/high temperature operation. First reactor temperature at $790^{\circ} \mathrm{F}$. No V1258 separator.

October 12 :

October 31:

November 9 :

coal feed rate increased to $300 \mathrm{lb} \mathrm{MF}$ coal $/ \mathrm{hr}$.

First stage temperature decreased to $775^{\circ} \mathrm{F}$.

First stage temperature increased to $805^{\circ} \mathrm{F}$.

Second stage temperature decreased to $750^{\circ} \mathrm{F}$ $\left(\right.$ Target $\left.=700^{\circ} \mathrm{F}\right)$. Inlet temperature approximately equals outlet temperature in B1201 interstage heater.

After the scheduled shutdown, the plant came on feed on september 26 at a coal feed rate of $250 \mathrm{MF} \mathrm{lb} / \mathrm{hr}$. The catalytic first stage reactor temperature was set at $790^{\circ} \mathrm{F}$. The second stage was targeted for an operating temperature of $825^{\circ} \mathrm{F}$. It soon became apparent that the second stage thermal reactor temperature would not exceed $770^{\circ} \mathrm{F}$ at the current operating conditions and with the interstage heater set at the maximum outlet temperature of $850^{\circ} \mathrm{F}$ (for prolonged safe operations).

In the catalytic/thermal mode of operation, a part of the second stage vent gas was recycled to the first stage where it was mixed with fresh hydrogen to achieve desired hydrogen partial pressure. Fresh hydrogen was fed to the second stage. At the start of the catalytic/thermal mode of operation, the fresh hydrogen flow to the second stage was maintained at $2 \mathrm{lb} / \mathrm{hr}$. It was felt that the hydrogen partial pressure may not be high enough in the second stage for sufficient hydrogenation and reaction. On october 1 , the fresh hydrogen feed to the second stage was increased to a maximum flowrate of $8 \mathrm{lb} / \mathrm{hr}$. This resulted in a $5^{\circ} \mathrm{F}$ increase in the second stage reactor temperature. The hydrogen flowrate was 
maintained at $8 \mathrm{lb} / \mathrm{hr}$ for the remainder of the run.

In the beginning of the catalytic/thermal mode of operation, the temperature difference between outlet and inlet of the first stage reactor was much higher than in the thermal/catalytic mode. The second stage had a high negative temperature rise in catalytic/thermal mode due to heat lossess and lack of reaction (Ref. 11). In order to decrease the first stage reactor exotherm and subsequently increase the second stage reactor exotherm, the coal feed rate was increased to $300 \mathrm{lb} \mathrm{MF} \mathrm{coal/hr}$ on october 12 . This resulted in an increase of the second stage reactor temperature by about $15^{\circ} \mathrm{F}$.

On October 14 to 17 , the unit was off coal feed due to a plug in the catalyst addition tube to R1236 and a leak in one of the ebulation pump heads. Attempts to dislodge the plug for about three days during operations were unsuccessful and the catalyst age continued to increase during this time. The plant was taken off feed and the plug was dislodged. On inspection, the plug material had a strong odor of ammonia, possibly due to ammonium sulfide or ammonium carbonate. The plug may have formed due to temperatures lower than normal around the catalyst addition pot. When the plant came back on coal feed on october 18 , the fresh catalyst was added. Twice the amount of normal replacement was employed on october 20 in order to bring the catalyst age back to an equilibrium age correspondng to $3 \mathrm{lb}$ catalyst/ton MF coal replacement rate.

On october 18 the coal feed rate was further increased to $350 \mathrm{MF}$ $1 \mathrm{~b} / \mathrm{hr}$ in order to increase the second stage reactor temperature. The first stage reactor temperature was maintained at $790^{\circ} \mathrm{F}$. The increase in the coal feed rate increased the second stage reactor temperature to a maximum of about $804^{\circ} \mathrm{F}$. There was some variation in the second stage reactor temperature, possibly due to a period of unusualiy cold weather. The second stage reactor temperature decreased gradually to about $797^{\circ} \mathrm{F}$ over a period of about 5 days.

On October 31 , the first stage temperature was decreased to $775^{\circ} \mathrm{F}$. The lower first stage temperature resulted in a lower first stage preheater outlet temperatures which might prevent retrogressive reactions and coke formation tendencies. Also, the lower first stage temperature resulted in a higher second stage temperature. The second stage temperature increased from about $797^{\circ} \mathrm{F}$ to $804^{\circ} \mathrm{F}$.

As was mentioned in section 3.1, the higher coal feed rate and subsequent decrease in the first stage temperature resulted in higher viscosity of the slurry. The viscosity of the process material in $\mathrm{R} 1236$ (first stage catalytic reactor) increased due to lower resid and coal conversions. The higher viscosity resulted in the operation of the $\mathrm{R} 1236$ ebullation pump at the lowest possible ebullation rate (Figure 8 ) in order to keep the catalyst bed ebullated to a fixed height. 
The lower ebullation flow rates resulted in a much higher temperature rise in the catalytio bed (Figure 9). On November 5 , the exotherm (temperature rise) in the bed increased from about $32^{\circ} \mathrm{F}$ to $50^{\circ} \mathrm{F}$. This might have been caused by a 1 inch diameter hole on top of the plenum chamber which was noticed during the shutdown at the end of the run when the reactor heads were pulled.

Throughout the catalytic/thermal mode of operation (September 26 - November 8), the interstage heater outlet was kept at the maximum temperature possible for safe operation. In spite of this, higher second stage temperatures could not be obtained due to heat losses in the reactor. In the future, the heat losses in the second stage in the low/high mode may be minimized by using $\mathrm{R} 1236$ as the second stage reactor, since R1236 is heat traded (a layer of insulation around the reactors followed by Dowtherm lines and additional insulation).

In addition, the possibility of using hot V1074 (T102 vacuum column bottoms) as the withdrawal tube flush (WTF) solvent can also be considered to achieve higher second stage temperatures. In this run, V182 (T102 overheads) at moderate temperatures was used as the WTF solvent. On November 4 , the WTF solvent flow to R1235 (second stage reactor) was stopped for about 10 minutes due to pump problems. The average reactor temperature immediately increased by about $20^{\circ} \mathrm{F}$. This indicated that V182 as WTF solvent at moderate temperatures had a large cooling effect on the process material in the reactor.

on November 9, the first stage temperature was increased to $805^{\circ} \mathrm{F}$ and the second stage temperature was decreased to $700^{\circ} \mathrm{F}$. The objective of this test was to quantify the effect of operating the interstage heater (B1201) at high outlet temperatures in the previous tests. In the catalytic/thermal mode of operation in this run up to November 8 , the second stage reactor was operating at temperatures much lower than B1201 (interstage heater) outlet temperature. The coal and resid conversions observed after the Eirst. stage reactor might have occured in B1201. The first stage temperature for this test was kept at $805^{\circ} \mathrm{F}$ to maintain operability with reasonable coal conversion, and at the same time, to ensure that the maximum temperature in R1236 was less than that recommended for the shell 324 catalyst.

operating the second stage reactor at $700^{\circ} \mathrm{F}$ resulted in poor separation of gas and liquid in the high pressure separator (V1247) after the second stage. Carryover of the process stream through the overhead of V1247, and at the same time, gases flowing through the bottom of V1247 caused system upset and loss of control in operations. The second stage reactor temperature of control in operations. The second
was immediately increased to $750^{\circ} \mathrm{F}$ which stabilized operations to
some degree. Operation of the second stage reactor at $750^{\circ} \mathrm{F}$ resulted in operation of $B 1201$ in such a way that the inlet temperature was approximately equal to the outlet temperature. After operating for two days at $750^{\circ} \mathrm{F}$ second stage temperature, 
the temperature was deoreased to $735^{\circ} \mathrm{F}$ on November 12 . Operation became ragged and the plant was taken off coal feed. Run 260 ended on November 13. The plant was shut down for modiflcations and maintenance work in preparation for Run 261 .

\section{3 .2 solids Buildup}

Deposition of solids primarily in the transfer line between the reactors and in the interstage separator have been a problem in many runs associated with the ilquefaction of low rank coals. Typical details concerning solid deposition can be found in Run 258 report (Ref. 9). Several solutions to the solid deposition problem were considered. The following solutions were implemented at the beginning of this run:

(1) The piping distance between the first stage reactor outlet and the interstage separator vessel was shortened considerably and heat losses in this transfer line were minimized by heat tracing the ine to achieve higher skin temperatures, and

(2) The interstage separator vessel (V1258) used in previous runs was replaced with a smaller diameter vessel, V1258B. The diameter of V1258B is the same as that of V1247 (V1247 is a high pressure separator located after the second stage reactors; no deposition in V1247 was observed in previous runs). The smalier diameter facilitates higher Iinear velocities through the vessel.

Prior to the start of Run 260, the above two suggestions were implemented. The existing interstage separator, V1258, was replaced by a new vessel, v1258B. The design of this new vessel is similar to V1247. The diameter of V1258B is about 4 times smaller than the original V1258.

The physical location of $\mathrm{V} 1258 \mathrm{~B}$ was between the two reactors and between the $50 \%$ volume and full volume draw off points. This location reduced the distance between the first stage reactor outlet and the new vessel. The minimum piping distance ( 13 feet) was between the vessel and the R1235 75\% volume draw off point. The distance between the original V1258 and the $75 \%$ volume draw off point was more than 90 feet.

In this run, the first stage reactor was operated at full volume, and the distance between reactor exit and V1258B inlet was about 30 feet. This transfer line was heat traced to minimize heat losses. Thermocouples were located on this line and on the separator liquid outlet to monitor the outer surface temperature of the pipe. onset of deposits in the transfer line can be reluted to changes in the pressure drop between the reactor and the vessel, as well as the outer surface temperature of the pipe.

Temperatures around the separator vessel are plotted in Figure 10. Even though the inlet stream temperature remained fairly constant 
between operation day 8 and 27 , both the inlet skin (1iquid inlet) and bottom skin (1iquid outlet) temperatures showed a gradual dec?ine. The increase in first stage temperature to $840^{\circ} \mathrm{F}$ (day 28) increased the liquid inlet and outlet temperatures, with a corresponding increase in skin temperatures.

Even though the gas outlet temperatures were scattered, a decreasing trend was indicated until about day 28 , when the first stage temperature was increased to $840^{\circ} \mathrm{F}$. At this first stage temperature, the gas outlet temperature remained fairly constant. But, when the coal feed rate was decreased from 350 to $300 \mathrm{MF} 1 \mathrm{~b} / \mathrm{hr}$ (day 35), the gas outlet temperature increased and remained fairly constant thereafter.

The gas outlet temperatures can be related to the V164 flow rate (Figure 11). The organic material flashed from the separator vessel is condensed and flows to V164 vessel. The higher amount of organics flashed increases the specific heat of the gas mixture which results in an increase in the gas outlet temperature.

The V164 flow rate decreased steadily from the beginning of the run until about day 28. This decrease might be related to solid deposition in the separator vessel. Sollds deposition decreases the volume of the vessel, increasing the linear velocity, and decreasing the residence time of the process stream in the vessel. The decrease in residence time decreases the amount of material flashed (both entrained bubbles and vaporization of dissolved inorganic gases such as carbon dioxide and organics) from the vessel.

The increase in the flrst stage temperature to $840^{\circ} \mathrm{F}$ increased the stream temperature in the separator vessel which compensated for the decrease in residence time through solids builaup. As a result, the V164 rate remained fairly constant between day 28 and 35. But, when the coal feed rate was decreased to $300 \mathrm{lb} \mathrm{MF}$ coal/hr, the V164 rate increased, probably due to an increase in residence time in the separator vessel.

The pressure drops between the reactor and the separator vessel and between the reactors are plotted in Figure 12 . The increase in pressure drop is a direct indication of solids buildup in both the transfer line and the separator vessel. The pressure drop varies inversely with the diameter available for flow and is proportional to tise square of linear velocity through the line.

The pressure arop between the reactor and separator vessel was nearly constant in the beginning of the run. It started increasing gradually from operating day 14 . The increase in the pressure drop accelerated at a higher first stage temperature and when the coal feed rate was decreased from 350 to $300 \mathrm{lb} \mathrm{MF}$ coal/hr (day 35).

The pressure drop between the reactors started increasing from 
the beginning of the run, but remained fairly constant between operating days 10 and 26. It started increasing gradually when the first stage temperature was increased from 825 to $840^{\circ} \mathrm{F}$. The decrease in feed rate (day 35) to $300 \mathrm{MF} 1 \mathrm{~b} / \mathrm{hr}$ shifted the curve to lower pressure drops, but the rate of increase in the pressure drop remained the same. Operations without the interstage separator (day 43; V1258B overhead blocked) did not arrest the increase in the pressure drop.

Because of the severity of the pressure drop between the reactors, further testing in the thermal/catalytic mode of operation was terminated in order to inspect and clean the lines. On inspection, severe deposit formation was noticed in the transfer line between the first -tage reactor and V1258B. An opening about the size of a pencil was left in the pipe for the process stream to flow. The separator vessel was reported to be clean of deposit, but the line from the separator vessel to the high pressure sampler had deposits as thick as in the line before the separator. A deposit sample showed 76 wt of ash with 2.5 wt $\%$ sulfur.

The conclusion up to this point of the run was that the shorter transfer line with heat tracing and narrower separator vessel did not help in alleviating the deposit problem. Further, problems were compounded since the new vessel was not sufficient to disengage all inorganic gases and water vapor from the process stream. Unlike previous subbituminous coal runs, deposits were observed after the interstage separator. No deposits were observed before the first stage reactor, and it appeared that the deposits started forming progressively after the first stage reactor. Surpxisingly, the separator vessel itself did not have any deposits.

The next step that was taken in order to determine its effect on deposit formation was to operate in the low/high temperature mode with catalyst in the first stage reactor. With lower preheater (B1200) and first stage reactor temperatures and with the catalyst in the first stage, the chances of formation of coke in the first stage reactor would be reduced. cracking activity of the catalyst will result in lower resid and higher distillate concentrations in the exit stream. The presence of catalyst also lowers phenolic concentrations. Hydrogenation activity of the catalyst will result in an increase in the hydrogen content of the process material in the reantor and exit stream. The increase in hydrogen content may prevent repolymerization reactions by effectively quenching free radicals.

In the catalytic/thermal mode of operation at $250 \mathrm{lb} \mathrm{MF}$ coal/hr, the pressure drop between the reactors (Figure 12 ) showed little increase. The coal feed rate was increased to $350 \mathrm{lb} \mathrm{MF} \mathrm{coal/hr}$ on operation day 66. This resulted in a slightly higher pressure drop. But, after about 30 days of operation, the rate of increase in the pressure drop was still much smaller compared to the thermalicatalytic mode of operation. The small slope observed in Figure 12 in the catalytic/thermal mode may be relaieu to incraasing 
viscosity, and not entirely due to deposit formation.

After the shutdown, the reactors, parts of the transfer line between the reactors, and the high pressure separator after the second stage reactor were inspected for signs of deposit formation. Table 3 gives the elemental analysis and the weight percent ash and CI of the solid deposition samples that were obtained. Figure 13 shows the locations at which the deposit samples were taken. Metal analyses of two deposit samples along with Black Thunder coal ash is given in Table 4. Typical metal analyses of solid deposit samples from Run 258 are also given in Table 4 for comparison.

The ebullating pump suction tube in R1235 (thermal second stage), which runs along the length of the reactor from the suction cup in the reactor through the bottom head and to the pump, had considerable deposit both on the inside and outside surfaces. The thickness of the deposit on the outside surface of the suction tube in the reactor was about $3 / 4$ inch and on the inside surface the deposit thickness was about $1 / 4$ inch. The thermal reactor had about a 5/16 inch thick buildup on the walls and considerable amounts of solids ( $132 \mathrm{lbs})$ at the bottom of the reactor.

About 1/8 inch thick solid deposits were also found in the V1247 bottom outlet pipe. The first stage catalytic reactor was fairly bottom outlet pipe. The first stage cataly stage reactor and the high
clean. The pipe between the first stage
pressure sampler was essentialiy clean. Since a steady, slowly increasing pressure drop was observed between the reactors during the catalytic/thermal mode of operation, it was suspected that the line between $\mathrm{B} 1201$ and the second stage reactor may have some buildup. However, the line feeding the second stage reactor was inspected and found to be essentially clean. A summary of equipment and piping inspections as well as analyses of samples is given in section 3.1 .

Metal analyses of deposit samples from Runs 258 and 260 are given in Table 4. The Black Thunder coal used in Run 260 (period 260C) had much higher calcium (metal analyses are reported in Table 4 as oxides) than Run 258 (24.0 versus 17.7 wt $\%$ ash). Even then, the Run 260 deposit samples showed calcium content which are similar to that observed in Run 258. The solids that settled in the thermal stage in Run 260 showed much higher iron content than in the deposits. Comparing Black Thunder coal deposits in Run 260 and 258 (SN 16411 versus SN 1477), it appears that aluminum (24.1 vs 14.4 wt 8 ash), magnesium ( 9.7 vs 3.8 ), sodium ( 5.1 vs 1.5), and titanium (5.4 vs 1.4 ) are present in much higher percentage in Run 260 ( 5.8 vs 27.6 wt \% ash). Based on metal analyses, it seems that the deposits observed in R1235 in Run 260 are different from that observed in Run 258 in V1258.

In summary, the catalytic/thermal mode of operation showed promise so far in preventing or at least in arresting rapid builaup of deposits between the reactors. The catalyst in the 
first stage and/or the low preheater (B1200) and first stage temperatures did help in preventing solid deposition after the first stage reactor. However, at first glance, it seems that the instead of being solved, the deposition problem was shifted downstream into the second stage reactor.

\subsubsection{Process Performance}

During the entire run, the CCR unit was on stream for 2253 hours for an on stream efficiency of $93.8 \%$. Coal and resid conversion, hydrogen consumption, distillate and resid yields were monitored daily as process performance indicators. A summary of Phase 2 TSL yields are given in Table 5. Table 6 gives the actual temperature rises observed within the reactors for different periods. A detailed discussion of process performance and unit conversions is given in section 4.0 .

The resid concentration in the interstage stream in the catalytic/thermal mode was lower than in the thermal/catalytic mode (Figure 14). Periods $260 \mathrm{C}$ and $260 \mathrm{D}$ were comparable since they were operated at the same coal feed rate and the same catalytic reactor temperature with no interstage separator. The average resid concentration during period $260 \mathrm{C}$ (thermal/catalytic) was about 40 wt 8 , and for period $260 \mathrm{D}$ (catalytic/thermal) about $33 \mathrm{wt} \%$. The lower resid concentration in the interstage sample for catalytic/thermal mode was caused by lower resid production in the first stage due to lower coal conversion. The first stage coal conversion in the thermal/catalytic mode was above $90 \mathrm{wt} \%$, whereas the coal conversion was only about 75 wt $\%$ in the catalytic/thermal mode.

The total ash entering the first stage reactor, as shown in Figure 15, was much lower in the catalytic/thermal operation than in the thermal/catalytic operation. Total ash is the sum of recycle ash, ash in the feed coal, and iron oxide that was added. The sum of coal ash and iron oxide as a percentage of MAF coal was fairly constant around $9 \mathrm{wt} \%$. Therefore, the changes in the total ash were mainly due to changes in the amount of ash recycled. Since the recycle solids were kept constant in the process solvent at $20 \mathrm{wt} \%$, the percentage of ash in the total recycle solids would be reduced if there was a higher percentage of UC from lower coal conversion. Higher UC in the recycle solids due to lower coal conversion in the catalytic/thermal mode caused lower total ash in the feed to the first stage reactor.

Having more ROSE-SR ${ }^{S M}$ resid in the process solvent is beneficial since it may be more reactive than the full range V1082 recycle resid. Figure 16 shows the resid from the ROSE-SR ${ }^{S M}$ unit as a percentage of total resid entering the first stage reactor. Total resid is the sum of the ROSE-SR ${ }^{S M}$ resid and resid from the V1082 vacuum flash bottoms recycle stream. Comparing periods $260 C$ and $260 D$, the ROSE-SR ${ }^{S M}$ resid averaged around 15 wt $\%$ for the thermal/catalytic mode and $20 \mathrm{wt} \%$ for the catalytic/thermal mode. The effect of the higher ROSE-SR ${ }^{S M}$ resid in $260 \mathrm{D}$ on conversions could not be ascertained because of different 
operating conditions between periods $260 \mathrm{C}$ and $260 \mathrm{D}$.

Throughout Run 260 , the process solvent contained 40 wt $\%$ resid and 20 wt $\% \mathrm{CI}$. About $83 \%$ of resid requirements came from directly recycling V1082 vacuum flash bottoms to meet the 20 wt 8 CI requirements for the process solvent. The ROSE-SR ${ }^{\text {SM }}$ unit contributed the rest of the resid ( $17 \%$ of the total resid) to the process solvent. If all the $40 \mathrm{wt}$ \% resid in the process solvent is to be met by the v1082 recycle and with no resid contribution from the ROSE-SR unit, then the process solvent will contain 24 wt CI (based on periods $260 \mathrm{C}$ and $260 \mathrm{D}$ data).

There was a large increase in the exotherm in the catalytic reactor when the catalytic reactor was used as the first stage. The temperature increase within the thermal stage was negligible in both thermal/catalytic and catalytic/thermal modes of operation (Figure 9). The increase in the first stage temperature from 825 to $840^{\circ} \mathrm{F}$ (day 28) decreased the exotherm significantly in the catalytic second stage reactor (from about $17^{\circ} \mathrm{F}$ to $\left.10^{\circ} \mathrm{F}\right)$. Operation without the interstage separation of gases decreased the exotherm slightly (operating day 43). This might be the result of decreased hydrogen partial pressure in the second stage. The decrease in catalyst exotherm going from 260A to $260 \mathrm{~B}$ and then an increase from $260 \mathrm{C}$ to $260 \mathrm{D}$ is more likely a reflection of the quality of the feedstock rather than a measure of intrinsic catalyst activity. It appears that the second stage preforms less work if first stage is operated at high conversion levels.

The higher exotherms in the catalytic reactor during the catalytic/thermal mode of operation were the result of higher conversions (resid conversion, water production, and hydrogenation activity) and lower ebullation rates. The lower ebullation rate was caused by higher viscosity of the process material in the reactor.

As seen in Figure 8 , the ebullation rate in the catalytic reactor decreased once the catalytic reactor became the first stage (the ordinate in the Figure is not labeled since the ebullation rates are proprietary). The ebullation rate also decreased when the coal feed rate increased to $350 \mathrm{lb} / \mathrm{hr}$ (day 66) and when the first stage temperature was decreased to $775^{\circ} \mathrm{F}$ (day 81 ). These process condition changes resulted in higher viscosities of the process material in the catalytic reactor requiring lower ebullation rates to maintain the catalyst bed height.

Average Phase 2 data for November 10 and 11 are summarized in Table 7. The first and second stage temperatures were 804 and $752^{\circ} \mathrm{F}$, respectively. Other run conditions were similar to period 260F. The first stage coal conversion was 82.2 wt: MAF and the overall TSL coal conversion was 84.3 wto MAF. The resid + UC conversions (wt $\%$ feed) in the first and second stage were 30.3 wt $q$ and -1.3 wt $\%$. These data indicate that virtually all the conversions took place in the first stage reactor. 
The increase in first stage temperature from $775^{\circ} \mathrm{F}$ to $805^{\circ} \mathrm{F}$ increased the first stage coal conversion from about 71 to 82 wt $\%$ MAF. The resid+UC conversion in the first stage increased from 24.8 to 30.3 wt $t$ feed. The decrease in the second stage temperature from about $804^{\circ} \mathrm{F}$ to $750^{\circ} \mathrm{F}$ decreased the resid+UC conversion from 7.1 to -1.3 wt $\&$ feed.

The TSL coal conversion decreased from 88.1 wt $\%$ MAF in $260 \mathrm{~F}$ to 84.3 wt $\%$ MAF during November 10 and 11 . The $C_{1}-C_{3}$ gas make and hydrogen consumption increased slightly during the November 10 and 11 test compared to 260F. However, the distillate yield and the ROSE-SR ${ }^{\text {SM }}$ unit solid product remained nearly the same.

Since in the catalytic/thermal mode of operation there was lower thermal severity in the first stage, the first stage coal conversions were checked with pyridine as the solvent. There was a possibility that pyridine solvency may be a better indicator than cresol solvency for operation with a lower first stage thermal severity. The interstage and V1082 samples were tested for pyridine insolubles (PI) for two days from both thermal/cataly+ic and catalytic/thermal modes of operation. The percentages of pyridine insolubles and cresol insolubles are presented in Table $D$. The first stage coal conversions using $C I$ and PI are compared in Table $E$.

\section{Table D. percentage of Pyridine Insolubles cresol Insolubles}

\begin{tabular}{|c|c|c|c|c|c|c|c|c|}
\hline \multirow[b]{2}{*}{ Date } & \multirow[b]{2}{*}{ Period } & \multirow{2}{*}{$\begin{array}{l}\text { Mode of } \\
\text { operation }\end{array}$} & \multicolumn{3}{|c|}{$\begin{array}{l}\text { Interstage } \\
\text { Stream (wt } f)\end{array}$} & \multicolumn{3}{|c|}{$\begin{array}{r}\mathrm{V} 1082 \\
\text { Bottoms } \\
\end{array}$} \\
\hline & & & $C I$ & $P I$ & $(C I-P I)$ & CI & PI & $(C I-P I)$ \\
\hline $\begin{array}{l}9 / 2 \\
9 / 3\end{array}$ & $\begin{array}{l}260 \mathrm{C} \\
260 \mathrm{C}\end{array}$ & $\begin{array}{l}\text { therm/cat } \\
\text { therm/cat }\end{array}$ & $\begin{array}{l}21.6 \\
23.0\end{array}$ & $\begin{array}{l}\overline{19.7} \\
21.1\end{array}$ & $\begin{array}{l}1.9 \\
1.9\end{array}$ & $\begin{array}{c}35.7 \\
-.\end{array}$ & $\begin{array}{c}33.3 \\
-.\end{array}$ & $\begin{array}{r}2.4 \\
-.\end{array}$ \\
\hline $\begin{array}{l}10 / 10 \\
10 / 11\end{array}$ & $\begin{array}{l}260 D \\
260 D\end{array}$ & $\begin{array}{l}\text { cat/therm } \\
\text { cat/therm }\end{array}$ & $\begin{array}{l}26.1 \\
26.2\end{array}$ & $\begin{array}{l}24.4 \\
24.7\end{array}$ & $\begin{array}{l}1.7 \\
1.5\end{array}$ & $3 \overline{7.4}$ & 35.9 & $1 . \overline{5}$ \\
\hline
\end{tabular}

rable E. First stage coal conversion Using CI and PI

\begin{tabular}{|c|c|c|c|c|c|}
\hline Date & Period & $\begin{array}{l}\text { Mode of } \\
\text { operation }\end{array}$ & $\frac{\text { 1st stage }}{\text { (using CI) }}$ & $\frac{1 \text { Conversio }}{\text { (using PI) }}$ & $\frac{\text { wt \& MAF }}{(P I-C I)}$ \\
\hline $\begin{array}{l}9 / 2 \\
9 / 3\end{array}$ & $\begin{array}{l}260 C \\
260 C\end{array}$ & $\begin{array}{l}\text { therm/cat } \\
\text { therm/cat }\end{array}$ & $\begin{array}{l}94.6 \\
90.4\end{array}$ & $\begin{array}{l}96.7 \\
92.2\end{array}$ & $\begin{array}{l}2.1 \\
1.8\end{array}$ \\
\hline $\begin{array}{l}10 / 10 \\
10 / 11\end{array}$ & $\begin{array}{l}260 D \\
260 D\end{array}$ & $\begin{array}{l}\text { cat/therm } \\
\text { cat/therm }\end{array}$ & $\begin{array}{l}79.8 \\
76.8\end{array}$ & $\begin{array}{l}84.0 \\
78.9\end{array}$ & $\begin{array}{l}4.2 \\
2.1\end{array}$ \\
\hline
\end{tabular}

Comparing the thermal/catalytic with the catalytic/thermal mode, there was not an appreciable change in the coal conversions using pyridine as an indicator. For the thermal/catalytic mode, the coal conversion increased by approximately 2 wt of MAF coal, when pyridine insolubles were used. In the catalytic/thermal mode, the coal conversion did not increase greatly when using pyridine 
insolubles as an indicator (average increase of 3.1 wt $\%$ MAF coal).

There was no appreciable difference when using cresol insolubles coinpared to pyridine insolubles for calculating the first stage coal conversion when comparing thermal/catalytic and catalytic/thermal modes. Cresol seemed to give just as accurate results as pyridine.

\subsection{Residuum oil Supercritical Extraction - Solids Rejection (ROSE-SR Unit}

The objectives for the ROSE-SR ${ }^{S M}$ unit during Run 260 were as follows:

1) To establish acceptable deashing performance while recovering full-range resid for recycle to coal slurry preparation,

2) To obtain maximum resid recovery and minimum organic rejection to the solid product, and

3) To evaluate ROSE-SR ${ }^{S M}$ performance, while operating in both CC-ITSL thermal/catalytic and catalytic/thermal modes with subbituminous Black Thunder Mine coal and Shell 324, 1/16" catalyst.

\subsubsection{Unit operation and Process Performance}

Feed to the ROSE-SR ${ }^{S M}$ unit began on July 19, 1990. Operability was very good during the thermal/catalytic operation, however, during the catalytic/thermal operation, there was lower resid recovery and higher organic rejection. Tables 8 and 9 present the performance parameters and the analytical data for the ROSE$S^{\text {SM }}$ unit. During $260 \mathrm{~F}$ on November 8 , the unit was off feed for a short time due to pumping problems. There were other occasional problems with plugging of the solid product letdown header. process conditions, such as deashing solvent, temperatures, and pressures, were adjusted to prevent letdown header pluggage and improve operability and performance. On August 29 and October $7,8,11$, and 12, there was a significant amount of ash carryover due to adjusting of the DAS strength after the short outage on october 5 and 6 and problems in pulling vacuum on V1082. Otherwise, there were no other notable incidences of ash carryover during Run 260.

For Run 260, the ROSE-SR ${ }^{S M}$ unit was on feed for 2064 hours of the time that feed was available resulting in an on-stream efficiency of 99.0\%. The ROSE-SR fMeed rate was normally maintained so that the rate of ash removal by the unit matched the ash in the feed coal. This was done to avoid accumulation and provided stable material balance data. The desired ash rate was maintained at the inlet to the ROSE-SR fM feed tank. The ROSE-SR unit was then operated as needed to maintain inventories. 
The resid recovery of the ROSE-SR ${ }^{S M}$ unit was 75 to 81 wt $\%$ of the resid fed to the unit during the thermal/catalytic operation $(260 \mathrm{~A}-260 \mathrm{C})$. After the change to the catalytic/thermal mode (260D-260F), the resid recovery gradually decreased from 76 to 62 wt $\%$. Figure 17 presents the resid recovery and the organic rejection for Run 260. Any further attempt to improve the resid recovery during catalytic/thermal mode resulted in plugging of the bottoms product header. The lower resid recovery might have been the result of lower preasphaltenes in the ROSE-SR ${ }^{S M}$ feed.

The organic rejection fell from 15 wt $\%$ MAF coal at the start of the run to 8.5 wt before the reactor switch. During catalytic/thermal mode, the organic rejection gradualiy increased from 12.5 wt $\%$ to as high as 25 wt $\%$ MAF coal. Higher organic rejection resulted from the lower coal conversion in catalytic/thermal mode compared to the thermal/catalytic mode.

In general, preasphaltenes in the ROSE-SR ${ }^{S M}$ feed were higher in the thermal/catalytic mode than in the catalytic/thermal mode. For the same feed rate, the preasphaltenes were higher at $14.3 \mathrm{wt}$ \& for the thermal/catalytic operation than at 7.2 wt $\%$ for the catalytic/thermal mode. In $260 \mathrm{~F}$ after the first reactor temperature was docreased from $790^{\circ} \mathrm{F}$ to $775^{\circ} \mathrm{F}$, the preasphaltenes increased to an ave of $11.0 \mathrm{wt} \%$

The ash content in the solid product, shown in Figure 18, reached 50 wt $\%$ with the cresol insolubles content (ash + unconverted coal) reaching 75 wt $\%$ at the end of the thermal/catalytic operation. This was the highest percentage of ash ever recorded in the solid product. At the completion of Run 260 in the catalytic/thermal operation, the ash content dropped to 26 wt $\%$ in the solid product. The primary reason for the decrease in percent ash during the catalytic/thermal operation was that there was not as much coal conversion in this mode. This resulted in higher organic rejection at the ROSE-SR ${ }^{S M}$ unit and therefore, the percentage of ash was less in the solid product.

Since the sulfur in the solid product depends on the percentage of ash in the solid product, a graph of organic-free sulfur was prepared. Figure 19 shows sulfur and Figure 20 shows the organicfree sulfur in the solid product. The organic-free sulfur content in the solid product was constant throughout Run 260. Therefore, the sulfur rejected in the solid product was part of ash and not organic material. The organic sulfur was not rejected in the organic rejection. The organic sulfur was most likely removed as hydrogen sulfide gas. organic-free sulfur in the resid product stream increased by $0.1 \mathrm{wt} \%$ in the catalytic/thermal mode compared to the thermal/catalytic mode. The small increase was due to a slightly higher percentage of ash in the resid for the catalytic/thermal operation.

Nitrogen in the solid product was found to depend upon the amount of organics rejected in the solid product. Figures 21 and 22 present the percentage of nitrogen and ash-free nitrogen in the bottoms 
product, respectively. In the thermal/catalytlo mode, the ash-free nitrogen remained constant at 1.45 wt $\%$ resid + UC. Once the reactors were switched, ash-free nitrogen slowly increased and reached 1.7 wt 8 resid $+U C$ in the solid product. The nitrogen content in the resid recycle stream was constant at 1.15 wt $q$ in the thermal/catalytic mode. In the catalytic/thermal mode, the nitrogen averaged 1.0 wt 8 .

The UC/ash ratio of the ROSE-SR fM feed decreased during the thermal/catalytic operation. For 260A, 260B, and 260C, the UC/ash ratios were $0.64,0.50$, and 0.44 , respectively. During the second half of Run 260 (catalytic/thermal mode), the UC/ash ratio increased from 0.78 to 1.33 . For $260 \mathrm{D}, 260 \mathrm{E}$, and $260 \mathrm{~F}$, the Uc/ash ratios of the feed averaged $0.92,1.03$, and 1.06 , respectively.

\subsection{Distillation System}

The objectives of the V1082/T105/T102 distillation system for Run 260 were:

\footnotetext{
- To remove low boiling point products in T105 from the interstage separator overheads (when in service) and from the liquid flashed overhead in the second stage reactor.

- To split in T102, the T105 bottoms and heavy vacuum flashed overheads (from V1082) into a product stream and a recycle distillate stream that is in balance with the recycle distillate needs for blending with the coal.
}

Run 260 was the second run to use T102 for adjusting the entire split between recycled distillates and product distillates. Essentially all of the cut points were above $770^{\circ} \mathrm{F}$ (Figure 23). During period 260A, seal oil (approximately 2 wt $\%$ MF coal) entered the system due to internal seal oil leaks on the coal slurry pumps (caused by high slurry viscosity) and T105 bottoms pumps. A level controller malfunction and high ambient temperatures caused light distillates to flow to the recycle distillate (V1074) for periods $260 \mathrm{~B}$ and $260 \mathrm{C}$. Cut points and overlaps were corrected for the light ends.

The cut point for period $260 \mathrm{D}$ was lower than it should have been, since the vacuum on T102 could not be lowered below 2.2 psia. The T102 tower was checked for leaks. None were found. The vacuum jet nozzles were replaced after which good vacuum could be obtained. The cut point increased to $810-820^{\circ} \mathrm{F}$ during periods $260 \mathrm{E}$ and 260F (Table F). The overlap (Figure 24) by the equal weight percent overlap method was $6-11 \%$ for most of the run, but was as high as 15 wt $z$ in November due to the steam boiler's intermittent operations.

The Iightest distillates (V161 in Figure 25) was from the 
overheads from the second stage reactor. The T105 overheads had a boiling point below $500^{\circ} \mathrm{F}$. For most of the run, the T102 overheads (V182, Figure 26) contained little distillate boiling above $850 \%$ except in periods $260 \mathrm{E}$ and $260 \mathrm{~F}$. The recycle distillate (V1074 in Figure 27) was very heavy with more than 60 wt of bolling above $850 \circ \mathrm{F}$. A summary of operating conditions is presented in Table 10.

\section{Table F}

Cut Points and overlaps in Each Period

Period

Avg Cut Point, ${ }^{\circ} \mathrm{F}$ Avg Overlap, wt of

\section{$260 A$}

$\underline{260 B}$

2600

$\underline{260 D}$

$\underline{260 E}$

773

11
790

9
782

8
11

814

9 $\underline{260 F}$

819

13 


\section{OVERALL TWO STAGE LIQUEFACTION YIELDS}

The overall TSL yields are the result of averaged elemental balances around the unit. The analytical data used for these balances are presented in Tables 11-12. Operating conditions, averaged elementally balanced overall yields and unit contributions are summarized in Tables $B$ and $C$ for all representative periods. The yield contributions are also shown schematically in material balance flow diagrams (Figures 28-33).

\subsection{TSL Performance}

The initial part of Run 260 consisted of testing the new interstage separator in the thermal/catalytic mode with full thermal volume and $3 / 4$ catalytic reactor volume. Shell $324,1 / 16 "$ catalyst, equilibrated to a catalyst age equivalent to $3 \mathrm{lb} /$ ton replacement rate was used for startup. However, due to the higher (3/4) reactor volume used in Run 260 compared to the catalytic stage volume (1/2) in Run 258, additional sulfided catalyst had to be added (about 140 ib) to makeup the required total catalyst charge $(300 \mathrm{lb})$.

In period 260A, at a coal feed rate of $352 \mathrm{lb} / \mathrm{hr}$ and $825 / 790^{\circ} \mathrm{F}$ reactor temperatures, the coal conversion was about 95 wt \%. In this period the process solvent contained $40 \mathrm{wt} \%$ resid and $20 \mathrm{wt} \%$ CI. The catalyst replacement in the second stage was $31 \mathrm{~b} /$ ton coal. Due to inadequate separation of light streams in the interstage separator, desirable material balances could not be made in periods $260 \mathrm{~A}$ and $\mathrm{B}$. Thus, these periods were termed unstable. The distillate yield in 260A was 55 wt $\frac{\circ}{5}$ MAF coal (Table B).

In period 260B, the coal feed rate was reduced from 352 to 303 $\mathrm{lb} / \mathrm{hr}$, while the first stage temperature was increased from 825 to $840^{\circ} \mathrm{F}$. Although the $\mathrm{C}_{4}+$ distillate yield remained nearly the same (about 55 wt $t$ ), the net resid yield was very low, about 2 wt 8 MAF coal. Because of the higher first stage temperature, higher carbon oxides and $c_{1}-C_{3}$ gas yields were obtained. The organic rejection in solid product was very low. The coal conversion was about 96 wt 8 . In contrast, the coal conversion was in the range of 88 to 93 wt $\%$ MAF coal in Run 258.

In period $260 \mathrm{C}$, the interstage separation was not performed. The $M F$ coal feed rate was reduced to $251 \mathrm{lb} / \mathrm{hr}$ and the first stage temperature was reduced to $825^{\circ} \mathrm{F}$. The coal conversion was about 9495 wt $\%$. Reducing the first stage temperature reduced both carbon oxides yield and $C_{1}-C_{3}$ gas make. The $C_{4}+$ distillate and organic rejection were about 54 and 11 wt $\%$ MAF coal, respectively. After reducing the coal feed rate from 352 to $303 \mathrm{lb} / \mathrm{hr}$ (from $260 \mathrm{~A}$ to $260 \mathrm{~B})$, it appeared that the flashed distillate (V1078) rate decreased more than expected. Thus, V1078 rate was prorated in periods $260 \mathrm{~B}$ and $260 \mathrm{C}$ based on August 8,9 , and 20 flow rates.

After completing the thermal/catalytic tests, in order to perform catalytic/thermal tests, the reactor sequence was reversed. That is, the process stream was rerouted such that $R 1236$ containing 
Shell 324 catalyst was the first stage reactor and R1235 was the thermal second stage reactor. The coal feed rate was maintained thermal second stage reactor.
same as in period $260 \mathrm{C}$ (about $2501 \mathrm{~b} / \mathrm{hr}$ ). The first stage was at
$790^{\circ} \mathrm{F}$ and the second stage was at $774^{\circ} \mathrm{F}$. Although a higher second stage temperature $\left(825^{\circ} \mathrm{F}\right)$ was targeted, it could not be obtained because of a high conversion in the first stage and higher heat losses in R1235. During this perlod, because of a

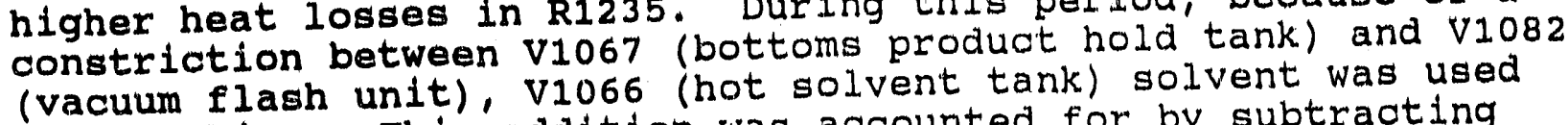
for flushing. This addition was accounted for by subtracting from 1072 distillate rate. The $\mathrm{C}_{4}+$ distillate and resid yields were 59.8 and 0.3 wt : MAF coal, respectively. Due to lower thermal second stage temperature, overall coal conversion decreased from 95 wt 8 in $260 \mathrm{~B} / 260 \mathrm{C}$ to about 88 wt is in $260 \mathrm{D}$. Thus, organic rejection increased to $18.5 \mathrm{wt} \%$ (Table $\mathrm{C}$ ). However, during this period the carbon oxides and $C_{1}-C_{3}$ gas make were low.

In period 260E, the coal feed rate was increased to about 350 $\mathrm{lb} / \mathrm{hr}$ (Vs. $250 \mathrm{lb} / \mathrm{hr}$ in 260D). The Increased coal feed rate allowed the second stage temperature to increase to about $797^{\circ} \mathrm{F}$. In spite of the higher second stage temperature, the first stage coal conversion as well as overali coal conversion decreased by 1 to 2 wt $\%$ MAF coal. There was a significant reduction in distillate yield (decreased from 59.8 to 52.2 wt $\%$ MAF coal).

In period 260F, the first stage temperature was lowered to $774^{\circ} \mathrm{F}$ and the second stage temperature marginally increased to $804^{\circ} \mathrm{F}$. Both first stage and overall coal conversions decreased to about 70.7 and 85.8 wt $\%$, respectively. The distiliate yield further decreased to 48 wt $\%$ MAF coal.

The following is a brief discussion on some of the differences observed between thermal/catalytio and catalytic/thermal operations. Because of heat losses, limitations on the interstage preheater outlet temperature, and low reaction exotherms in the second stage, the target temperature of $825^{\circ} \mathrm{F}$ could not be obtained in the second (thermal) stage. Thus, attempts were made to increase the second stage temperature by increasing the coal feed rate and lowering the first stage temperature. These increased the second stage temperature to a limited extent. Thus, coal conversion in the catalytic/thermal operation was 7-8 wt o lower than in the thermal/catalytio operation. In the TSL yield summary, the sum of $\mathrm{H}_{2} \mathrm{~S}, \mathrm{CO}, \mathrm{CO}_{2}, \mathrm{NH}_{3}$ is reported. In general, the sum of $\mathrm{H}_{2} \mathrm{~S}$ and $\mathrm{NH}_{3}$ was about 1 wt $\frac{z}{6}$ MAF coal. Thus, most of the remaining was carbon oxides. It was interesting to note that this gas yleld was about 4 wt $\%$ in period $260 \mathrm{C}-\mathrm{F}$, during which the interstage separator was not used. Whereas, with interstage separator in periods 260A and $260 \mathrm{~B}$, the average was about $8.5 \mathrm{wt} \%$. Thus, there was a significant reduction in the carbon oxides gas make without the interstage separator. The exact reason for this observation was not clear. 
It may be noted that in period 260D, although the second (thermal) stage temperature was very low, higher overall distillate yleld of about 59.8 wt $\%$ was observed. Based on resid + UC conversion (average of 260A, 260B, 260C $=13.7 \mathrm{wt} 8$ feed, 260D $=29.1 \mathrm{wt} \%$ ) the

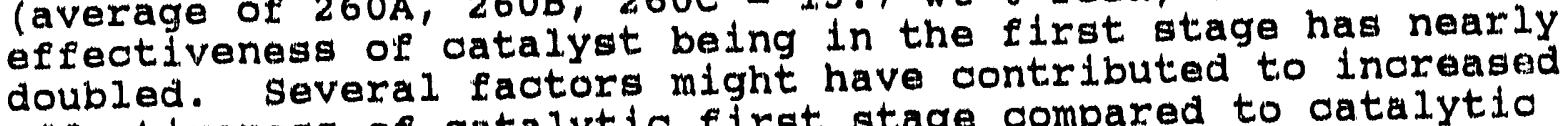
effectiveness of catalytic first stage compared to catalytio wecond stage, although the reactor temperature and catalyst replacement rate were similar in both cases. One reason is that the feedstock entering the first stage is more reactive than that entering the second stage. The other reasons could be that the resid concentration in the catalytic first stage and hydrogen partial pressures were higher in the first stage. In addition, the first pressures were higher in the first deposition and thus presumably a
stage datalyst showed lower carbon deporition may be more
lower rate of deactivation. A low reactivity feedstock may be prone to leaving carbon deposits on the catalyst. It may be speculated that coke or precursor forming reactions occurring at higher temperatures in the upstream sections of the reactor system may be responsible for the higher carbon deposits on the second stage catalyst. In other words, it appeared that the performance of Shell 324 significantly improved under sultable hydrogenation conditions in the first stage (vs. second stage).

The coal feed rate could not be further increased because of limitations on slurry drying capacity at the front end. At present, the slurry heating capacity allows enough drying to obtain $350 \mathrm{MF}$ ib coal/hr feed rate for the coal containing about 20 wt o moisture. In order to obtain a higher coal feed rate, modifications are required to the front end. or, the coal should have significantiy lower moisture to start with before slurry drying.

The average water yield in Run 260 was about 17.2 wt 8 MAF coal; whereas in Run 258, it was about 12.9 wt 8 MAF (Black Thunder. coal). The average $\mathrm{H}_{2}$ consumptions in Runs 258 and 260 were 5.28 and 5.73 wt 8 , respectively. Approximately, the percent of total hydrogen consumed that went into water make was about $27 \%$ in Run 258 and $33 \%$ in Run 260. In other words, nearly $1 / 3$ of total hydrogen consumption was due to water make in Run 260, which is not desirable. Higher water ylelds in Run 260 may be due to reaction of carbon oxides with hydrogen to give water and methane. The higher hydrogen consumptions for water yleld indicated the need for some kind of pretreatment.

It may be noted that the $C_{1}-C_{3}$ gas yields were low in the catalytic/thermal operation (in the range of 5-6 wt $q$ ) primarily because the target thermal stage temperatures could not be obtained.

\subsection{Process Solvent Quality and Hydrogenation}

The process solvent qualities (for the entire solvent containing distillate, resid, and CI) from this run were comparable to other subbituminous coal runs. Table G compares process solvent 
qualities from this run with those from Run 258 . The solvent

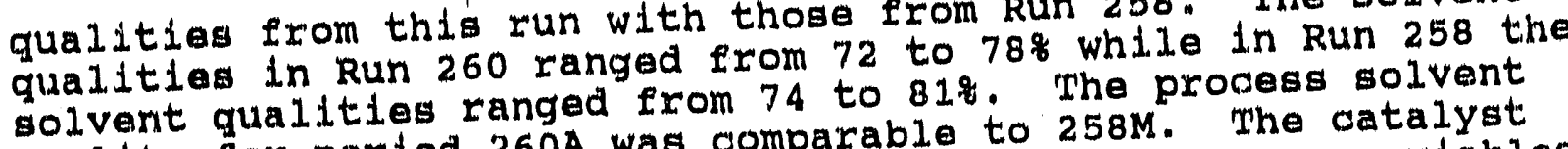
quality for period $260 \mathrm{~A}$ was comparable to $258 \mathrm{M}$. The catalyst ages in $258 \mathrm{M}$ and $260 \mathrm{~A}$ were simliar, but other process varlables were different.

The increase in the first stage temperature on August 15 (frm 825 to $840^{\circ} \mathrm{F}$ ) decreased the process solvent quality to $70 \%$ from $73 \%$ in period 260A. The subsequent decrease in coal feed rate on August 22 (from 350 to 300 ib MF coal/hr) increased the solvent quality to about $72 \%$ (period 260B). When the first stage temperature was reduced and the coal feed rate was further reduced on August 30 (260C pertad) (from 840 to $825^{\circ} \mathrm{F} ;$ and from 300 to $250 \mathrm{lb} \mathrm{MF}$ coal/hr), the solvent quality increased to about 768 .

The solvent quality during the catalytio/thermal operation was higher compared to the thermal/catalytio mode ( $76 \%$ in $260 \mathrm{C}$ vs $78 \%$ In 260D). After the coal feed rate was increased during ootober 12 and 18 (260E period), the solvent quality decreased by $4 \%$ in (from $78 \%$ in 2600 to $74 \%$ in $260 \mathrm{E}$ ) lower first stage temperature (a change increased as a result of lower quality showed a decrease to $73.3 \%$ from $790^{\circ} \mathrm{F}$ to $775^{\circ} \mathrm{F}$. to $805^{\circ} \mathrm{F}$ during November 10 and 11 .

Table G. Bolvent Quality

$\begin{array}{ccc} & \text { Period } & \text { solvent ouadity } 8 \\ \text { Run } 260 & & 73.1 \\ & 260 \mathrm{~A} & 72.1 \\ & 260 \mathrm{~B} & 76.0 \\ & 260 \mathrm{C} & 78.1 \\ & 260 \mathrm{D} & 73.8 \\ & 260 \mathrm{E} & 75.6 \\ & 260 \mathrm{~F} & 73.3 \\ & \text { Nov } 10 / 11 & 75.2 \\ \text { Run } 258 & & 73.7 \\ & 258 \mathrm{H} & 78.2 \\ & 258 \mathrm{I} & 81.3 \\ & 258 \mathrm{~J} & 75.3 \\ & 258 \mathrm{~K} & \\ & 258 \mathrm{M} & \end{array}$

The hydrogen content in the process solvent and interstage stream (Figure 34) was much greater in the catalytic/thermal than in the thermal/catalytic mode of operation. The interstage stream feeds the second stage reactor, while the process solvent and coal feed the flrst stage reactor. Unlike the thermal/catalytic mode of operation, in the catalytic/thermal mode, the interstage stream contalned slightiy more hydrogen than the process solvent.

Both distillate and resid portions of the process solvent showed a considerable increase in hydrogen content in the catalytic/thermal 
mode of operation (Figure 35 ). This increase in the hydrogen content was mainiy due to higher hydrogenation activity. in the catalytic stage and lower thermal stage temperatures.

In the catalytio/thermal mode of operation, the hydrogen content in the resid and distiliate portions of the interstage stream show significant improvements compared to the thermal/catalytio mode (Figure 36). These improvements are due to the catalyst in the first stage and operations with lower ficst stage temperatures. Changes in provess conditions in the thermal/catalytio mode such as increasing the first stage temperature to $840^{\circ} \mathrm{F}$ (operating day 28) decreased the resid hydrogen content in the interstage stream. The resid hydrogen oontent increased when the feed rate was decreased from 350 to $300 \mathrm{lb} / \mathrm{hr}$ MF coal (operating day 35 ).

A comparison of the process solvent and interstage stream resid hydrogen content showed that both streams were similar. (Figure 37). However, the important point to note is that the resid hydrogen of both the process solvent and interstage stream were much higher in the catalytic/thermal mode than in the thermal/catalytic mode of operation. 


\section{Catalyst}

A total of 1480 lbs of Shell $3241 / 16^{\prime \prime}$ catalyst was sulfided in four batches between July 9 and 16 for use in the catalyst replacement program during the run.

The second stage reactor was initially charged with 280 lbs (dry) Sheil catalyst. The catalyst charge was a mixture of $1201 \mathrm{bs}$ of fresh sulfided catalyst and $160 \mathrm{lbs}$ of ased catalyst from Run 258 (aged with Black Thunder coal; catalyst ages were 664 lb MF coal/lb catalyst and $1324 \mathrm{lb}$ (resid+CI)/lb catalyst). A mixture of fresh and aged catalyst was used to reduce the time required to reach an equilibrium age. Since the reactors were operated at half volume in Run 258, the amount of catalyst from Run 258 was not enough, therefore, fresh catalyst was added to the charge. Because the mixed catalyst charge had a younger age than the age desired, the catalyst was batch aged from July 19 to August 5.

On July 24 , the catalyst charge was increased to the target of 300 lbs. On August 2, catalyst replacement began in the second stage at 3 ib cat/ton MF coal to maintain the equilibrium catalyst age at 670 Ib MF coal/1b catalyst. Catalyst replacement was scheduled for every other day. The catalyst ages for Run 260 are presented in Figure 38. The Resid + CI catalyst age increased gradually throughout the run.

There were problems with catalyst withdrawal on August 2, the first catalyst replacement day. The withdrawal tube on R1236 was plugged. After several attempts, the necessary amount of catalyst was finally withdrawn and fresh catalyst was added back on August 4. To maintain the equilibrium age, another replacement was done on August 4 .

On october 12, fresh sulfided catalyst could not be added as scheduled due to a plug in the catalyst addition tube. Attempts to dislodge the plug for over a three day operation period were unsuccessful, resulting in an increase in catalyst age. The plant was taken off feed and the plug was dislodged. When the plant came back on coal feed on october 18, the fresh catalyst was added. Twice the normal amount for replacement was added on october 20 in order to bring the catalyst age back to an equilibrium age corresponding to 3 lb catalyst/ton MF coal.

on inspection, the plug material of october 12 had a strong odor of ammonium sulfide or ammonium carbonate. The plug might have formed due to temperatures lower than normal around the catalyst addition pot. The plug was removed, and the plant was put on coal feed.

\subsection{Catalyst sulfiding Procedure}

The Shell 324 catalyst used in hün 260 was sulfided using the following procedure: 
The fresh catalyst was sulfided with dimethyl disulfide (DMDS) at 1.5 wt $z$ initial concentration in recirculating No. 2 diesel

(fuel) oil. The feed gas rate was maintained at $3,000 \mathrm{SCFH}$, and catalyst bed ebullation began when the reactor temperature reached $250^{\circ} \mathrm{F}$. The reactor was heated stepwise by $50^{\circ} \mathrm{F}$ from 250 to $400^{\circ} \mathrm{F}$. Each temperature was held until the hydrogen sulfide "breakthrough" occurred, indicating the end point of the sulfiding at this temperature. During the sulfiding, the hydrogen-rich vent gas was recycled and DMDS was added to the diesel oil at a rate of $12 \mathrm{lbs} / \mathrm{hr}$. The reactor temperature was again increased stepwise by $50^{\circ} \mathrm{F}$ and held at $500^{\circ} \mathrm{F}, 600^{\circ} \mathrm{F}$, and $700^{\circ} \mathrm{F}$ until the breakthrough occurred. At the maximum temperature $\left(700^{\circ}\right)$, the reactor was held until the analysis of the catalyst samples indicated a sulfur content ${ }^{1}$ of at least 9.0 wt $\%$. The reactor was cooled at a maximum rate of $100^{\circ} \mathrm{F} / \mathrm{hr}$ until it was less than $300^{\circ} \mathrm{F}$. The catalyst was withdrawn and stored in drums at ambient conditions and covered with fuel oil.

The analytical results for the fresh sulfided shell 324 catalyst and withdrawn. catalyst along with the daily analytical results, are shown in Table 13. Fresh sulfided Shell catalyst had an average naphthalene activity of 162 mmoles $\mathrm{H}_{2}$ consumed. The average carbon buildup during sulfiding was 1.0 wt $\%$. Very little breakage occurred to the shell catalyst during the sulfiding process:

\section{Shell Catalyst}

R1236

\begin{tabular}{cccc} 
U.S. Standard Screen & Size Distribution \\
\hline 14 & $\# 18$ & $\# 25$ & -25 \\
98.9 & 1.9 & 0.1 & 0.2
\end{tabular}

\subsection{Analytical Results and Recovery}

Analytical results of each catalyst sample include an elemental analysis, a screen analysis, an ash evaluation, and a naphthalene activity test. The carbon content was evaluated to determine any buildup that would inhibit catalyst activity. The naphthalene activity test determines the hydrogen consumption during the hydrogenation of a fixed volume of catalyst in a laboratory microautoclave reactor, measured in units of millimoles of hydrogen consumed per $100 \mathrm{~g}$ of liquid sample. Naphthalene is the model compound used to measure relative catalyst activity in a laboratory microautoclave reactor and is independent of pilot plant reactor or TSI system performance.

Recovery of catalyst was calculated when the entire catalyst bed was removed from the reactor. Since the reported weight was always a dry weight, the ash analysis was used to determine the difference in the actual wet weight and the theoretical dry weight. Due to the

1

$$
\text { wt } \& S=\frac{\text { "as is" wt } \% S}{\text { wt \& ash }}
$$


additional process ash remaining in the reactor after shutdown, the optimum recovery was usually 107 wt $\%$.

Several catalyst samples were sent to outside laboratories (Alabama Power Company General Laboratory and Galbraith Laboratories) for metals deposition analysis. These results are shown in Table 13.

\section{2 .1 Catalyst size and Recovery}

In previous runs at wilsonville with shell 324 catalyst, no problems were observed with catalyst breaking or fracturing, and Run 260 was no exception. The Shell 324 catalyst had a screen analysis (Table 12) indicating a high catalyst integrity with only a small fraction of the original charge being broken.

The screen analysis of the withdrawal samples during the run with Shell catalyst showed that the catalyst held its size very well, with average values for the +14 screen size greater than 98 wt $\%$ for the catalyst. At the end of the run, catalyst was withdrawn from the reactor following the normal witharawal procedure. catalyst recovery in $\mathrm{R} 1236$ was 104 wt $\%$.

The screen analysis of the end-of-run sample showed that 3.3 wt 8 of the catalyst charge consisted of non-supported catalytic fines. The color of calcined samples (calcine-burn carbon off the THF extracted samples) of these fines were much different from that of the Shell catalyst. Shell catalyst had a yellowish green color, while the fines had a reddish brown color, typical of iron compounds. The 14 mesh screen retained about 92 wt\% of the end-of-run shell 324 catalyst, which was similar to that observed in Run 258. The end-of-run screen analyses in Table 13 were prorated by excluding the fines.

\subsubsection{Catalyst Elemental Analysis and Naphthalene Activity}

Carbon on the fresh sulfided catalyst was approximately 1 wt $q$. In the beginning of the run (period 260A), the carbon deposits averaged 11.5 wt $\%$. At the end of the thermal/catalytic operation in period $260 \mathrm{C}$, the carbon deposits increased to almost 15 wt: . However, after the reactors were switched, and with the catalyst in the low temperature first stage, the carbon on the catalyst started decreasing to below $10 \mathrm{wt} \%$. The lowest wt $\%$ of carbon on the catalyst observed in $260 \mathrm{~F}$ was still higher than 8.8 wt $\&$ observed in $258 \mathrm{M}$. The increase in the first stage temperature from $775^{\circ} \mathrm{F}$ to $805^{\circ} \mathrm{F}$ resulted in an increase in carbon deposition from about 10 to about 12 wt $\%$

The catalyst retained the sulfur well in Run 260 , in fact, the sulfur showed a slight increase in the catalytic/thermal mode. Figure 39 presents the carbon and sulfur deposits on the catalyst.

Although not as pronounced, both the hydrogen and nitrogen 
deposits showed similar trends to the carbon deposits. The hydrogen and nitrogen gradually increased in the thermal/catalytic mode and gradually decreased in the catalytic/thermal mode. In Figure 40, it appeared that the nitrogen and hydrogen on the catalyst during the run were similar to fresh catalyst values. However, the catalyst weight increased during the run due to carbon deposition, and therefore, the amount of nitrogen and hydrogen per gram of ashy (calcined) catalyst during the run would be more than the fresh catalyst values.

The Shell catalyst carbon to hydrogen atomic ratio averaged 1.2 until october 18, when the coal feed rate was increased, after which the ratio averaged 1.1 (Figure 41 ). This ratio suggested that most of the carbon on the catalyst existed in the form of aromatic compounds. To give an idea of what this ratio implicates, naphthalene has a carbon to hydrogen atomic ratio of 1.25 .

on the other hand, the carbon to hydrogen atomic ratio for the On the other hand, the carbon to hydrogen ato fresh catalyst
fresh catalyst. was hard to rationalize. The fred
seemed to have abundant hydrogen on the catalyst compared to carbon ( 0.1 ratio). To give an idea about this ratio, hexane has an atomic ratio of 0.43 . The very low ratio for the fresh catalyst might be due to water vapor in the measuring instrument or hydroxl groups in the form of metal hydroxides or metal hydrides present on the catalyst.

The fresh catalyst had an average naphthalene activity of 162 mmoles of $\mathrm{H}_{2}$ (Figure 42). This was less than in Run 258 where the fresh catalyst naphthalene activity was about 190 . During thermal/catalytic mode, the naphthalene activity averaged 20 . But with catalyst in the first stage, the values of the same catalyst more than doubled to 45-50 (operating day 52). The increase in the naphthalene activity of the catalyst during the catalytic/thermal mode might be related to the lower carbon deposition on the catalyst. Naphthalene activity in Run 260 was less than in period 258M where it averaged about 60 .

Metal analyses of the shell catalyst withdrawn during the run are given in Table 14. Catalyst samples were THF extracted and then calcined before performing metal analysis. The analyses reported in Table 14 are for the metals in the most probable form of their oxides. Iron on the catalyst was much more when the catalyst was present in the first stage $(260 \mathrm{D}-\mathrm{F})$ than when it was in the second stage $(260 \mathrm{~A}-\mathrm{C})$. This may have resulted due to catalyst in the first stage (26OD-F) coming in contact with fresh coal, iron oxide, and a sulfiding agent (TNPS).

Nickel on the catalyst remained fairly constant throughout the run. Sodium on the catalyst showed of operations. Sodium averaged $5.1 \mathrm{wt}$ the catalye of samples indicated by $a *$ in Table 14) in $260 \mathrm{~A}-\mathrm{C}$ and \& (average of samples in Run 258 , sodium on the catalyst was about 
3.5 wt $\%$ and 7.0 wt $\%$, respectively, when Black Thunder mine and spring creek mine coals were processed. Sulfur on the catalyst shows that it was retained well during calcining of $260 \mathrm{~A}-\mathrm{C}$ samples about ( 8.9 wt $\%$ ) than $260 \mathrm{D}-\mathrm{F}$ samples ( 1.7 wt $\%$ ). Higher sodium may have retained sulfur on the $260 \mathrm{~A}-\mathrm{C}$ catalyst samples.

\subsection{Run 260 Catalyst Activity and Thermal Conversion Analyses}

Shell $3241 / 16 "$ catalyst activity and thermal conversion were evaluated and analyzed for Black Thunder coal, based on Phase 2 and 3 resid + UC conversion trend data. The first stage, the second stage, and the overall two-stage conversion for both first and second stage conversions were compared for TSL performance evaluation.

Run 260 in the thermal/catalytic mode of operation began on July 17 with a full-volume reactor in the first stage and a threequarters-volume reactor in the second stage and continued for the period July 25 - September 7 (7-51 operation days) (260A-C MB periods). In Run 258 , with half-volume reactors satisfactory coal and resid conversions were not obtained at high space velocities. Thus, in Run 260 larger reactor volumes were selected expecting to give better conversions. The start-up process solvent was derived from the previous run (259) processing Ireland Mine (Pittsburgh No. 8 seam) bituminous coal. Catalyst charge in the second stage was increased from 280 to 300 lbs on July 24. Batch deactivation continued until the age equivalent to the equilibrium age with catalyst replacement at 3 1b/ton MF coal rate. There were operational difficulties with the new interstage separator during this period. It seemed that the product and hydrogen gases from the first stage were not completely separated due to the smaller size of the interstage separator used, which appeared not providing enough gas residence time for separation. The gas stream analyses in the second stage indicated that a significant portion of the product and hydrogen gases from the first stage continuously traveled through to the second stage. The operational problems of the interstage separator caused difficulties in calculations of each stage performance data and continued until August 30 (43 operation days), when the vent line on the interstage gas separator was blocked to send all of the first stage products to the second stage.

Catalyst and thermal conversion activities were analyzed based on phase 2 TSL resid yield by adjusting to a common organic rejection of 10 wt o MAF coal. Steady-state operation began on August 4 ( 17 operation days) with catalyst replacement in the second stage at a 3 Ib/ton MF coal. rate, and continued during this portion of the run. Reaction temperatures studied for this period were $825-840^{\circ} \mathrm{F}$ in the first stage and $790^{\circ} \mathrm{F}$ in the second stage. Coal feed rates were 250-350 MF $\mathrm{lb} / \mathrm{hr}$, and recycle resid and CI concentrations were 40 and 20 wt $\%$, respectively, in the recycle process solvent. Ironoxide addition was 2 wt $\%$ MF coal and di-tertiary-Nonyl-Polysulfide (TNPS, $\mathrm{C}_{9} \mathrm{H}_{19} \mathrm{~S}_{\times} \mathrm{C}_{9} \mathrm{H}_{19}$ ) was used as a sulfiding agent. 
Results are illustrated in Figures 43 to 45 . Cracking activity (resid conversion) is not the only function of the catalyst. Hydrogenation activity of the catalyst was not considered in these catalyst activity analyses. Trend data for the catalyst hydrogenation were discussed based on hydrogen contents of recycle resid and distillate in section 4.2 solvent Quality and Hydrogenation.

Due to the operational problems of the interstage separator, each stage performance data could not be calculated because the product streams of the first stage were not accurately measured. However, TSL performance data were calculated for evaluation. For each stage, resid + UC conversion the forced ash balance method (FAB) was used to calculate the resid conversion and each stage conversion was adjusted by proration to match the measured TSL conversion. The resid + UC conversion in the second stage could have been affected due to a lower hydrogen partial pressure without good interstage gas separation.

The plant was shut down during september 8-25 in preparation for the catalytic/thermal mode of operation. The interstage separator was eliminated from the process and the reactor sequence was reversed. on september 26, the plant operation resumed in the catalytic/thermal mode of operation.

During the period september 27 - November 13 (operation days 5294) (260D-F MB periods and period November 10-13) in the catalytic/thermal and low/high mode of operation, reaction temperatures studied were $775-805^{\circ} \mathrm{F}$ in the first stage and 735$805^{\circ} \mathrm{F}$ in the second stage. Coal feed rates were 250-350 MF $\mathrm{lb} / \mathrm{hr}$, and other operating conditions were similar to those in the previous thermal/catalytic mode. In the catalytic/thermal mode of operation, the second stage reaction temperature could not be increased to the target $\left(825^{\circ} \mathrm{F}\right)$ due to a low process heat generated in the second stage. In period $260 \mathrm{E}$ at a higher coal feed rate of $350 \mathrm{MF} \mathrm{lb} / \mathrm{hr}$, the second stage reaction temperature increased from 774 to $797^{\circ} \mathrm{F}$; in period $260 \mathrm{~F}$ at a lower first stage reaction temperature of $775^{\circ} \mathrm{F}$, the temperature further improved to $804^{\circ} \mathrm{F}$. The outlet temperature of the interstage heater was set at $850^{\circ} \mathrm{F}$, which might have affected the process performance, although the residence time in the heater is very small compared to that in the reactor. In order to evaluate the effect of the high interstage heater temperature, the second stage operated at a very low reaction temperature of $735-750^{\circ} \mathrm{F}$ during November 9-13. The outlet temperature of the interstage heater was lower, $790-805^{\circ} \mathrm{F}$, and similar to the first stage reaction temperature of $805^{\circ} \mathrm{F}$.

Without the interstage separation, each stage performance data could not be calculated because the product streams of the first stage were not measured. For each stage resid + UC conversion the forced ash balance method (FAB) was used to calculate the resid conversion and each stage conversion was adjusted by proration to match the measured TSL conversion. The resid + UC 
conversion in the second stage could have been affected due to a lower hydrogen partial pressure without the interstage gas separation.

Results from the catalytic/thermal mode of operation are illustrated in Figures 46 to 50 . Coal conversion gradually decreased from (in thermal/catalytic mode) 94 to 86 wt 8 MAF coal

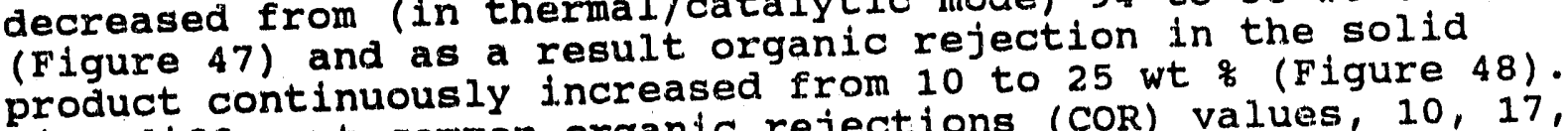
Five different common organic rejections (COR) values, 10,17 , 19,21 and 25 wt $\%$, were selected for transitional trend analysis (Figure 46). The resid + UC conversion data with the forced ash balance method used only for the first stage and by difference for the second stage were also calculated for comparison as discussed below (Figure 50 ).

\subsection{1 overall 2wo-8tage conversion Activity}

overall two-stage conversion activities were calculated for periods $260 \mathrm{~A}-\mathrm{F}$ and period November 10-13, and are illustrated in Figures 44 and 49 . TSL resid yield is listed below for these perlods along with phase 3 data. Standard deviation of the resid yield for the steady-state operation periods $(260 \mathrm{~A}-\mathrm{F})$ is 2 to 4 wt \& MAF coal.

\section{Resid with $\operatorname{COR}=10$ to 25 wt $\%$ wt \& MAF COa 1}

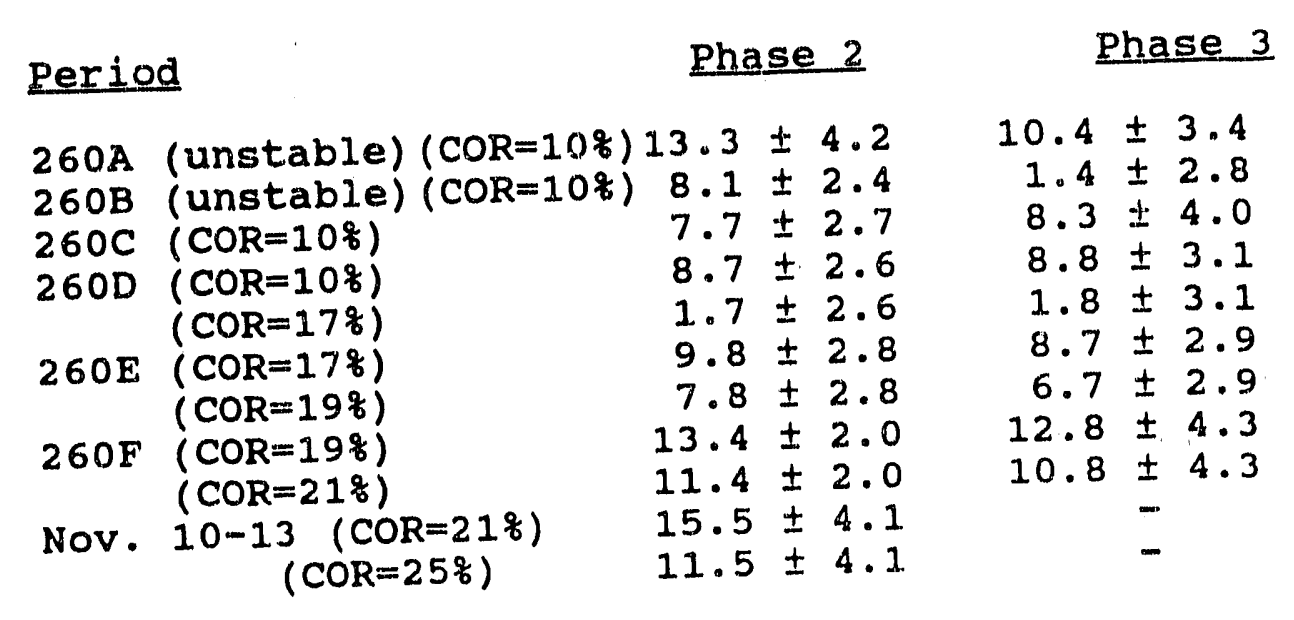

Key process variable changes are summarized below.

\section{Period}

$260 A$

$260 B$

$260 \mathrm{C}$

260D

\section{process condition}

thermal/catalytic mode catalyst replacement $=31 \mathrm{~b} /$ ton $\mathrm{MF}$ coal $\mathrm{T}_{1 \text { st }} /$ 2nd $=825 / 790^{\circ} \mathrm{F}, 350 \mathrm{lb} \mathrm{MF} \mathrm{coal} / \mathrm{hr}$ 40 and 20 wt $\%$ resid and CI recycles $\mathrm{T}_{1 \mathrm{st}}=840^{\circ} \mathrm{F}, 300 \mathrm{lb} \mathrm{MF} \mathrm{coal} / \mathrm{hr}$ $\mathrm{T}_{1 \mathrm{st}}=825^{\circ} \mathrm{F}, 250 \mathrm{lb} \mathrm{MF}$ coal $/ \mathrm{hr}$ catalytic/thermal mode reactor sequence reversed 


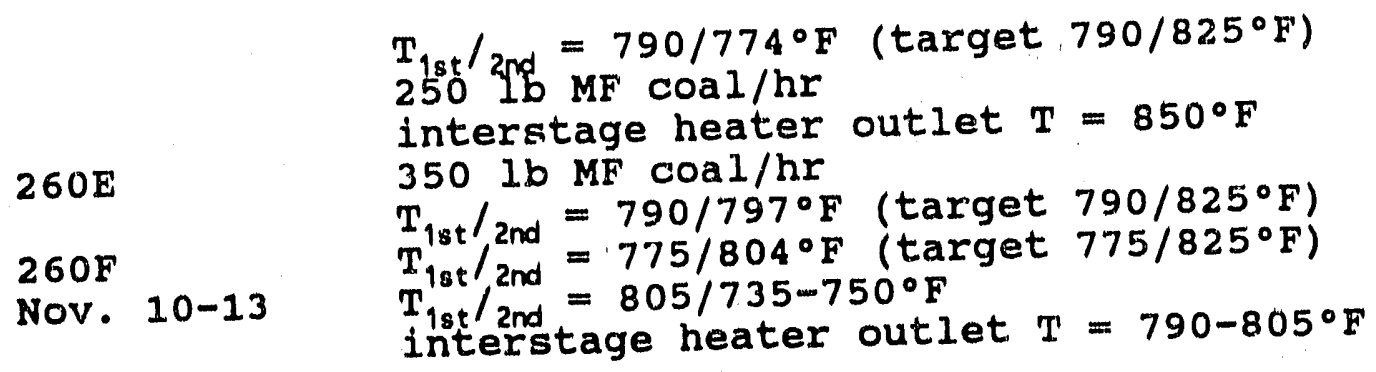

Resid + UC conversion data for these periods are listed below. standard deviation of the conversion for the steady-state operation periods $(260 \mathrm{~A}-\mathrm{F})$ is 2 to 5 wt 8 MAF coal in overall and higher in each stage, 2 to 8 wt $\%$.

\begin{tabular}{|c|c|c|c|c|}
\hline \multirow[b]{2}{*}{ period } & & \multicolumn{2}{|c|}{$\begin{array}{l}\text { Resid + UC conversion } \\
\text { wt \& MAF coal }\end{array}$} & \\
\hline & & Phase 2 & phase & \\
\hline $260 A$ & $\begin{array}{l}\text { 1st stage } \\
\text { 2nd stage } \\
\text { overall }\end{array}$ & $\begin{array}{l}58.9 \pm 1.8 \\
17.8 \pm 4.9 \\
76.7 \pm 4.2\end{array}$ & $80.1 \pm$ & $\overline{ \pm}+3.9$ \\
\hline $260 B$ & $\begin{array}{l}\text { 1st stage } \\
\text { 2nd stage } \\
\text { overall }\end{array}$ & $\begin{array}{l}65.7 \pm 5.9 \\
16.2 \pm 7.8 \\
81.9 \pm 2.4\end{array}$ & $88.6 \pm$ & $\bar{E} \pm 2.8$ \\
\hline $260 C$ & $\begin{array}{l}\text { 1st stage } \\
\text { 2nd stage } \\
\text { overall }\end{array}$ & $\begin{array}{l}61.7 \pm 3.9 \\
20.6 \pm 3.7 \\
82.3 \pm 2.7\end{array}$ & 81.8 & \pm \\
\hline 2600 & $\begin{array}{l}\text { 1st stage } \\
\text { 2nd stage } \\
\text { overall }\end{array}$ & $\begin{array}{l}64.7 \pm 2.7 \\
16.6 \pm 4.4 \\
81.3 \pm 2.6\end{array}$ & 91.2 & \pm \\
\hline $260 E$ & $\begin{array}{l}\text { 1st stage } \\
\text { 2nd stage } \\
\text { overall }\end{array}$ & $\begin{array}{l}54.4 \pm 3.5 \\
18.8 \pm 1.3 \\
73.2 \pm 2.8\end{array}$ & 74.3 & $\begin{array}{l}\overline{-} \\
\pm 2.9\end{array}$ \\
\hline $260 F$ & $\begin{array}{l}\text { 1st stage } \\
\text { 2nd stage } \\
\text { overall }\end{array}$ & $\begin{array}{l}51.3 \pm 4.4 \\
16.3 \pm 3.6 \\
67.6 \pm 2.0\end{array}$ & 68.2 & $\begin{array}{l}- \\
\pm \\
\pm\end{array}$ \\
\hline Nov $10-13$ & $\begin{array}{l}\text { lst stage } \\
\text { 2nd stage } \\
\text { overall }\end{array}$ & $\begin{array}{r}60.8 \pm 8.1 \\
2.7 \pm 8.7 \\
63.5 \pm 4.1\end{array}$ & & $\bar{z}$ \\
\hline
\end{tabular}

As shown in the above two tables significant differences could be observed between Phase 2 data and Phase 3 data for periods $260 \mathrm{~A}$ and 260B. These two periods were unstable, and thus the phase 2 material balances obtained by ash balance did agree well with the material balances obtained by elemental balance.

In period $260 \mathrm{C}$, in the thermal/catalytic mode and without interstage gas separation, the "all-distillate" product slate was not achieved. TSI excess resid yield was 8 wt $\%$ MAF coal with 11 wt $\%$ organic rejection. C4t distillate yield was 54 wt $\%$. The full- and threequarters-volume reactors operation with different reactor temperature profiles and the lower hydrogen partial pressure in the second stage due to no gas separation might have affected the 
process performance, compared to Run 258 operated with half-volume reactors and an interstage separator. Run 260 operated at a higher inlet hydrogen partial pressure to the first stage than Run 258 (2700-2800 vs 2400-2500 psia).

In period 260D in the catalytic/thermal mode without an interstage separator, the second stage reaction temperature was $774^{\circ} \mathrm{F}$, lower than the target $825^{\circ} \mathrm{F}$, which could not be increased due to the less process heat generated in the second stage. Coal conversion was low, 91 wt $\%$, and as a result organic rejection was high, 18 wt $\%$. C4+ distillate yield was 60 wt $\%$ with zero resid make. The "alldistillate" product slate was achieved with a high distillate selectivity due to low reaction temperatures operated. The resid + UC conversion was 81 wt $z$, which is similar to that in $260 \mathrm{C}$ in the thermal/catalytic mode. The inlet hydrogen partial pressure to the first stage was $2700-2800$ psia, similar for both periods.

The first stage coal conversion at $790^{\circ} \mathrm{F}$ in period $260 \mathrm{D}$ was 74 wt o with a three-quarters-volume reactor, which is significantly lower than that in $260 \mathrm{C}$ at $825^{\circ} \mathrm{F}$ (93 wt $\%$ ) with a full-volume reactor. This indicates that thermal severity is more important than catalyst to improve the coal conversion in the first stage. The first and second stage coal conversion further improved to 91 wt 8 in $260 \mathrm{D}$, although the second stage reaction temperature was $774^{\circ} \mathrm{F}$, lower than the first stage. It appears that more residence time at this low second stage reaction temperature increases the coal conversion. This might also have been affected by the operation of the interstage heater at high temperature $\left(850^{\circ} \mathrm{F}\right.$ outlet) in $260 \mathrm{D}$. Previous studies such as SRC-I, SRC-II, EDS, etc. have shown that a supported catalyst is not needed to achieve good coal conversion; however, thermal severity with iron catalyst is important.

In period $260 \mathrm{E}$ at a higher coal feed rate of $350 \mathrm{MF} / \mathrm{b} / \mathrm{hr}$ in the catalytic/thermal mode without an interstage separator, the second stage reaction temperature further improved to $797^{\circ} \mathrm{F}$, lower than the target $825^{\circ} \mathrm{F}$. However, due to a lower severity compared to 260D, coal conversion decreased to 89 wt \& MAF coal, and as a result organic rejection increased to $20 \mathrm{wt}$ \% . C4t distillate yield was 52 wt 8 with 6 wt of resid make. The "alldistillate" product slate was not achieved due to low reaction temperatures operated. The resid + UC conversion decreased to 74 wt 8 , which is lower than that in 260D. The first stage coal conversion decreased to 72 wt $q$

In period $260 \mathrm{~F}$ at a lower first stage reaction temperature of $775^{\circ} \mathrm{F}$, the second stage reaction temperature increased to $804^{\circ} \mathrm{F}$. Due to a lower severity in the first stage compared to 260E, coal conversion decreased to 88 wt \& MAF coal; organic rejection increased to 23 wt $\%$. C4t distillate yield was 48 wt $\%$. The resid + UC conversion decreased to 68 wt $\%$. The first stage coal conversion decreased to 71 wt $\%$.

In period November $10-13$ at a higher first stage reaction 
temperature of $804^{\circ} \mathrm{F}$ and a lower second stage reaction temperature of $735-750^{\circ} \mathrm{F}$ compared to $260 \mathrm{~F}$ (based on Phase 2 data), the first stage coal and resid + UC conversions s.tgnificantly increased to 82 and 61 wt. $\&$ MAF coal, respectively. However, the two stage coal and overall resid + UC conversions decreased to 86 and 64 wt 8 , respectively. The lower second stage reaction temperature used in this period improved the coal conversion by 4 wt 8 and increased the resid + UC conversion by 3 wt $f$ in the second stage. Note that negative resid + UC conversion values were observed in the second stage on November 9,11 and 12. The lower interstage heater outlet temperature $\left(790-805^{\circ} \mathrm{F}\right)$ might have affected the performance, compared to 260D-F with $850^{\circ} \mathrm{F}$.

Trend analyses are summarized in Tables 15 to 19 . Resid + UC conversion, TSL excess resid yield, coal conversion and organio rejection data are compared.

\section{3 .2 Irgt stage Conversion Activity}

Thermal resid + UC conversion activities were calculated for the period July 25 - September 7, assuming that the resid + UC conversion reaction follows first-order kinetics for a continuous stirred tank reactor. The conversion rate constant (K) is expressed in terms of two experimentally determined quantities: feed weight-hourly space velocity (SV) and resid + UC conversion $(\epsilon)$.

$K / C=(S V / C) \epsilon /(1-\epsilon)$,

where $C$ : constant equating thermal reaction volume to catalytic reaction volume.

The dependence of the conversion rate constant on temperature ( $T$ ) is described by the Arxhenius equation.

$$
\begin{aligned}
& K / C=(A / C) e^{-E / R T}, \\
& \text { where } K: \text { rate constant, }\left[\mathrm{hr}^{-1}\right],[S V] \\
& S V: \text { feed space velocity, } \\
& \text { [lb feed/hr/cu ft-reactor] } \\
& \epsilon: \text { resid }+ \text { UC conversion, [Wt f feed] } \\
& A: \text { frequency factor } \\
& \mathrm{E}: \text { apparent activation energy, [Btu/Ib-mole] } \\
& \mathrm{R}: \text { ideal gas constant, [Btu/1b-mole-oR] } \\
& \mathrm{T}: \text { temperature, [०R] }
\end{aligned}
$$

The linear regression analysis equation becomes:

$$
\ln (K / C)=\ln (A / C)-E / R(1 / T)
$$

Thermal conversion activities in the first stage were analyzed based on Phase 2 resid + UC conversion data. Results are illustrated in Figures 51 and 52. The forced ash balance method (FAB) was used to calculate conversion and the conversion was adjusted by proration to match the measured TSL conversion. 
The average in $\mathrm{K} / \mathrm{C}$ values for perlods $260 \mathrm{~A}-\mathrm{C}$ were calculated and are listed below. Reactor volume was used in calculation of the conversion rate constant (K).

Average in $\mathrm{K} / \mathrm{C}(\mathrm{I} / \mathrm{h} / \mathrm{c})$

\section{Period}

$260 A$

$260 \mathrm{~B}$

$260 \mathrm{C}$
Phase 2

$$
\begin{aligned}
& 4.01 \pm 0.04 \\
& 4.04 \pm 0.14 \\
& 3.76 \pm 0.09
\end{aligned}
$$

\section{Phase 3}

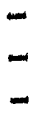

Temperature dependency on thermal conversion for pertods $260 \mathrm{~A}, \mathrm{~B}$, and $C$ is shown in Figure 53. Apparent activation energy was determined by using the inear regression analysis technique. For 260BC periods:

$$
\ln (K / C)=28.7-32100(1 / T), r^{2}=0.63 ;
$$

For $260 \mathrm{AB}$ perlods:

$$
\ln (K / C)=6.7-3400\left(1 / T^{\prime}\right), r^{2}=0.03 i
$$

Thermal activity with a full-volume reactor in Run 260 is slightly lower than that with a half-volume reactor in Run 258 prooessing Black Thunder coal (Figure 54). However, higher thermal activity in $260 \mathrm{~A}$ compared to $260 \mathrm{C}$ could be in error due to unstable operation in 260A. The target gas flows and hydrogen purity in $260 \mathrm{AB}$ were not obtained in the feed gas stream due to interstage separator problems, which somewhat improved in per.od 260B. Another explanation is possible considering different coal space velocities tested. Thermal activity in $260 \mathrm{~A}$ at high coal space velocity is higher compared to the low space velocity point $260 \mathrm{C}$, both of which were operated at $825^{\circ} \mathrm{F}$. Note that the points for $260 \mathrm{~A}$ fit quite well on the projected line for Run 258 with Black Thunder coal (Figure 54). All of these points were obtained at relatively high space velocity, while the lower space velocity points 260B, 260C and 251-IID show lower rate constants (when allowing for temperature dependence). Thus a dependency of thermal rate constant on space velocity is indicated. A possible qualitative explanation is that the conversion of additional resid when already operating at high conversion levels becomes more difficult, therefore volding a simple first order model. The low space velocity point (250 lb/hr in 251-IID) apparently causes the higher energy of activation calculation for Wyodak coal (Figure 54).

Shell 324 1/16" catalyst activities at steady-state operation with catalyst replacement in the first stage were analyzed based on phase 2 resid + UC conversion data for the period September 27 - November 13 In the catalytic/thermal mode. Results are illustrated in Figure 55. The forced ash balance method (FAB) was used to calculate conversion and the conversion was adjusted by proration to match the measured TSL conversion. 
Catalyst aotivities were caloulated assuming that the resid + vC conversion reaction follows firat-order kinetios for a continuous stirred tank reactor. The conversion rate constant (K) 1 o expressed in terms of two experimentaliy determined quantities: feed welghthourly spade veloclty (WHSV) and resld + UC conversion $(\epsilon)$.

$$
K=\text { WHSV } \epsilon /(1-6)
$$

The dependence of the convergion rate constant on temperature (IT) Is desoribed by the Arrhentus equation and that on oatalyst

deactivation with oatalyst age (t) ls described by a deactivation model.

$$
K=A e^{-E / R T} e^{-\alpha t}
$$

In this equation, $A$ is the frequency factor, $E$ is the apparent activation energy, and $\alpha$ is the demctivation coeffioient. The equilibrium catalyot aotivity $\left(K_{0 q}\right)$ with catalyst replacement 1 s profected by using the residence time distribution function, RTD(t).

$$
K_{e q}=\int_{0}^{\infty} \operatorname{RTD}(t) K(t) d t
$$

The linear regression analysis equation for the conversion rate constant (K) becomes:

$$
\begin{aligned}
& \text { In } \mathrm{K}=\text { In } \mathrm{A}-\mathrm{E} / \mathrm{R}(1 / \mathrm{T})-\alpha \mathrm{t} \\
& \mathrm{K}: \text { resid }+\mathrm{UC} \text { oonversion activity, [WHSV] } \\
& \mathrm{A}: \text { frequency factor } \\
& \mathrm{E}: \text { apparent activation energy, Btu/Ib-mole } \\
& \mathrm{R}: \text { ideal gas constant, Btu/Ib-mole-o } \mathrm{F} \\
& \mathrm{T}: \text { reaction temperature, oR } \\
& \alpha: \text { deactivation coefficient, }[1 / \mathrm{t}] \\
& \text { t: catalyst age }
\end{aligned}
$$

\begin{tabular}{|c|c|c|}
\hline Pertod & Phase 2 & Phase 3 \\
\hline $260 D$ & $4.20 \pm 0.04$ & - \\
\hline $260 E$ & $4.26 \pm 0.10$ & - \\
\hline $260 F$ & $4.18 \pm 0.10$ & - \\
\hline Nov, $10-1$ & $4.37 \pm 0.20$ & - \\
\hline $\begin{array}{l}\text { nd stage } \\
260 \mathrm{~A}\end{array}$ & tdo convers & \\
\hline $260 A$ & $3.32 \pm 0.31$ & - \\
\hline $260 B$ & $3.10 \pm 0.44$ & - \\
\hline $260 C$ & $3.25 \pm 0.20$ & - \\
\hline
\end{tabular}

The average in $\mathrm{k}$ values of the first stage catalytio conversion for periods 260D-F and period November 10-13 were caloulated and are isted below. Catalyst volume was used in calculation of the conversion rate constant (K). The values of the secorid stage catalytio conversion for the previous perlods $260 \mathrm{~A}-\mathrm{C}$ in the thermal/catalytic mode are also included for comparison.

$$
\text { Average } \ln \mathrm{K}(1 / \mathrm{hr})
$$


The firet atage catalytio restd + UC conversion at $790^{\circ} \mathrm{F}$ in $260 \mathrm{D}$ was 65 wt * MAF coal with a three-quarterswolume reactor, whioh is much higher than the geoond atage oonversion at $790^{\circ} \mathrm{F}$ in $260 \mathrm{C}$ (21 wt if) with the oame reactor volume, is almilar to the flrst stage thermal conversion at $825^{\circ} \mathrm{w}$ in 2600 with a fuli-volume reactor (62 wt 8 ) (See seation 5.3.1.). The activity value (K) Inoreased by $155 \%$ from 26.1 to $66.5 \mathrm{hr}^{\mathrm{m}}$. This indioates that datalyst in the first stage signifloantly dmproves the resld + UC conversion. The higher iniet hyluogen partial pressure (2710 vo. 2110 pala) could contribute to the observed improvement in performance.

Temperature dependenoy on the etrst stage catalytio oonvereion for pertods $260 \mathrm{D}+\mathrm{F}$ and pertod November 10-12 is shown in Figure 56 . Days selected for MB perlods were used for calculations. Apparent autivation energy was determined by using the linear regression analysis technlque. Results are:

$$
\text { In } \mathrm{K}=14.4-12700(1 / \mathrm{T})
$$

The caloulated activation energy may be a little low due to inclusion of rate constant data for 260D, whtoh was operated at a lower space veloulty. A space velocity dependency may be operating here also. A contributing factor may be inacourate cholce of temperature values due to the steep temperature rise in the bed.

Figure 57 is a revised version of Figure 56 by using screened data points. Stable operation days, November 1, 2 and 3 were inolided, and November 5 and 8 were not included because of problems of temperature control in the first stage and interstage sampling. Results based on these selected days are:

$$
\text { In } K=1.8 .9-18400(1 / T)
$$

Trend analyses are summarlzed in Tables 20 and 21 .

\section{3 .3 second stage Conversion Aotivity}

Shel1 32.4 1/1.6" catalyst activitles at both batch and steady-state operations with catalyst replacement in the second stage were analyzed based on Phase 2 resla + UC conversion data for the period July 25 - September 7. Results are 11lustrated in Figures 51 and 58. The forced ash balance method (FAB) was used to caloulate conversion and the converston was adjusted by prorat 4 un to match the measured TSI conversion. The resid + UC conversion rate constant (K) Is described in section 5.3.2.

The average in $\mathrm{K}$ values for perlods $260 \mathrm{~A}-\mathrm{C}$ were calculated and are 1.sted below. Catalyst volume was used in caloulation of the conversion rate constant (K). 


\section{Average $10 \mathrm{~K}(\mathrm{t} / \mathrm{hr})$}

Perto
$260 A$
$260 B$
$260 \mathrm{C}$

Phase 2

Phase 3

$3.32 \pm 0.31$
$3.10 \pm 0.44$
$3.25 \pm 0.20$

These values for $260 \mathrm{~A}-\mathrm{C}$ are significantly lower than those for 258H, I and $M(3.6-3.9)$. Reaction temperature was $790^{\circ} \mathrm{F}$ and catalyst replacement was 1.5 for $258 \mathrm{H}$ and $I, 31 \mathrm{~b} /$ ton $M F$ for $258 \mathrm{M}$ (See Ref. 9) and $260 \mathrm{~A}-\mathrm{C}$. This indicates that catalyst activity for $260 \mathrm{~A}-\mathrm{C}$ might have been affected due to the incomplete interstage gas separation. The lower catalyst activity may be related to the higher carbon laydown, perhaps caused by the lower hydrogen partial pressure in the second stage. Thus, Run 258 data were obtained with a half-volume reactor that had a higher thermal cortribution which is not accounted for in this comparison.

Thermal conversion activities in the second stage were calculated for the period September 27 - November 1.3 in the catalytic/thermal mode. Results are 1llustrated in Figure 55. The resid + UC conversion rate constant $(K / C)$ is described in section 5.3 .2 . The forced ash balance method (FAB) was used to calculate conversion and the conversion was adjusted by proration to match the measured ISL conversion.

The average in $\mathrm{K} / \mathrm{C}$ values of the second stage thermal conversion for periods $260 \mathrm{D}-\mathrm{F}$ and pertod November 10-13 were calculated and are iisted below. Reactor volume was used in calculation of the conversion rate constant (K). The values of the first stage thermal conversion for the previous periods $260 \mathrm{~A}-\mathrm{C}$ are also included for comparison. In calculating the second stage conversion and data analysis, the contribution of interstage heater, if any, is ignored.

\begin{tabular}{llc} 
& \multicolumn{2}{c}{ Average in $\mathrm{K} / \mathrm{C}(1 / \mathrm{hr})$} \\
Period & Phase 2 & Phase 3 \\
2600 & $2.53 \pm 0.31$ & - \\
$260 \mathrm{E}$ & $2.97 \pm 0.05$ & - \\
$260 \mathrm{~F}$ & $2.75 \pm 0.25$ & - \\
NOV. 10-13 & $0.99(\mathrm{a})$ & -
\end{tabular}

(a) Using an average value of $\mathrm{K} / \mathrm{C}$ due to negative conversion values observed on November 11 and 12 .

(first stage thermal conversion)

$\begin{array}{ll}260 \mathrm{~A} & 4.01 \pm 0.04 \\ 260 \mathrm{~B} & 4.04 \pm 0.14 \\ 260 \mathrm{C} & 3.76 \pm 0.09\end{array}$


The second stage thermal resid + UC conversion at $774^{\circ} \mathrm{F}$ in $260 \mathrm{D}$ was 17 wt $\%$ MAF coal with a full-volume reactor, which is lower than the second stage catalytic conversion at $790^{\circ} \mathrm{F}$ in $260 \mathrm{C}$ with a threequarters-volume reactor (2I wt $\left.\frac{\circ}{b}\right) ;$ is much lower than the first stage thermal conversion at $825^{\circ} \mathrm{F}$ in $260 \mathrm{C}$ with a full-volume reactor ( 62 wt $\%$ ). This indicates that catalyst in the second stage might slightly improve the conversion. The primary role of catalyst in the second stage at low thermal severity seems hydrogenation of resid to improve further hydrocracking in the first stage at high thermal severity and to maintain recycle solvent quality.

Temperature dependency on the second stage thermal conversion for periods 260D-F and period November $10-13$ is shown in Figure 59 . Days selected for $M B$ periods and an average value of $K / C$ in November 10-13 were used for calculation. Negative conversion was observed on November 11 and 12. Apparent activation energy was determined by the linear regression analysis technique. Results are:

$$
\begin{aligned}
\ln (K / C) & =31.7-36200(1 / T) \\
r^{2} & =0.63
\end{aligned}
$$

Figure 60 is a revised version of figure 59 by using screened data, as discussed in section 5.3.2.

$$
\begin{aligned}
\ln (K / C) & =34.1-39300(I / T) \\
r^{2} & =0.77
\end{aligned}
$$

An extrapolation of this line to the range of $825-840^{\circ} \mathrm{F}$ tested in the first stage for $260 \mathrm{BC}$ (Figure 53 ) suggests that thermal conversion activity is not significantly dependent on the stage in contrast with catalytic conversion. The higher inlet hydrogen partial pressure in 260BC $(2680-2780$ psia) in the first stage did not significantly improve the performance when compared with that in $260 D-F(2150-2240$ psia in the second stage).

Trend analyses are summarized in Tables 22 and 23 .

\subsection{Catalyst Requirement and Performance Comparisons}

Phase 3 overall resid + UC conversion data for $260 \mathrm{~B}$ (unstable) and $260 \mathrm{C}$ are plotted in Figure 61 . Projected lines for $260 \mathrm{~B}$ (unstable) and $260 \mathrm{C}$ generated by assuming CSTR first order kinetics are shown through the data plotted in Figures 62 and 63 . Coal space velocity was selected as $x$-coordinate variable to evaluate process responses in resid + UC conversion and catalyst requirement. Catalyst volume was used in Figures 61 to 63 , while first stage reactor volume was used in Figures 64 to 66 . The period $260 \mathrm{~A}$ (unstable) was not included in this comparison due to improper gas flows and hydrogen purities. Although both $260 \mathrm{~A}$ and $260 \mathrm{~B}$ are unstable periods, gas flows and $\mathrm{H}_{2}$ purity somewhat improved in $260 \mathrm{~B}$. To better evaluate catalyst requirement and coal throughput for Run 260 with shell 324 1/16" catalyst (unimoủal), coal feed rates were projected for resid extinction by using process performance responses estimated by assuming CSTR first order kinetics. Catalyst replacement rates for 
steady-state operation were calculated for comparison with actual replacement rates used at the plant. Results are listed in Table 24. The TSL process performance data measured at the plant are shown in Table 25 for comparison.

To evaluate the quality and accuracy of the calculated rate constants, parity plots of $\mathrm{C}_{4}+$ distillate yields and coal feed rates are illustrated in Figures 67 and 68 for periods 260C-F. Comparison results are summarized in Table 26. The error between the predicted and experimental coal feed rate was 1 to $13 \%$, when model equations derived from Run $260 \mathrm{~B}-\mathrm{F}$ data were used. However, the error was very high, about 28\%, when used model equations derived from Run $258 \mathrm{H}-\mathrm{M}$ data. Run $260 \mathrm{C}$ produced less distillate by 17 wt $\%$ MAF coal, compared to that predicted by using Run $258 \mathrm{H}-\mathrm{M}$ data. This lowex distillate yield seems primarily due to a lower hydrogen partial pressure in the catalytic second stage (about 400 psia less) without. interstage separation and a less isothermal temperature profile in the second stage with a three-quarters-volume reactor compared to a half-volume reactor. Other process variables might have affected the result:

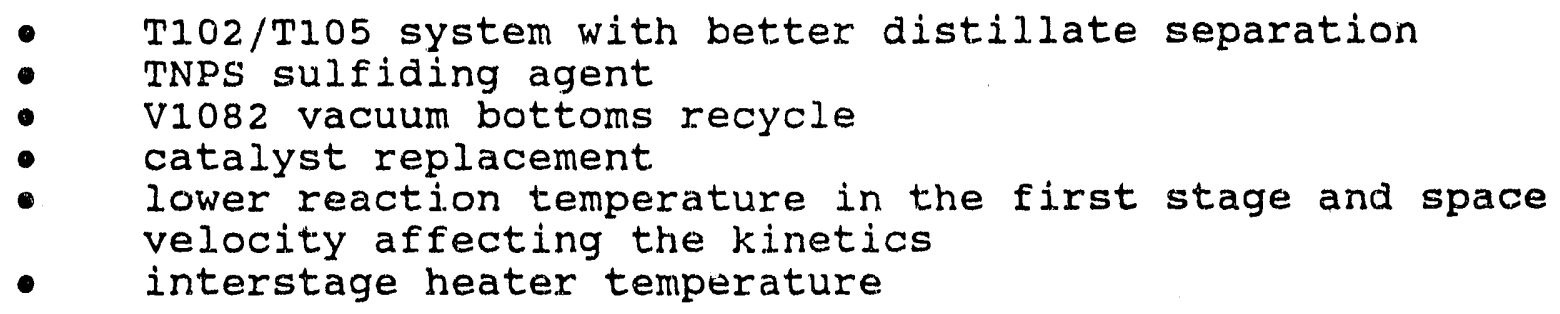

The first stage also contributed to less-than-expected results for Run 260 compared to Run $258 \mathrm{H}-M$ data. It appears that Iiquefaction yields are limited to the range of 55-60\% distillate with this particular process scheme/catalyst, and increasing the reaction volume (lowering space velocity) does not help much. In addition, in the half-volume catalytic data thermal contributions are included. Figures 61 and 64 show the process response due to the first stage thermal. reaction temperature change from 840 to $825^{\circ} \mathrm{F}$ in 260C. The temperature increase improved the coal throughput by $20 \%$ or increased the resid + UC conversion by 12 wt $\%$ MAF coal.

Figures 69 to 74 compare thermal/catalytic (260C) vs catalytic/thermal (260D-F and November 10-13) mode in resid + UC conversion and $\mathrm{C} 4+$ distillate yield. Projection results of $260 \mathrm{C}$ in the resid + UC conversion by using CSTR first order kinetics are also included for comparison along with data obtained for Run 251-IIB and 251-IIIB with Wyodak coal. Catalyst volume was used in Figures 69 to 71 , while CCR unit reactors volume was used in Figure 72 to 74 . Although the resid + UC conversion was similar, 81 wt $\%$ MAF coal, For both $260 \mathrm{C}$ and 260D (Figures 67 and 70), $260 \mathrm{D}$ in the catalytic/thermal mode had 4 wt $\%$ higher $\mathrm{C} 4+$ distillate yield, compared to $260 \mathrm{C}$ in the thermal/catalytic mode (Figures 71 and 74). This high distillate selectivity was due to low thermal severity in 2600 . 
Phase 3 overall resid + UC conversion data for periods $260 \mathrm{~A}-\mathrm{C}$, Run 258 with Black Thunder and Spring Creek coals, Run 251-II with Wyodak coal and Run 255 with Texas Lignite are plotted in Figures 75 and 76 . These data were obtained in the thermal/catajytic mode of operation. Figure 75 is plotted with respect to coal space velocity using catalyst volume and Figure 76 with coal space rate using CCR unit reactors volume. Data for periods 260D-F and period November 10-13 (Phase 2 data) in the catalytic/thermal mode are also included for comparison. The data for Run 251-IID may not be accurate because of a significant solids buildup in the first stage reactor.

Figure 77 compares two stage coal conversion for low-rank coal runs such as Runs 251-II, 255, 258 and 260. Coal space velocity was selected as $x$-coordinate variable (as in Figure 75 ). Reactor and catalyst volumes for these runs are summarized below. Coal conversion insignificantly varied with respect to coal space velocity, while resid + UC conversion varied more than the coal conversion. This indicated that the resid conversion was more dependent on the coal space velocity than the coal conversion. Variation in the (resid $+U C$ ) conversion (Figure 73) were 18 wt $\%$ MAF coal (260D vs. period November 10-13), 8 wt $\%$ (258E vs. B) and 9 wt $\%$ (258I vs. L), while variations in the coal conversion (Figure 75 ) were 5,4 and 4 wt $\%$, respectively.

\begin{tabular}{|c|c|c|c|c|}
\hline Run & $251-I I$ & 255 & $\underline{258}$ & $\underline{260}$ \\
\hline $\begin{array}{l}\text { reactor size } \\
\text { 1st } \\
2 \text { nd }\end{array}$ & $\begin{array}{l}\text { full } \\
\text { full }\end{array}$ & $\begin{array}{l}\text { half } \\
\text { full }\end{array}$ & $\begin{array}{l}\text { half } \\
\text { half }\end{array}$ & $\begin{array}{l}\text { full } \\
\text { tqs (a) }\end{array}$ \\
\hline $\begin{array}{l}\text { reactor volume } \\
\text { (xfactor) } \\
\text { ist } \\
\text { 2nd }\end{array}$ & $\begin{array}{l}1.00 \\
1.00\end{array}$ & $\begin{array}{l}0.47 \\
1.00\end{array}$ & $\begin{array}{l}0.47 \\
0.47\end{array}$ & $\begin{array}{l}1.00 \\
0.71\end{array}$ \\
\hline $\begin{array}{c}\text { catalyst volume } \\
\text { (slump) }\left(\mathrm{ft}^{3}\right) \\
\text { (ratio) }\end{array}$ & $\begin{array}{l}8.1 \\
1.00\end{array}$ & $\begin{array}{l}4.0 \\
0.49\end{array}$ & $\begin{array}{l}3.1 \\
0.38\end{array}$ & $\begin{array}{l}5.6 \\
0.68\end{array}$ \\
\hline
\end{tabular}

(a) A three-quarters-volume reactor in the second stage. Reversed reactors in the catalytic/thermal mode after september 26 .

Figures 78 to 84 show comparisons for selected periods processing low-rank coals in boiling-point cut conversion and yield (based on Phase 2 data for $260 \mathrm{C}$ and $D$ ), distillate end point and selectivity (260C and D, 251-IIB and 251-IIIB), distillate product distribution, distillate yield in the thermal/catalytic mode $(260 C, 258 B, D$ and $H)$, etc. Distillate end points for Runs 251-II and III, 255 and 258 were estimated by assuring that the recycle of the heavy end distillate in the process solvent stream reached steady-state.

A thermal reaction severity factor (TPSF) is defined as a 
function of system pressure (P), coal space velocity above $700^{\circ} \mathrm{F}$ (SV) and average reaction temperature (T) as shown below, in order to evaluate process responses in coal and resid + UC conversions.

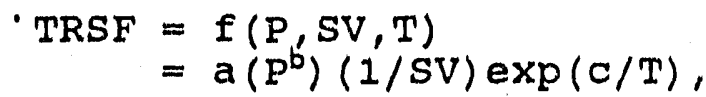

where $P$ : system pressure (psia)

SV: coal space vel. (MF Ib/hr/cuft-reaction volume) $\mathrm{T}$ : volumetric average reaction temperature $\left({ }^{\circ} \mathrm{R}\right)$ $a, b, c:$ constants

Coal conversion for periods $260 \mathrm{~A}-\mathrm{F}$ and period November $10-13$ is compered in Figure 85 , showing a good second order correlation.

$$
\begin{aligned}
& Y=A+B x+C x^{2} \\
& r^{2}=0.97 \\
& A, B, C: \text { constants }
\end{aligned}
$$

The comparison result in Figure 85 suggests that coal conversion seems to be primarily dependent on thermal severity and ironoxide slurry catalyst, but not improved by shell 324 catalyst in the first stage.

Resid + UC conversion for periods $260 \mathrm{~A}-\mathrm{F}$ and period November 1013 is compared in Figure 86 . The first stage thermal conversion $\left(Y_{1}\right)$ was curve-fitted using data from periods $260 \mathrm{~A}-\mathrm{C}$ and $258 \mathrm{~A}-\mathrm{H}$, along with the TSL thermal/catalytic conversion $\left(Y_{2}\right)$ using data from $260 \mathrm{~A}-\mathrm{C}$ in Figure 87 and the catalytic/thermal conversion $\left(Y_{3}\right)$ including first stage and TSL using data from $260 \mathrm{D}-\mathrm{F}$ and period November 10-13 in Figure 86 .

$$
\begin{aligned}
& Y_{1}=A_{1} X^{a 1}, r^{2}=0.77 \\
& Y_{2}=A_{2} X^{a 2}, r^{2}=0.91 \\
& Y_{3}=A_{3} X^{a 3}, r^{2}=0.93 \\
& A_{1}, A_{2}, A_{3}, a 1, a 2, a 3: \text { constants }
\end{aligned}
$$

The comparison result in Figure 86 suggests that catalyst significantly improved resid conversion. It appears that UC conversion to resid becomes more important at lower severity operation and resid conversion to distillate becomes not any more a rate limiting step.

\subsection{Thermal History in TSL Process system}

Thermal histories during periods $A, C, D, E, F$ and November 10-13 in Run 260 are illustrated in Figures 88 to 93 by using temperature profiles and approximate relative residence time through TSL process system. Periods $260 \mathrm{~A}$ and $\mathrm{C}$ operated with a full-volume thermal reactor in the first stage, a three-quartersvolume catalytic reactor in the second stage and an interstage separator. Periods $260 \mathrm{D}-\mathrm{F}$ and November 10-13 operated with a tinree-quarters-volume catalytic reactor in the first stage, a 
full-volume thermal reactor in the second stage without an interstage separator. process times for slurry blend and feed tanks, and process solvent storage tank were significantly reduced for 11 lustration.

Figure 94 is a trend plot of B1201 interstage heater outlet temperature during the period July 25-August 22. The interstage heater outlet temperature was significantly lower than reaction temperatures during $260 \mathrm{~A}$ and $C$, as shown in Figures 88 and 89.

Figure 95 is a trend plot of B1201 interstage heater outlet temperature during the period october 23 - November 13 . The interstage heater outlet temperature was significantly higher than reaction temperatures during $260 \mathrm{D}-\mathrm{F}$, as shown in Figures 90 to 92 , operating at the maximum temperature set for the interstage heater $\left(850^{\circ} \mathrm{F}\right)$, due to the less process heat generated in the second stage in the catalytic/thermal mode. During the period November 9-13 (Figure 93), the interstage heater outlet temperature was lower $\left(790-805^{\circ} \mathrm{F}\right)$ than the first stage reaction temperature $\left(805^{\circ} \mathrm{F}\right)$, due to operations with lower second stage reaction temperature $\left(735-750^{\circ} \mathrm{F}\right)$. 


\section{DIGTILLATE PRODUCT QUALTTY AND UNIT BOLVENTS}

The primary products produced in Run 260 were distillates defined by gas chromatography simulated distillation as naphtha (IBP-350\% $\mathrm{F}$ ), light midale distillate $\left(350-450^{\circ} \mathrm{F}\right)$, heavy miadie distillate (450$\left.650^{\circ} \mathrm{F}\right)$ and distillate solvent $\left(650^{\circ} \mathrm{F}-\mathrm{EP}\right)$. These distillates were also analyzed to determine compositions of carbon, hydrogen, nitrogen, and sulfur. oxygen was found by difference.

During Run 260, the interstage separator was used in periods $260 \mathrm{~A}$ and $260 \mathrm{~B}$, however, only partial separation occurred. For periods $260 \mathrm{C}$ through $260 \mathrm{~F}$, the interstage separation was not performed. The fractionation scheme is shown on Figure 94. Thus, only periods 260A and $260 \mathrm{~B}$ had a distillate product, V164, from the first stage reactor. In period $260 \mathrm{C}$, all of the distillate was from the catalytic reactor. In periods $260 \mathrm{D}, 260 \mathrm{E}$, and $260 \mathrm{~F}$, the distillate, V1078, was from the second stage thermal reactor.

The distillate product streams consisted of T105 Atmospheric Distillation Column overheads and T102 Vacuum Column overheads. The operation and process performance of these columns were described in Section 3.5 .

\subsection{Product Quality}

This section summarizes distillate product properties obtained from liquefying Black Thunder Coal in the CC-ITSL operating mode. The properties studied include carbon, hydrogen, nitrogen, and sulfur. simulated distillations were also performed and end points were determined by ASTM D-1160 distillations.

Product characteristics are reported for six periods. Operating conditions that differed for these respective periods were summarized and presented in previous sections.

\subsubsection{Blending and Process Streams}

A blend or total oil was prepared for each period by combining samples from respective process streams. The various streams are shown in Figure 96. Samples from two streams constituted the total oil for all of the periods. One was the T105 atmospheric column overhead material (V161) and the other was the T102 vacuum column overhead sample (V182). The atmospheric column overhead stream has naphtha product characteristics. Its boiling range is from 75 to $500^{\circ} \mathrm{F}$ and hydrogen content is usually between 12.0 and $13.0 \mathrm{wt} \%$. Vacuum column material, V182, is heavier compared to V161 and its boiling range is from 400 to $800^{\circ} \mathrm{F}$. It has less hydrogen than V161. and the content ranges from 10.0 to 11.0 wt $\%$. Table 27 gives the percentages of atmospheric column material and the vacuum column product used to prepare the blends for the respective periods.

Total oil 
Properties of the total oil are shown in Table 28. Hydrogen content ranges from 11.0 to 11.9 wt $\%$ but no trend is evident. Sulfur is found to be the lowest heteroatom and is below 0.1 wt of for all periods. Nitrogen content is similar for all of the total oils and averages 0.4 wt $\%$.

Weight distribution versus boiling point were determined by oldershaw column distillation. The majority of these oils boiled in the 450 to $650^{\circ} \mathrm{F}$ range. End points were measured by a D1160 distillation. They ranged from 723 to $778^{\circ} \mathrm{F}$ and the average was $756^{\circ} \mathrm{F}$.

Naphtha (IBP-350 $\mathrm{F})$

Naphtha constituted from 14 to 25 wt $\%$ of the total oil product. However, its properties were similar for all periods. The API gravities ranged from 50 to 60 . This fraction had the highest hydrogen content which averaged 14.2 wt $\%$ for all periods. Nitrogen and sulfur contents were similar in each fraction. Nitrogen averaged $0.09 \mathrm{wt} z$ and sulfur averaged 0.07 wt $t$. properties of the naphtha fraction are shown in Table 29.

Middle Distillate $\left(350-450^{\circ} \mathrm{F}\right)$

By weight, this boiling fraction constituted the smallest fraction of the total oil. It ranged from 8 to 14 wt $z$. As expected, the API gravities and hydrogen contents dropped for these fractions. Compared to sulfurs in the IBP to $350^{\circ} \mathrm{F}$ fraction, the sulfurs stay about the same. However, nitrogen content shows a slight increase. The properties of the middle distillate are shown in Table 30 .

Middle Distillate $\left(450-650^{\circ} \mathrm{F}\right)$

By weight, this fraction was the predominant one in all of the total oils. It ranged from 32 to 48 wt $\%$. Hydrogen content continued to decline and sulfur also showed a slight decrease compared to sulfur in the lower boiling fraction. Hydrogen content averaged 11.0 wt $q$ and sulfur averaged 0.04 wt $q$. Nitrogen content was about the same in all fractions and averaged 0.57 wt $\%$. This was an increase compared to nitrogen content in the lower boiling fractions. Properties of this distillate are shown in Table 31 .

Gas $0 i 1\left(650+^{\circ} \mathrm{F}\right)$

The gas oil boiled primarily in the 650 to $750^{\circ} \mathrm{F}$ range. It constituted from 21 to 32 wt $\&$ of the total blend. Hydrogen content averaged 10.1 wt $\%$. Sulfur and nitrogen contents were similar to those in the $450-650^{\circ} \mathrm{F}$ fraction. Sulfur averaged 0.03 wt $\%$ and nitrogen 0.61 wt $\%$. These properties are summarized in Table 32 . 


\section{1 .2 Summary}

Product quality blends were characterized for six periods in Run 260 using the black Thunder coal feedstock. No major differences were observed in the characteristics despite operational changes for each period. For all periods, the hydrogen content of the total o11 blend averaged 11.35 wt $\%$. Sulfur was the lowest heteroatom and averaged 0.05 wt $\%$. Nitrogen was significantly more than sulfur and averaged 0.43 wt for all periods. oxygen by difference, is estimated to be in the 1.0 to $2.0 \mathrm{wt} f$ range in the total oils. End points were measured by D-1160 distillations and ranged from 723 to $778^{\circ} \mathrm{F}$. The average end point for all blends in thermal/catalytic mode of operation was about $780^{\circ} \mathrm{F}$ and catalytic/thermal mode about $800^{\circ} \mathrm{F}$.

\subsection{Unit Solvents}

\section{2 .1 CCR Unit Recycle Solvent}

The recycle process solvent was composed of solids-free resid recovered from the ROSE-SR unit, solids recycle material from the V1082 vacuum flash bottoms $(30-40$ wt of CI, 60-70 wt $\%$ resid), and heavy distillate from the vacuum distillation column (T102 bottoms stream). These three streams were combined to give the process solvent the following composition through the entire run:

$$
\begin{aligned}
& 40 \text { wt } \& \text { Resid } \\
& 20 \text { wt } \& \text { CI } \\
& 40 \text { wt } \& \text { Distillate. }
\end{aligned}
$$

The coal concentration in the CCR feed slurry throughout Run 260 was about 30 wt \& MF coal ( 70 wto process solvent). The T102 vacuum distillation column overhead product was used as tho withdrawal tube flush.

The heavy distillate (V1074) from the T102 vacuum column bottoms usually contains 98 wt of material with a boiling point above $650^{\circ} \mathrm{F}$. However, from August 16 to september 7, there was up to 8 wt 8 naphtha fraction in V1074. The higher than normal amounts of naphtha caused problems in the coal slurry tank since it would vent off along with the moisture.

\section{2 .2 ROSE-SR Unit Deashing Solvent}

The ROSE-SR ${ }^{S M}$ unit uses a proprietary deashing solvent to process material containing ash. These deashing solvents are designated by

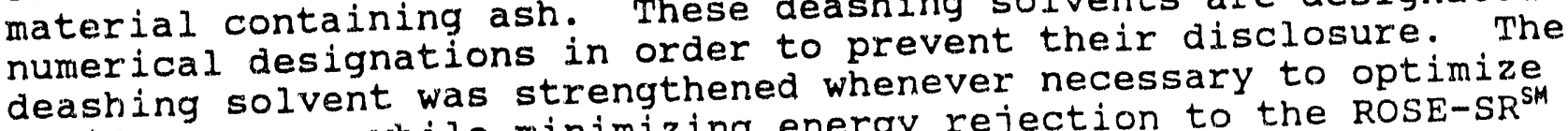
resid recovery while minimizing energy rejection to the ROSE-SR ${ }^{S M}$ bottoms product and maintaining efficient, stable deashing in the first stage. 


\section{REFERENCES}

Catalytic, Inc., Technical Progress Report, "Run 250 with Illinois No. 6 Coal", DOE Contract No. DE-AC22-82PC50041, EPRI contract No. RP1234-1-2, Document No. 50041-81, November 1987.

2. Catalytic, Inc., Technical Progress Report, "Run 251 with IIlinois No. 6 and Wyodak Coal", DOE Contract No. DE-AC2282PC50041, EPRI Contract No. RP1234-1-2, Document No. DOE/PC/50041-88, April 1988 .

3. Catalytic, Ino., Technical Progress Report, "Run 252 with Illinois No. 6 Coal", DOE Contract No. DE-AC22-82PC50041, EPRI. Contract No. RP1234-1-2, Document No. DOE/PC/50041-98. May 1990.

4. Catalytic, Inc., Technical Progress Report, "Run 253 with Illinois No. 6 Coal", DOE Contract No. DE-AC22-82PC500-41, EPRI Contract No. RP1234-1-2, Document No. DOE/PC/50041-99. Report to be published.

5. Catalyst, Inc., Technical Progress Report,"Run 254 with ohio No. 6 Coal", DOE Contract No. DE-AC22-82PC50041, EPRI Contract No. RP1234-1-2, Document No. DOE/PC/50041-111. February 1990.

6. Catalytic, Inc., Technical Progress Report, "Run 255 with Martin Lake Texas Lignite Coal", DOE Contract No. DE-AC2282PC50041, EPRI Contract No. RP1234-1-2, Document No. $\mathrm{DOE} / \mathrm{PC} / 50041-113$. Report to be published.

7. Southern Electric International, Inc., Technical Progress Report, "Run 256 with Ohio No. 6 Coal", DOE Contract No. DEAC2 2-82PC50041, EPRI Contract NO. RP1234-1-2, Document No. DOE/PC/50041-114. Report to be published.

8. Southern Electric International, Inc., Technical Progress Report, "Run 257 with Illinois No. 6 Coal", DOE Contract No. De-AC22-82PC50041, EPRI Contract No. RP1234-1-2, Document NO. DOE/PC/50041-121. Report to be published.

9. Southern Electric International, Inc., Technical Progress Report, "Run 258 with Subbituminous Coal", DOE Contract NO. DEAC-82PC50041, EPRI Contract No. RP1234-1-2, Document No. DOE/PC/50041-130. Report to be published.

10. Southern Electric International, Inc., Technical Progress Report, "Run 259 with Pittsburgh No. 8 (Ireland Mine) Coal", DOE Contract No. DE-AC-82PC50041, EPRI Contract No. RP1234-1-2. Report to be published.

11. Southern Electric International, Inc., Technical Review Meeting No. 107, November 14-15, 1990. 


\section{APPENDIX A \\ Nomenclature and Definitiona}

Al1-distillate: For experimental data, the resid yield is in the range of \pm 5 wt MAF coal. Projected values are based on a zero resid yield.

Ash: Non-organic material obtained by muffle furnace burning at $800^{\circ} \mathrm{C}$ for 4 hours (adapted ASTM D-482).

Asphaltenes: A toluene-soluble and pentane-insoluble material which is non-distillable at $600^{\circ} \mathrm{F}$ and $0.1 \mathrm{~mm} \mathrm{Hg}$ in the laboratory.

B102: T102 Vacuum Column Reboller

B1200: First stage reactor preheater

B1201: Interstage heater

CC-ITSL: close-Coupled Integrated Two-stage Liquefaction

CCR: Close Coupled Reactor Unit

CI: Material which is insoluble in hot cresol. This material is composed of both ash and unconverted coal.

COR: Common Organic Rejection

DAS (Deashing Solvent): Deashing solvent in the ROSE-SR unit. A solvent used to extract the resid from the feed to the ROSE-SR unit.

Distillate solvent: A coal-derived distillate fraction which boils between $450^{\circ} \mathrm{F}$ and $600^{\circ} \mathrm{F}$ at $0.1 \mathrm{~mm} \mathrm{Hg}$ in a laboratory batch

distillation apparatus.

DITSL: Double Integrated Two-stage Liquefaction

Dowtherm: Heat transfer fluid used in the process. Dowtherm is a trademark of the Dow Chemical Company.

DMDS: Dimethyl disulfide

Energy rejection: The heating value lost to the solid product as a percent of the feed coal heating value.

Feed Solvency Index: Laboratory analysis for fraction of ROSE-SR feed soluble in actual deashing solvent compared to its solubility in a solvent standard.

HTR: Hydrotreater. Catalytic hydrogenation reactor unit. 


\section{Appendix A (continued)}

IBP: Initial Bolling Point

\section{ITSL: Integrated Two-Stage Iiquefaction}

K111: Vacuum system Precondenser. The vessel used as the middle distillate product condenser in Tio2 Vacuum Column.

LTR: Light Thermal Resid

MAF coal: Molsture and Ash Free coal

MB period: Material Balance period

MF coal: Molsture Free coal

Middle distillate: A coal-derived distillate fraction which bolls between 350 and $450^{\circ} \mathrm{F}$ at $760 \mathrm{~mm} \mathrm{Hg}$ (GC and ASTM D-86).

Naphtha: A coal-derived distillate fraction which bolis less than $350^{\circ} \mathrm{F}$ at $760 \mathrm{~mm} \mathrm{Hg}$ (GC and ASTM D-86).

Naphthalene Activity: Catalyst activity test: Mililmoles of hydrogen consumed per $100 \mathrm{~g}$ of $10 \%$ naphthalene solution.

oils: A pentane-soluble material which is non-distillable at 600 and $0.1 \mathrm{~mm} \mathrm{Hg}$ in the laboratory.

Preasphaltenes: A cresol-soluble and toluene-insoluble material which is non-distillable at $600^{\circ} \mathrm{F}$ and $0.1 \mathrm{~mm} \mathrm{Hg}$ in the laboratory.

process solvent: The material mixed with coal in slurry preparation which is normally a blend of distillate solvent, resid and CI in specified concentrations.

P171: Pump used to transfer T102 overhead material to product storage. Also designates a sample point.

P1222: Ebullating pump on R1235.

P1236: Ebullating pump on R1236.

R.1235 OTL: Interstage sample.

Resid: A cresol-soluble material which is non-distillable at $600^{\circ} \mathrm{F}$ and $0.1 \mathrm{~mm} \mathrm{Hg}$ in the laboratory. Normally refers to deashed resid from the ROSE-SR ${ }^{S H}$ unit.

Resid + UC conversion: The fraction of the feed resid and UC that is converted to material that is distiliable at $600^{\circ} \mathrm{F}$ and $0.1 \mathrm{~mm} \mathrm{Hg}$.

$$
\text { Percent conversion }=\frac{\text { Resid+UC in }- \text { Resid+UC out }}{\text { Resid+UC in }} \times 100
$$




\section{Appendix A (continued)}

Resid recovery: The percent of ROSE-SR ${ }^{\mathrm{SM}}$ feed resid that is recovered in the deashed resid and not lost to solid product.

\section{RITSL: Reconflgured Integrated Two-stage Liquefaction}

ROSE-SR: Residuum OLI Superoritlcal Extraction-solids Refection Unit. The unit used to remove ash and unconverted coal from the process.

Solid Product: A product of the Kerr MCGee ROSE-SR ${ }^{M}$ unit first stage separator that is rich in cresol insolubles (ash and UC) with lesser amounts of resid and solvent (previously known as ash conoentrate).

Solvent (SOLV): A coal-derlved distiliate fraction which bolls above $450^{\circ} \mathrm{F}$ and is distiliable at $600^{\circ} \mathrm{F}$ at $0.1 \mathrm{~mm} \mathrm{Hg}$ in a laboratory batoh distillation apparatus.

TLU: Thermal Liquefaction Unit. Reactor operating in thermal mode.

TR: Thermal Resid

T102: Vacuum Distillation Column

T105: Atmospheric Distiliation Column

Unconverted Coal (UC): Ash free organic materlal that is insoluble in hot cresol.

V101A: Coal slurry Blend Tank. The vessel in which coal is added to process solvent to form a coal slurry for feed to the reactors.

V101B: Coal slurry Feed Tank

V131B: Process Solvent Blend Tank. The vessel used to blend material from V1067 (or V1082) and V1074 with deashed resid from the ROSE-SR unit to make process solvent for recycle to the coal slurry blend section of the plant.

V138: T102 Tray 3 Pot. The vessel used as the collection drum for the T102 Vacuum column Tray 3 product draw.

V161: T105 Distillate overhead Tank. The vessel used to collect T105 overhead material for transfer to product storage.

V182: O11/Water Separator. This vessel is used to remove water from the middle distillate product stream from the T102 Vacuum Column.

V1067: Bottoms Product Hold Tank. The vessel used to collect bottoms material from the atmospheric flash vessel. 


\section{Appendix A (continued)}

V1072: Vacuum overhead Drum. The vessel used to collect overhead material from the vacuum flash drum.

V1074: Distillate Bottoms Tank. The vessel used as a surge drum for the 102 column bottoms materlal used in the reayole solvent.

V1078: Atmospherlo Overhead pot. The vessel used to measure overhead material from the atmospherio flash vessel.

V1079: Bottoms Measuring Pot. The vessel which measures the amount of material transfexred from the atmospheric flash vessel to the V1067 Bottoms product Hold Tank.

V1080: Sour Water Measuring pot. The vessel ul.timately used to measure the amount of water removed from the second stage reactor effluent via a series of flash drums and separators.

\section{V1082: Vacuum Flash Vessel}

V1247: The vessel used to separate the liquid and gas fractions of the second stage reactor effluent.

V1258B: Interstage Separator. The vessel used to separate the liquid and gas fractions of the first stage reactor effluent.

WHSV: Welght Hourly space Velocity, 1b/hr feed per 1b catalyst. Space velocity with catalyst volume units are $1 \mathrm{~b} \mathrm{MF}$ coal/hr-f. $\mathrm{f}^{3}$ settled catalyst. 


\section{APRENDIX B \\ Matgrial BALANCE METHODOLOGY}

\section{B.1 Elemental Balancing of ylelds}

The total mass and elemental balances around each process unit are determined from the measured stream flow rates and laboratory analyses for the following elements in each stream.

$\begin{array}{ll} & \text { Carbon } \\ -\quad \text { Hydrogen } \\ \text { - Nitrogen } \\ \text { - } \quad \text { oxylur } \\ \text { Ash }\end{array}$

Elemental analyses ( $C, H, N, S, O)$ are not adjusted. Weighing factors, based on assumed flow rate errors fox each stream and relative stream flow rate sizes, are applied to the process flow rates. The method minimizes the required adjustments to a stream flow rate to close the mass and elemental balance for each unit.

Since the streams are composed primarily of hydrogen and carbon, the balance is first. developed based on these elements. Next, sulfur, nitrogen, an oxygen are balanced along with carbon and hydrogen, primarily by adjusting hydrogen sulfide, ammonia, and water rates. Ash is balanced by adjusting the ash analysis of output streams to equal the ash that entered with the coal. For ash recycle operations the vacuum bottoms (V1082) rate to the ROSE-SR unit is adjusted based on both coal ash and vacuum bottoms ash to ensure that all of the coal ash was purged In the ash concentrate (steadystate assumption). The adjusted stream flow rates between units are then corrected for inventory changes to achieve steadyanstate flow rate.

The CCR unit balance is developed with the above procedure. Since the ROSE-SR ${ }^{54}$ has fewer streams than components, the measured stream the ROSE-SR has fewer streams than componen to calculate elemental
flow rates and elemental analyses are used to for adjusting the
errors. The errors are used as the basis for adjustion compositions of the streams to close the balance.

The overall two-stage (TSL) yields are calculated by combining the balances of the CCR and the ROSE-SR ${ }^{S H}$ units.

\section{B.2 Material Balance Methodology}

Material balance data are routinely available for plant monitoring. In calculating the final ylelds, there are two intermediate stages of data. The "as-is" material balance data (Phase 2) uses measured flow rates in calculating yields. Included with phase 2 data are the mass balance closure errors. These data for Run 260 can be found in Table 4. When elemental analyses are complete on all input 
and output streams for a given day, elementally balanced yields
(Phase 3) are calculated for that day. Phase 3 elementaliy bal yield data are averaged for each set of stable operating conditions to obtain the final yield used throughout this report (Phase 4 ).

An evaluation of the material balance methodology was conducted to assess the usefulness of the different phases of material balance reports for plant monitoring, daily decision making, and technical accuracy of yields. Quantitative guidelines were desired to screen the data as it continued through the data phase system from Phase 2 to Phase 3 to phase 4. For the evaluation, a statistical approach was used to assess the variance of the material balance data before and after elemental balancing.

In general, it was found that the Phase 2 and Phase 3 yields were in good agreement. Thus, the phase 2 yields are considered to be adequate for plant monitoring and daily decision making. As an exception to this rule, only phase 3 data is used to monitor plant performance with regard to production of $\mathrm{C}_{4}+$ distillate. Daily comparison of Phase 2 and Phase 3 data proved to be useful in locating and correcting sources of balance errors.

For final yield characterization (Phase 4), Phase 3 yields are averaged for stable operating periods. These are the yields that have been used throughout this report.

\section{B.3 Material Balance Data Selection Criteria}

statistical analysis was used to develop selection criteria for deciding which days to include in Phase 3 and Phase 4 data.

Phase 2-3 selection Criteria are related to flow closure error, inventory changes, and plant stability. A total of \pm 10 wt $\%$ MAF flow closure error and \pm 15 wt MAF inventory changes are allowed. Both are obtained by summing the contributions from individual units. In addition, days may be eliminated due to plant upsets or step changes in operating conditions.

Phase 3-4 selection criteria are related to elemental balance closire errors. Elemental closure error should be within the $95 \%$ confidence intervals for each individual unit and overall TSL system. Yields on days highlighted by excessive elemental closure errors are then compared with yields from the other clemental balance days in the Phase 4 period. If important yicids on these days are outside an $80 \%$ confidence interval, the days are eliminated from the Phase 4 yields. The averages and standard deviations of the Phase 3-4 Selection criteria are reported in Table 33 for each representative operating period (Phase 4 Period).

In addition to the selection critexia, changes in Phase 2 or Phase 3 yielus from one day to the next are used to assess TSL stability. Material balance data have defined quantitative guidelines, tinat indicate system stability, as the data flow through the data phase system from phase 2 to phase 3 to Phase 4. 


\section{APPENDIX C}

\section{Microautoclave Activity Test Descriptions}

\section{C.1 Solvent ouality.}

Solvent quality is determined in the wilsonville laboratory as follows:

Standard coal (Indiana $V$ ) and solvent are charged to a $30 \mathrm{cC}$ microautoclave reactor to which a mixing ball is added. The slurry is mixed and heated to a specific temperature $\left( \pm 5^{\circ} \mathrm{F}\right)$ within a three minute period and is maintained for a specific period of time. The microautoclave is quenched in water and the reaction products are washed and extracted with tetrahydrofuran (THF).

The ratio of the amount of reacted coal to the original sample weight is expressed as percentage conversion which is referred to as "solvent quality".

Both kinetic and equilibrium tests can be performed. The equilibrium test is used to monitor solvent quality. The kinetic test gives a relative indication of the hydrogen transfer rate and hydrogen shuttling ability of the solvent. The equilibrium test gives a relative indication of the concentration of donatable hydrogen in the solvent. The conditions used for these tests are listed below:

\begin{tabular}{lccc} 
Test type & $\begin{array}{c}\text { Reaction } \\
\text { Temp., }\end{array}$ & $\begin{array}{c}\text { solvent-to- } \\
\text { coal ratio }\end{array}$ & $\begin{array}{c}\text { Time } \\
\text { min. }\end{array}$ \\
\cline { 2 - 3 } & 750 & $8: 1$ & 10 \\
Kintic & 750 & $2: 1$ & 30 \\
Equilibrium & 75 & &
\end{tabular}

\section{2 Catalyst Activity}

Catalyst activity is determined in the wilsonville laboratory as follows:

Two grams of $10 q$ naphthalene in hexadecane is catalytically hydrogenated in a microautoclave reactor at the following conditions:
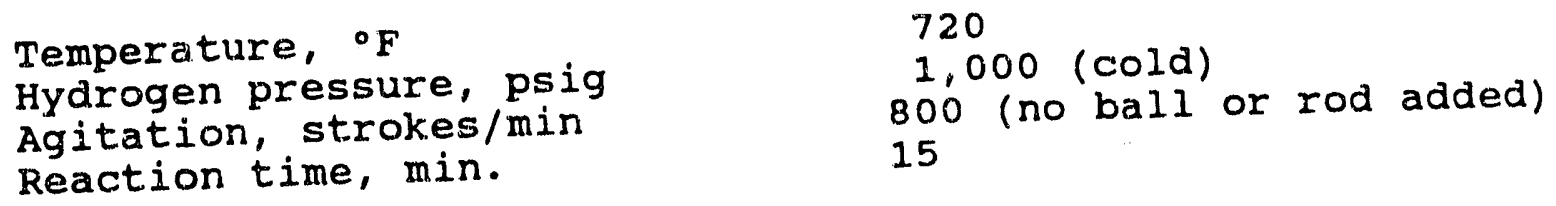

The reactor is quenched with cold water and the contents are filtered. The concentrations of tetralin and decalin, which are the products of naphthalene hydrogenation, anu naphthalene are determined by gas chromatography. The hydrogen consumption is then determined by stoichiometric calculations. The catalyst activity or 
naphthalene activity is the millimoles of hydrogen consumed per 100 $g$ of $10 \%$ naphthalene solution. 
Table 1

TYPICAL PROPERTIES OF BLACK TEUNDER COAL IN RUN 260

\begin{tabular}{|c|c|c|c|c|c|c|}
\hline Period & $260 A$ & 260B & $\underline{260 C}$ & 2600 & 260E & 260F \\
\hline $\begin{array}{l}\text { Proximate (MF) o } \\
\text { Volatile matter } \\
\text { Fixed carbon } \\
\text { Ash }\end{array}$ & $\begin{array}{r}44.8 \\
49.2 \\
6.0\end{array}$ & $\begin{array}{r}45.1 \\
49.0 \\
5.9\end{array}$ & $\begin{array}{r}44.4 \\
49.3 \\
6.3\end{array}$ & $\begin{array}{r}44.2 \\
49.9 \\
5.9\end{array}$ & $\begin{array}{r}44.5 \\
49.4 \\
6.1\end{array}$ & $\begin{array}{r}43.7 \\
49.7 \\
6.6\end{array}$ \\
\hline Moisture & 21.1 & 21.1 & 22.1 & 18.4 & 20.2 & 20.8 \\
\hline $\begin{array}{l}\text { Ultimate (MF) } \\
\text { Carbon } \\
\text { Hydrogen } \\
\text { Nitrogen } \\
\text { Sulfur } \\
\text { Ash } \\
\text { Oxygen (diff.) }\end{array}$ & $\begin{array}{r}68.7 \\
5.1 \\
1.0 \\
0.4 \\
6.1 \\
18.7\end{array}$ & $\begin{array}{r}67.9 \\
5.2 \\
0.9 \\
0.7 \\
6.1 \\
19.2\end{array}$ & $\begin{array}{r}69.0 \\
5.2 \\
1.0 \\
0.6 \\
6.2 \\
17.9\end{array}$ & $\begin{array}{r}68.9 \\
5.0 \\
1.0 \\
0.6 \\
6.2 \\
17.9\end{array}$ & $\begin{array}{r}68.5 \\
5.0 \\
1.0 \\
0.5 \\
6.3 \\
18.7\end{array}$ & $\begin{array}{r}69.1 \\
4.9 \\
1.0 \\
0.6 \\
6.4 \\
18.0\end{array}$ \\
\hline H/C atomic ratio & 0.89 & 0.92 & 0.90 & 0.87 & 0.87 & 0.85 \\
\hline Dry heating valiue (Btu/Lb) & - & - & 11,876 & - & - & $\cdots$ \\
\hline $\begin{array}{l}\text { Sulfur forms, wt } 8 \\
\text { Pyrite } \\
\text { sulfate } \\
\text { Organic }\end{array}$ & $\begin{array}{l}- \\
-\end{array}$ & - & $\begin{array}{l}0.05 \\
0.03 \\
0.33\end{array}$ & - & - & $\overline{-}$ \\
\hline $\begin{array}{l}\text { Mineral analyois, (wt of } \\
\text { silica, } \mathrm{SiO}_{2} \\
\text { Ferric oxide, } \mathrm{Fe}_{2} \mathrm{O}_{3} \\
\text { Alumina, } \mathrm{Al}_{2} \mathrm{O}_{3} \\
\text { Iime, CaO } \\
\text { Magnesia, Mgo } \\
\text { Potassium oxide, } \mathrm{K}_{2} \mathrm{O} \\
\text { Sodium oxide, } \mathrm{Na}_{2} \mathrm{O}^{2}\end{array}$ & $\begin{array}{r}\text { ashl } \\
31.2 \\
4.8 \\
15.5 \\
24.1 \\
4.7 \\
1.0 \\
0.9\end{array}$ & $\begin{array}{l}- \\
- \\
- \\
- \\
-\end{array}$ & $\begin{array}{r}35 \cdot 3 \\
5.3 \\
16.3 \\
24.0 \\
4.9 \\
0.4 \\
1.2\end{array}$ & $\begin{array}{l}- \\
- \\
- \\
-\end{array}$ & $\begin{array}{l}- \\
\overline{-} \\
- \\
- \\
-\end{array}$ & $\begin{array}{l}- \\
- \\
- \\
-\end{array}$ \\
\hline Reactivity, \& THF Conv. & 55.7 & - & 58.2 & 66.3 & 63.2 & 58.7 \\
\hline
\end{tabular}


Table 2

\section{RECYCLE PROCESS BOLVENT ANALYTICAL DATA}

\begin{tabular}{|c|c|c|c|c|c|c|}
\hline \multirow{3}{*}{$\begin{array}{l}\text { Operating } \\
\text { Period } \\
\end{array}$} & \multicolumn{6}{|c|}{$V 131 B$} \\
\hline & \multicolumn{3}{|c|}{ CI-Free Resid wt $q$} & \multicolumn{3}{|c|}{ Distillate, wt 8} \\
\hline & $\mathrm{C}$ & $\mathrm{H}$ & $N$ & C & $\mathrm{H}$ & $N$ \\
\hline \multicolumn{7}{|c|}{ Thermal/Catalytic Tests } \\
\hline $260 A$ & 90.3 & 6.7 & 1.1 & 90.0 & 9.2 & 0.5 \\
\hline $260 B$ & 91.3 & 6.4 & 1.1 & 90.2 & 8.9 & 0.6 \\
\hline $260 \mathrm{C}$ & 91.0 & 6.3 & 1.2 & 89.8 & 9.1 & 0.7 \\
\hline \multicolumn{7}{|c|}{ Catalytic/Thermal Tests } \\
\hline $260 p$ & 89.3 & 6.9 & 1.2 & 89.6 & 9.4 & 0.4 \\
\hline $260 E$ & 89.2 & 7.1 & 1.2 & 89.8 & 9.8 & 0.4 \\
\hline $260 F$ & 89.6 & 6.9 & 1.3 & 89.9 & 9.8 & 0.4 \\
\hline
\end{tabular}




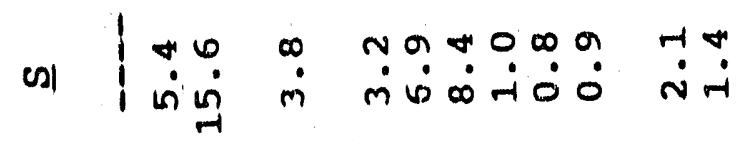

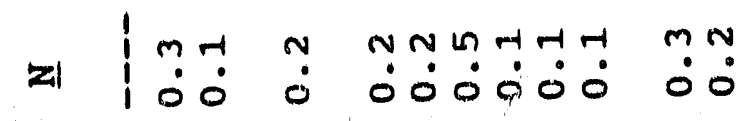

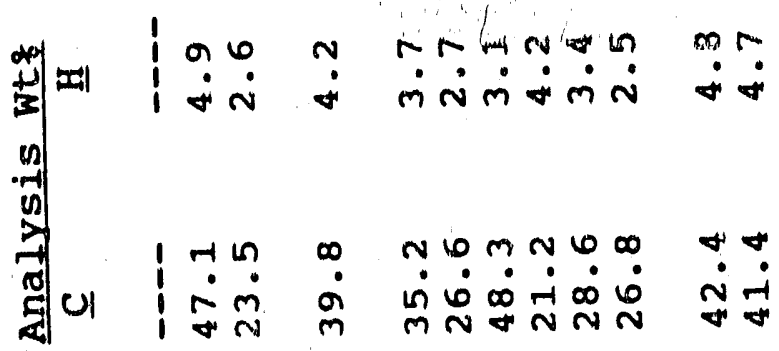

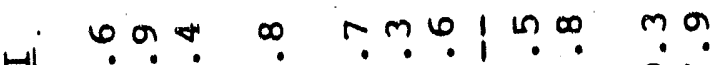

Uौ

$\begin{array}{cc} & 0 \\ m & 0 \\ 0 & 0 \\ 0 & 0 \\ 0 & 0 \\ 0 & 0 \\ 0 & 0 \\ 0 & 0 \\ 0 & 0\end{array}$

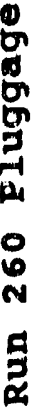

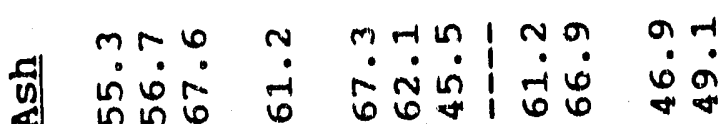
in in 6

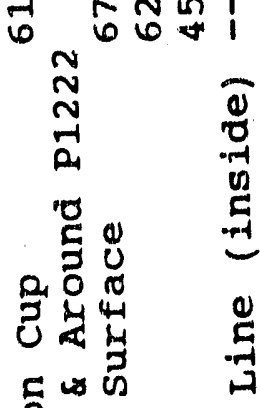

동

声

ช里

I

동도

대.

耑苟苟

in 3

兵

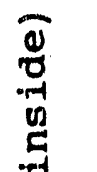

0

$\begin{array}{lll}0 & 0 & 0 \\ m & m & m\end{array}$

ก $\mathrm{N}$

$\rightarrow-1-1$

c:

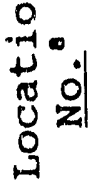

\&

$>$.

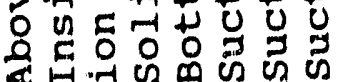

दमनुण बत

กำ

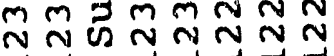

-1

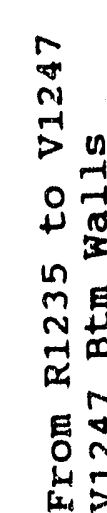

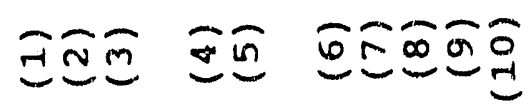

Eฐ

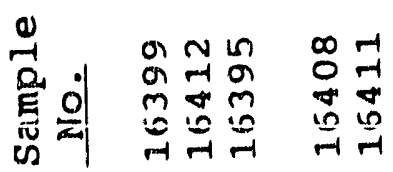

mm

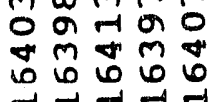

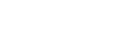

i⿻

另目苍出

舟

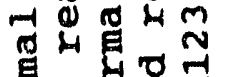
乐边要 过 $\Phi . \rightarrow 00$

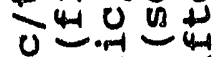
H 0 茓

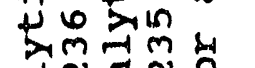

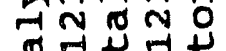

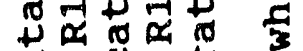

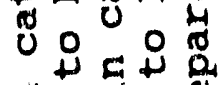
.

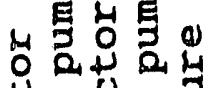
Don on en ong

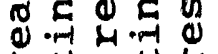
4. 㟧。 $\downarrow \rightarrow-1$

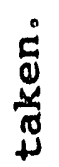
嵌 品 为 - 0 ० 0.

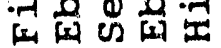
11111 告 06 Un ํํNNNN

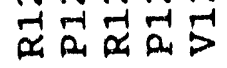




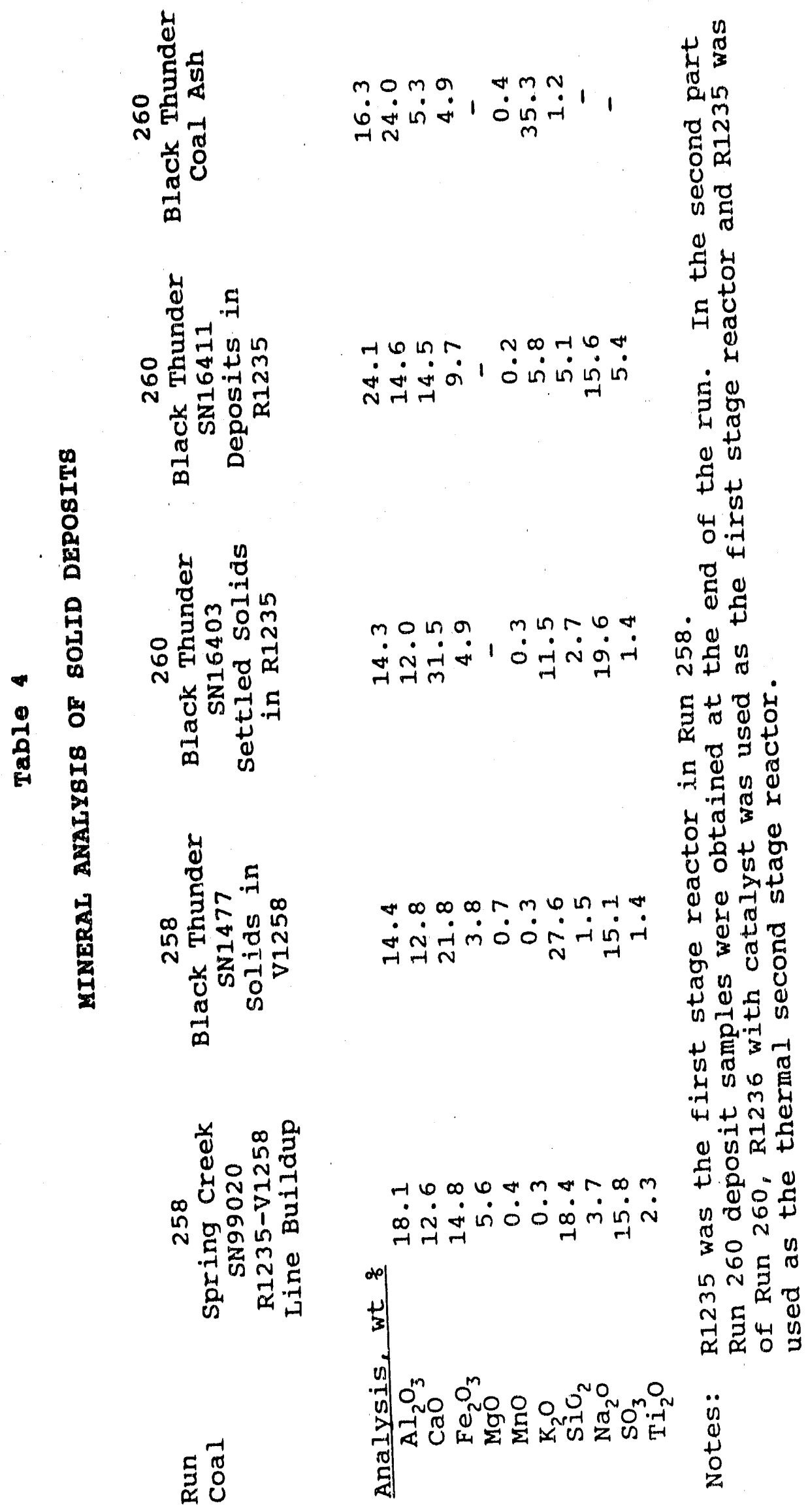


Table 5

TSL YIELDS BEFORE ELEMENTAL. BALANCING (PHASE 2 DATA)

\section{Yield, wt \% MAF}

$\mathrm{H}_{2}$ consumed

Sour water

Acid gases

$C_{1}-C_{3}$ gases

$\mathrm{C}_{4}+$ distillate

$\mathrm{C}_{4}-\mathrm{C}_{6}$

$I B P-350^{\circ} \mathrm{F}$

$350-450^{\circ} \mathrm{F}$

$450-650^{\circ} \mathrm{F}$

$650^{\circ} \mathrm{F}-850^{\circ} \mathrm{F}$

$850^{\circ} \mathrm{F}-\mathrm{EP}$

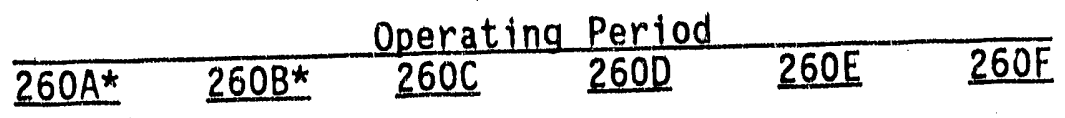

$\begin{array}{llllll}-6.2 & -6.3 & -7.5 & -6.8 & -6.7 & -5.5\end{array}$

$14.0 \quad 13.9$

16.4

18.9

18.9

18.9

4.5

5.0

2.8

2.1

3.7

3.3

8.1

12.3

10.7

5.6

6.2

5.2

$58.9 \quad 55.0$

2.8

5.3

12.7

5.5

55.4

58.8

54.3

1.7

2.4

47.5

5.6

2.4

10.6

12.0

5.6

6.0

6.9

$18.2 \quad 15.6$

19.7

21.9

22.5

19.4

22.8

20.5

$-8.2$

6.1

2.9

3.5

6.2

5.5

9.0

8.7

20.2

19.2

$8.2-2.0$

1.2

2.7

0.1

4.9

17.3

19.2

2.8

$-3.2$

4.5

2.0

33.2

33.3

11.9

29.2
12.5

2nd stage

* Unstable periods.

Notes: Thermal/Catalytic mode: Periods 260A, B, C.

No interstage separation in periods $260 C, D, E, F$. No interstage separation in periods $260 C, 1,{ }^{2}, B$. 
Tab1e 6

CLOSE-COUPLED REACTORS OPERATING DATA

\begin{tabular}{|c|c|c|c|c|c|}
\hline \multirow[b]{2}{*}{$\begin{array}{l}\text { operating } \\
\text { perlod }\end{array}$} & \multirow{2}{*}{$\begin{array}{l}\text { Coal } \\
\text { feed rate } \\
M F \text { Ib/hr }\end{array}$} & \multicolumn{2}{|c|}{ Firat stage } & \multicolumn{2}{|c|}{ Second stage } \\
\hline & & $\begin{array}{r}\text { Avg } \\
\text { temp. (OF) } \\
\end{array}$ & $\begin{array}{l}\text { Bed } \\
\text { exotherm (OF) }\end{array}$ & $\begin{array}{c}\text { Avg } \\
\text { temp.e( } 10 \mathrm{~g}) \\
\end{array}$ & $\begin{array}{r}\text { Bed } \\
\text { exotherm (०F) }\end{array}$ \\
\hline \multicolumn{6}{|c|}{ Therma 1/Catalytio Mode } \\
\hline $260 A$ & 352 & 825 & 1.4 & 790 & 16.3 \\
\hline $260 B$ & 303 & 840 & 2.3 & 790 & 9.6 \\
\hline $260 \mathrm{C}$ & 251 & 825 & 2.0 & 790 & 8.2 \\
\hline \multicolumn{6}{|c|}{ Catalytic/Thermal Mode } \\
\hline 2600 & 253 & 790 & 26.0 & 774 & 0.8 \\
\hline $260 \mathrm{E}$ & 348 & 789 & 31.1 & 797 & 1.5 \\
\hline $260 F$ & 347 & 774 & 43.0 & 804 & 2.2 \\
\hline
\end{tabular}


Process Conditions and TBI Bystem Yields (Phase 2 Data)

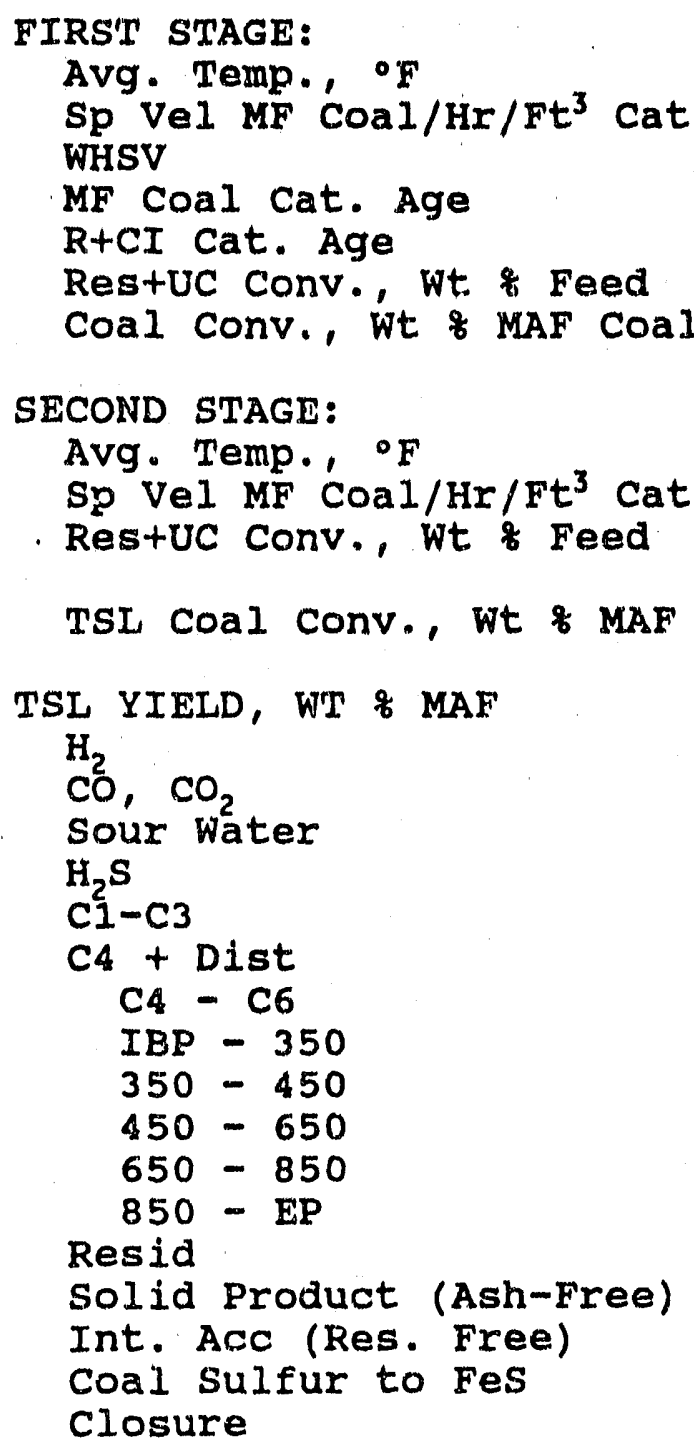

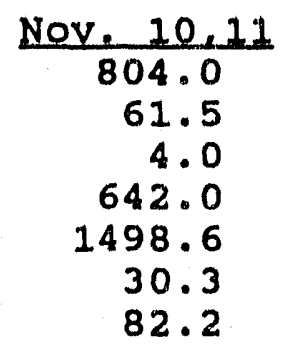

752.0

42.0

$-1.3$

84.3

$-6.0$

3.3

18.9

0.5

6.0

46.2

3.0

10.7

6.8

18.2

26.5

$-19.0$

3.3

24.0

5.8

0.0

$-2.1$ 
Table 8

SUMMARY OF ROSE-SR PN PERFORMANCE PARAMETERS

\begin{tabular}{|c|c|c|c|c|c|c|c|}
\hline $\begin{array}{l}\text { Operating } \\
\text { period }\end{array}$ & DAS type & $\begin{array}{l}\text { Resid } \\
\frac{\text { recovery }}{(w t \%)}\end{array}$ & $\begin{array}{l}\text { Energy } \\
\frac{\text { content }}{(\%)}\end{array}$ & $\begin{array}{l}\text { Organic } \\
\text { content } \\
\text { (Wt \% MAF) }\end{array}$ & $\begin{array}{l}\text { Toluene } \\
\text { solubles } \\
\text { (wt \%) }\end{array}$ & $E S \int(a)$ & $\begin{array}{l}\text { Solid Product } \\
\text { consistency }\end{array}$ \\
\hline \multicolumn{8}{|c|}{ Thermal/Catalytic Mode } \\
\hline $260 \mathrm{~A}$ & 2614 & 75.9 & 12.4 & 11.8 & 12.5 & 0.71 & Extruded \\
\hline $260 B$ & 2544 & 80.9 & 9.6 & 9.0 & 14.4 & 0.76 & Extruded \\
\hline $260 C$ & 2504 & 78.6 & 9.2 & 8.6 & 16.0 & 0.77 & $\begin{array}{l}\text { Extruded/ } \\
\text { Powder }\end{array}$ \\
\hline \multicolumn{8}{|c|}{ Catalytic/Thermal Mode } \\
\hline 2600 & 2414 & 68.6 & 16.7 & 17.2 & 12.8 & 0.64 & Powder \\
\hline $260 E$ & 2444 & 67.9 & 19.0 & 19.2 & 12.2 & 0.60 & $\begin{array}{l}\text { Chunky \& } \\
\text { Powder }\end{array}$ \\
\hline $260 F$ & 2464 & 66.7 & 20.7 & 21.6 & 14.8 & 0.59 & Extruded \\
\hline in & 1. & & & & & & \\
\hline
\end{tabular}


Table 9

ROSE-SR ${ }^{\text {SH }}$ ANALYTICAL DATA

\begin{tabular}{|c|c|c|c|c|c|c|}
\hline perating Period & $260 \mathrm{~A}$ & $260 \mathrm{~B}$ & 2600 & 2600 & $\underline{260 E}$ & $260 \mathrm{~F}$ \\
\hline $\begin{array}{l}\text { Feed Composition } \\
\text { Wt \% Ash } \\
\text { Wt \% UC } \\
\text { Wt \% Solvent } \\
\text { wt \% Carbon } \\
\text { Wt \% Hydrogen } \\
\text { Wt \% Nitrogen } \\
\text { wt \% Sulfur } \\
\text { wt \% Oxygen (a) } \\
\text { soft. Pt. ( F) } \\
\text { Fusion Pt. ( F) } \\
\text { Wt \% Preasphaltenes }\end{array}$ & $\begin{array}{r}21.5 \\
13.7 \\
2.5 \\
72.6 \\
4.9 \\
1.0 \\
2.1 \\
19.4 \\
220.2 \\
244.5 \\
9.0\end{array}$ & $\begin{array}{r}24.0 \\
11.8 \\
3.5 \\
70.7 \\
4.7 \\
0.9 \\
2.2 \\
21.5 \\
196.7 \\
221.7 \\
10.2\end{array}$ & $\begin{array}{r}25.0 \\
11.1 \\
4.6 \\
69.2 \\
4.6 \\
0.9 \\
2.2 \\
23.1 \\
198.2 \\
244.5 \\
14.3\end{array}$ & $\begin{array}{r}19.7 \\
18.3 \\
2.2 \\
72.6 \\
5.4 \\
1.1 \\
1.9 \\
19.0 \\
189.8 \\
242.0 \\
7.2\end{array}$ & $\begin{array}{r}18.1 \\
18.6 \\
5.0 \\
73.5 \\
5.4 \\
1.1 \\
1.6 \\
18.4 \\
189.4 \\
247.2 \\
7.4\end{array}$ & $\begin{array}{r}17.3 \\
18.3 \\
3.0 \\
74.2 \\
5.4 \\
1.1 \\
1.6 \\
17.7 \\
206.4 \\
247.0 \\
11.0\end{array}$ \\
\hline $\begin{array}{l}\text { Solid Product Composition } \\
\text { Wt \% Ash (b) } \\
\text { Wt \% UC(b) } \\
\text { Wt \% Resid (a) (b) } \\
\text { Wt \% Solvent (b) } \\
\text { Wt \% DAS } \\
\text { Wt \% Carbon } \\
\text { Wt \% Hydrogen } \\
\text { Wt \% Nitrogen } \\
\text { Wt \% Sulfur } \\
\text { Wt \% Oxygen (a) }\end{array}$ & $\begin{array}{r}42.2 \\
28.2 \\
27.7 \\
0.6 \\
1.5 \\
55.6 \\
3.2 \\
0.9 \\
3.9 \\
36.4\end{array}$ & $\begin{array}{r}48.2 \\
25.6 \\
25.4 \\
0.5 \\
1.2 \\
49.9 \\
2.8 \\
0.7 \\
4.4 \\
42.2\end{array}$ & $\begin{array}{r}50.1 \\
24.4 \\
25.3 \\
0.7 \\
1.0 \\
48.4 \\
2.7 \\
0.7 \\
4.2 \\
44.0\end{array}$ & $\begin{array}{r}34.3 \\
38.0 \\
25.9 \\
1.6 \\
0.6 \\
59.0 \\
3.7 \\
1.0 \\
3.1 \\
33.2\end{array}$ & $\begin{array}{r}31.9 \\
39.4 \\
27.2 \\
1.5 \\
0.7 \\
61.2 \\
3.8 \\
1.1 \\
2.6 \\
31.3\end{array}$ & $\begin{array}{r}30.3 \\
37.9 \\
30.1 \\
1.7 \\
1.2 \\
62.5 \\
3.9 \\
1.2 \\
2.6 \\
29.8\end{array}$ \\
\hline
\end{tabular}

Recycle Resid Composition

Wt \% Ash (b)

Wt $\%$ Solvent (b)

Wt \% DAS

Wt \% Sulfur

Soft. Pt. ( $\left.{ }^{\circ} F\right)$

Fuston $\mathrm{Pt} .\left({ }^{\circ} \mathrm{F}\right)$

Wt \% Carbon

Wt \% Hydrogen

Wt. \% Nitrogen

$\begin{array}{rrrrrr}0.0 & 0.4 & 0.0 & 1.0 & 0.1 & 0.1 \\ 8.4 & 13.0 & 10.2 & 11.7 & 12.6 & 16.0 \\ 0.9 & 0.4 & 0.2 & 0.6 & 0.4 & 0.5 \\ 0.0 & 0.1 & 0.0 & 0.2 & 0.0 & 0.1 \\ 138.2 & 147.0 & 153.5 & 148.0 & 114.4 & 118.6 \\ 160.2 & 166.8 & 197.5 & 209.0 & 162.4 & 196.4 \\ 91.3 & 91.4 & 91.5 & 89.5 & 89.7 & 89.7 \\ 6.8 & 6.6 & 6.6 & 7.3 & 7.5 & 7.5 \\ 1.1 & 1.1 & 1.1 & 1.0 & 1.0 & 1.0\end{array}$

Notes: Thermal/Catalytic mode: Periods 260A, B, C.

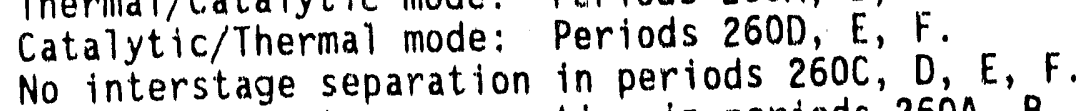
Partial interstage separation in periods 260A, B.

(a) Calculated by difference.

(b) "DAS-free" basis. 
Table 10

T102 operating Conditions

\begin{tabular}{|c|c|c|c|c|c|c|c|}
\hline & RUN PERIOD & $260 A$ & $260 \mathrm{~B}$ & $260 \mathrm{C}$ & 260D & 260E & $260 \mathrm{~F}$ \\
\hline T102 & Top Vapor temp, ${ }^{\circ} \mathrm{F}$ & 496 & 494 & 503 & 502 & 505 & 503 \\
\hline $\mathrm{T} 102$ & Tray 2 temp, ${ }^{\circ} \mathrm{F}$ & 496 & 506 & 500 & 505 & 509 & 507 \\
\hline $\mathrm{T} 102$ & Tray 3 temp, $\circ \mathrm{F}$ & 517 & 528 & 522 & 524 & 527 & 525 \\
\hline $\mathrm{T} 102$ & Top Pack temp, ${ }^{\circ} \mathrm{F}$ & 551 & 562 & 556 & 557 & 560 & 557 \\
\hline $\mathrm{T} 102$ & Tray 8 temp, ${ }^{\circ} \mathrm{F}$ & 577 & 585 & 588 & 594 & 588 & 582 \\
\hline $\mathrm{T} 102$ & Bottom temp, ${ }^{\circ} \mathrm{F}$ & 625 & 626 & 631 & 637 & 629 & 628 \\
\hline $\mathrm{T} 1.02$ & TR3 Reflux temp, ${ }^{\circ} \mathrm{F}$ & 247 & 252 & 248 & 245 & 235 & 230 \\
\hline $\mathrm{T} 102$ & Top Pres, psia & 1.8 & 1.8 & 2.2 & 2.2 & 1.5 & 1.5 \\
\hline $\mathrm{T} 1.02$ & Reflux flow, LB/HR & 629 & 633 & 628 & 625 & 635 & 619 \\
\hline $\mathrm{B} 102$ & Inlet temp, ${ }^{\circ} \mathrm{F}$ & 615 & 615 & 619 & 625 & 619 & 618 \\
\hline B102 & stack temp, of & 904 & 888 & 886 & 894 & 883 & 878 \\
\hline B102 & Process flow, GPM & 102 & 101 & 99 & 99 & 99 & 102 \\
\hline Notes & $\begin{array}{l}\text { s: Thermal/Catalytic } \\
\text { Catalytic/Therma } \\
\text { No interstage se } \\
\text { Partial interstac }\end{array}$ & $\begin{array}{l}\text { mode: } \\
\text { 1 mode: } \\
\text { paration } \\
\text { ge separ }\end{array}$ & $\begin{array}{l}\text { Periods } \\
\text { poriods } \\
\text { in perio } \\
\text { ation in }\end{array}$ & $\begin{array}{l}260 \mathrm{~A}, \\
2600 \\
\text { ds } 260 \\
\text { perioc }\end{array}$ & 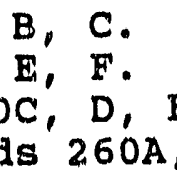 & & \\
\hline
\end{tabular}


Table 11

ANALYTIGAL DATA FOR THE INTERSTAGE STREAM

\begin{tabular}{|c|c|c|c|c|c|c|c|c|c|c|}
\hline & & & & nter & ge $S$ & ple, $w$ & & & & \\
\hline Operating & & & & & -Fres & Residu & & & $1 s+111$ & \\
\hline Period & Solv & Resid & $\underline{U C}$ & Ash & $c$ & $\mathrm{H}$ & $N$ & $C$ & $\mathrm{H}$ & $N$ \\
\hline Thermal/C & atalyt & c Test: & & & & & & & & \\
\hline $260 A$ & 36.2 & 42.0 & 9.1 & 12.7 & 89.3 & 6.45 & 1.2 & 89.0 & 9.2 & 0.6 \\
\hline $260 B$ & 37.9 & 40.1 & 7.7 & 13.8 & 90.7 & 6.00 & 1.2 & 88.8 & 8.8 & 0.7 \\
\hline 2600 & 37.5 & 40.2 & 8.0 & 14.3 & 90.2 & 6.32 & 1.2 & 88.4 & 8.9 & 0.8 \\
\hline Catalytic & /Therm & 1 Test & & & & & & & & \\
\hline 2600 & 41.9 & 32.1 & 15.3 & 10.6 & 89.2 & 6.99 & 1.1 & 89.2 & 10.0 & 0.4 \\
\hline $260 E$ & 39.9 & 33.4 & 16.4 & 10.2 & 89.9 & 5.70 & 0.9 & 88.7 & 10.0 & 0.4 \\
\hline $260 \mathrm{~F}$ & 38.8 & 34.4 & 96.7 & 10.0 & 88.7 & 6.98 & 1.3 & 88.8 & 10.3 & 0.4 \\
\hline
\end{tabular}



ANAIYTICAL DATA OF BTREAMS OSED IN THE
ELEMENTAL MATERIAL BATANCEB

operating

Period

operating

Period

$260 A$
$260 B$
$260 C$
$260 D$
$260 E$
$260 F$

$260 \mathrm{~F}$

*Similar to ROSE-SR feed.

\begin{tabular}{l}
\hline$C$ \\
\hline 68.7 \\
67.9 \\
69.0 \\
68.9 \\
68.5 \\
69.1
\end{tabular}

69.1 $\operatorname{coa}$

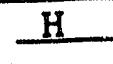

\section{1}

5.2

5.3

5.0

5.0

4.9

1.0
0.9
1.0
1.0
0.9
1.0

1.0

0.4

0.7

0.6

0.6

0.5

0.6

Recycle Materia

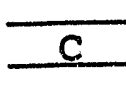

70.4

69.4

69.5

72.5

74.0

74.1

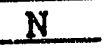

1. 0

4.9

4.6

4.7

5.4

5.4

5.4
0.9

0.9

1.1

1.1

1.1
2.2

2.2

2.2

1.8

1.6

$\left(V_{1082}\right) *$ wt $\%$

18.7

19.2

17.9

17.9

18.7

18.0

Ash

6.1

6.1

6.2

6.2

6.3

6.4

$\mathrm{S} \quad \mathrm{O}(\mathrm{a})$

Ash

0.0

21.4

0.0

22.9

0.0

22.6

0.3

18.9

0.1

17.8

0.8

16.9

Operating Period

operating

260A

$260 \mathrm{~B}$

$260 \mathrm{C}$

260D

$260 \mathrm{E}$

$260 F$
260A

$260 B$

$260 \mathrm{C}$

$260 D$

$260 \mathrm{E}$

$260 \mathrm{~F}$
Flashed

\begin{tabular}{|c|c|}
\hline C & H \\
\hline $\begin{array}{l}87.0 \\
87.6 \\
87.7 \\
86.4 \\
85.8 \\
85.4\end{array}$ & $\begin{array}{l}11.6 \\
10.9 \\
11.0 \\
11.1 \\
11.3 \\
11.1\end{array}$ \\
\hline
\end{tabular}

N

0.4

0.5

0.5

0.3

0.4

0.4
(V1078), wt \&

$\mathrm{s}$

0.03

0.04

0.04

0.06

0.03

0.08
Q(a)

1.0

0.9

0.7

1.5

2.4

2.9

$\begin{array}{lllll}89.9 & 9.3 & 0.5 & 0.01 & 0.2 \\ 88.8 & 9.3 & 0.5 & 0.03 & 1.4 \\ 89.1 & 9.5 & 0.6 & 0.01 & 0.8 \\ 89.2 & 9.8 & 0.5 & 0.03 & 0.4 \\ 89.1 & 9.9 & 0.4 & 0.03 & 0.5 \\ 89.1 & 9.9 & 0.5 & 0.05 & 0.5\end{array}$


Table 12 (continued)

ANALXTICAL DATA OF GTREAMB USED IN THE

ELEMENTSAL MATERIAL BALANCES

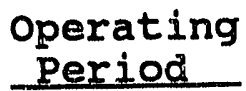

$260 A$

$260 B$

$260 C$

$260 D$

$260 \mathrm{E}$

$260 \mathrm{~F}$

operating

Period

$260 A$
$260 B$
$260 \mathrm{C}$
$260 \mathrm{D}$
$260 \mathrm{E}$
$260 \mathrm{~F}$

$260 A$

60C

$260 \mathrm{~F}$
Vaccum Flash Overhead

\begin{tabular}{ll}
\hline$C$ & H \\
\hline 89.9 & 9.3 \\
90.2 & 9.0 \\
89.9 & 9.2 \\
89.6 & 9.8 \\
89.0 & 9.7 \\
89.4 & 9.9
\end{tabular}

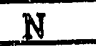

0.6

0.6

0.6

0.5

0.4

0.5
O(a)

0.02

0.02

0.02

0.03

0.03

0.04

0.2

0.2

0.3

0.1

0.8

0.2

(a) oxygen by difference.

ROSE-SR ${ }^{\text {SH }}$ Resid, wt \%

\begin{tabular}{llllll}
\hline $\mathrm{C}$ & $\mathrm{H}$ & $\mathrm{N}$ & $\mathrm{S}$ & $\mathrm{O}$ (a) & Ash \\
\cline { 2 - 3 } & & & & & \\
91.3 & 6.8 & 1.1 & 0.03 & 0.7 & 0.1 \\
91.3 & 6.5 & 1.1 & 0.06 & 0.6 & 0.4 \\
91.2 & 6.6 & 1.1 & 0.79 & 0.0 & 0.1 \\
89.9 & 7.3 & 1.0 & 0.19 & 1.0 & 0.6 \\
89.8 & 7.5 & 1.0 & 0.05 & 1.6 & 0.1 \\
89.7 & 7.5 & 1.0 & 0.08 & 1.6 & 0.1
\end{tabular}


१ิ

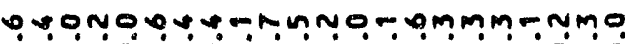

o go-munnnnomo-o-monomannm-

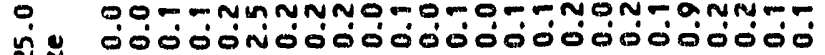

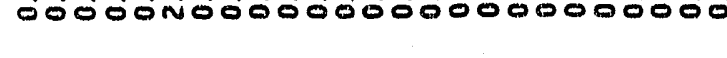

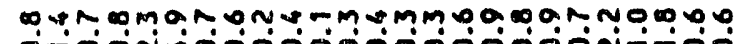

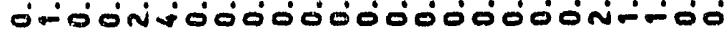

(1)

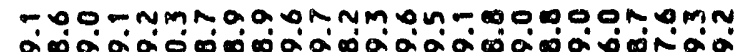

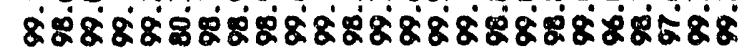

จำ

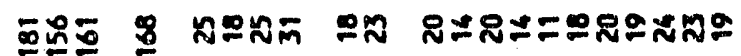

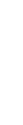

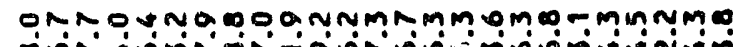

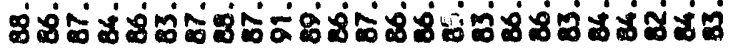

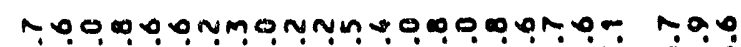

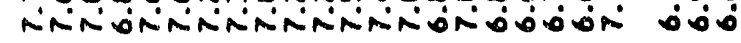

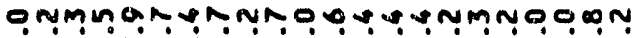

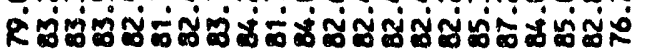

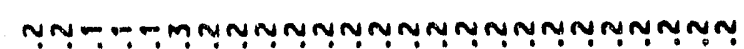

$=\underline{3}$

00000000000000000000000000

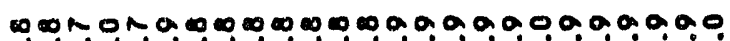

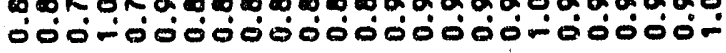

\section{(n)}

ن MỸO⿻

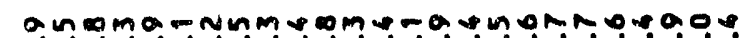

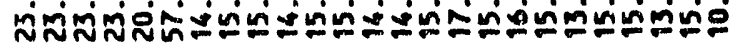

क

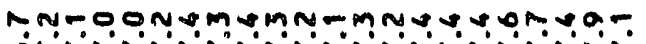

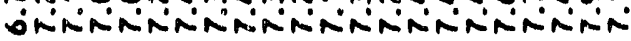

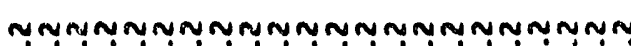
00000000000000000000000

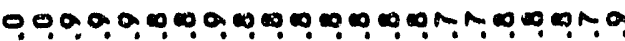
- -000000000000000000

NaA-n commmmomsomoonaompro Nomita nioboboboniniminiminim

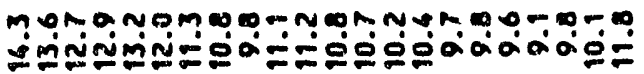

-0.0-000m+nn-100000mn-n-

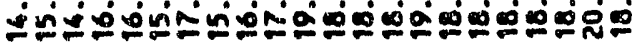

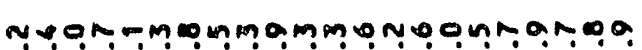

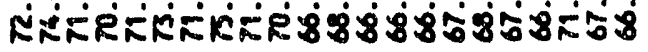

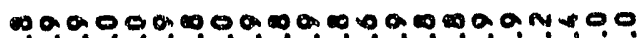

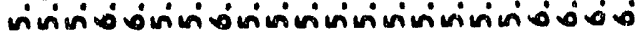

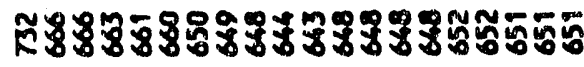

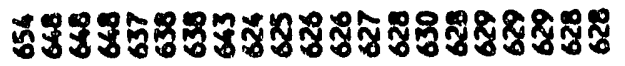

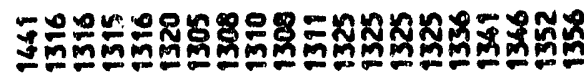

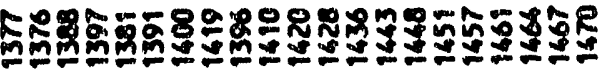

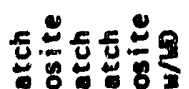

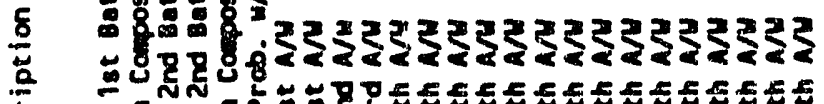

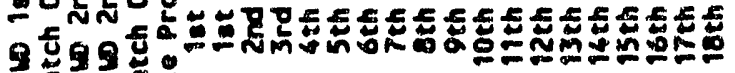

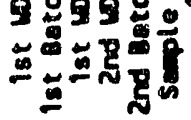

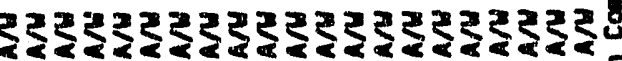
t: 势

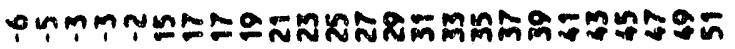
这

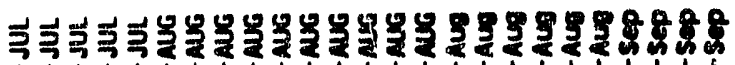

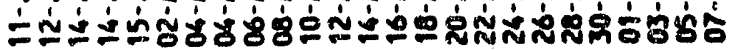

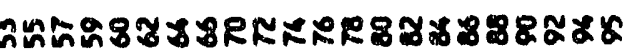

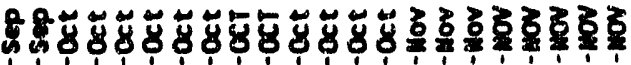

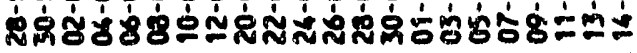




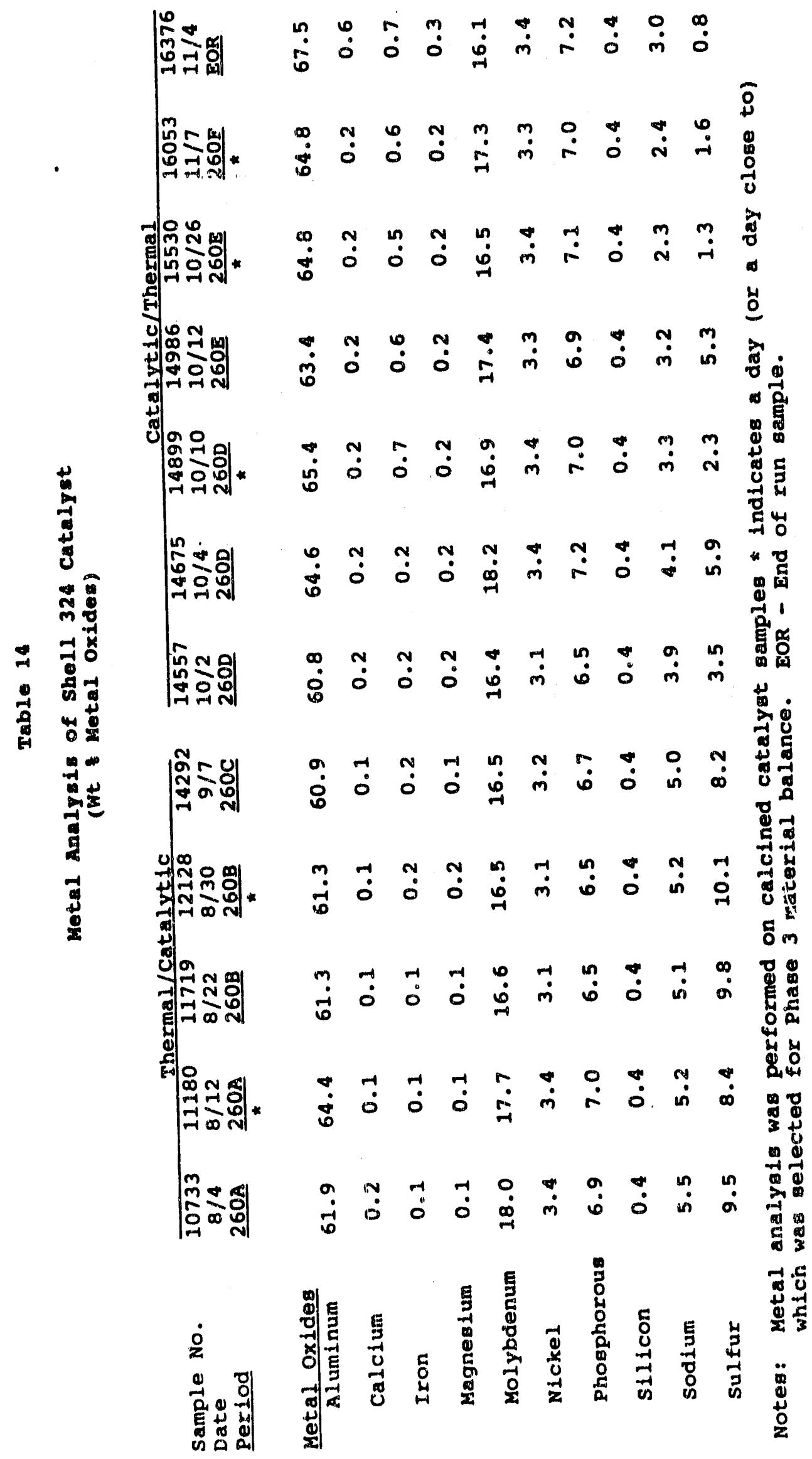




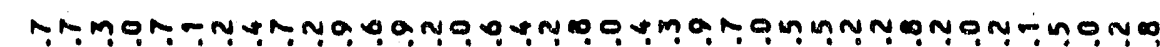

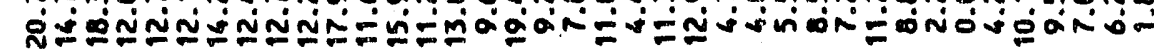

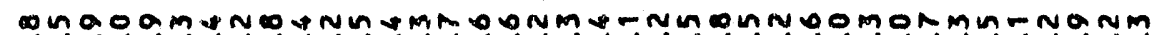

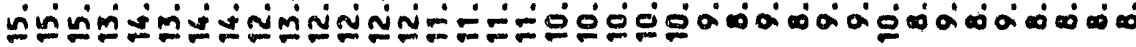

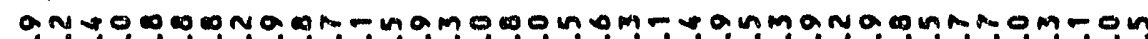

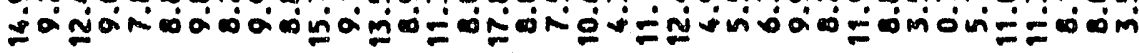
कू

ఏ

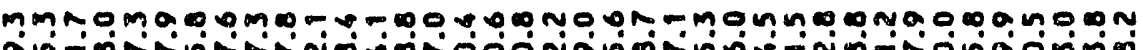

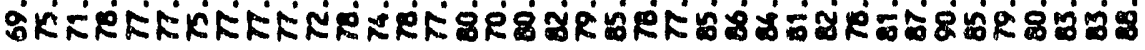
m=ñ 罢

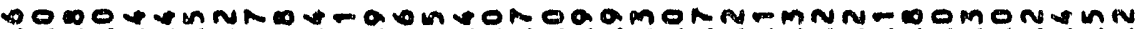
जูड क्ष

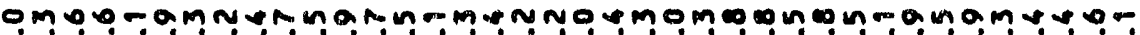

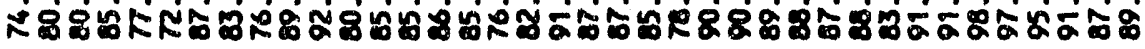

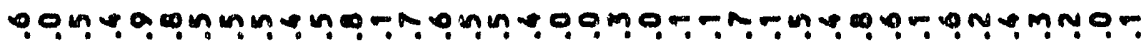

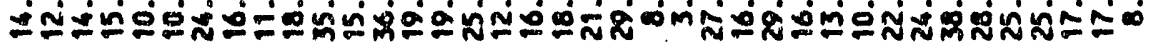
8

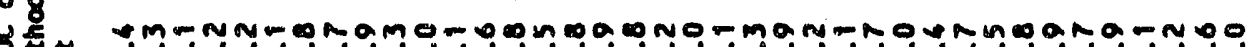

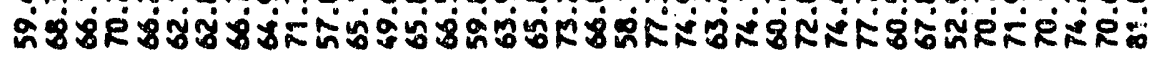
象

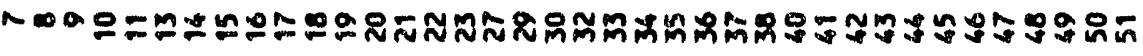

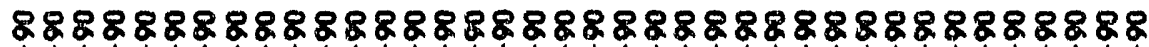

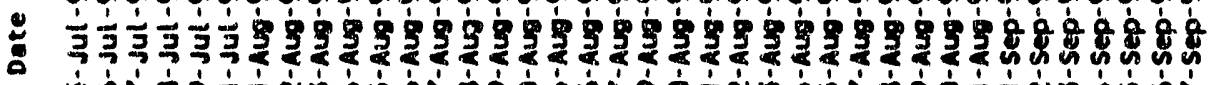

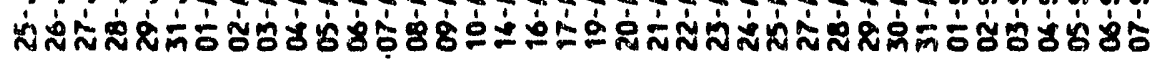




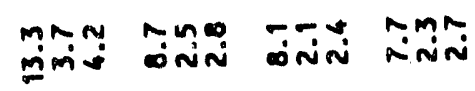

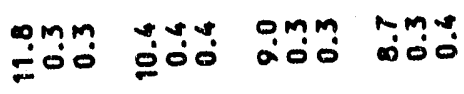

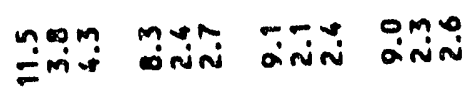

总

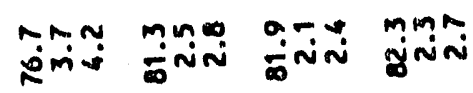

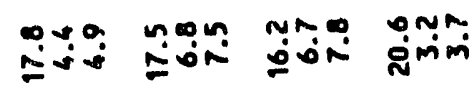

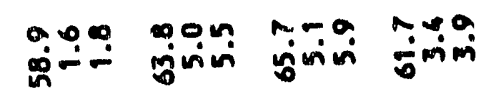

mon

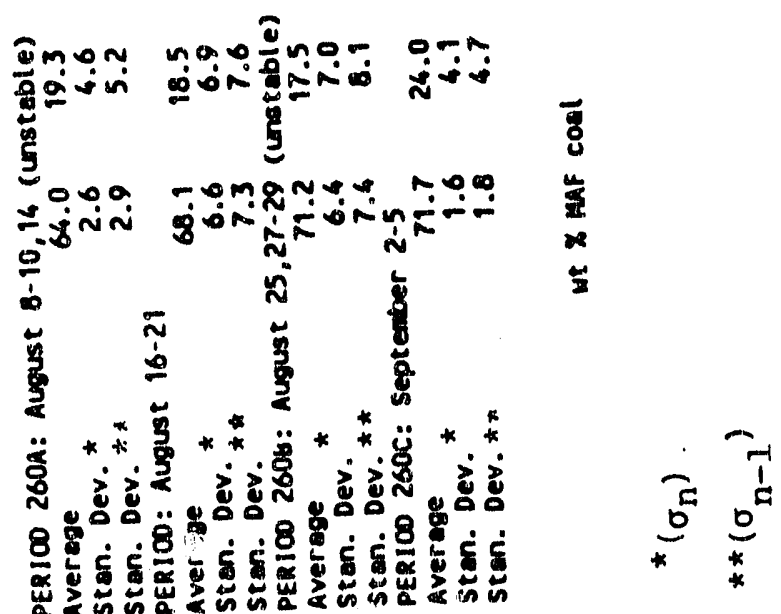




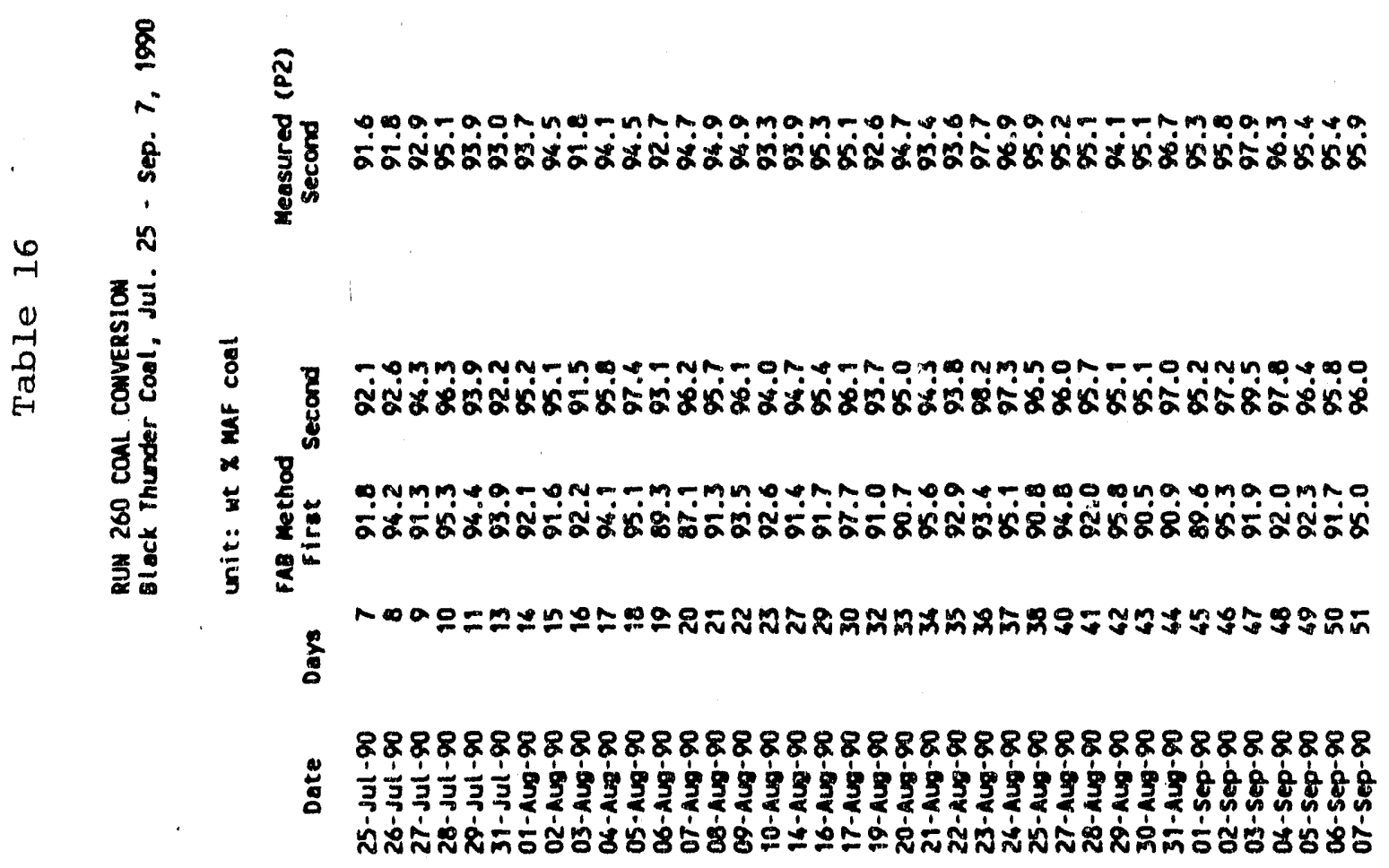




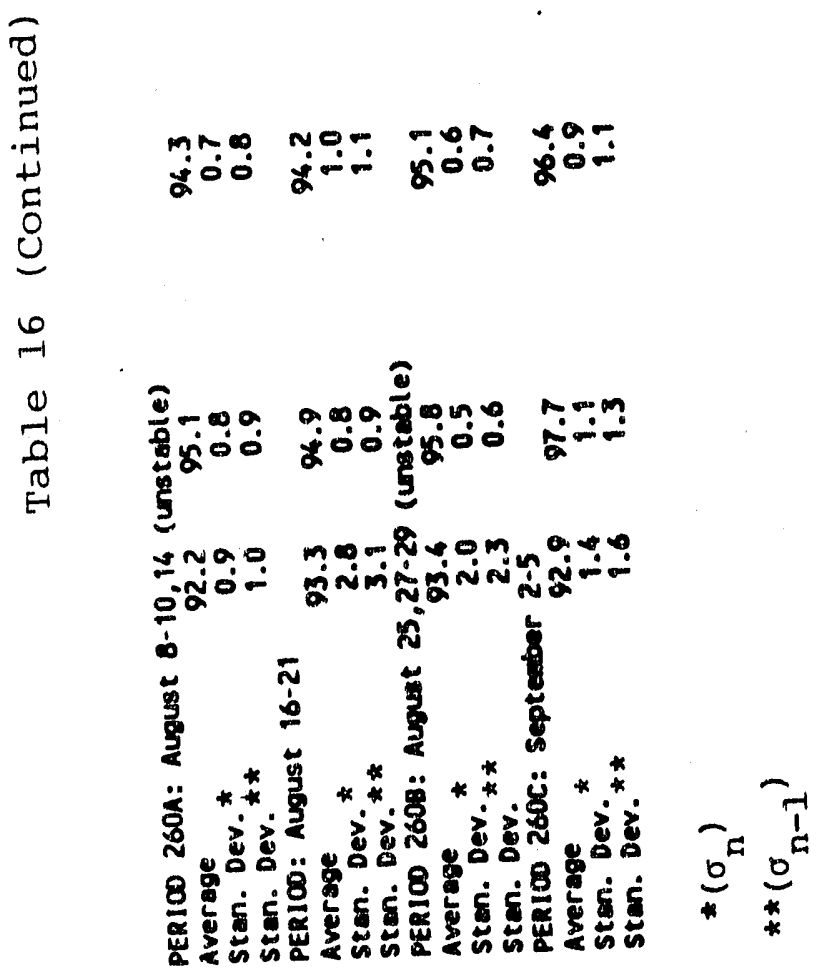




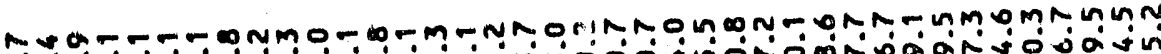
8

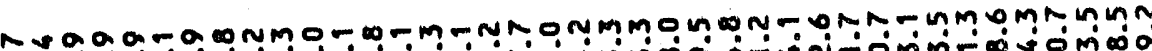
西

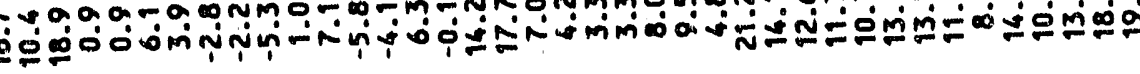

NRONMmOU⿻一亅八 $\frac{8}{8}$

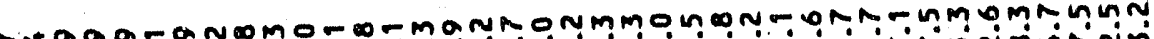
$\stackrel{4}{8}$

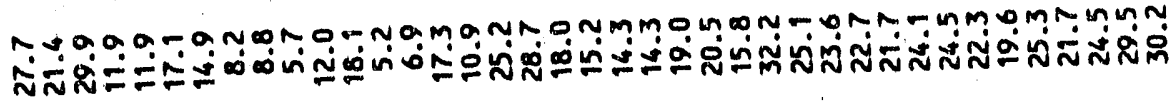

量
豙

它贴

宊$$
=
$$

亏ัँ

mo-

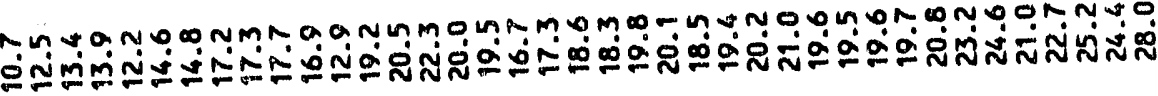

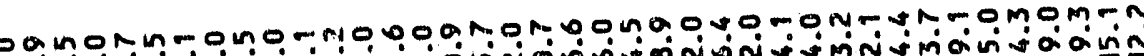
กิ tMm

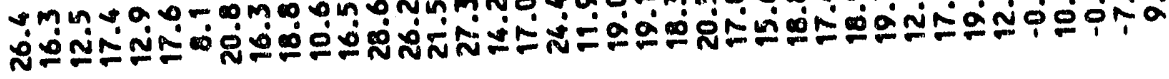

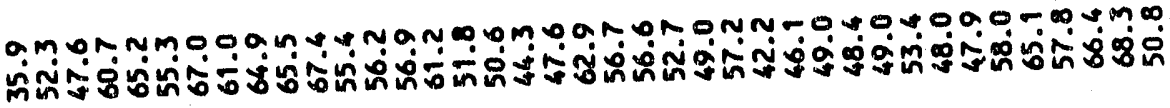

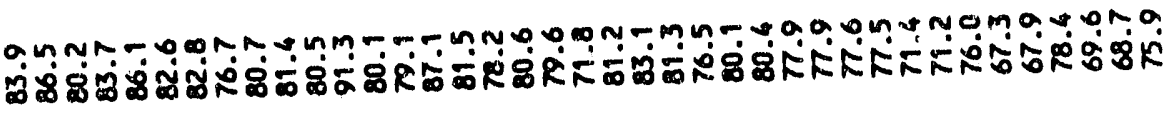

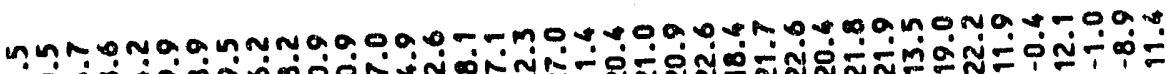

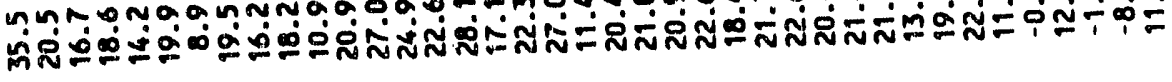

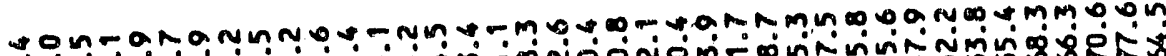

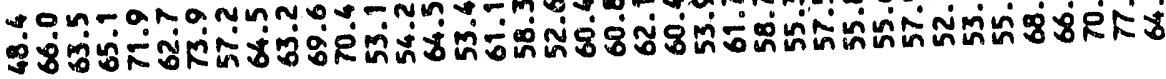

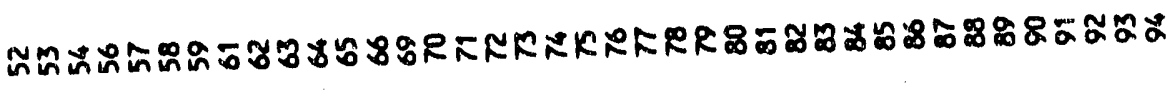

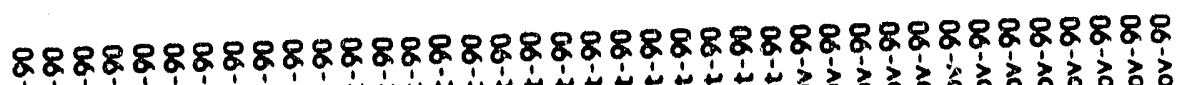
: 落 


\section{ำฺำ \\ $=$}

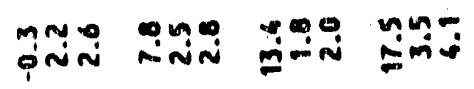

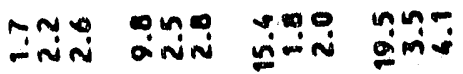

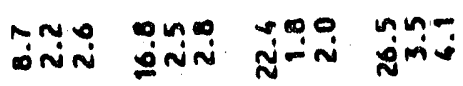

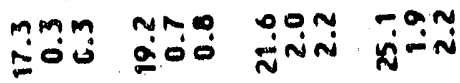

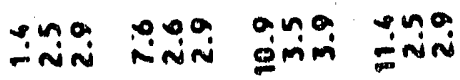

范

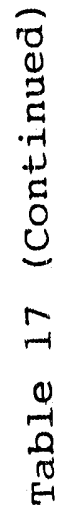

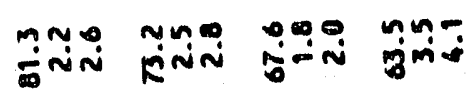

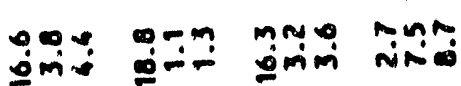

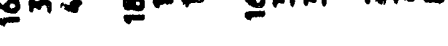

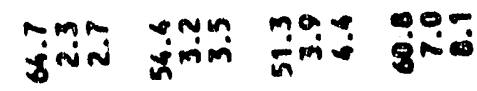

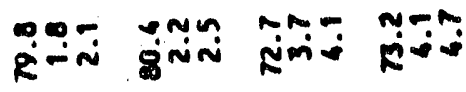

$\frac{n}{20}$

.

苞

\%

品

है

ร

$\stackrel{+-1}{+-1}$

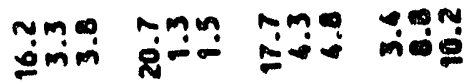

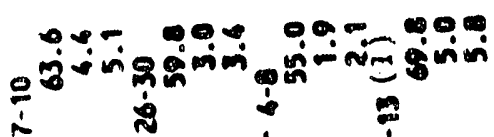




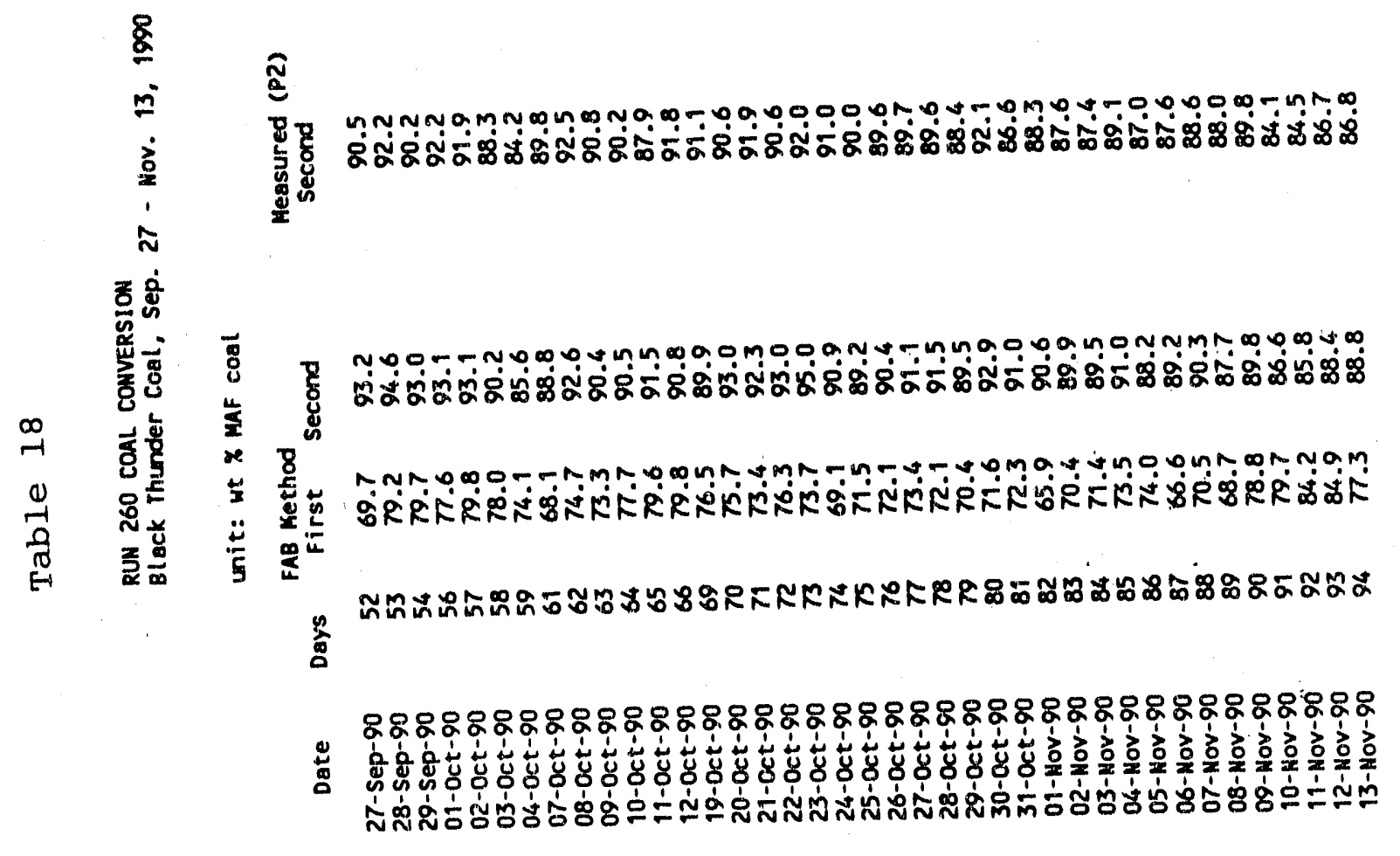




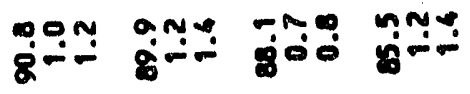

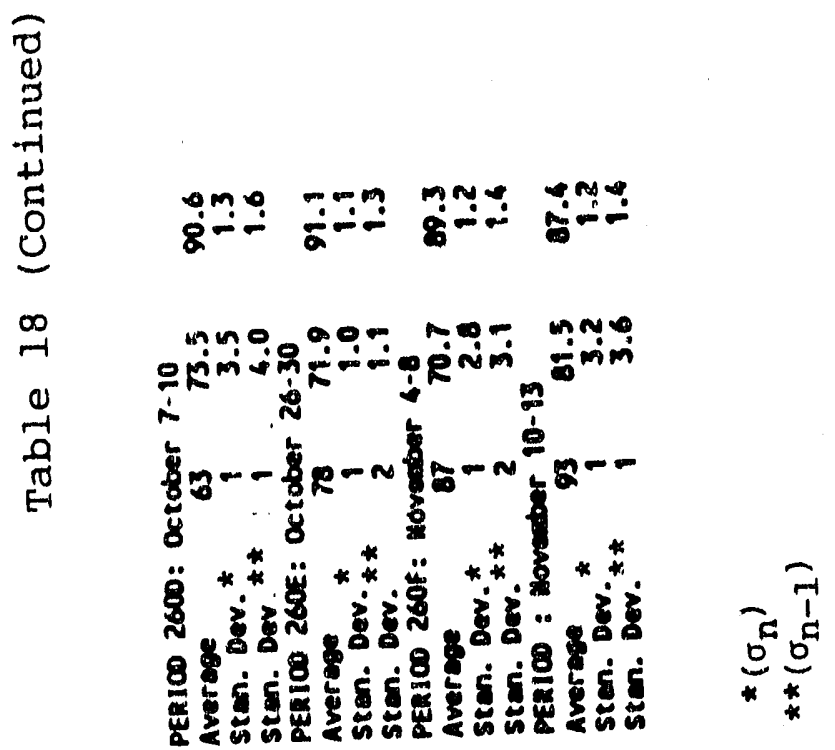




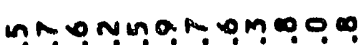

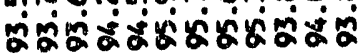

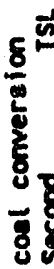

ชั

雚

$\frac{8}{x}$

$\frac{k}{4}$

웅

a$$
\text { is }
$$

:

密

$\stackrel{4}{a}$

岂量

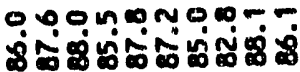

๑m

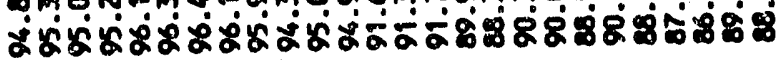

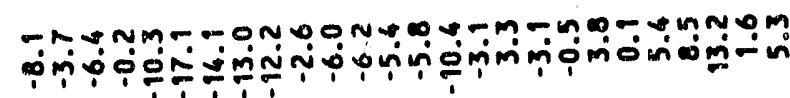

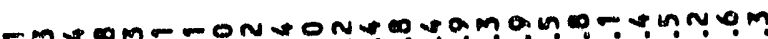

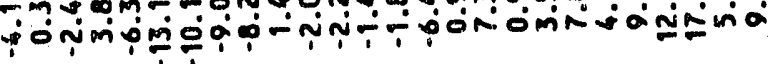

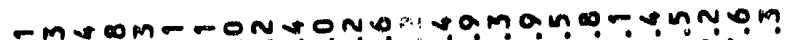

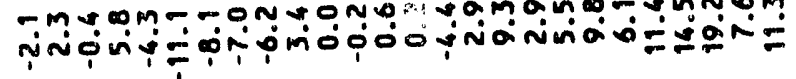

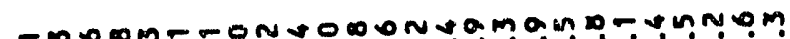

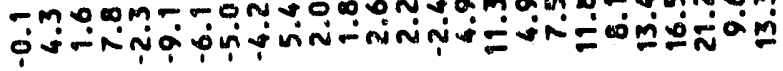

amoon-acosodonoamamo-s innom

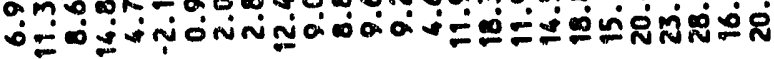

MNMNOOOM-MN

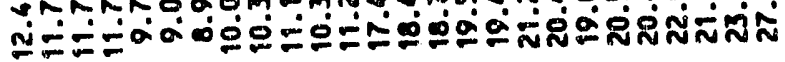

문

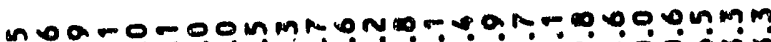

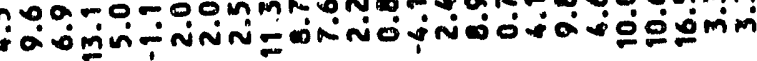

פิ

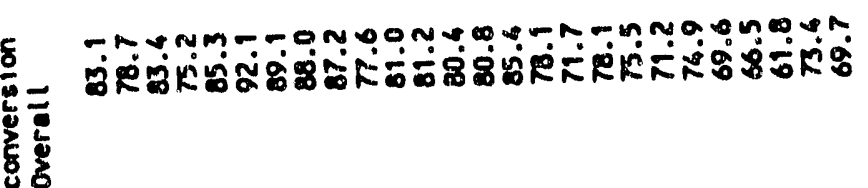

豈

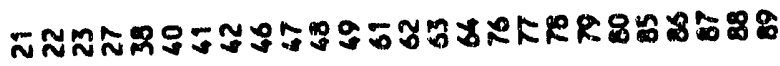

ติ

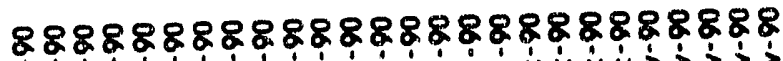

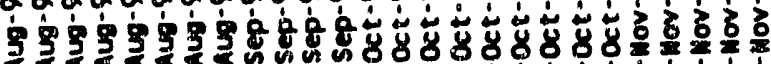

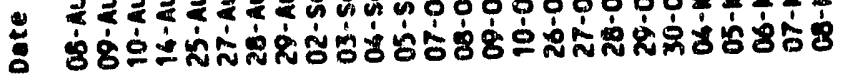




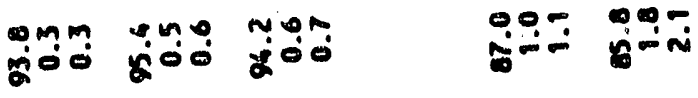

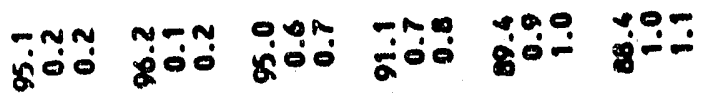

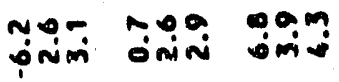

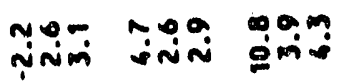

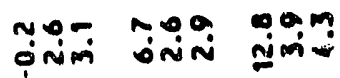

$$
\begin{aligned}
& \text { ำ }
\end{aligned}
$$

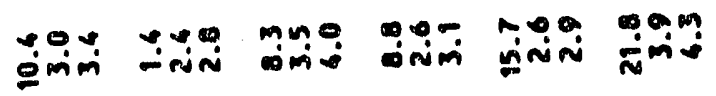

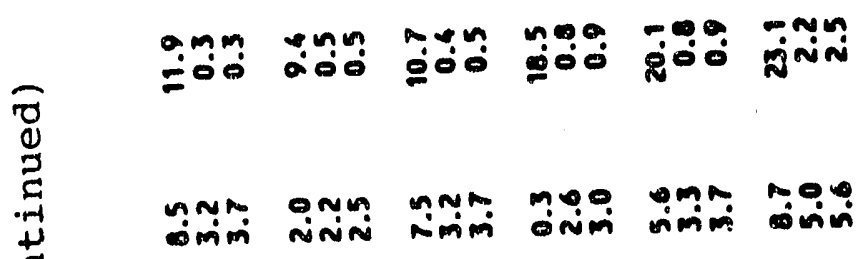

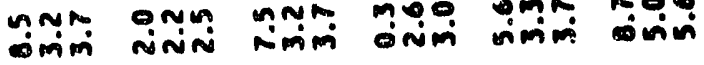

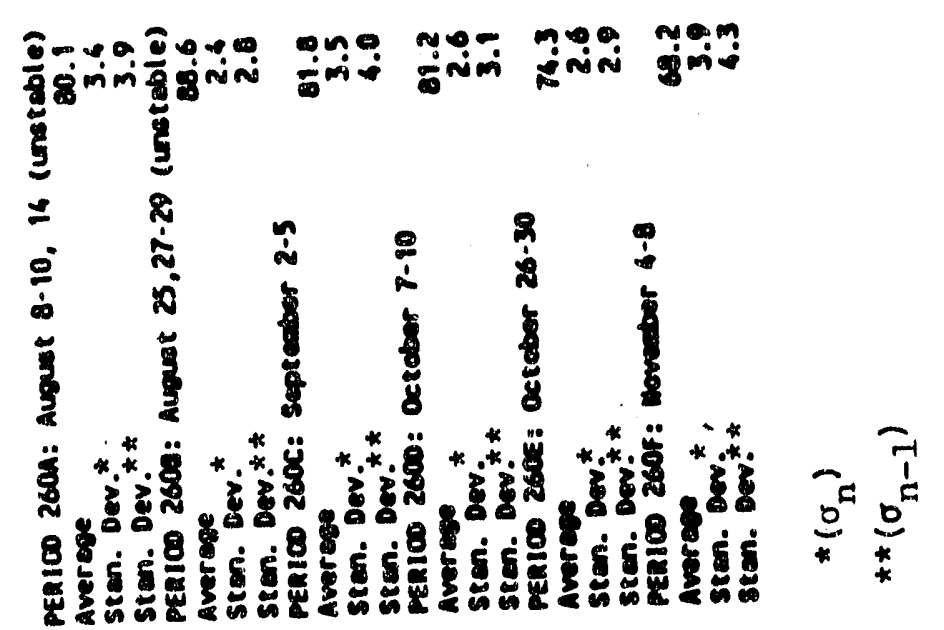




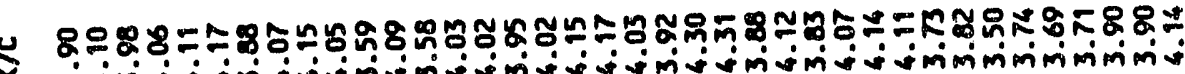
జ

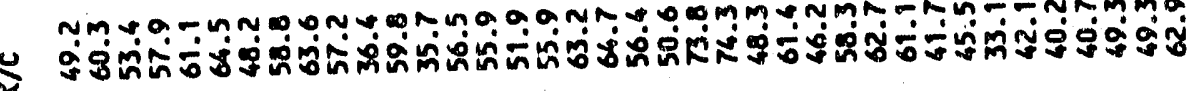

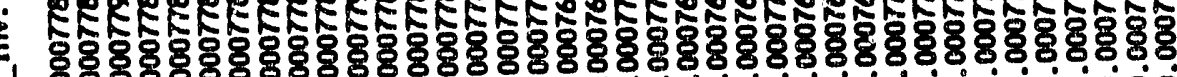

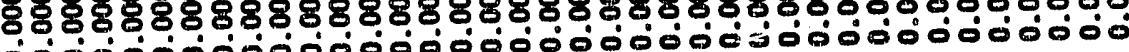
$0000000000000 \%$ $8=5 \%=5$ ล

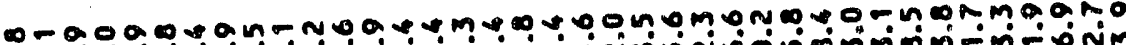

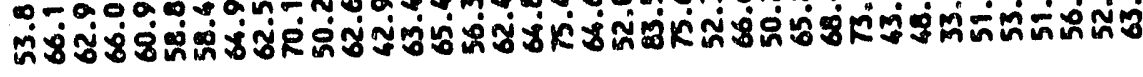

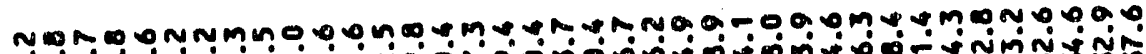
2.

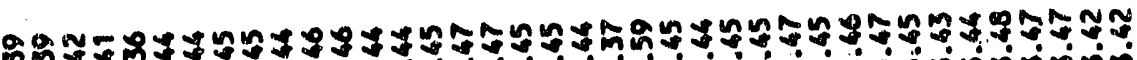

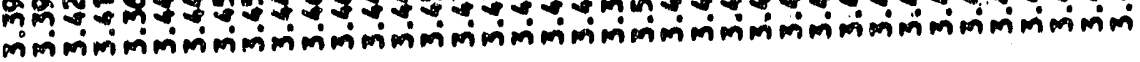

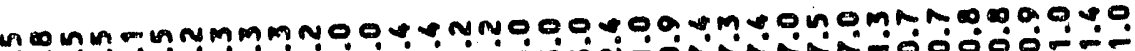

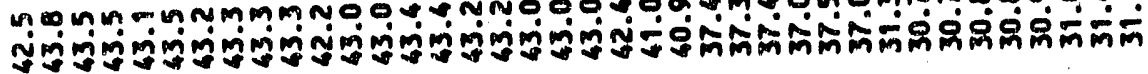
g

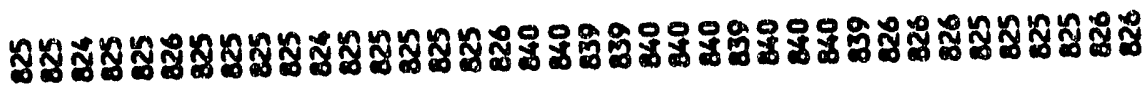
咅

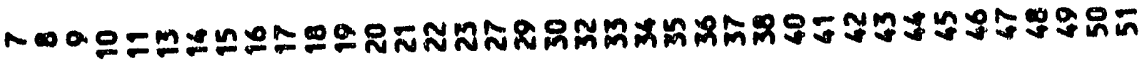

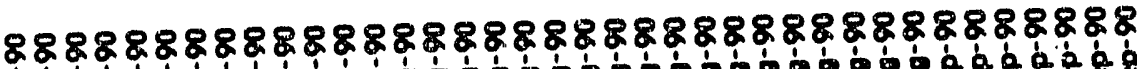

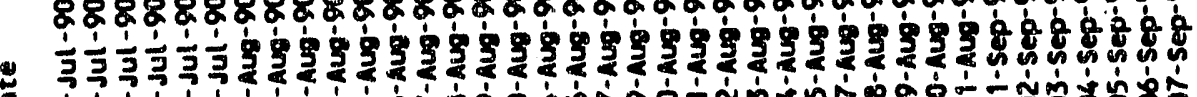

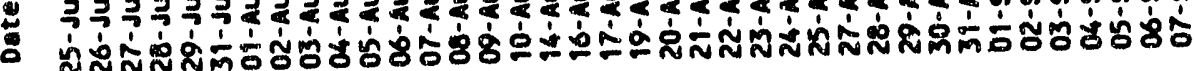




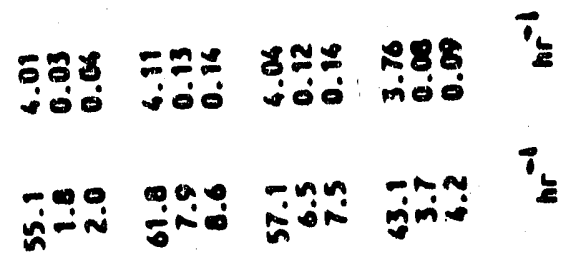

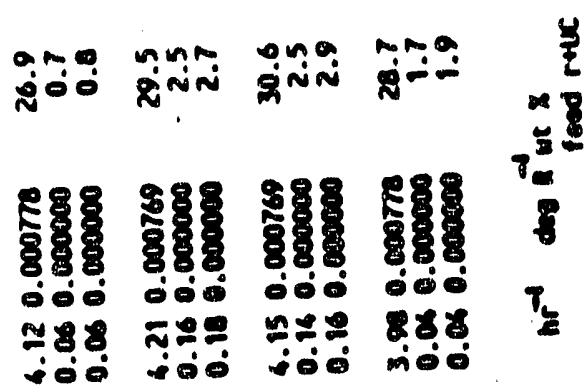

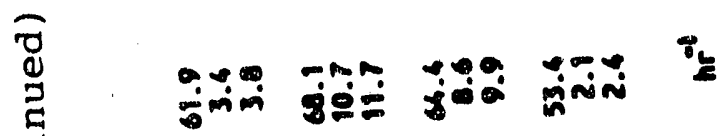

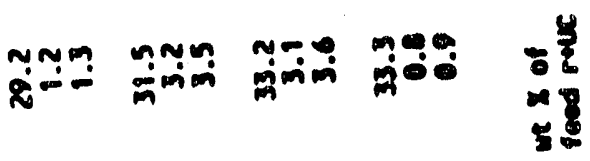

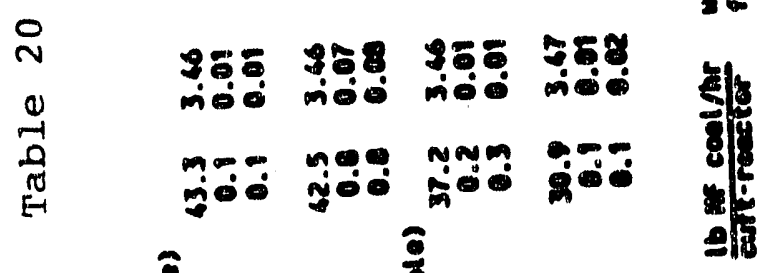

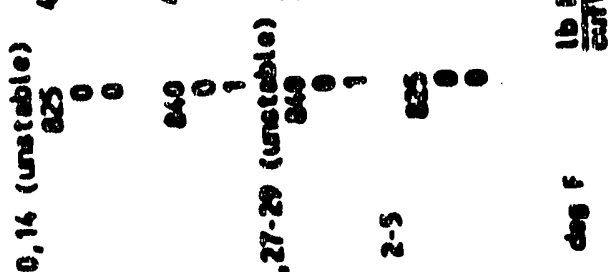

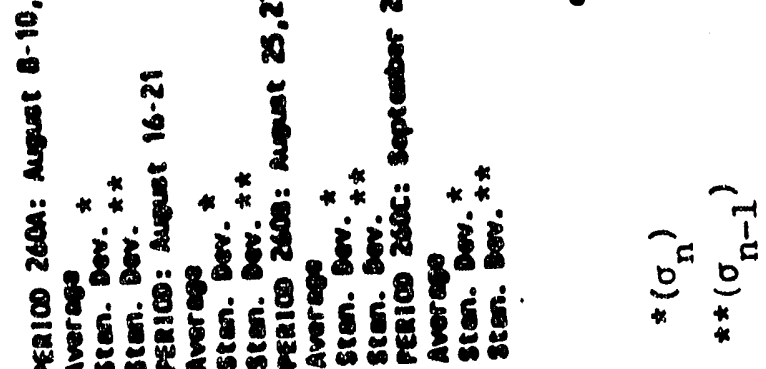




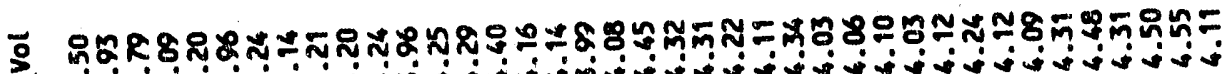

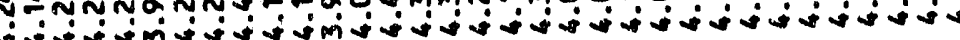

3

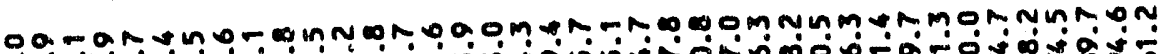

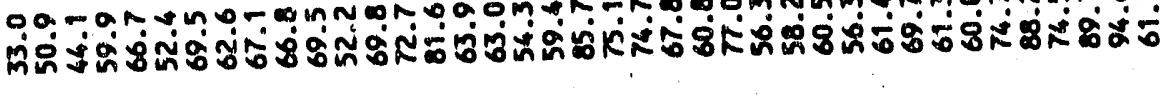

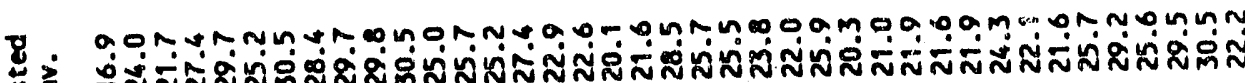
量焉 \%

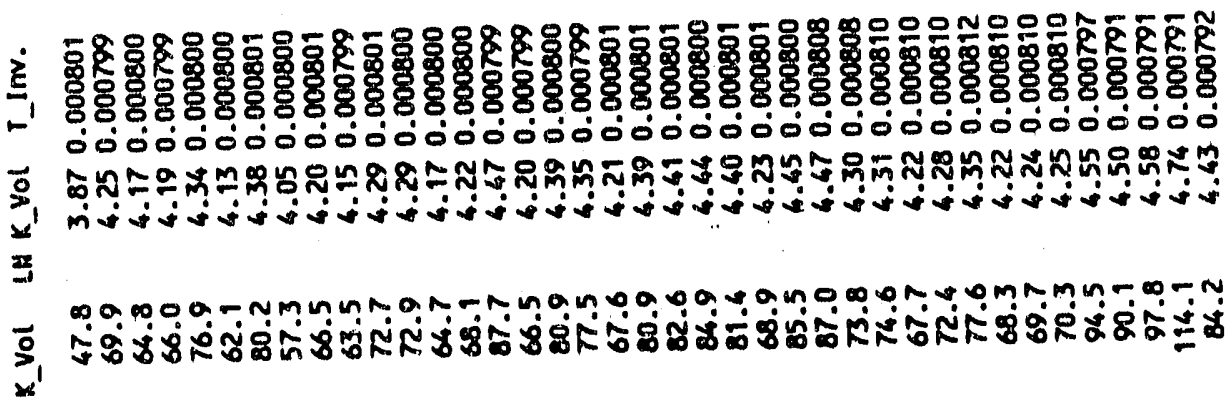

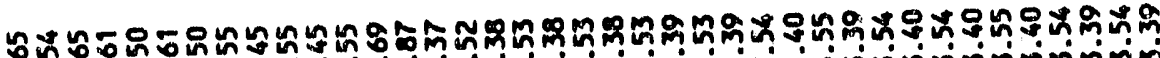

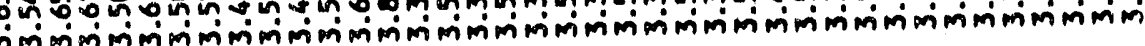

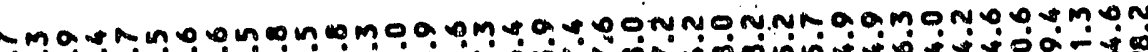
造曾

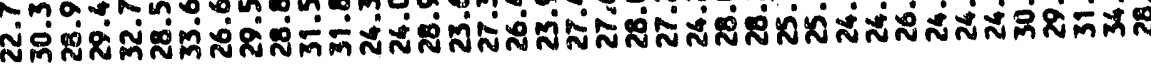

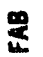

D ON Tomn

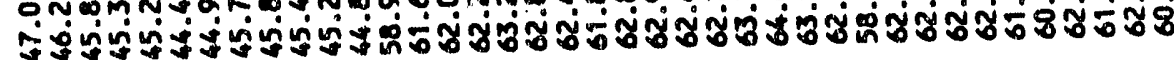

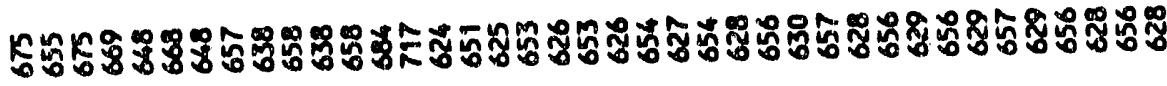

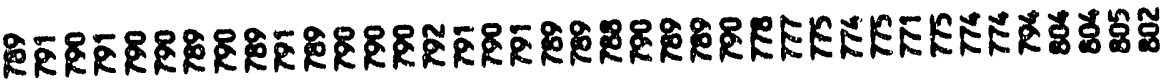

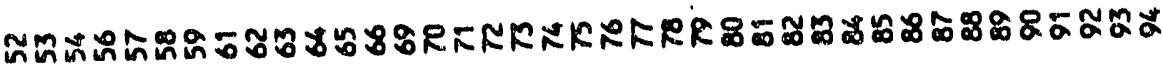

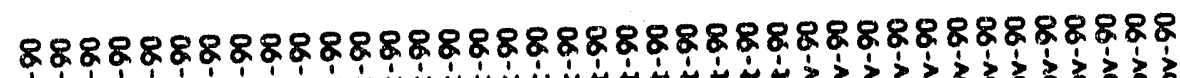

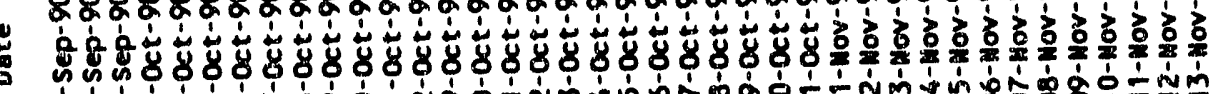

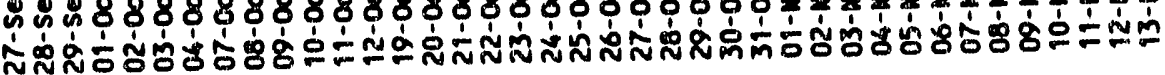




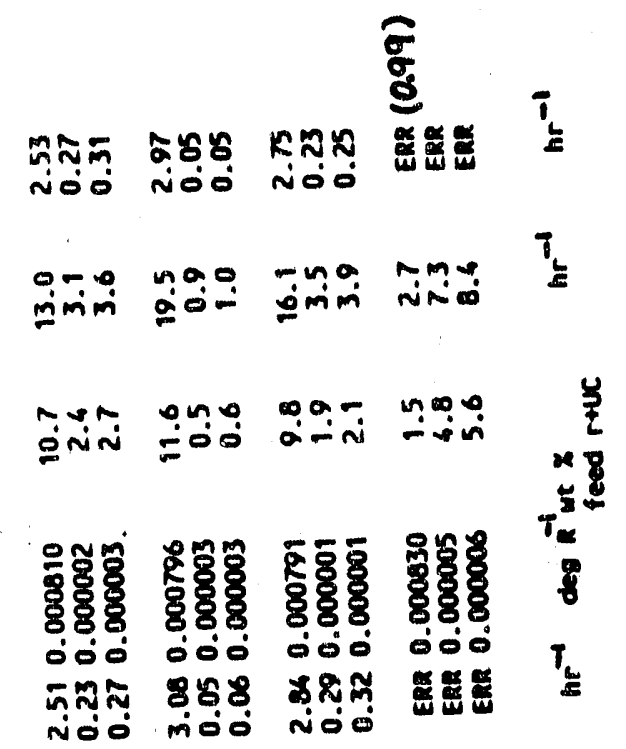

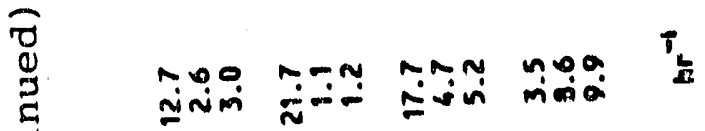

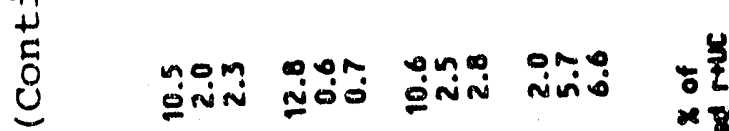

-1

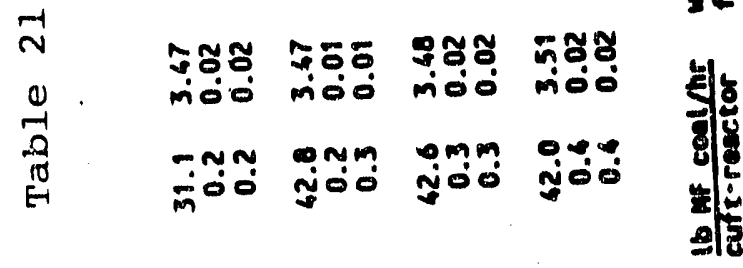

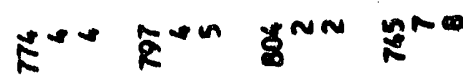

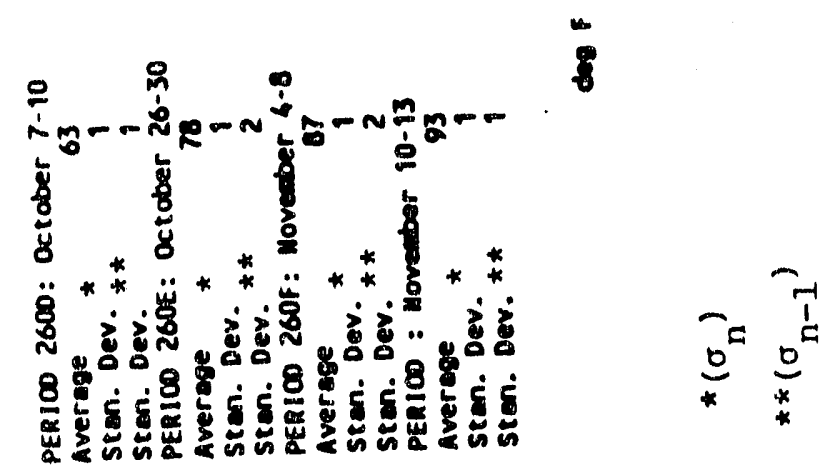




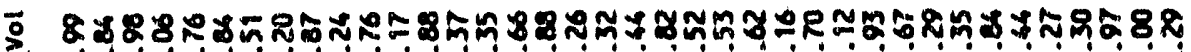

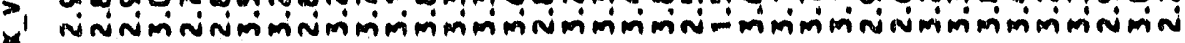
$\exists$

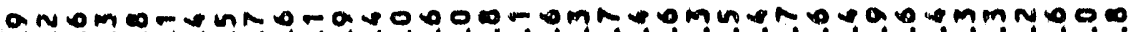

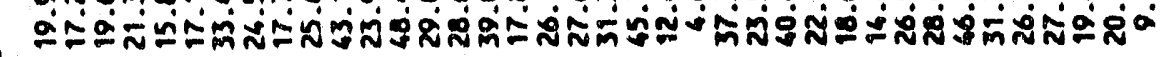

롱 onmo âm

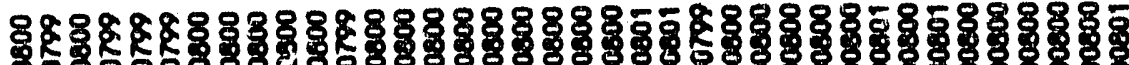

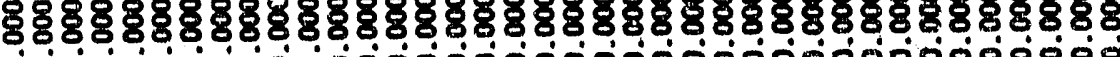

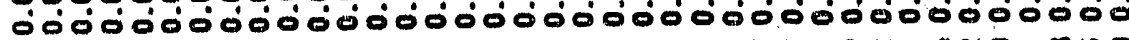

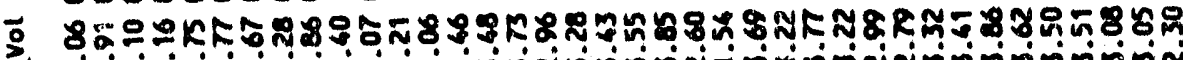

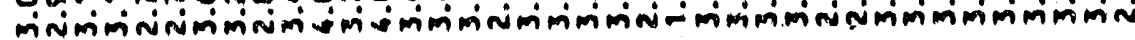

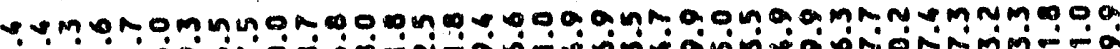

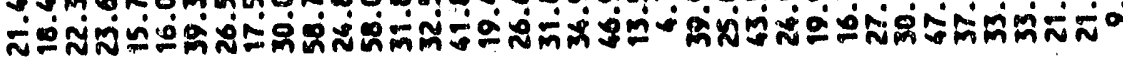

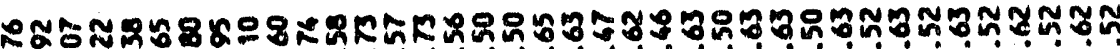
要

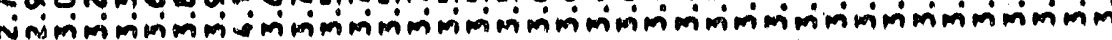

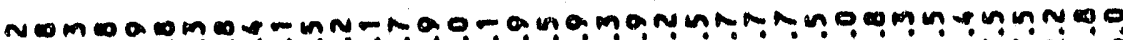

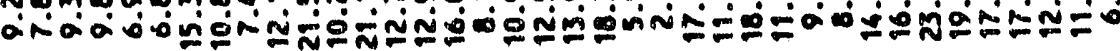

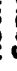

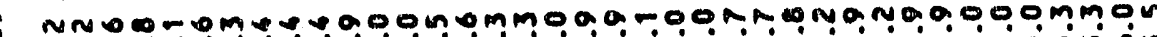

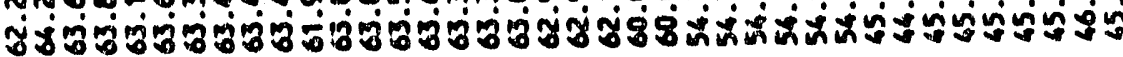

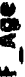

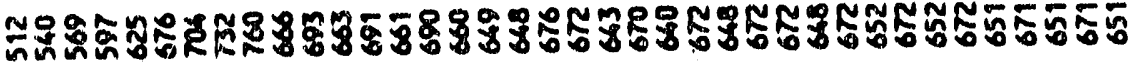

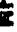

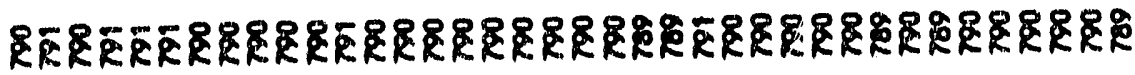

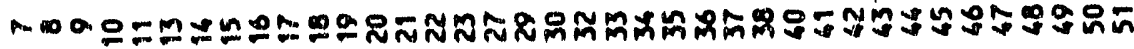

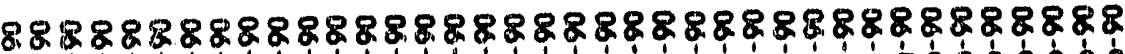

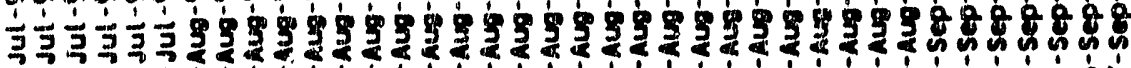

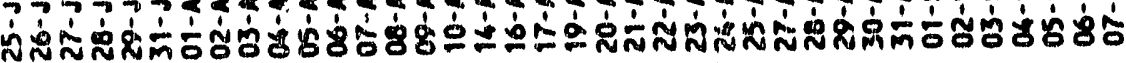




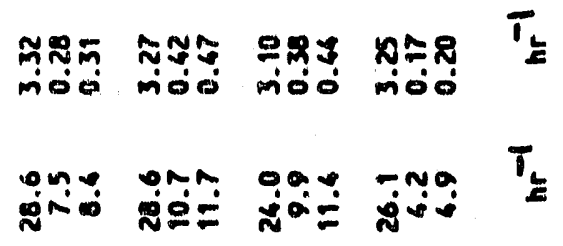

そñơ

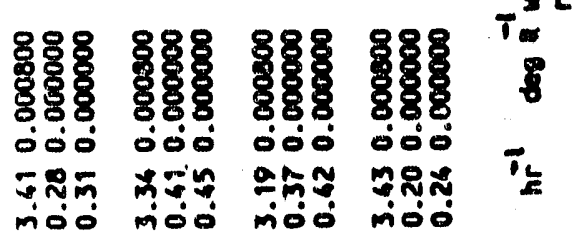

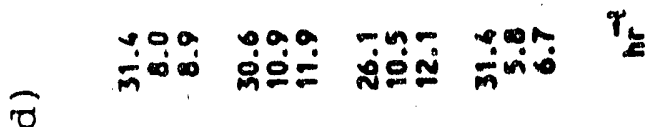

בֶּ

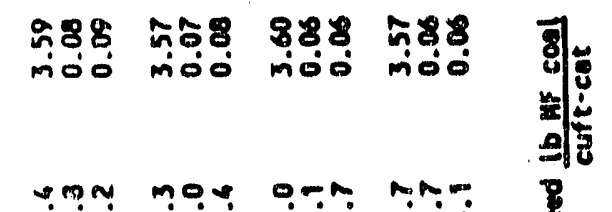

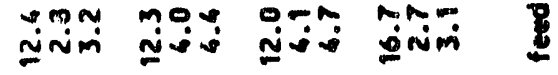

N

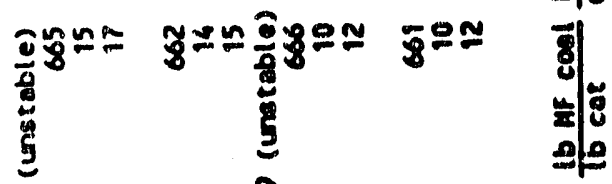

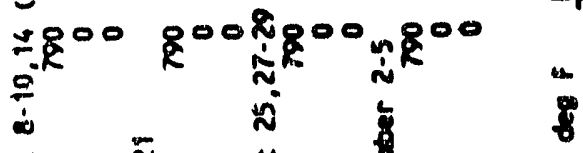

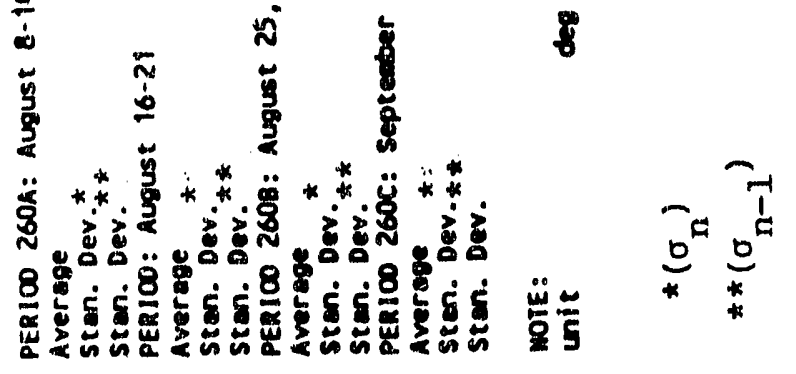




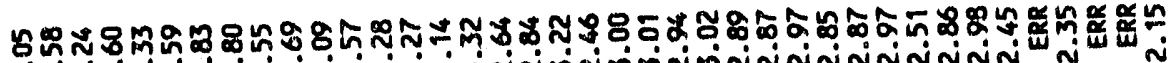

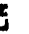

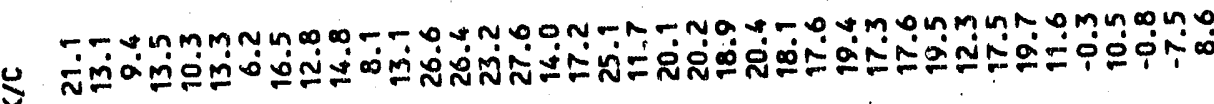

Nom

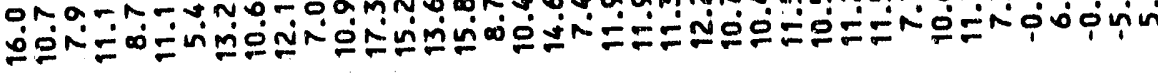

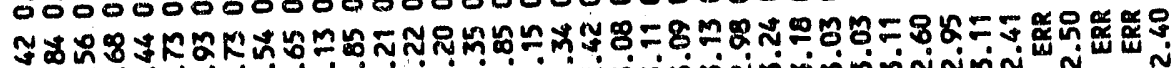

3

- O D mMamMN N

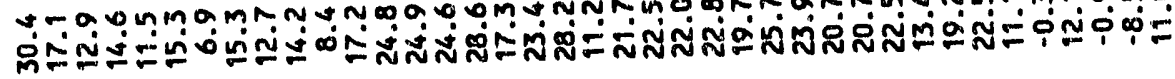

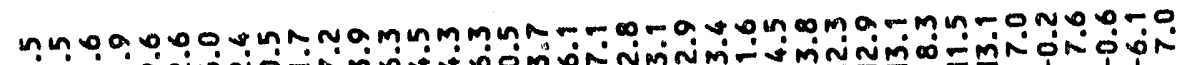

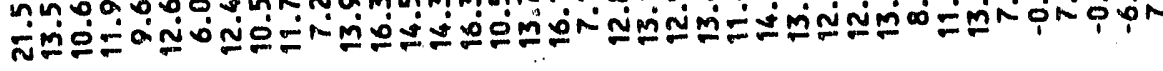

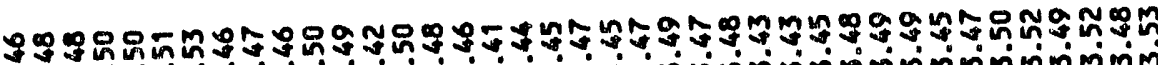
min

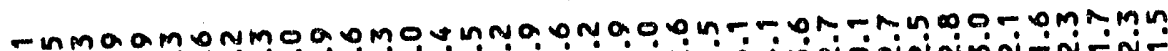
$\sum_{i}^{1}$

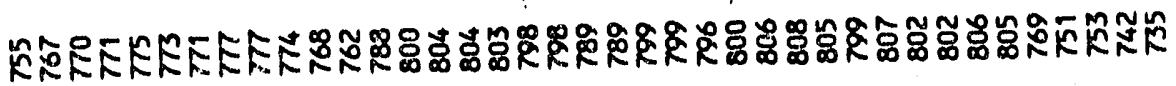

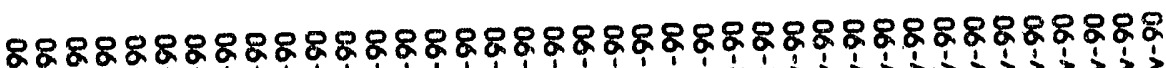

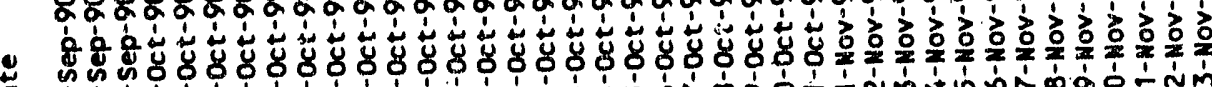

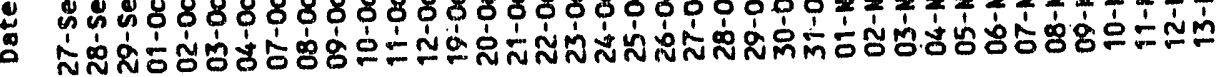




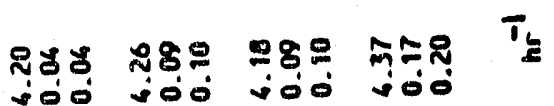

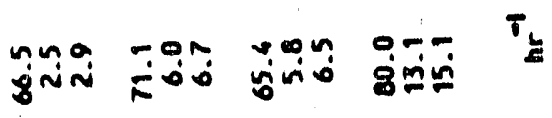

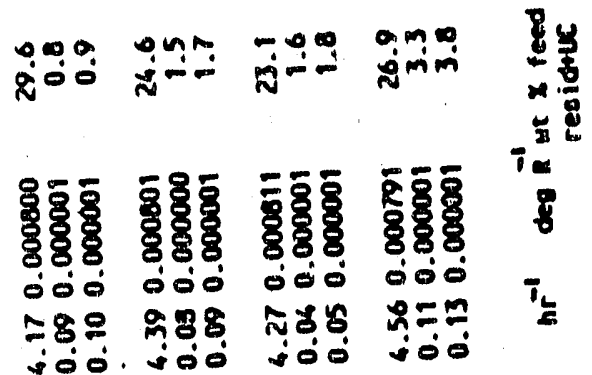

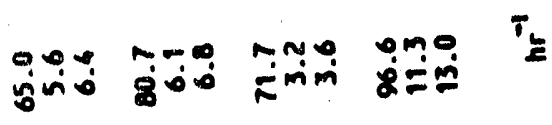

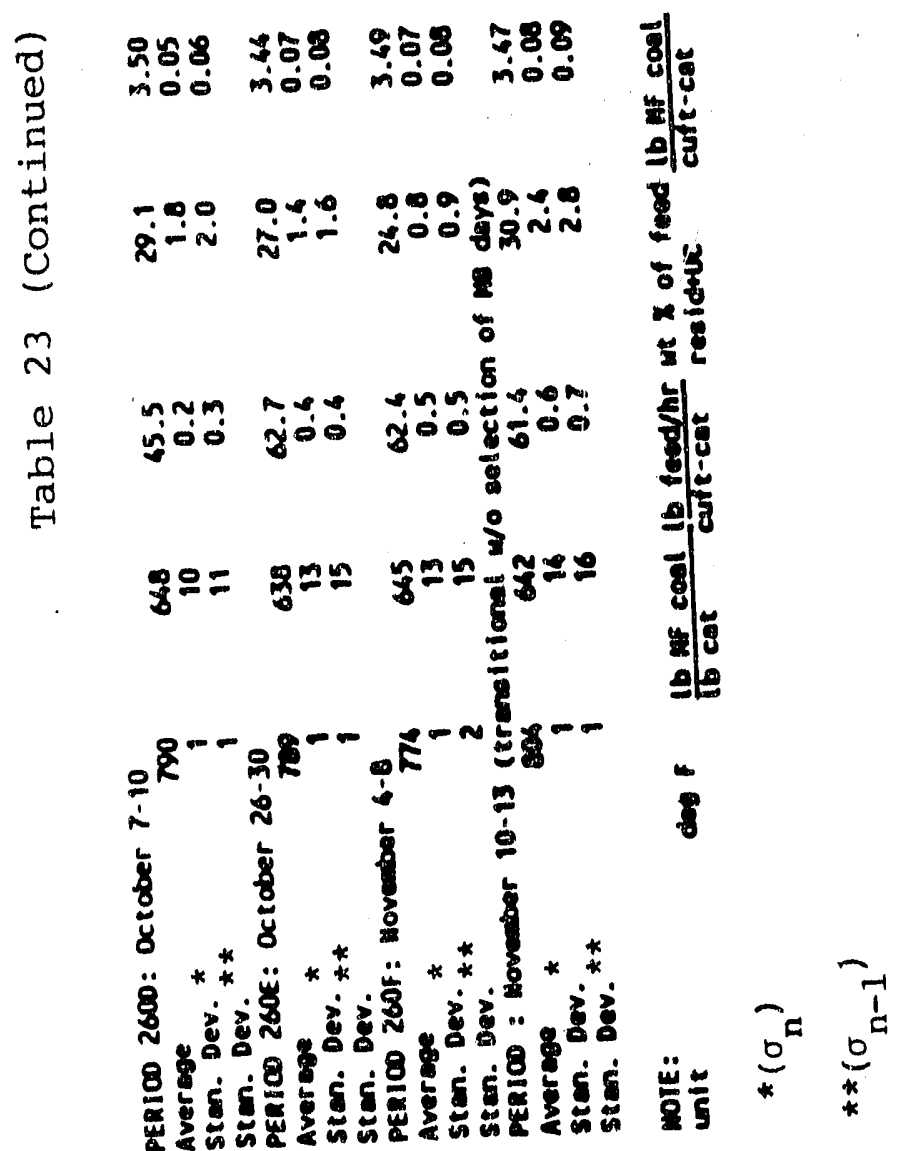




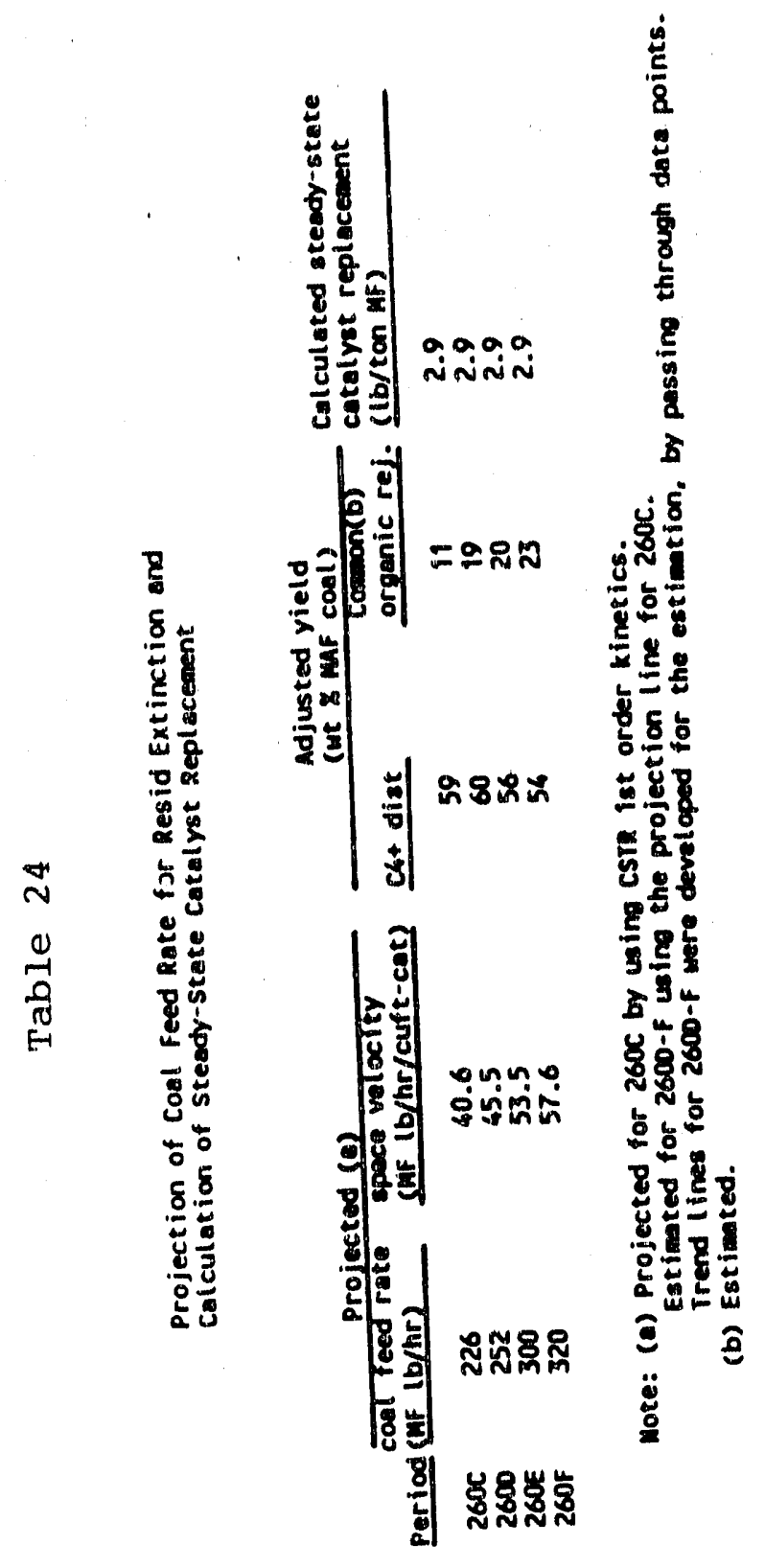



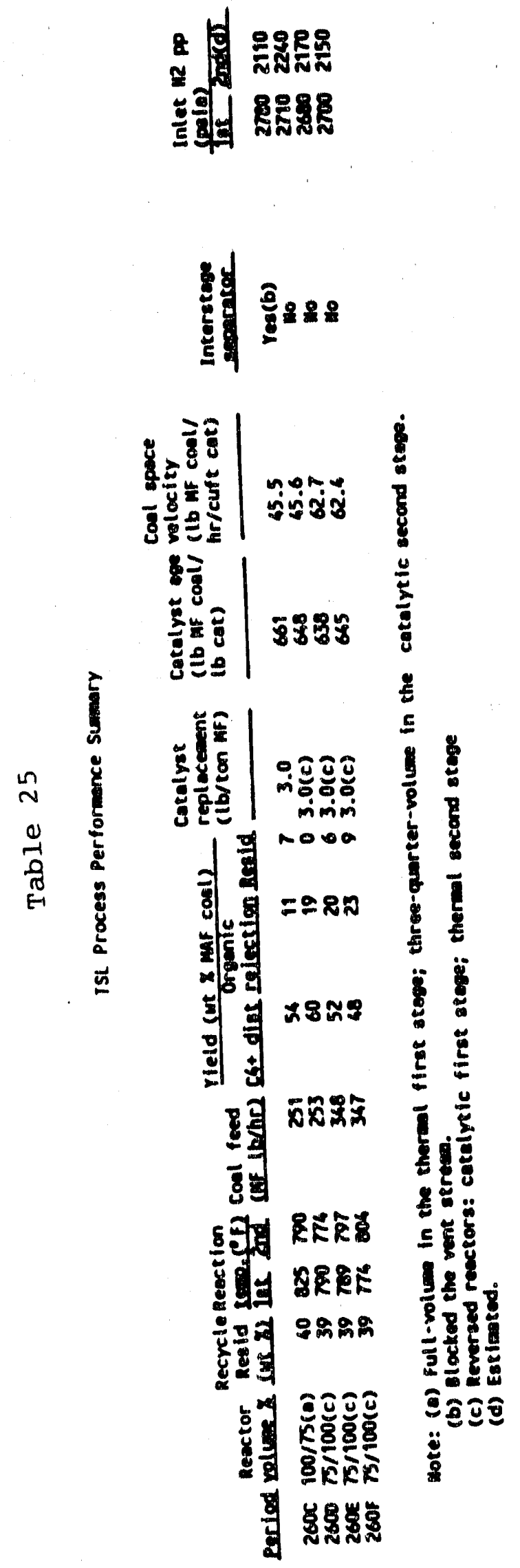
Experimentel and Model Predicted Conl faed Rate Comparisons

\begin{tabular}{|c|c|c|c|c|c|c|}
\hline Run & stape & Temp: & 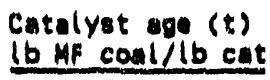 & $\begin{array}{l}\text { Rote constent } \\
k / C \text { or } k, i / h r\end{array}$ & $\begin{array}{l}\text { Conversion (E) } \\
\text { we } x \text { feed }\end{array}$ & $\begin{array}{l}\text { Cht dist yield } \\
\text { we } x \text { MAf cosl } \\
\end{array}$ \\
\hline \multicolumn{7}{|c|}{$\begin{array}{l}\text { 260C. based on model equations derived from } 2608 \mathrm{c} \text { date } \\
\text { 1st stage: } \ln (K / C)=28.7=32100(1 / T) \\
\text { 2nd stege: } \ln K=3.18\end{array}$} \\
\hline - & $\begin{array}{l}18 t \\
\text { 2nd }\end{array}$ & $\begin{array}{l}825 \\
790\end{array}$ & 661 & $\begin{array}{l}49.2 \\
25.1\end{array}$ & $\begin{array}{l}27.8 \\
13.8\end{array}$ & 53.8 \\
\hline \multicolumn{7}{|c|}{$\begin{array}{l}\text { - besed on model equations derived from } 258 \mathrm{H}-\mathrm{H} \text { date } \\
\text { 1st stage: } \ln (K / C)=24.8=26700(1 / T) \\
\text { 2nd stage: } \ln K=16.9=15800(1 / T) \div 0.00001168 \mathrm{t}\end{array}$} \\
\hline & & & & $\begin{array}{l}55.8 \\
47.6\end{array}$ & $\begin{array}{l}34.2 \\
23.3\end{array}$ & 70.7 \\
\hline \multicolumn{7}{|c|}{ 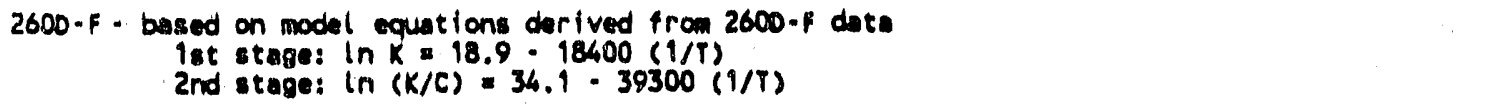 } \\
\hline 2600 & $\begin{array}{l}\text { iet } \\
\text { and }\end{array}$ & $\begin{array}{l}790 \\
776\end{array}$ & 648 & $\begin{array}{r}65.6 \\
9.5\end{array}$ & $\begin{array}{r}29.3 \\
8.1\end{array}$ & 56.3 \\
\hline $260 E$ & $\begin{array}{l}18 t \\
\text { 2nd }\end{array}$ & $\begin{array}{l}789 \\
797\end{array}$ & 638 & $\begin{array}{l}64.6 \\
17.0\end{array}$ & $\begin{array}{l}22.9 \\
10.3\end{array}$ & 48.0 \\
\hline $260 F$ & $\begin{array}{l}\text { lat } \\
\text { 2nd }\end{array}$ & $\begin{array}{l}776 \\
804\end{array}$ & 645 & $\begin{array}{l}54.0 \\
20.3\end{array}$ & $\begin{array}{l}19.9 \\
12.0\end{array}$ & 46.1 \\
\hline
\end{tabular}

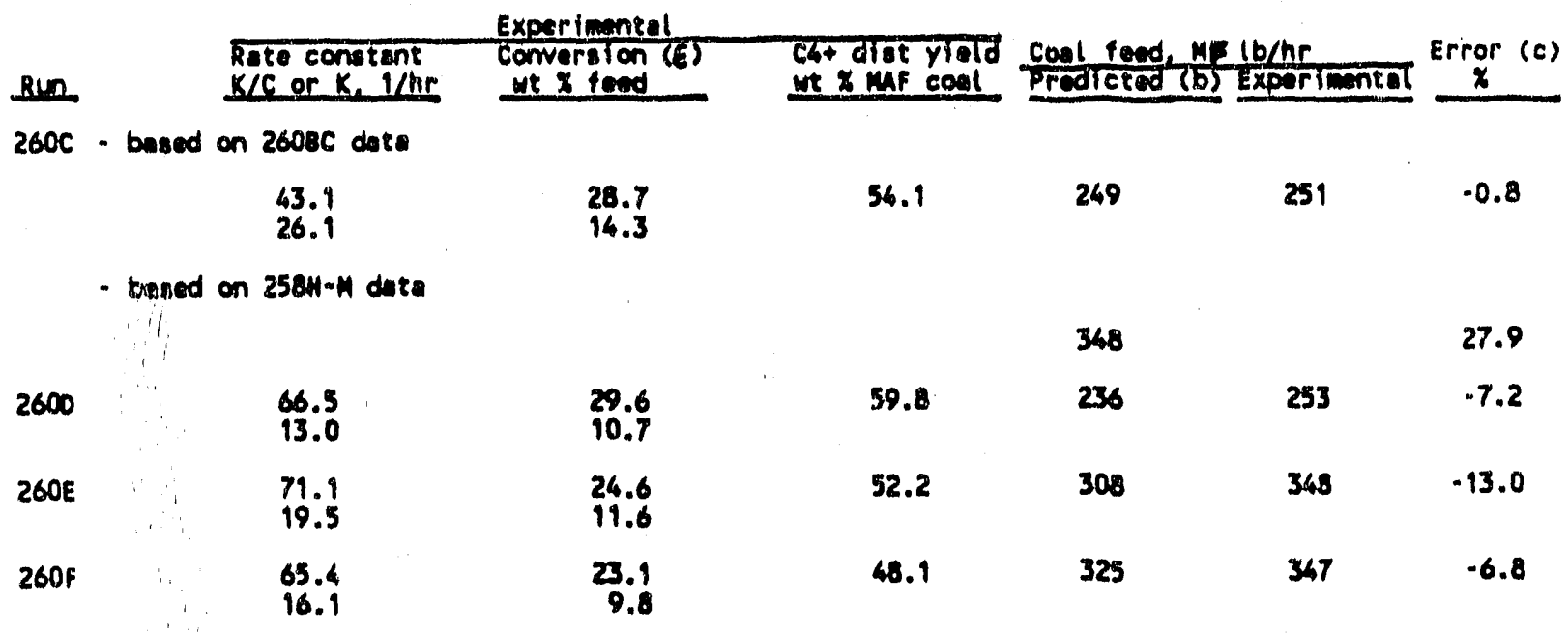

(a) Experimantsl overall dietillate selectivity usen used for prediction of the c4t distillate.

(b) Casl tend ratu predicted for the cht distillate vield as the experimental.

(c) $x$ error in the coal feed rate $=19$. experimental/predicted $\times 100$. 
Table 27

PERCENTAGES CT PROCEBS BTREAME UBED

TO RREPARE YRODUCT OUAIITY BLELDB

\section{PERIOD \\ 260A \\ 260B \\ $260 \mathrm{C}$ \\ 2600 \\ $260 \mathrm{E}$ \\ $260 F$}

\& V161

46.0

49.3

51.3

36.7

42.6

38.4
\& V182

54.0

50.7

48.7

63.3

57.4

61.6 
TABLE 28

PROPERTIEB OF 260 TOTAL OIL BLENDB

\begin{tabular}{|c|c|c|c|c|c|c|}
\hline PERIOD & 2608 & $260 B$ & $260 C$ & 260D & 260E & $260 F$ \\
\hline $\begin{array}{l}\text { Elemental, wt: } \\
\text { Carbon } \\
\text { Hydrogen } \\
\text { Nitrogen } \\
\text { Sulfur } \\
\text { oxygen(direct) }\end{array}$ & $\begin{array}{c}86.30 \\
11.64 \quad 1 \\
0.37 \\
0.05 \\
1.64(1.58)\end{array}$ & $\begin{array}{r}86.41 \\
11.04 \\
0.56 \\
0.05 \\
1.94\end{array}$ & $\begin{array}{r}87.22 \\
11.85 \\
0.42 \\
0.04 \\
0.47\end{array}$ & $\begin{array}{r}87.09 \\
11.13 \\
0.45 \\
0.04 \\
1.29\end{array}$ & $\begin{array}{r}86.09 \\
11.38 \\
0.36 \\
0.07 \\
2.10\end{array}$ & $\begin{array}{r}85.58 \\
11.08 \\
0.41 \\
0.07 \\
2.86\end{array}$ \\
\hline API Gravity & 27.0 & 21.2 & 26.2 & $22 \cdot 1$ & 24.3 & 19.1 \\
\hline $\begin{array}{l}\text { GC Sim. Dist. } \\
\text { IBP } \\
10 \% \\
20 \% \\
30 \% \\
40 \% \\
50 \% \\
60 \% \\
70 \% \\
80 \% \\
90 \% \\
958 \\
\text { EP }\end{array}$ & $\begin{array}{l}97 \\
241 \\
307 \\
397 \\
466 \\
515 \\
604 \\
656 \\
697 \\
740 \\
778 \\
838\end{array}$ & $\begin{array}{l}134 \\
307 \\
400 \\
460 \\
492 \\
539 \\
604 \\
665 \\
708 \\
758 \\
792 \\
852\end{array}$ & $\begin{array}{l}156 \\
269 \\
319 \\
390 \\
475 \\
539 \\
606 \\
659 \\
705 \\
760 \\
781 \\
869\end{array}$ & $\begin{array}{l}97 \\
250 \\
350 \\
450 \\
502 \\
561 \\
611 \\
652 \\
685 \\
722 \\
751 \\
813\end{array}$ & $\begin{array}{r}97 \\
241 \\
333 \\
400 \\
486 \\
568 \\
637 \\
685 \\
740 \\
794 \\
819 \\
865\end{array}$ & $\begin{array}{l}97 \\
260 \\
343 \\
405 \\
477 \\
531 \\
613 \\
676 \\
745 \\
802 \\
829 \\
864\end{array}$ \\
\hline $\begin{array}{l}\text { Distribution, wt? } \\
\text { IBP/350० } \mathrm{F} \\
350 / 450^{\circ} \mathrm{F} \\
450 / 650^{\circ} \mathrm{F} \\
650+/ \mathrm{EP} \\
\mathrm{EP} \text {. } \mathrm{F}(\mathrm{D} 1160)\end{array}$ & $\begin{array}{r}23.0 \\
13.1 \\
42.5 \\
21.4 \\
775\end{array}$ & $\begin{array}{r}13.7 \\
14.3 \\
47.6 \\
24.4 \\
733\end{array}$ & $\begin{array}{r}21.8 \\
11.7 \\
35.5 \\
31.0 \\
778\end{array}$ & $\begin{array}{r}15.2 \\
8.3 \\
44.0 \\
32.5 \\
723\end{array}$ & $\begin{array}{r}26.1 \\
13.6 \\
32.4 \\
27.9 \\
759\end{array}$ & $\begin{array}{r}19.1 \\
13.2 \\
35.8 \\
31.9 \\
769\end{array}$ \\
\hline
\end{tabular}


Table 29

PROPERTIES OF NAPHTHA (IBP-350 5 )

PERIOD

Elemental, wt:

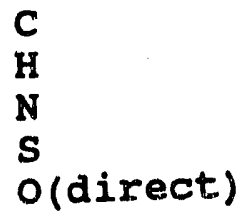

Gravity (API)

GC Sim. Dist.

IBP

$10 \%$

$20 \%$

$30 \%$

$40 \%$

$50 \%$

$60 \%$

$70 \%$

$80 \%$

$90 \%$

$95 \%$

EP

$260 \mathrm{~A} 260 \mathrm{~B} 260 \mathrm{C} \quad 260 \mathrm{D}$ 260E 260F

$\begin{array}{crrrrr}84.95 & 84.52 & 84.71 & 85.14 & 82.74 & 84.72 \\ 14.46 & 13.92 & 14.24 & 14.34 & 14.20 & 14.15 \\ 0.09 & 0.08 & 0.08 & 0.12 & 0.04 & 0.12 \\ 0.06 & 0.05 & 0.04 & 0.06 & 0.05 & 0.13 \\ 0.44(0.92) & 1.43 & 0.93 & 0.34 & 2.97 & 0.88 \\ & & & & & \\ 54.1 & 59.7 & 53.5 & 53.5 & 56.2 & 50.1\end{array}$

$\begin{array}{rrrrrr}70 & 70 & 97 & 69 & 70 & 97 \\ 156 & 164 & 176 & 156 & 143 & 165 \\ 176 & 176 & 231 & 176 & 164 & 176 \\ 231 & 241 & 241 & 231 & 176 & 241 \\ 241 & 241 & 252 & 241 & 209 & 243 \\ 253 & 269 & 270 & 248 & 241 & 270 \\ 269 & 269 & 270 & 270 & 241 & 270 \\ 281 & 281 & 231 & 281 & 247 & 301 \\ 291 & 310 & 301 & 291 & 270 & 322 \\ 308 & 344 & 317 & 309 & 270 & 341 \\ 335 & 360 & 326 & 335 & 281 & 357 \\ 360 & 360 & 360 & 360 & 360 & 360\end{array}$


TABLE 30

PROPERTIES OF MIDDLE DIBTILIATE $\left(350-450^{\circ} \mathrm{I}\right)$

$\begin{array}{lrrrrrr}\text { PERIOD } & \text { 260A } & \text { 260B } & \text { 260C } & \text { 260D } & \text { 260E } & \text { 260F } \\ \text { Elemental, wtz } & & & & & & \\ \text { C } & 86.21 & 85.54 & 86.66 & 86.25 & 85.41 & 85.60 \\ \text { H } & 12.30 & 11.42 & 12.52 & 12.03 & 11.86 & 11.84 \\ \text { N } & 0.20 & 0.24 & 0.21 & 0.16 & 0.21 & 0.20 \\ \text { S } & 0.11 & 0.07 & 0.13 & 0.08 & 0.07 & 0.11 \\ \text { O(DIRECT) } & 1.18(2.19) & 2.73 & 0.48 & 1.48 & 2.45 & 2.25 \\ \text { Gravity (API) } & 30.8 & 25.7 & 31.7 & 28.6 & 27.3 & 27.0 \\ \text { GC Sim. Dist. } & & & & & & \\ \text { IBP , } & 337 & 291 & 340 & 306 & 333 & 338 \\ 10 \% & 345 & 354 & 350 & 350 & 363 & 362 \\ 20 \% & 360 & 364 & 360 & 361 & 363 & 369 \\ 30 \% & 369 & 378 & 362 & 369 & 381 & 383 \\ 40 \% & 376 & 395 & 376 & 383 & 405 & 405 \\ 50 \% & 395 & 405 & 385 & 405 & 405 & 405 \\ \text { 60\% } & 405 & 424 & 405 & 405 & 424 & 432 \\ 70 \% & 424 & 434 & 424 & 436 & 434 & 436 \\ 80 \% & 436 & 448 & 431 & 451 & 456 & 460 \\ 90 \% & 458 & 457 & 449 & 460 & 466 & 460 \\ 95 \% & 460 & 460 & 456 & 460 & 472 & 466 \\ \text { EP } & 469 & 488 & 460 & 483 & 472 & 492\end{array}$


TABLE 31

PROPERTIES OF MIDDIE DISTILIATE (450-650・P)

$\begin{array}{lrrrrrr}\text { PERIOD } & \text { 260A } & \text { 260B } & \text { 260C } & \text { 260D } & \text { 260E } & \text { 260F } \\ \text { Elemental, wt8 } & & & & & & \\ \text { C } & 87.45 & 86.74 & 87.67 & 87.15 & 87.31 & 86.86 \\ \text { H } & 11.03 & 11.00 & 11.21 & 10.94 & 10.95 & 10.79 \\ \text { N } & 0.52 & 0.61 & 0.58 & 0.50 & 0.56 & 0.52 \\ \text { S } & 0.04 & 0.03 & 0.02 & 0.03 & 0.05 & 0.06 \\ \text { O(DIRECT) } & 0.96(1.91) & 1.62 & 0.52 & 1.38 & 1.13 & 1.77 \\ & & & & & & \\ \text { Gravity (API) } & 19.2 & 17.8 & 18.9 & 18.4 & 16.5 & 17.0 \\ \text { GC Sim. Dist. } & & & & & & \\ \text { IBP } & 452 & 405 & 405 & 415 & 449 & 430 \\ \text { 10\% } & 466 & 466 & 466 & 475 & 488 & 483 \\ 20 \% & 496 & 478 & 496 & 501 & 509 & 496 \\ \text { 30\% } & 509 & 496 & 522 & 538 & 540 & 522 \\ 40 \% & 531 & 514 & 549 & 560 & 561 & 554 \\ 50 \% & 568 & 531 & 575 & 575 & 588 & 578 \\ 60 \% & 593 & 558 & 600 & 600 & 610 & 601 \\ 70 \% & 643 & 581 & 623 & 625 & 630 & 621 \\ \text { 80\% } & 643 & 612 & 643 & 651 & 656 & 653 \\ 90 \% & 676 & 622 & 658 & 672 & 668 & 670 \\ 95 \% & 676 & 643 & 676 & 675 & 676 & 676 \\ \text { EP } & 676 & 685 & 685 & 705 & 722 & 685\end{array}$


TABLE 32

\section{PROPERTIES OF GAB OIL (650-EP)}

\begin{tabular}{|c|c|c|c|c|c|c|}
\hline PERIOD & $260 A$ & 260B & $260 C$ & 260D & 260E & $260 F$ \\
\hline $\begin{array}{l}\text { Elemental, wt\% } \\
\mathrm{C} \\
\mathrm{H} \\
\mathrm{N} \\
\mathrm{S} \\
\mathrm{O}(\mathrm{DIRECT})\end{array}$ & $\begin{array}{l}89.13 \\
10.14 \\
0.60 \\
0.03 \\
0.10(2.54)\end{array}$ & $\begin{array}{r}88.94 \\
9.87 \\
0.65 \\
0.02 \\
0.52\end{array}$ & $\begin{array}{r}88.83 \\
10.05 \\
0.67 \\
0.01 \\
0.44\end{array}$ & $\begin{array}{r}88.30 \\
10.27 \\
0.58 \\
0.03 \\
0.82\end{array}$ & $\begin{array}{r}87.68 \\
10.18 \\
0.54 \\
0.04 \\
1.56\end{array}$ & $\begin{array}{r}88.44 \\
10.35 \\
0.50 \\
0.05 \\
0.70\end{array}$ \\
\hline Gravity (API) & 11.0 & 8.9 & 10.0 & 10.6 & 10.0 & 10.6 \\
\hline $\begin{array}{l}\text { GC Sim. Dist. } \\
\text { IBP } \\
10 \% \\
208 \\
30 \% \\
40 \% \\
50 \% \\
60 \% \\
70 \% \\
808 \\
908 \\
95 \% \\
\text { EP }\end{array}$ & $\begin{array}{l}740 \\
740 \\
740 \\
740 \\
740 \\
764 \\
779 \\
779 \\
794 \\
816 \\
838 \\
910\end{array}$ & $\begin{array}{l}722 \\
722 \\
740 \\
756 \\
756 \\
770 \\
779 \\
788 \\
799 \\
818 \\
823 \\
889\end{array}$ & $\begin{array}{l}685 \\
685 \\
722 \\
740 \\
750 \\
767 \\
783 \\
795 \\
800 \\
816 \\
838 \\
891\end{array}$ & $\begin{array}{l}685 \\
685 \\
722 \\
722 \\
722 \\
722 \\
740 \\
754 \\
763 \\
787 \\
812 \\
905\end{array}$ & $\begin{array}{l}685 \\
695 \\
710 \\
740 \\
775 \\
780 \\
805 \\
805 \\
835 \\
842 \\
860 \\
895\end{array}$ & $\begin{array}{l}722 \\
722 \\
740 \\
750 \\
782 \\
782 \\
810 \\
810 \\
838 \\
850 \\
861 \\
912\end{array}$ \\
\hline
\end{tabular}




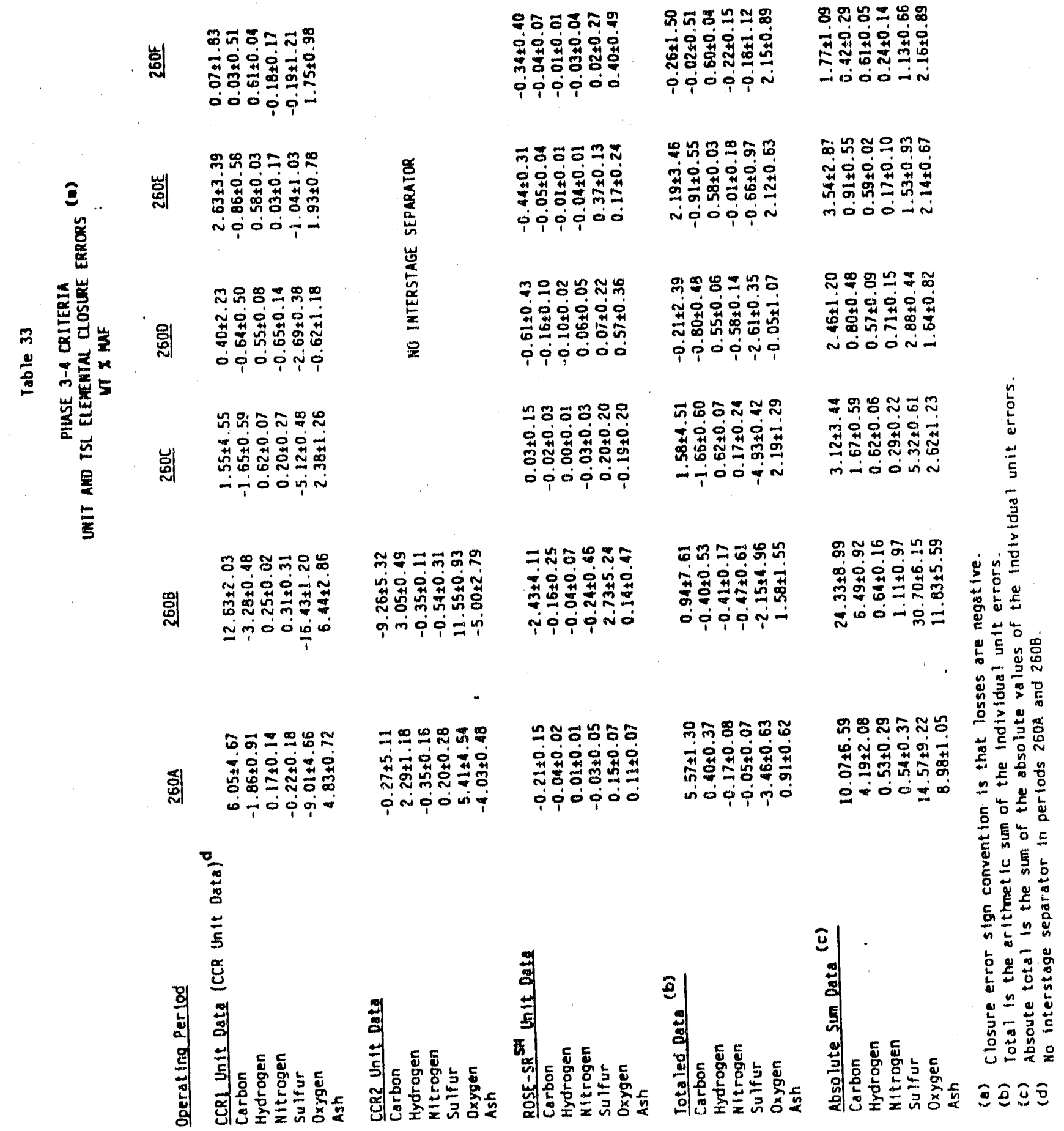

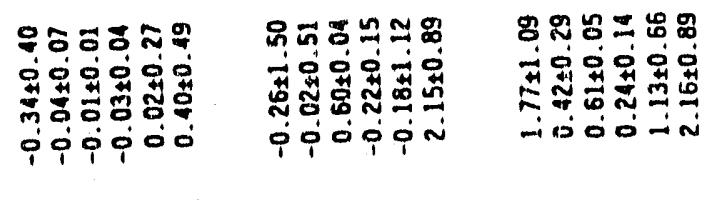

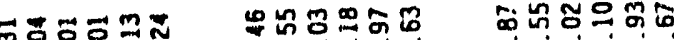

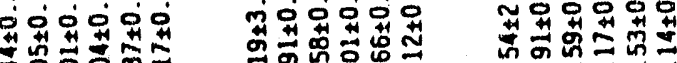

iojoio Nooion modotin

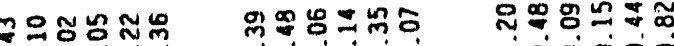

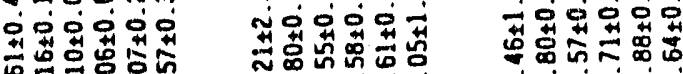

00000 pioini Noón-

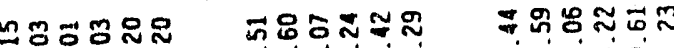

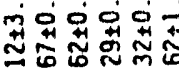

लंखिंक्षि

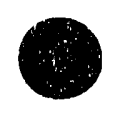

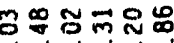

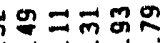

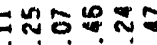

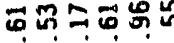

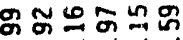

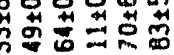

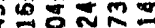

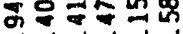

त00-

$=$

空虽

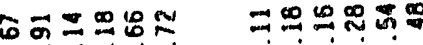

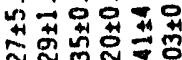

둥형응

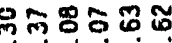

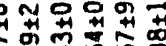

से

nocióno

$0 \div 00 \div$

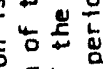

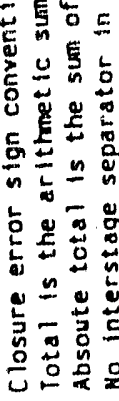

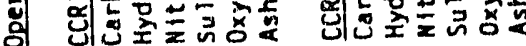




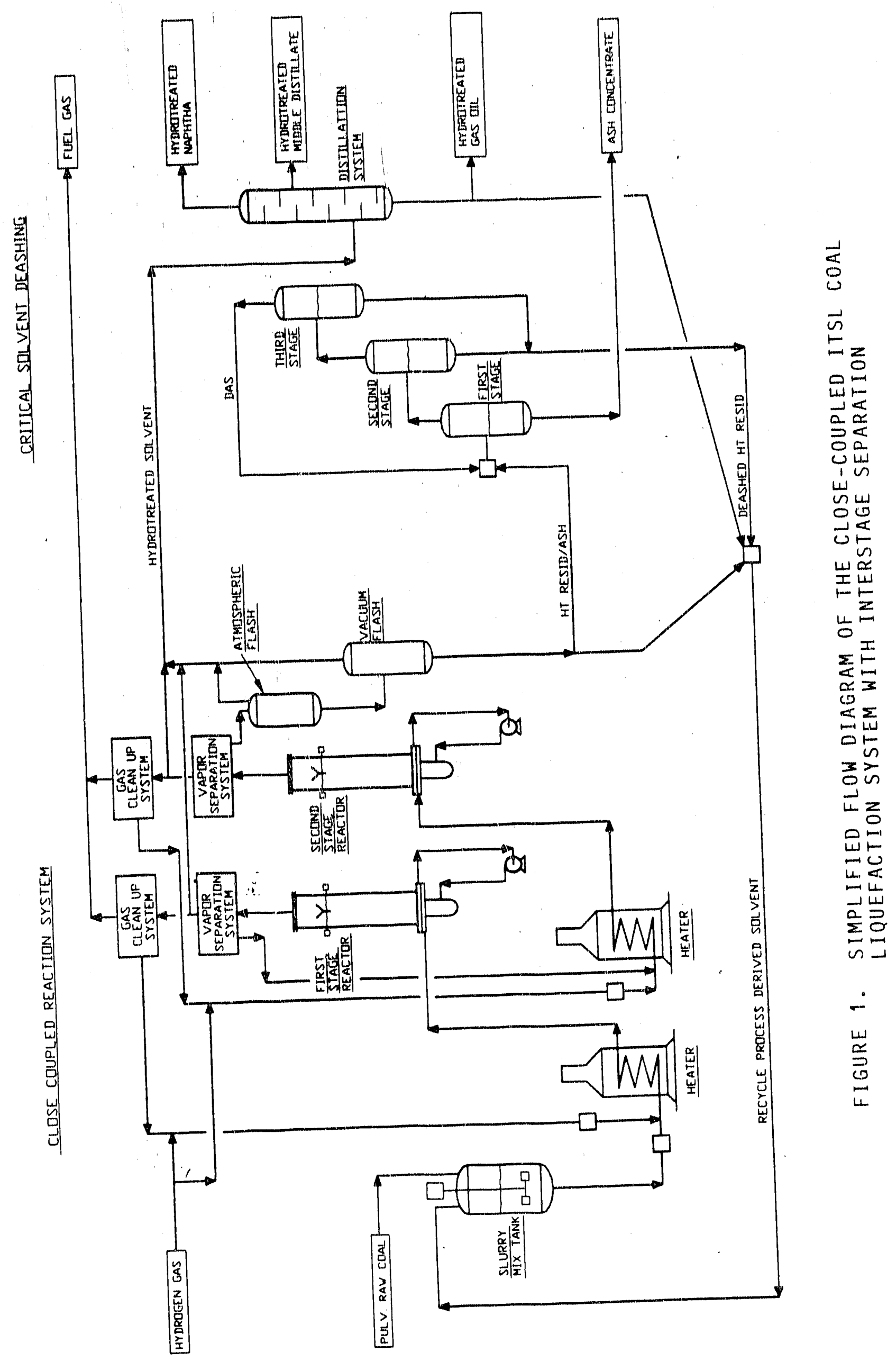




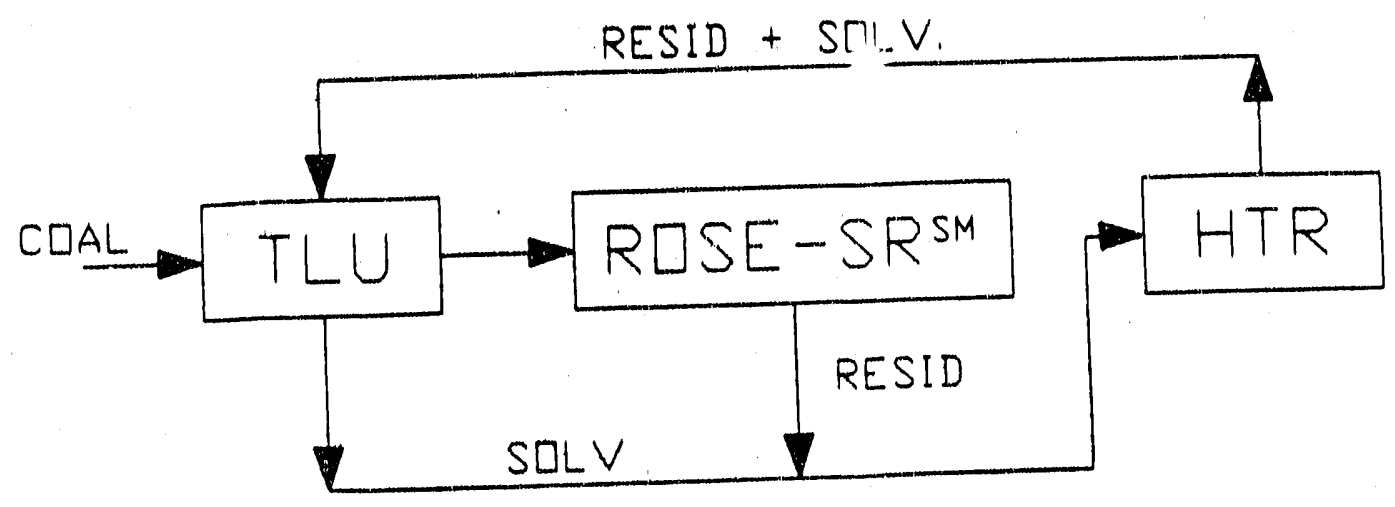

INTEGRATED TWQ-STAGE LIQUEFACTION

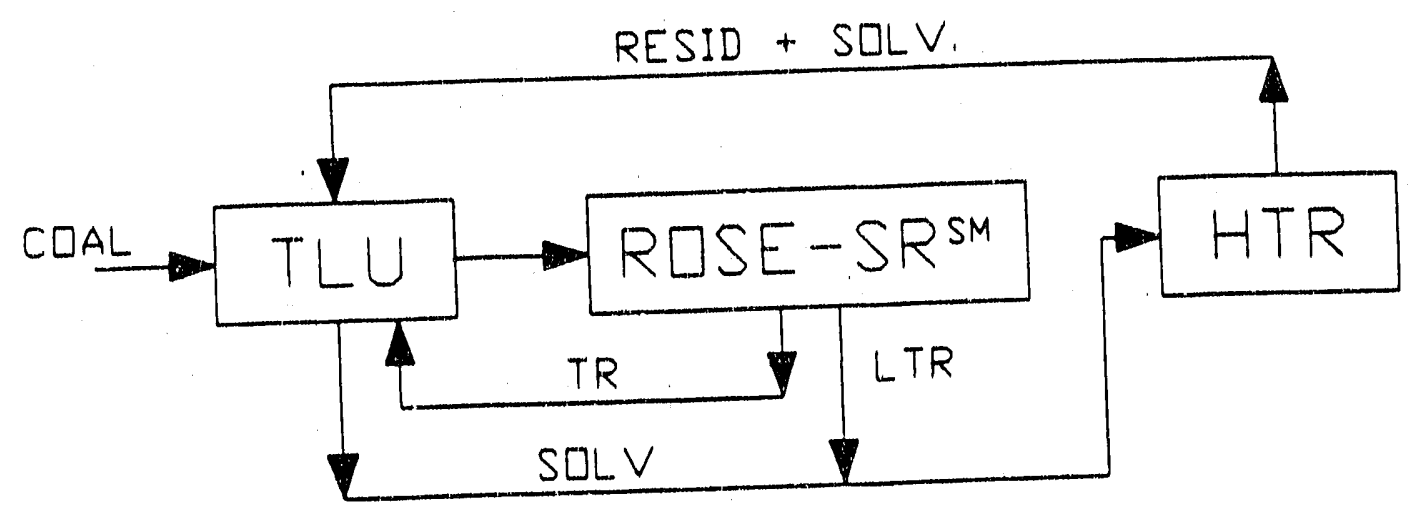

\section{DQUBLE INTEGRATED TWD-STAGE LIQUEFACTION}

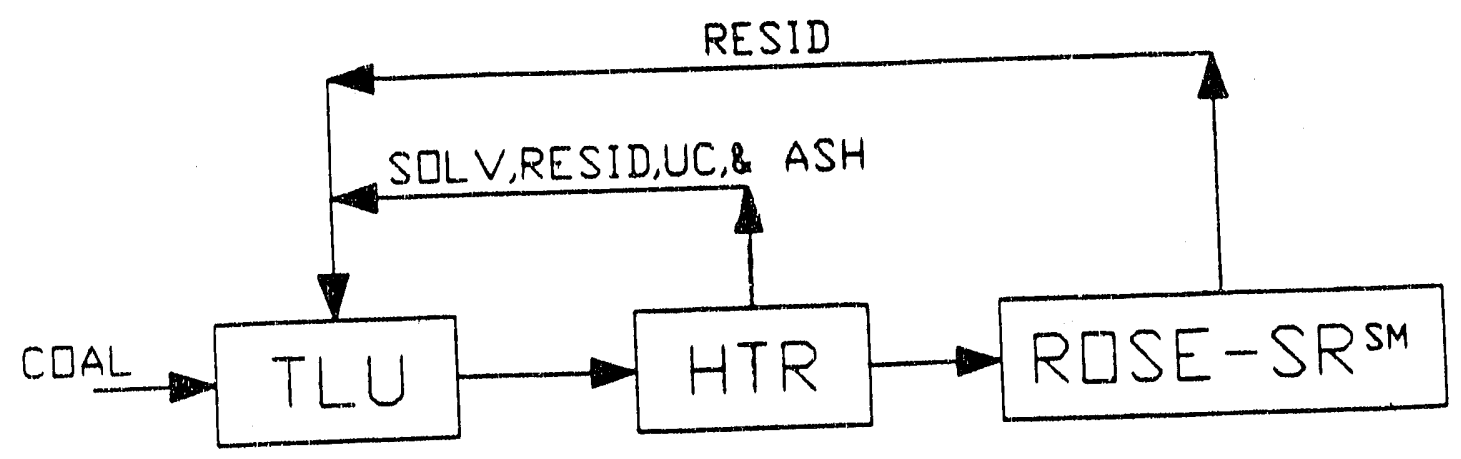

CLOSE-CQUPLED INTEGRATED TWO-STAGE LIQUEFACTION

FIGURE 2. LIQUEFACTION MODES TESTED SINCE RUN 242 


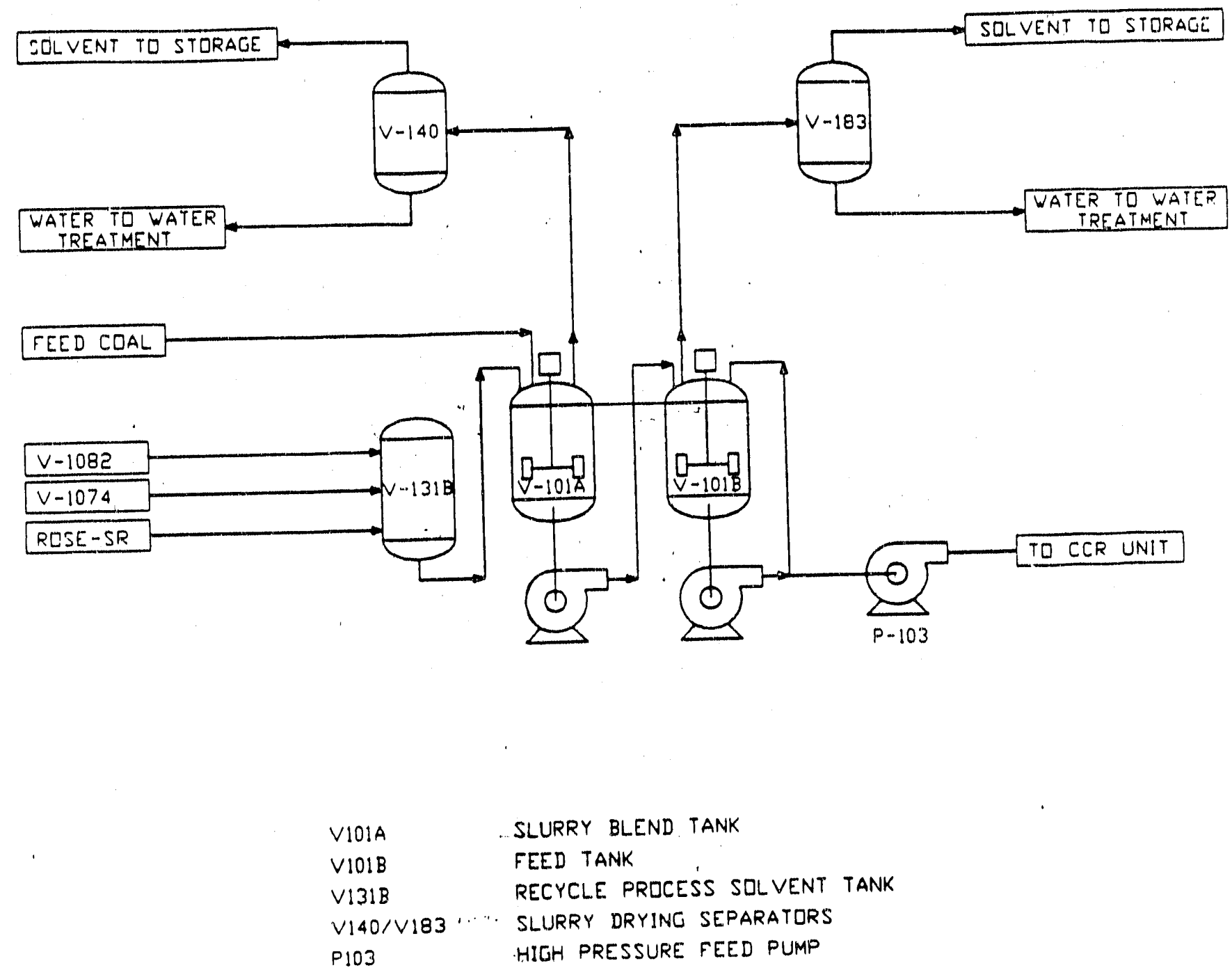

FIGURE 3. FLOW DIAGRAM OF COAL SLURRY PREPARATION SYSTEM 


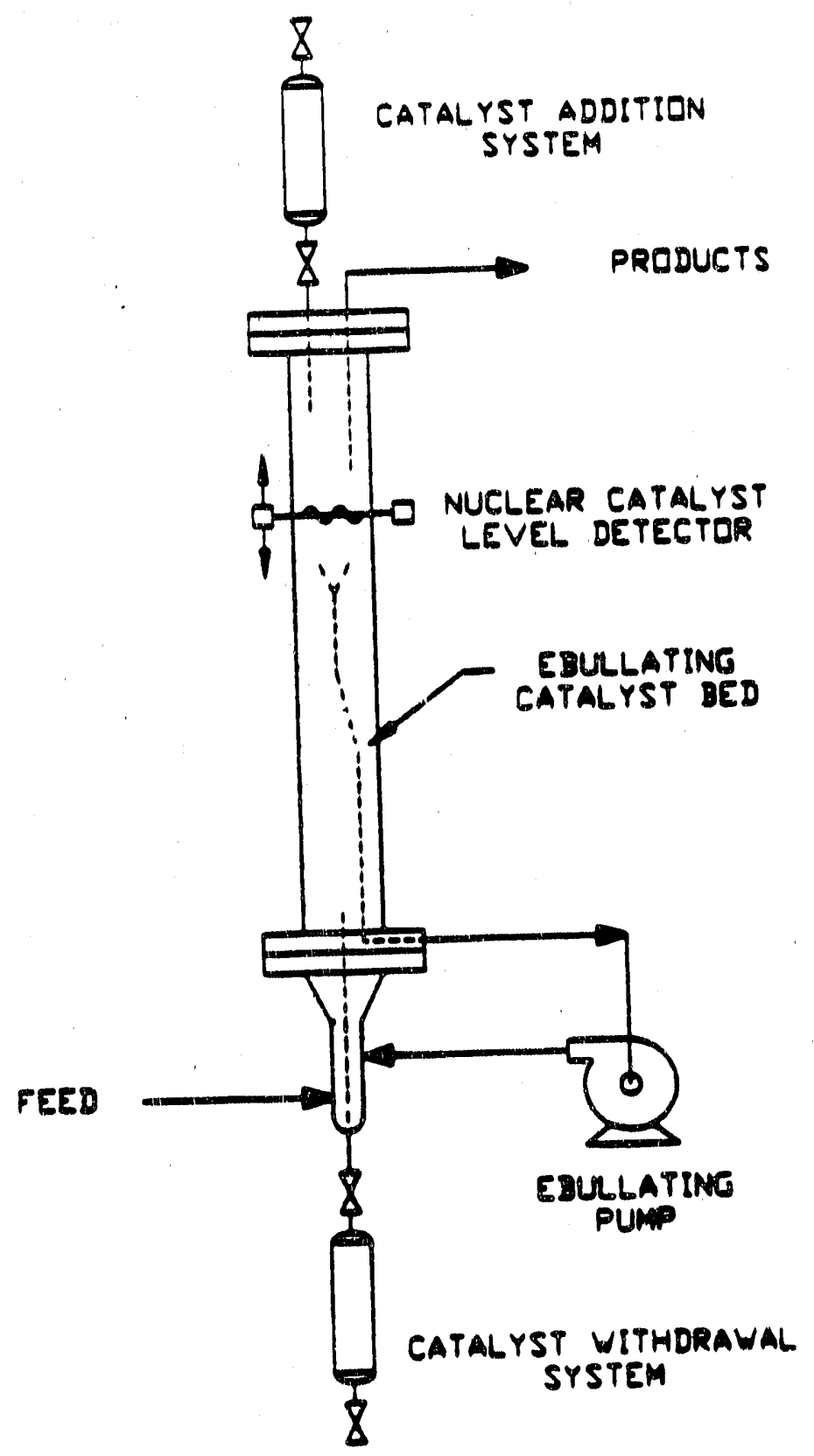

FIGURE 4. H-OIL(®) EBULLATED BED REACTOR 


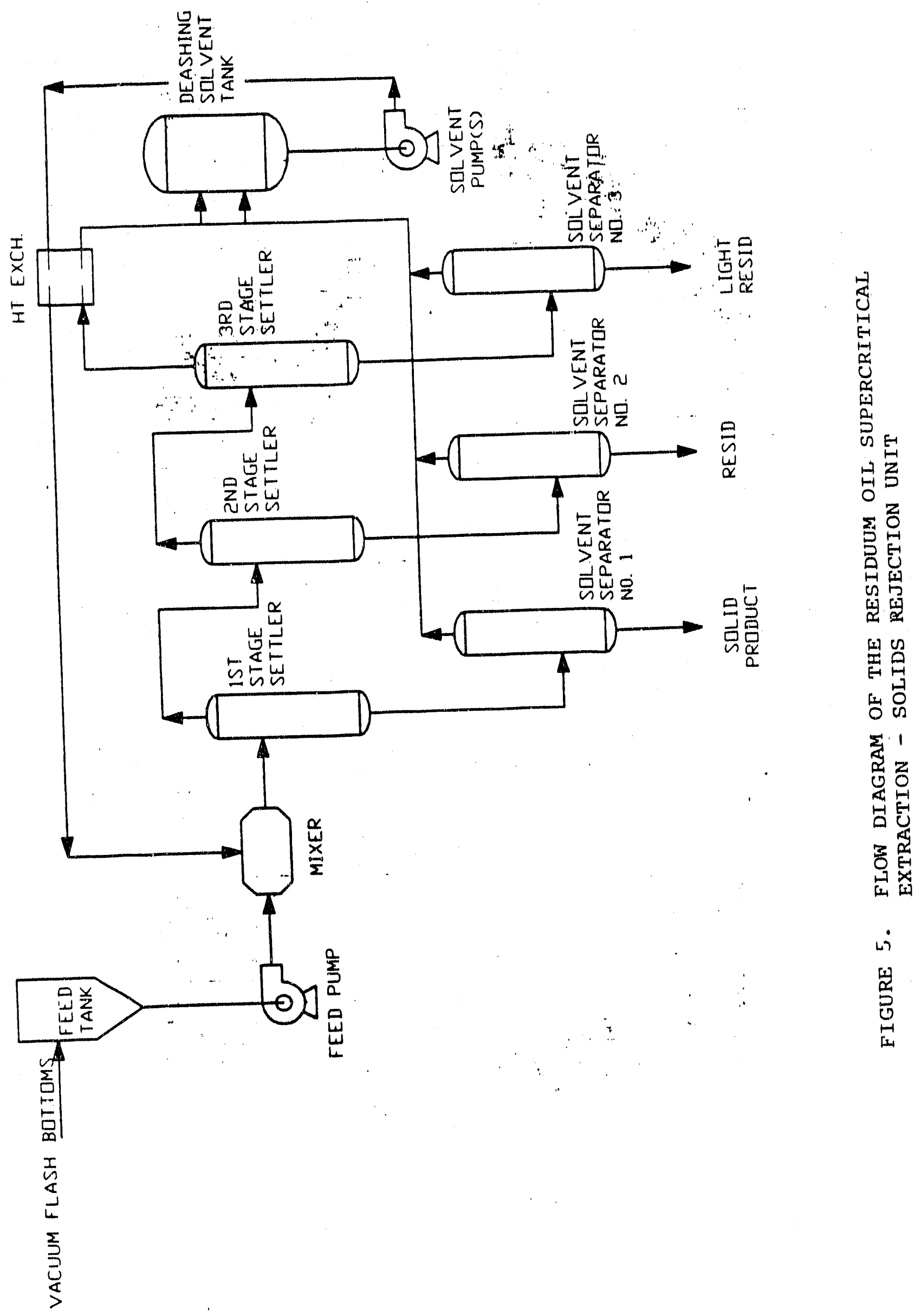


FIGURE 6. COAL CONVERSION BY FORCED ASH BALANCE

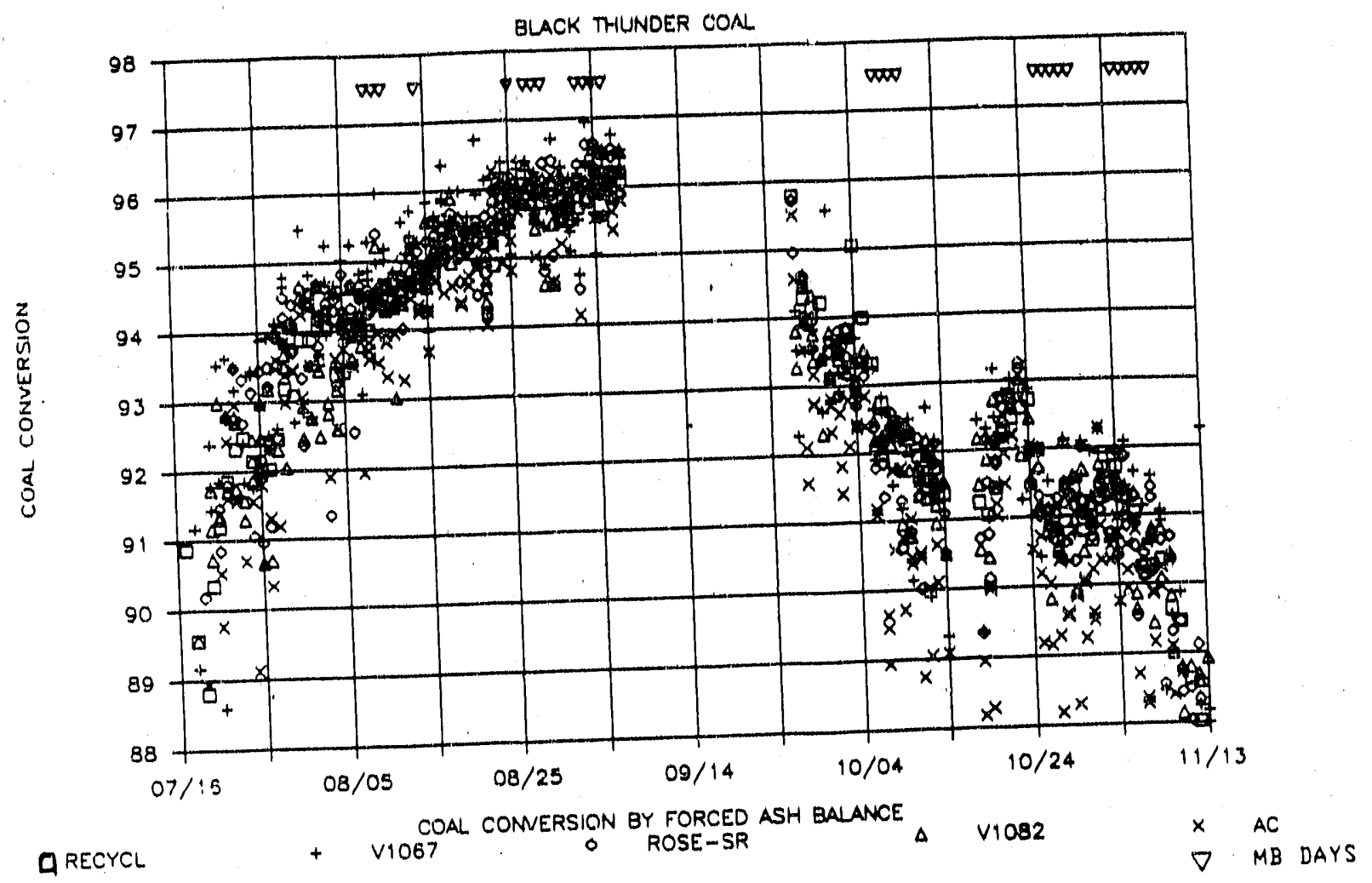

FIGURE 7. COAI SLURRY VISCOSITY

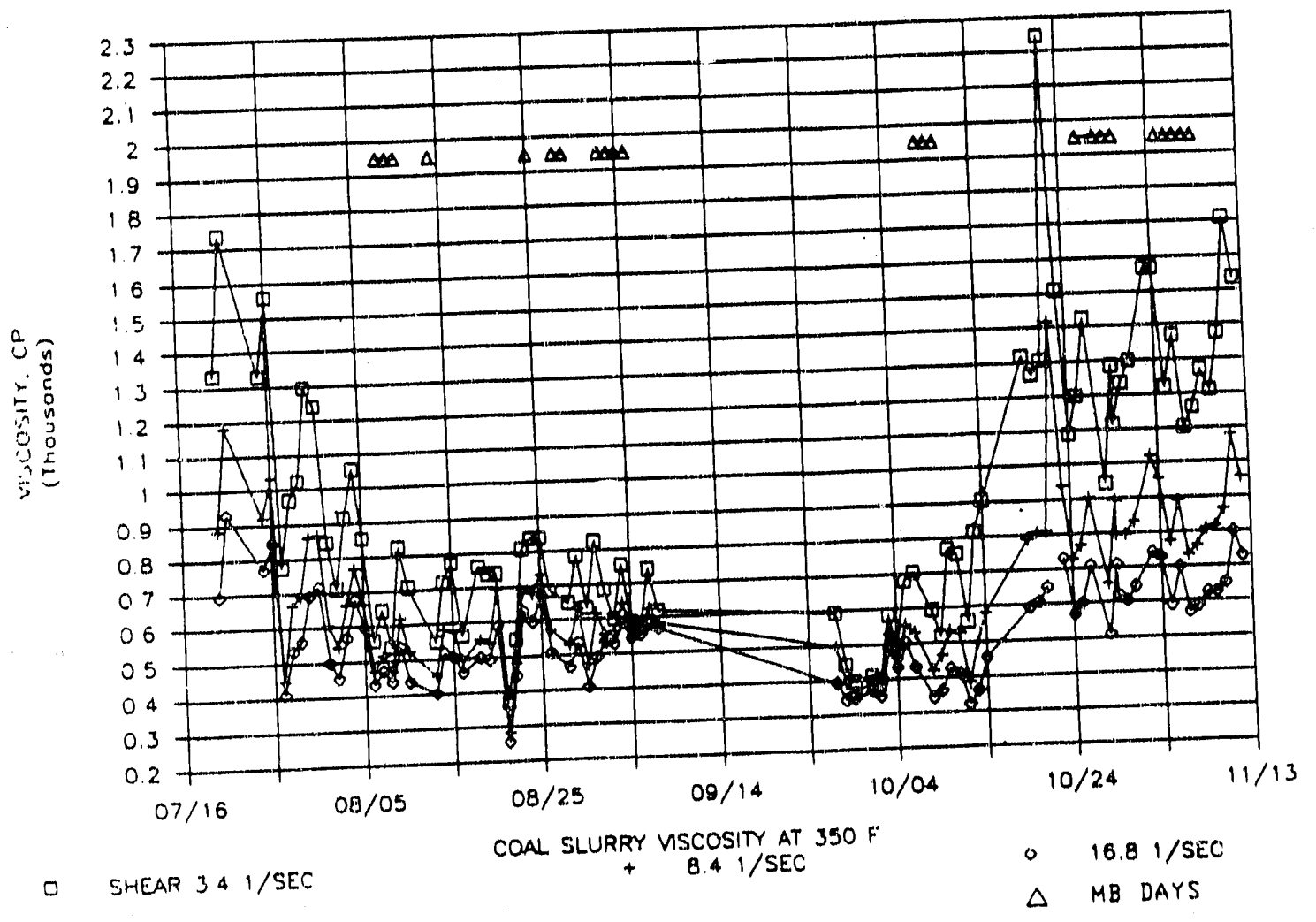




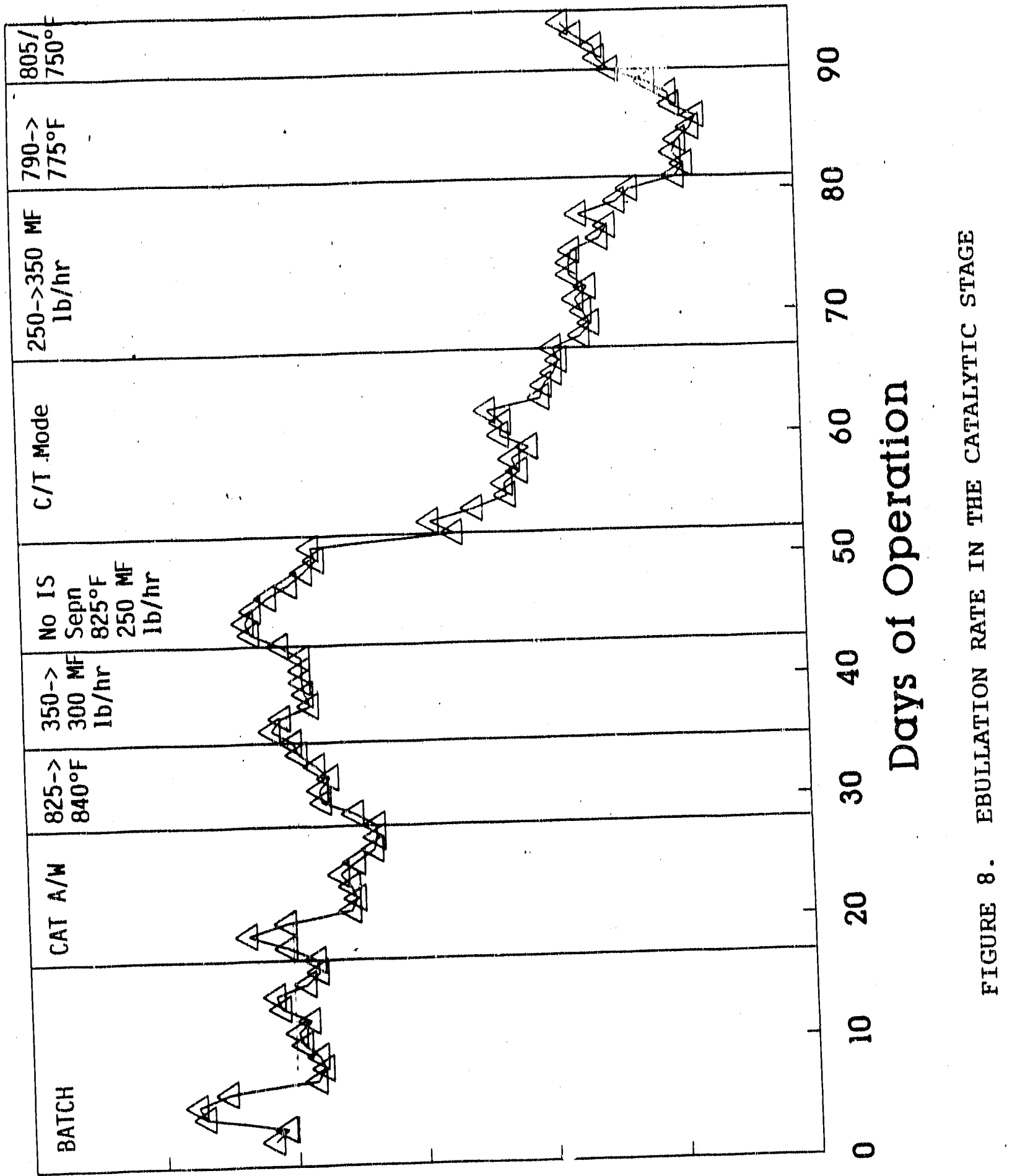




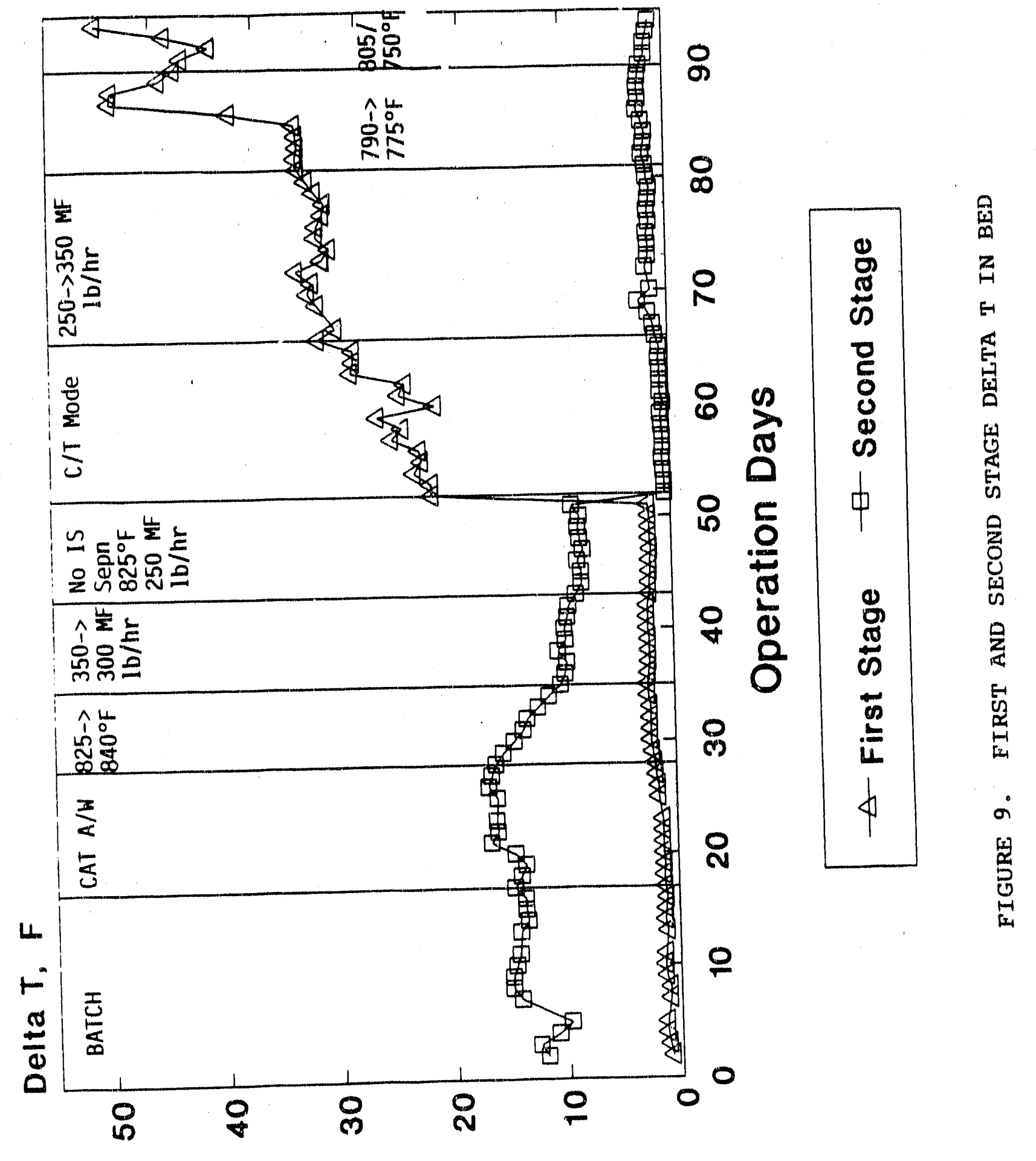




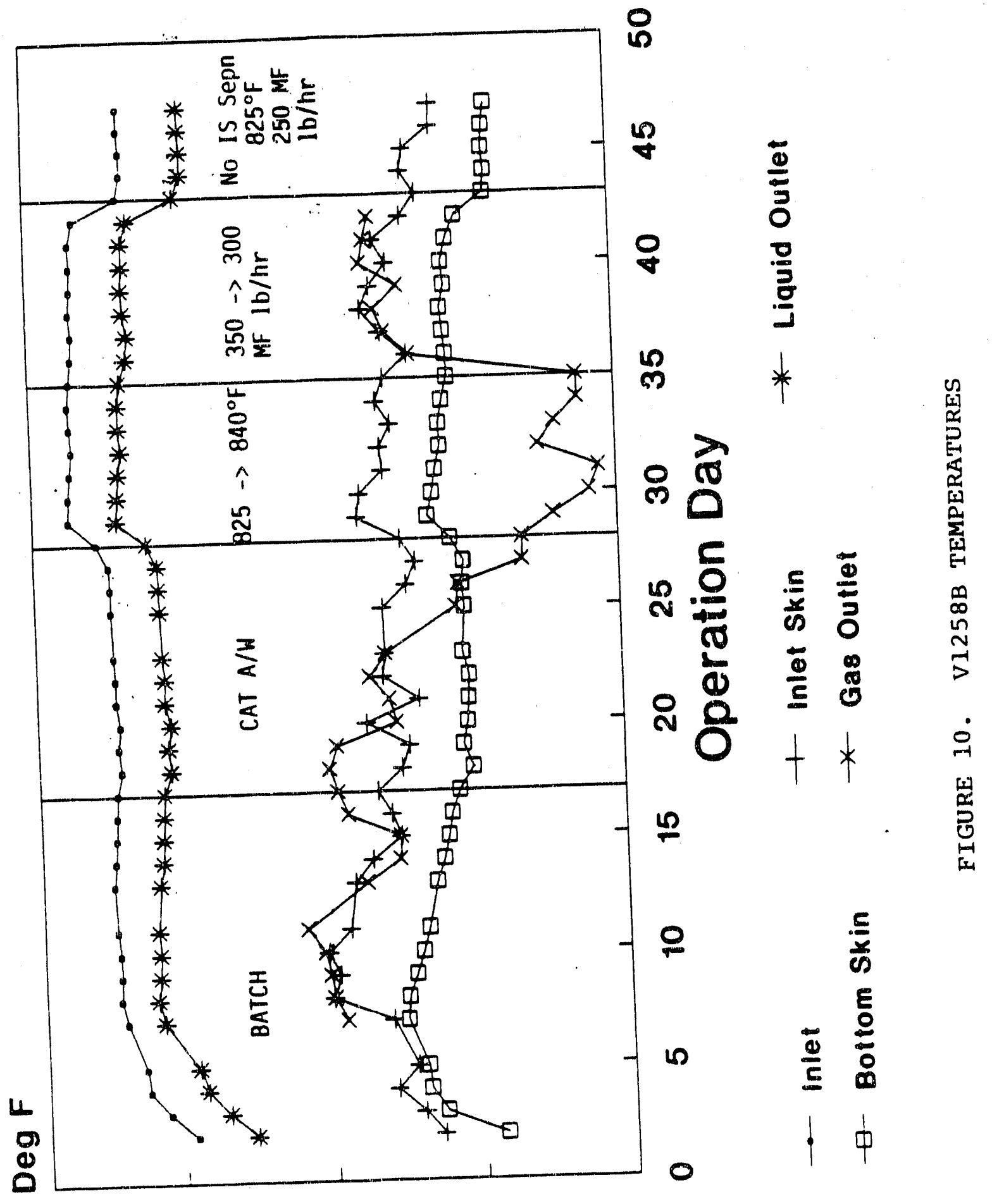




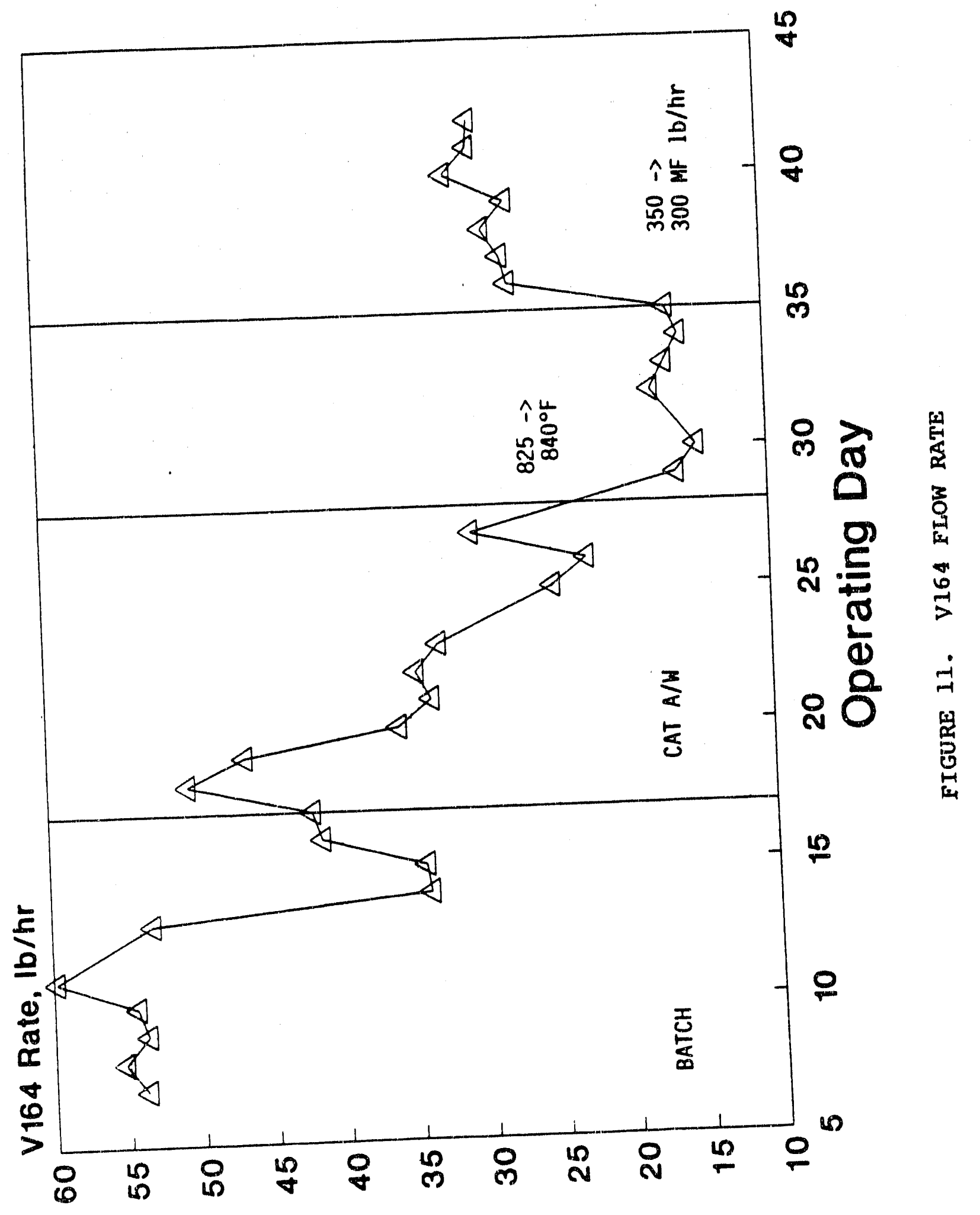




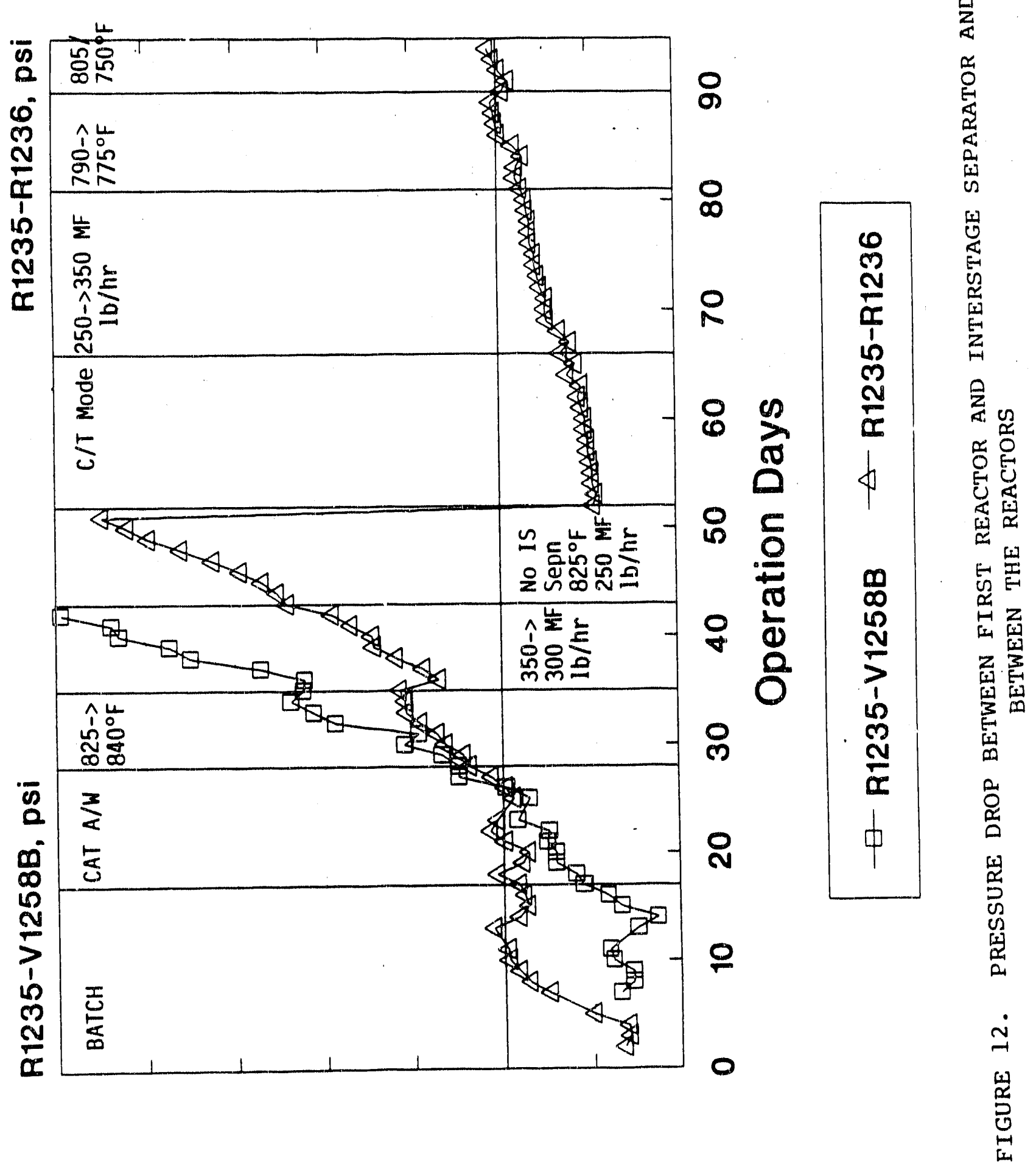



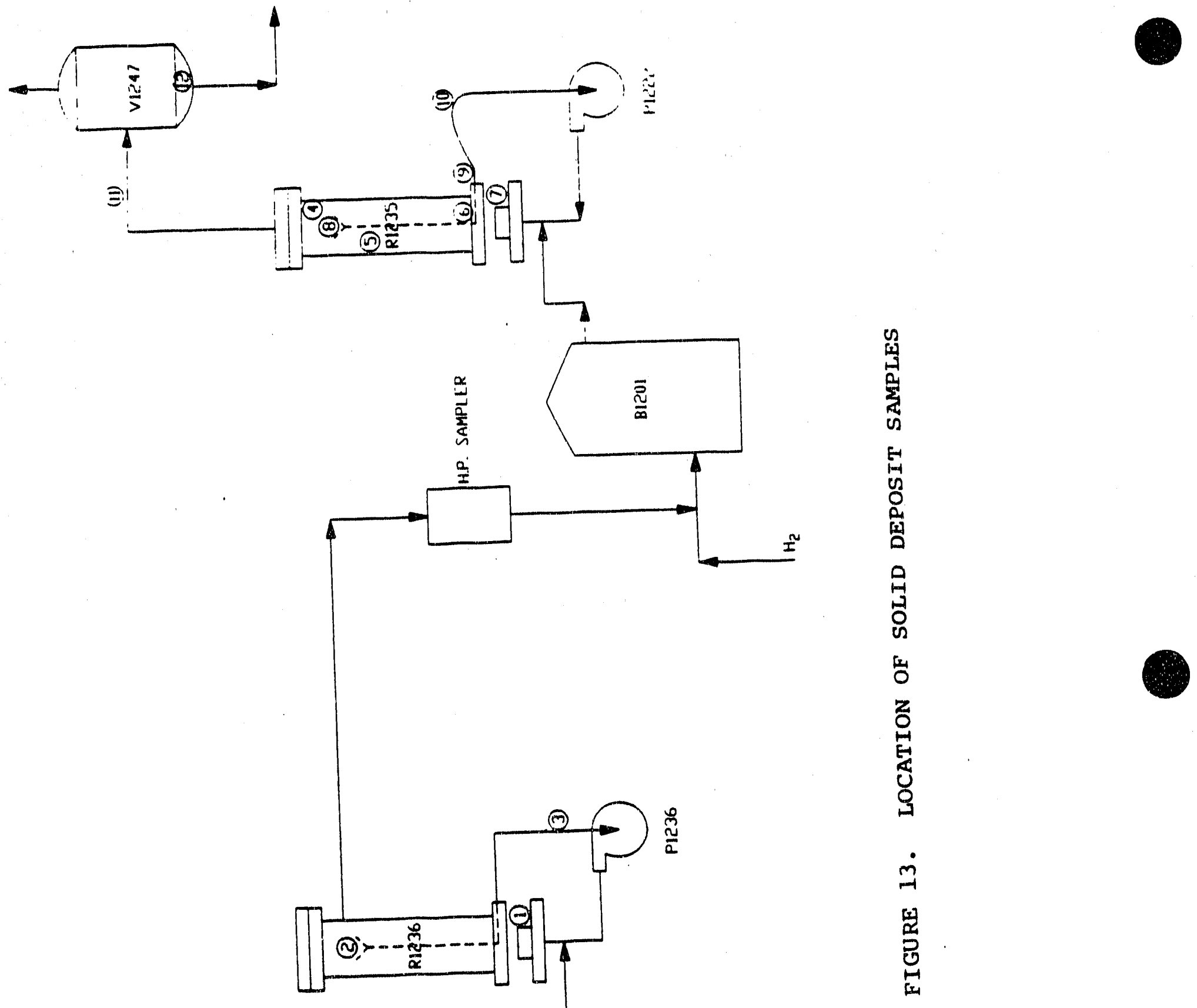

孞

孚

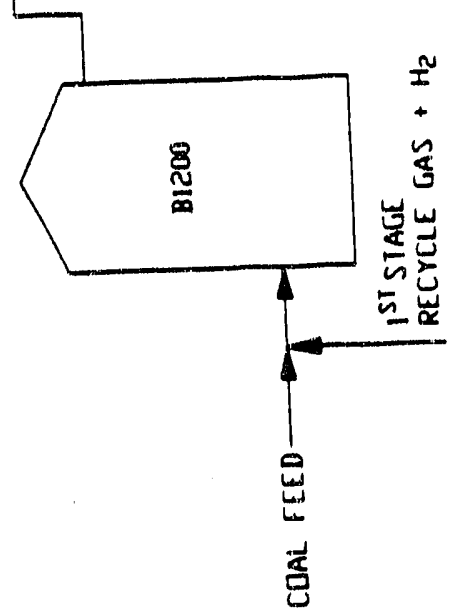




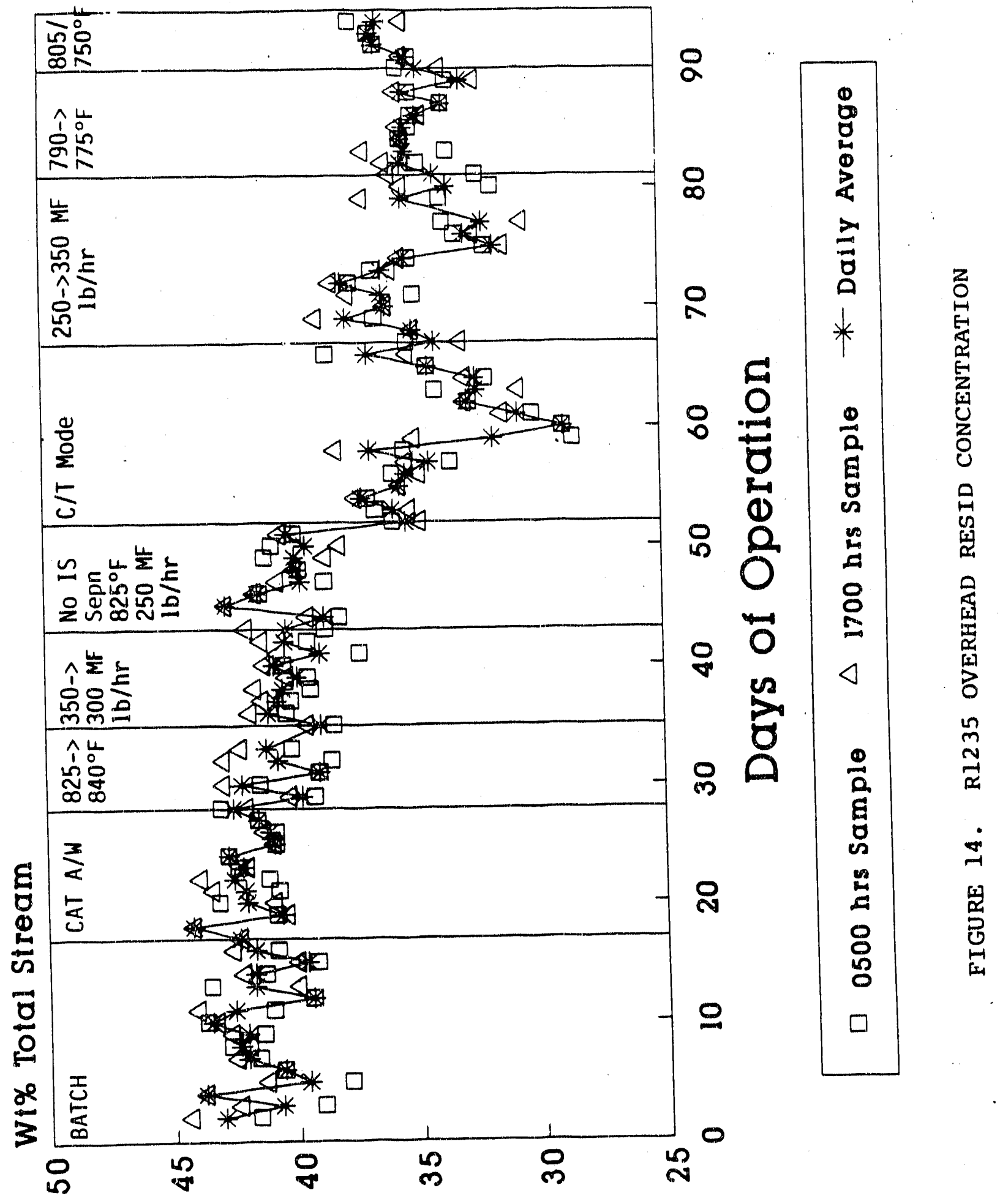




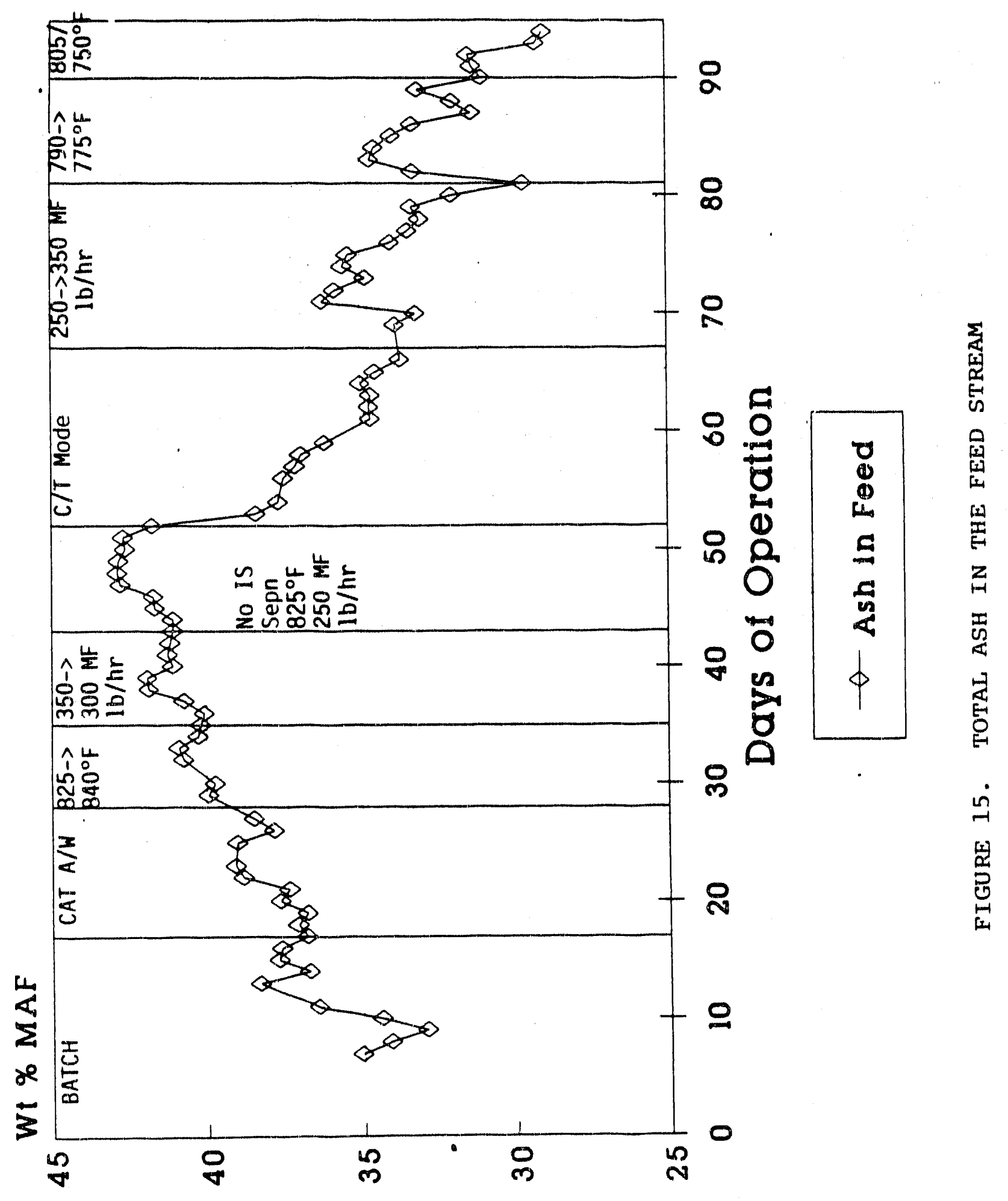




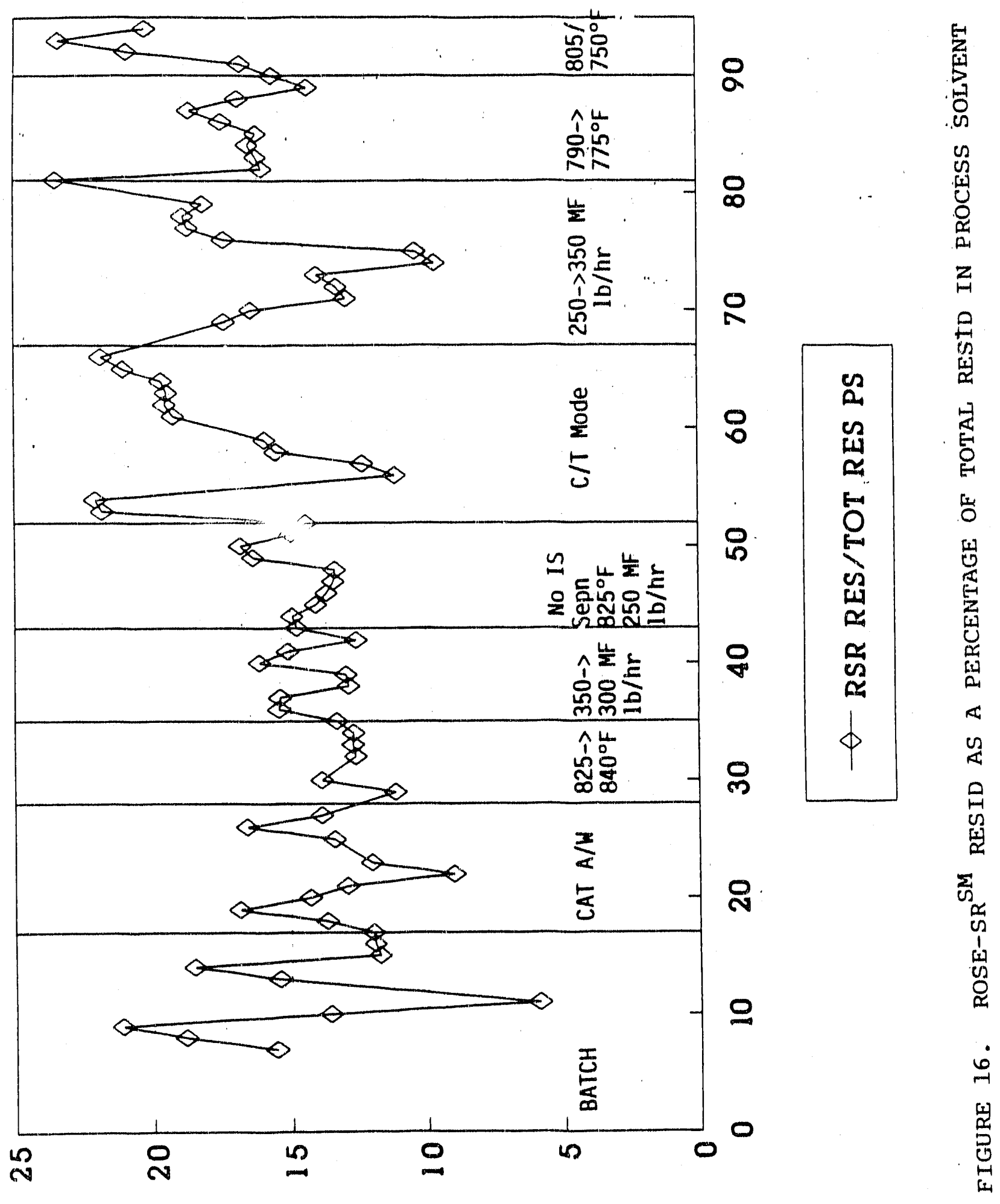




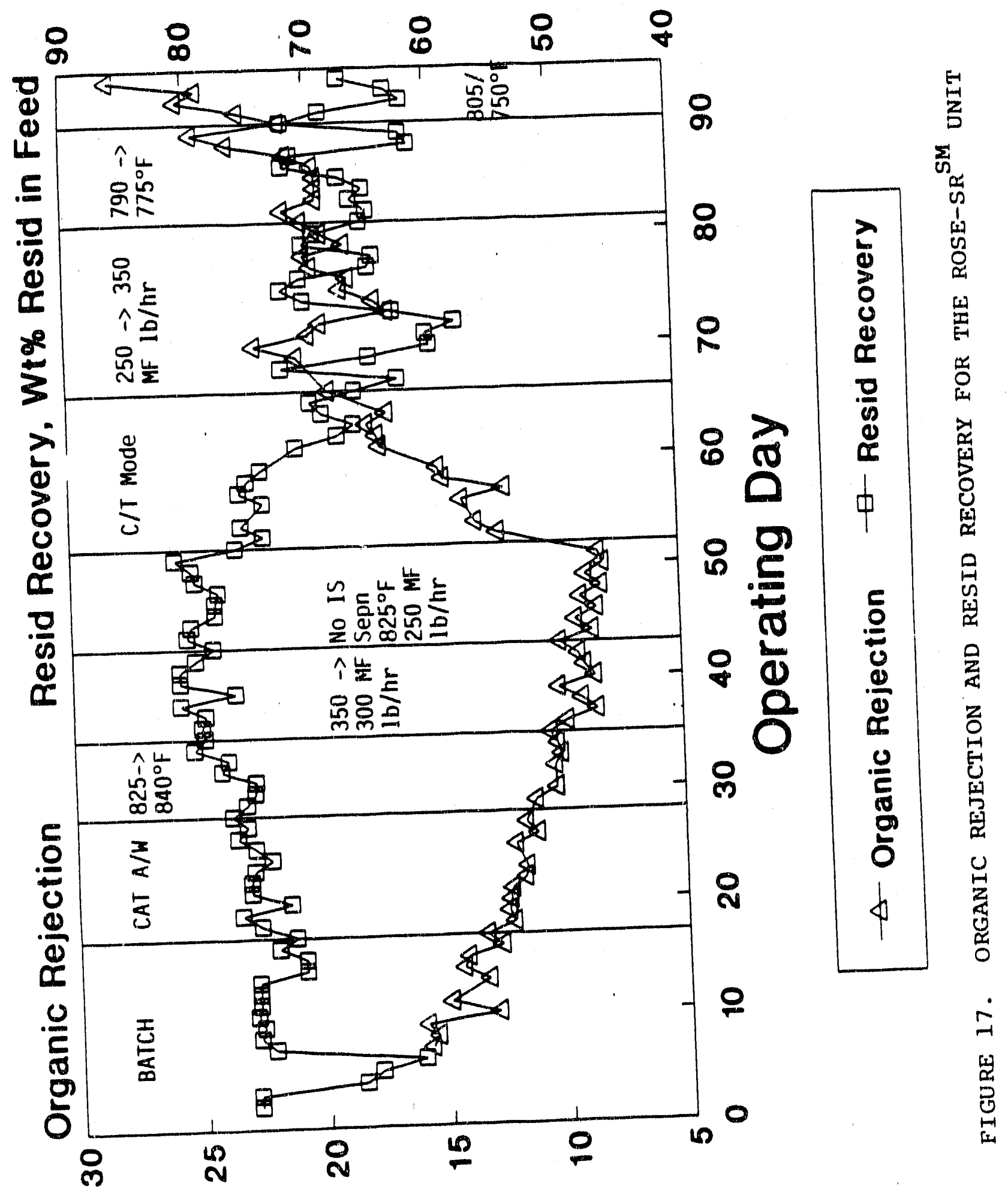




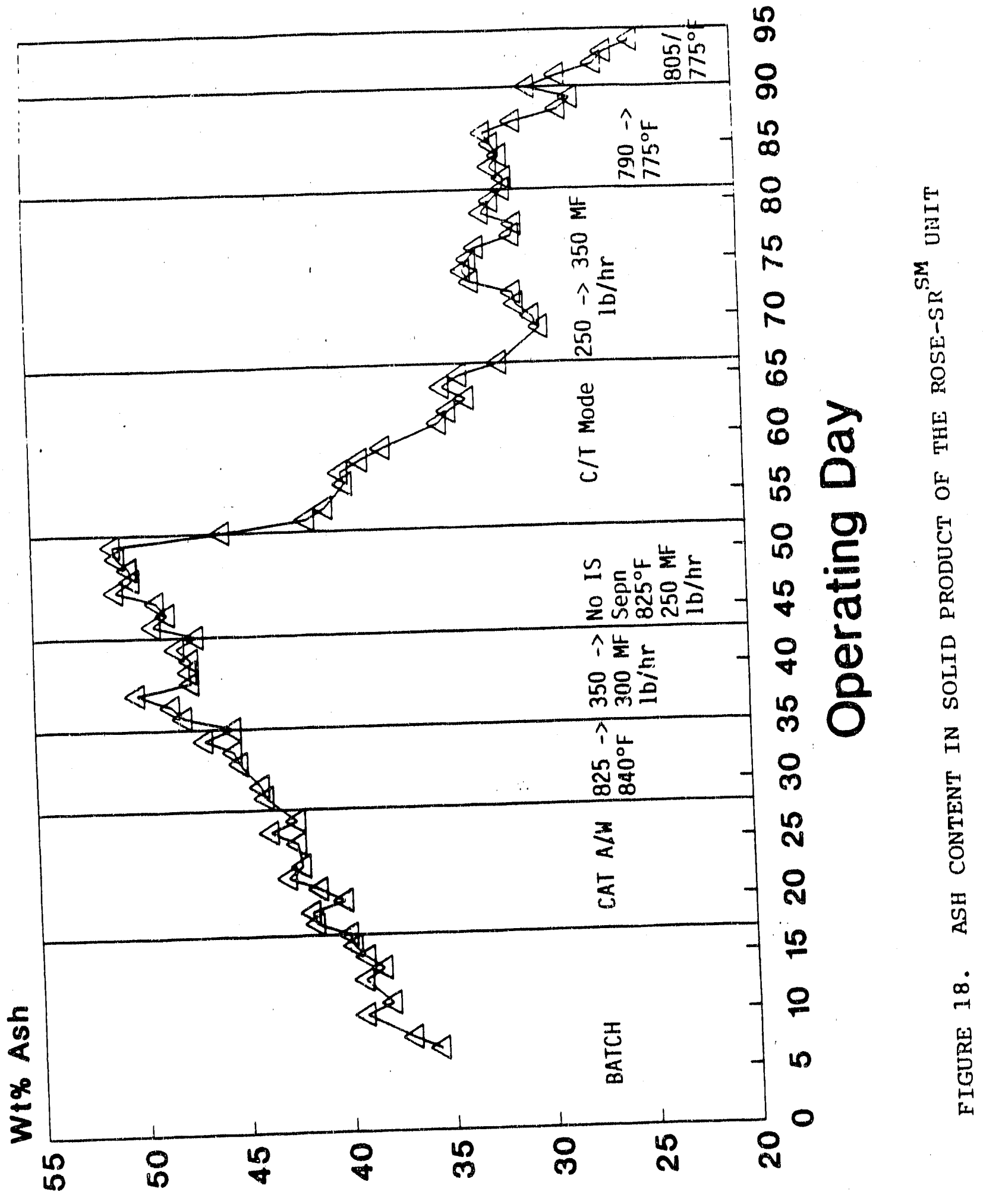




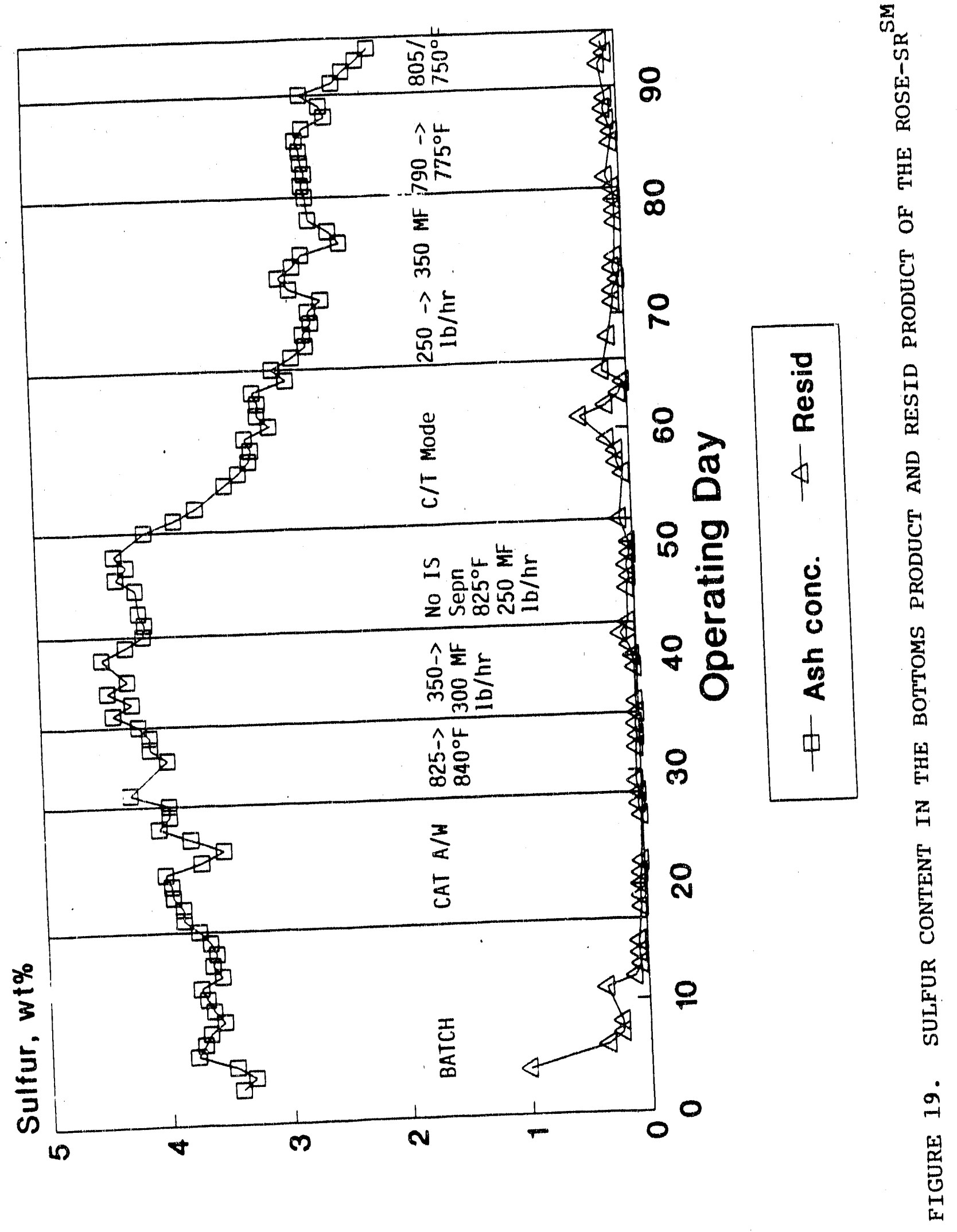




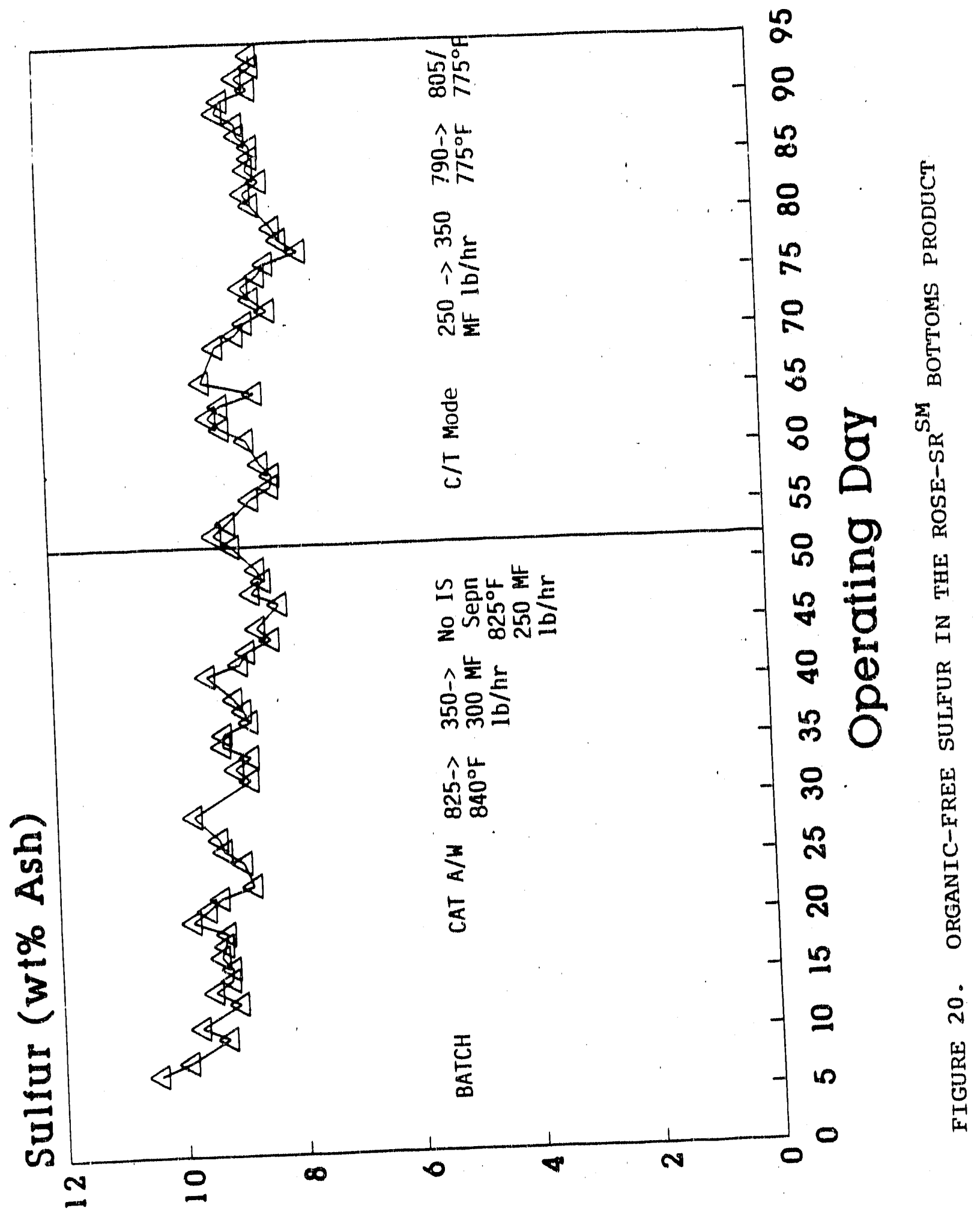




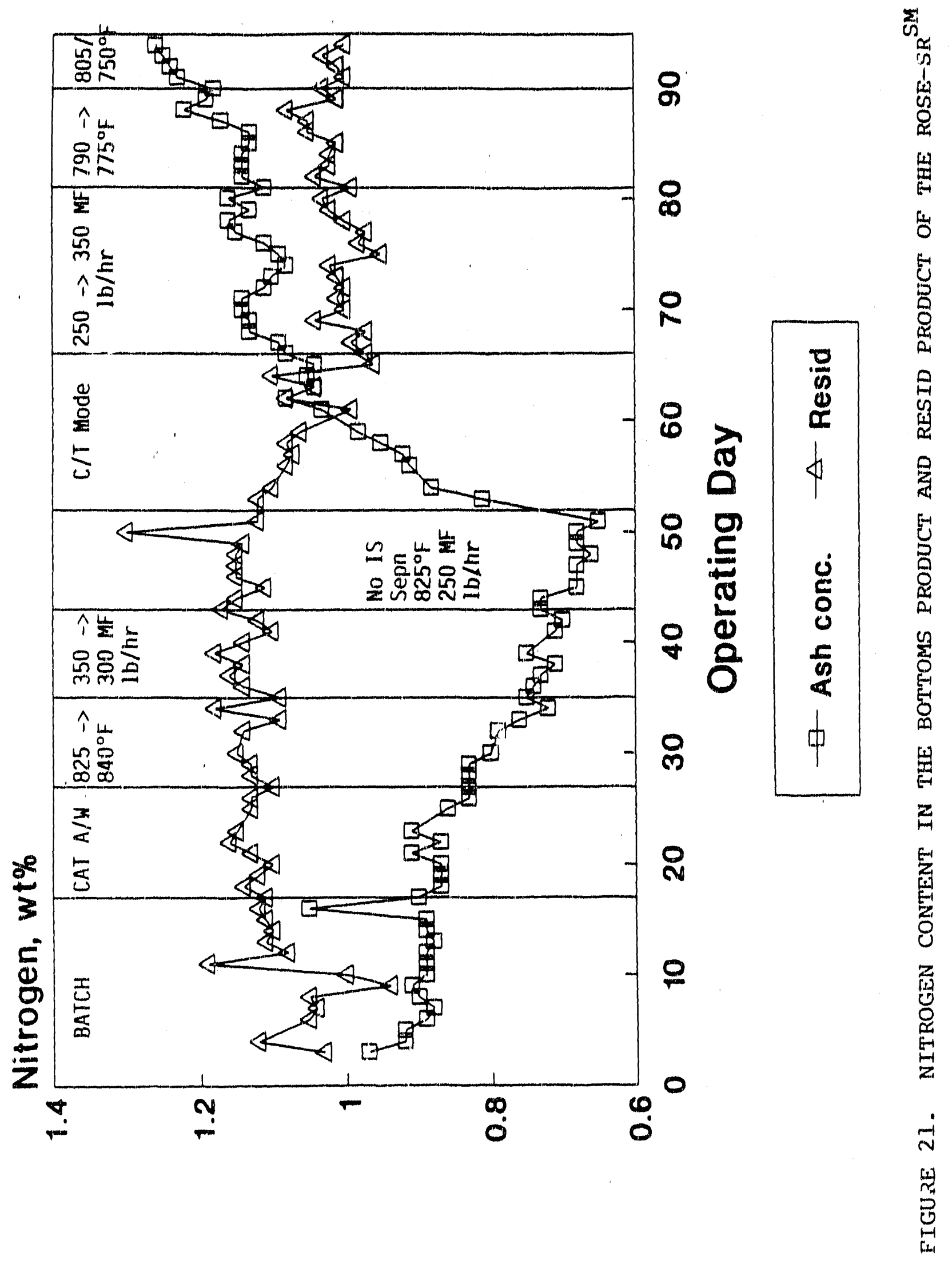




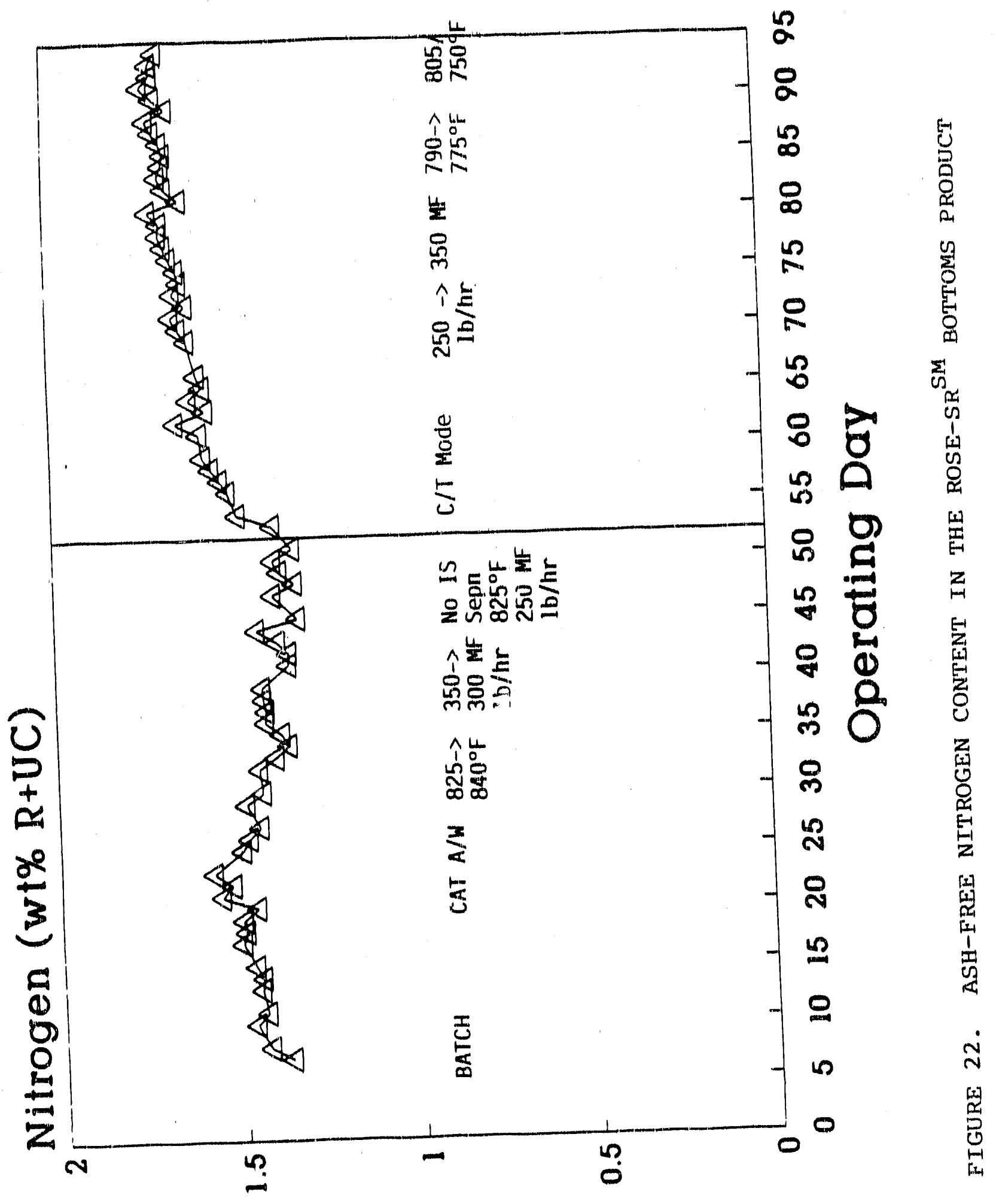


FIGURE 23. TLO2 VACUUM COLUMN CUT POINT

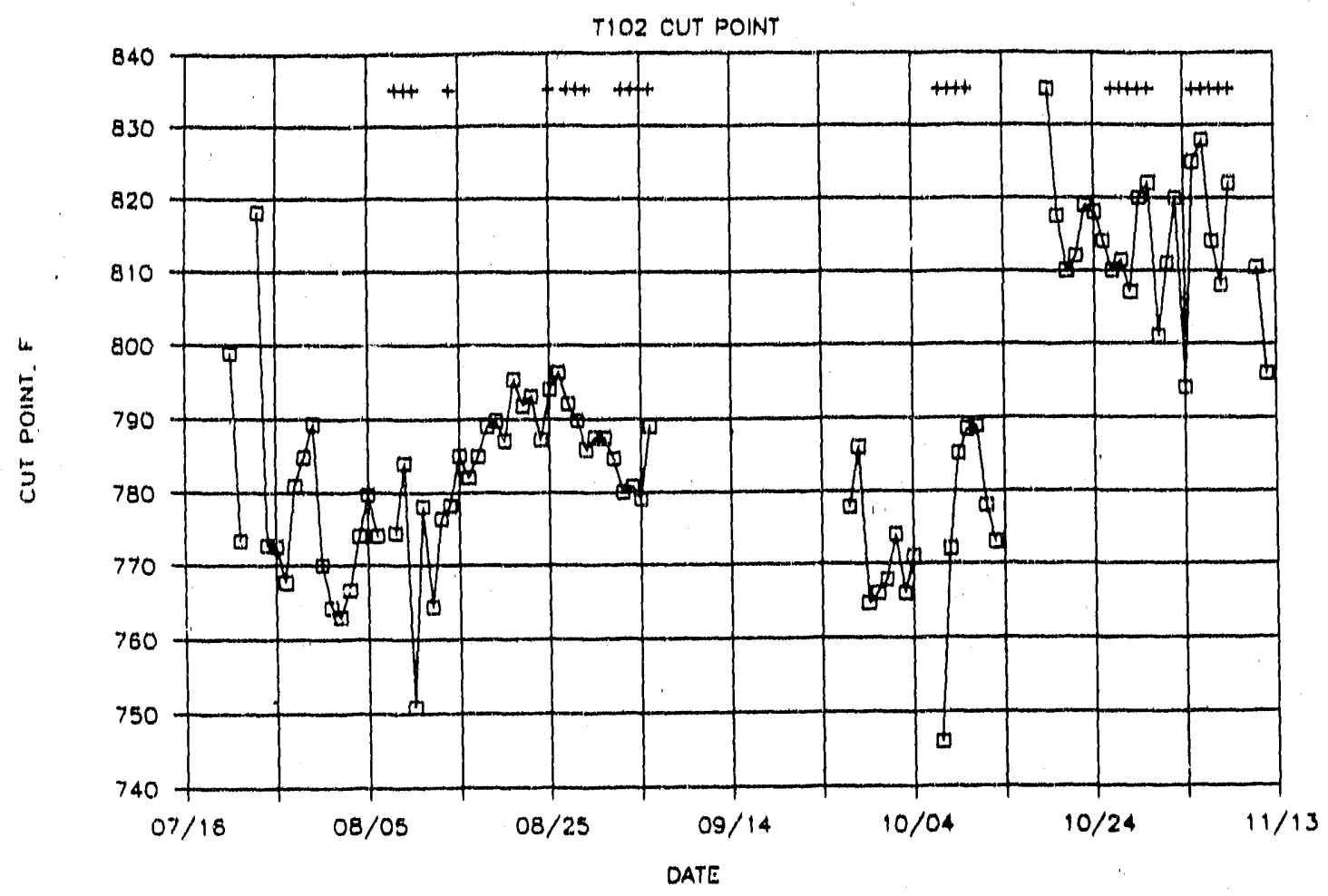

FIGURE 24. TIO2 VACUUM COLUMN OVERLAP BETWEEN OVERHEADS AND BOTTOMS

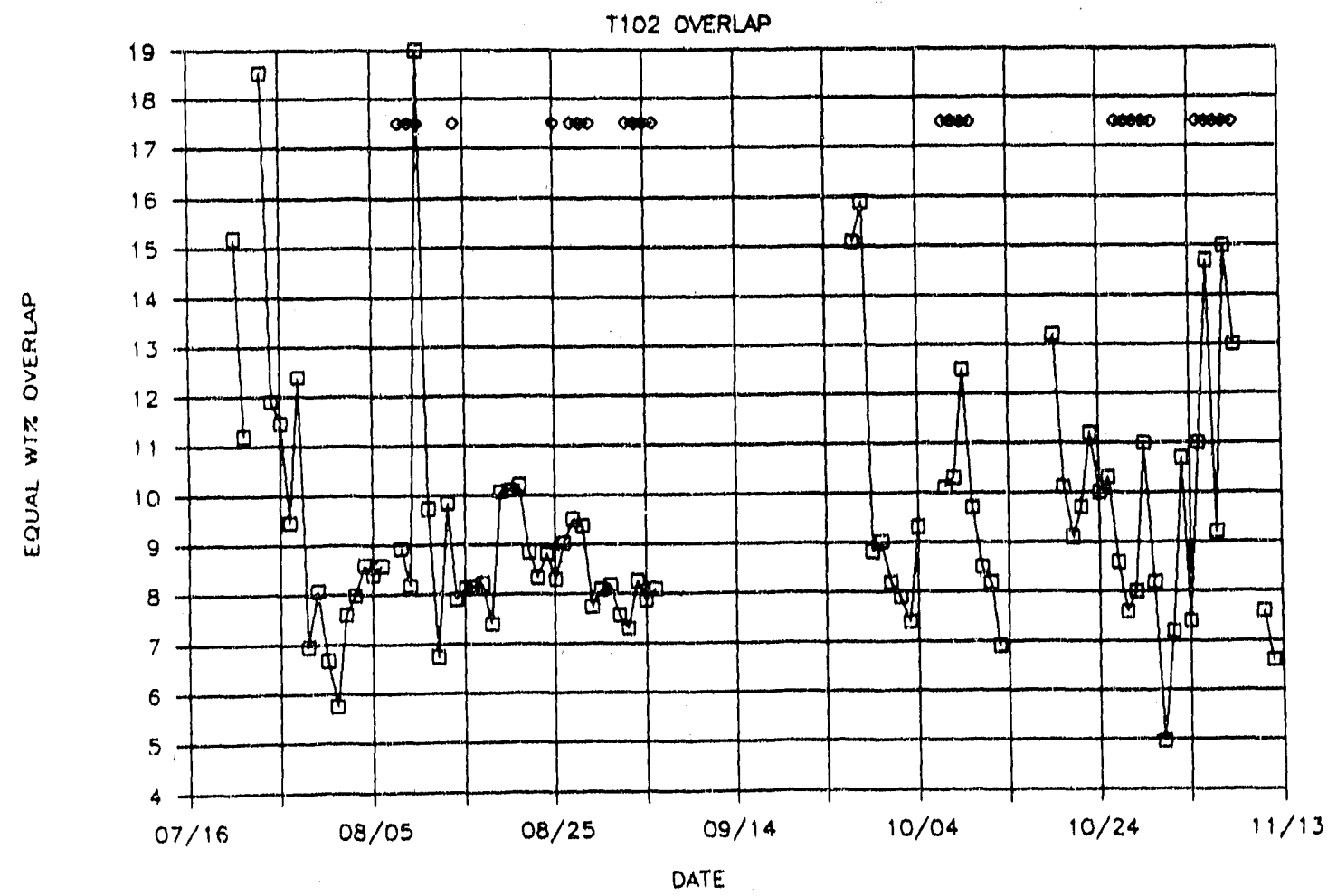


$\stackrel{2}{5}$

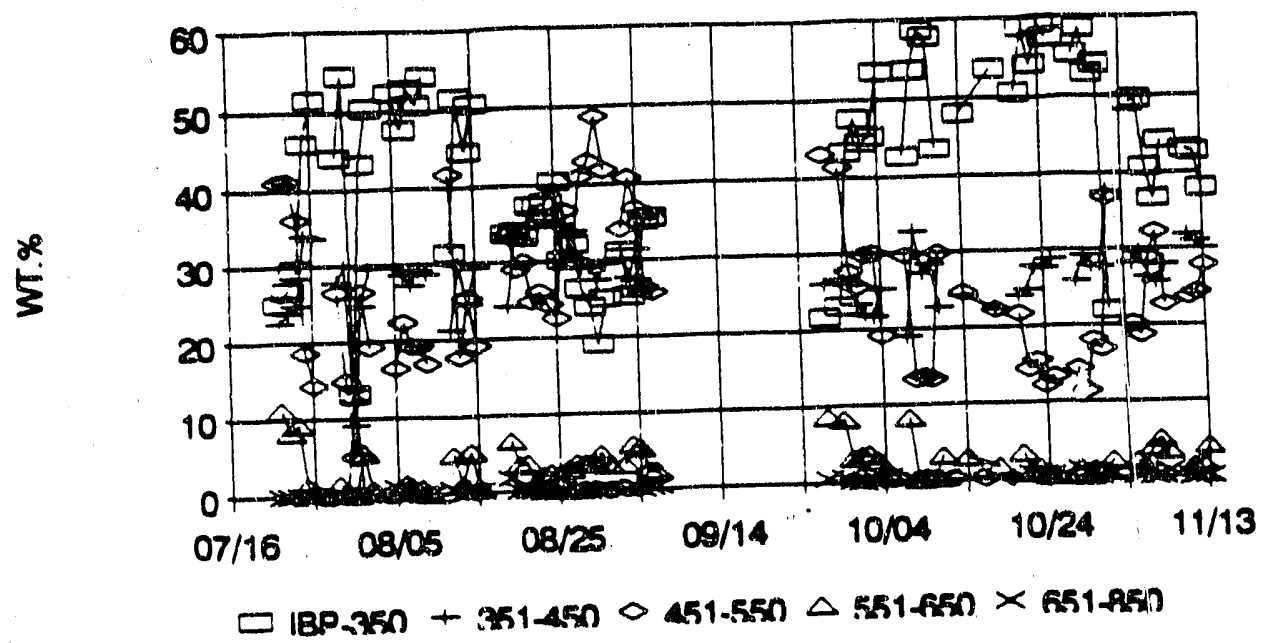

EIGURE 26. TIO2 OVERHEADS DISTRIBUTION

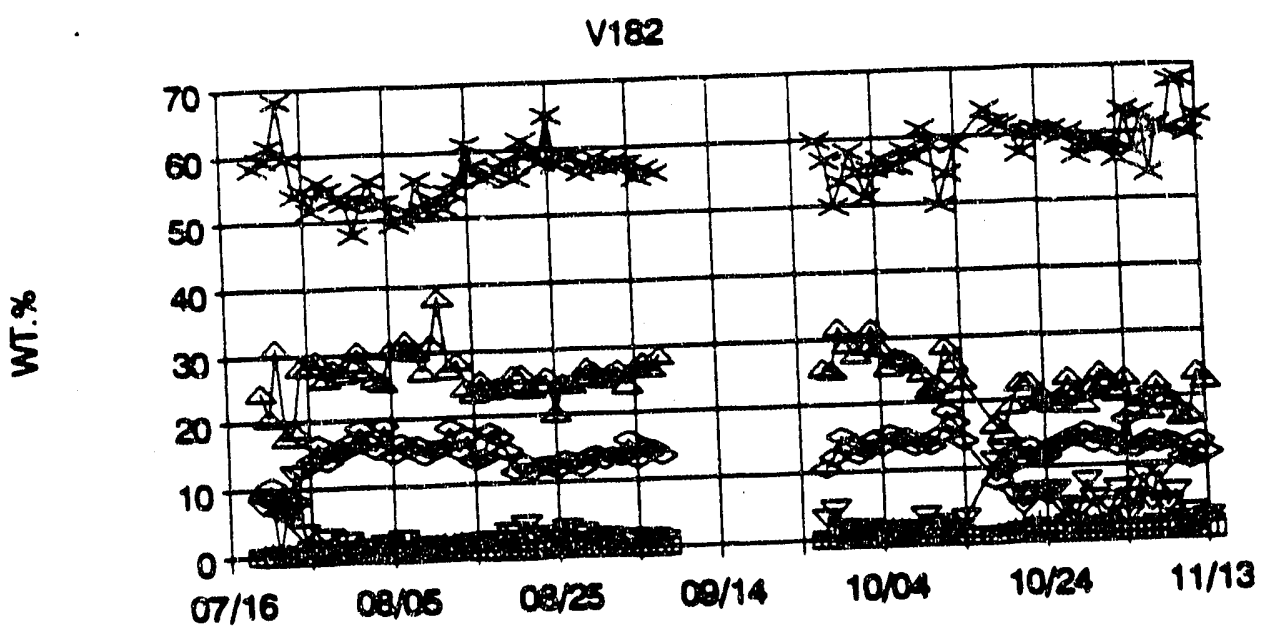

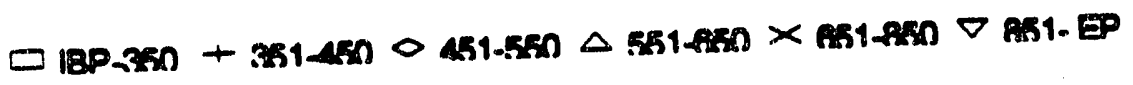

FIGURE 27. T102 BOTTOMS DISTRIBUTION V1074

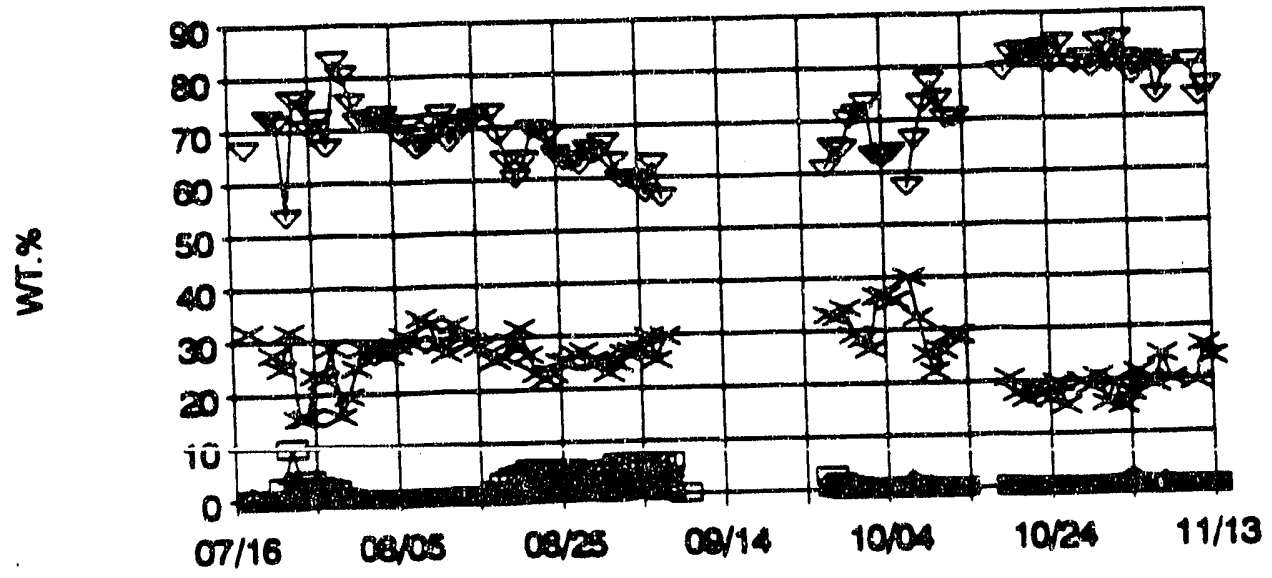

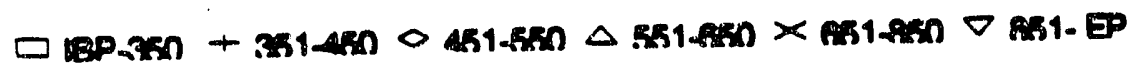




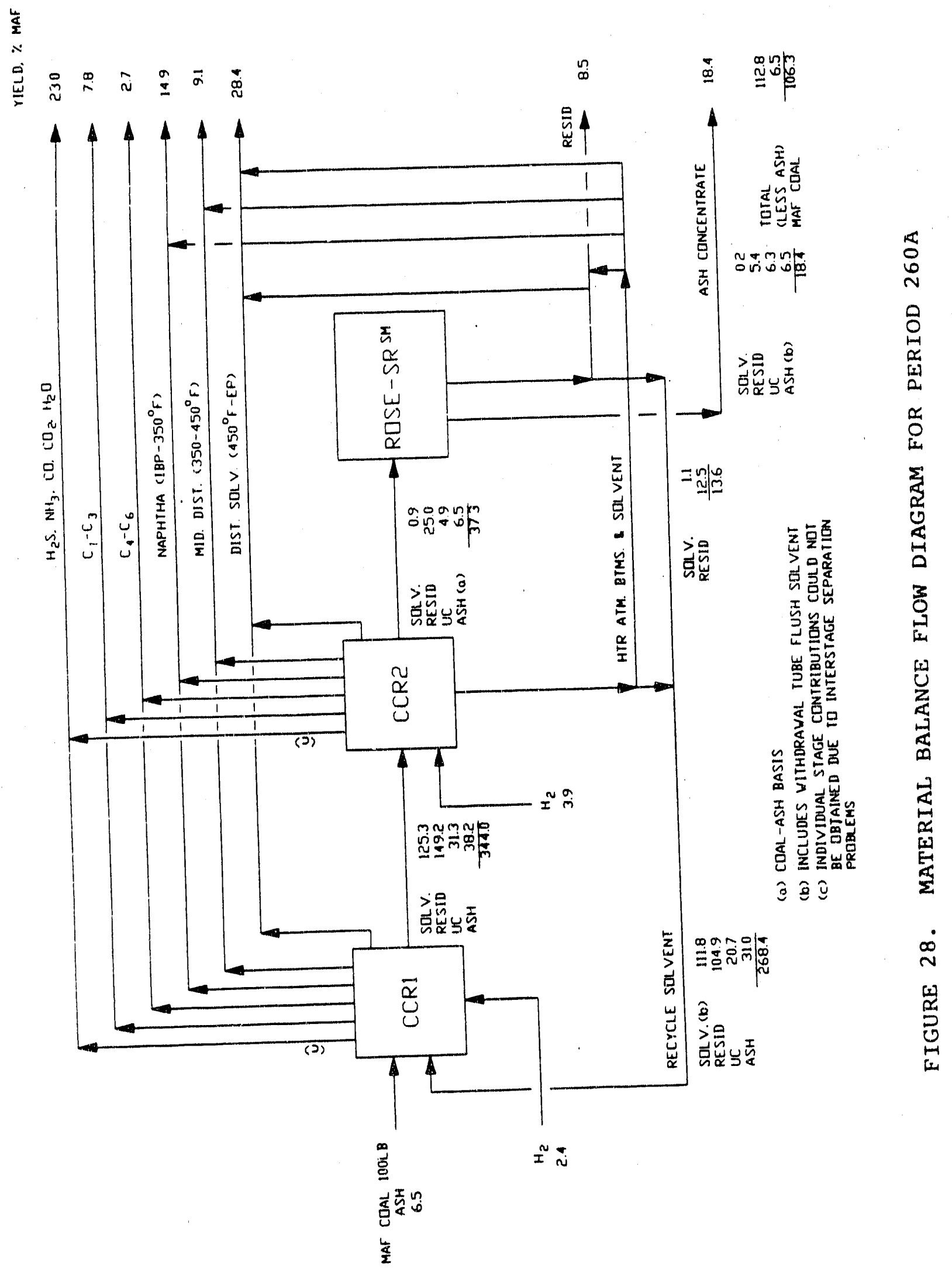




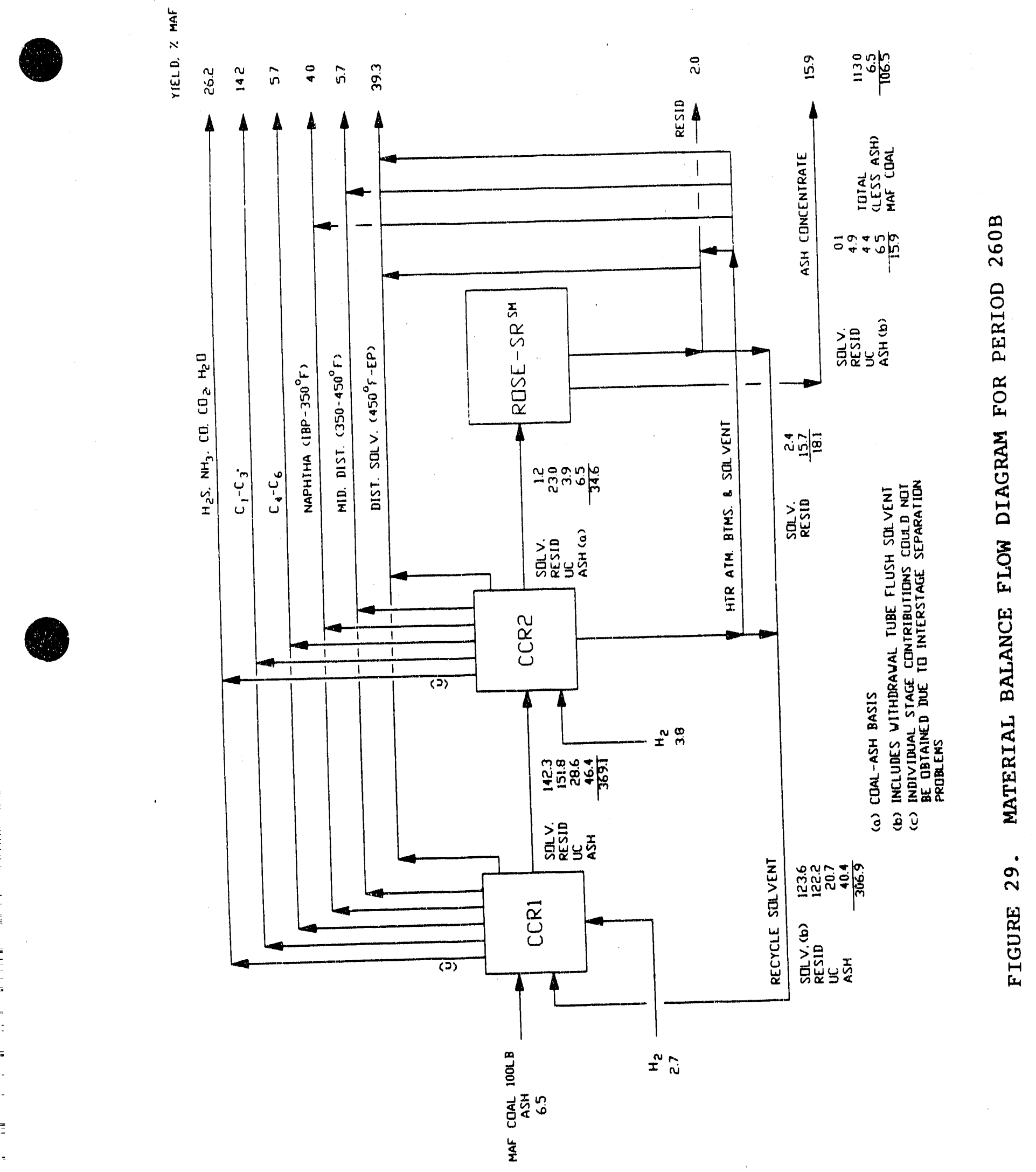




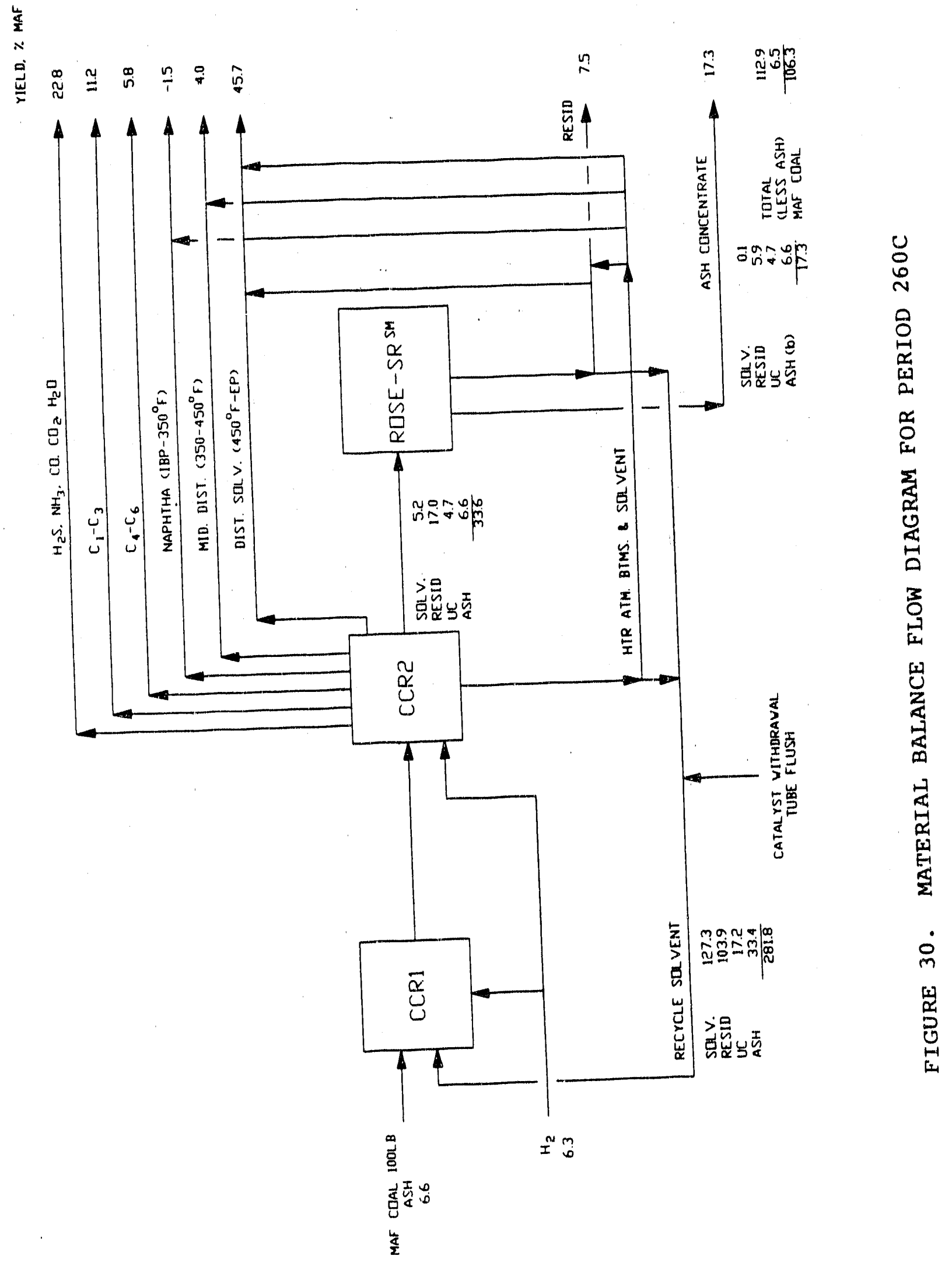




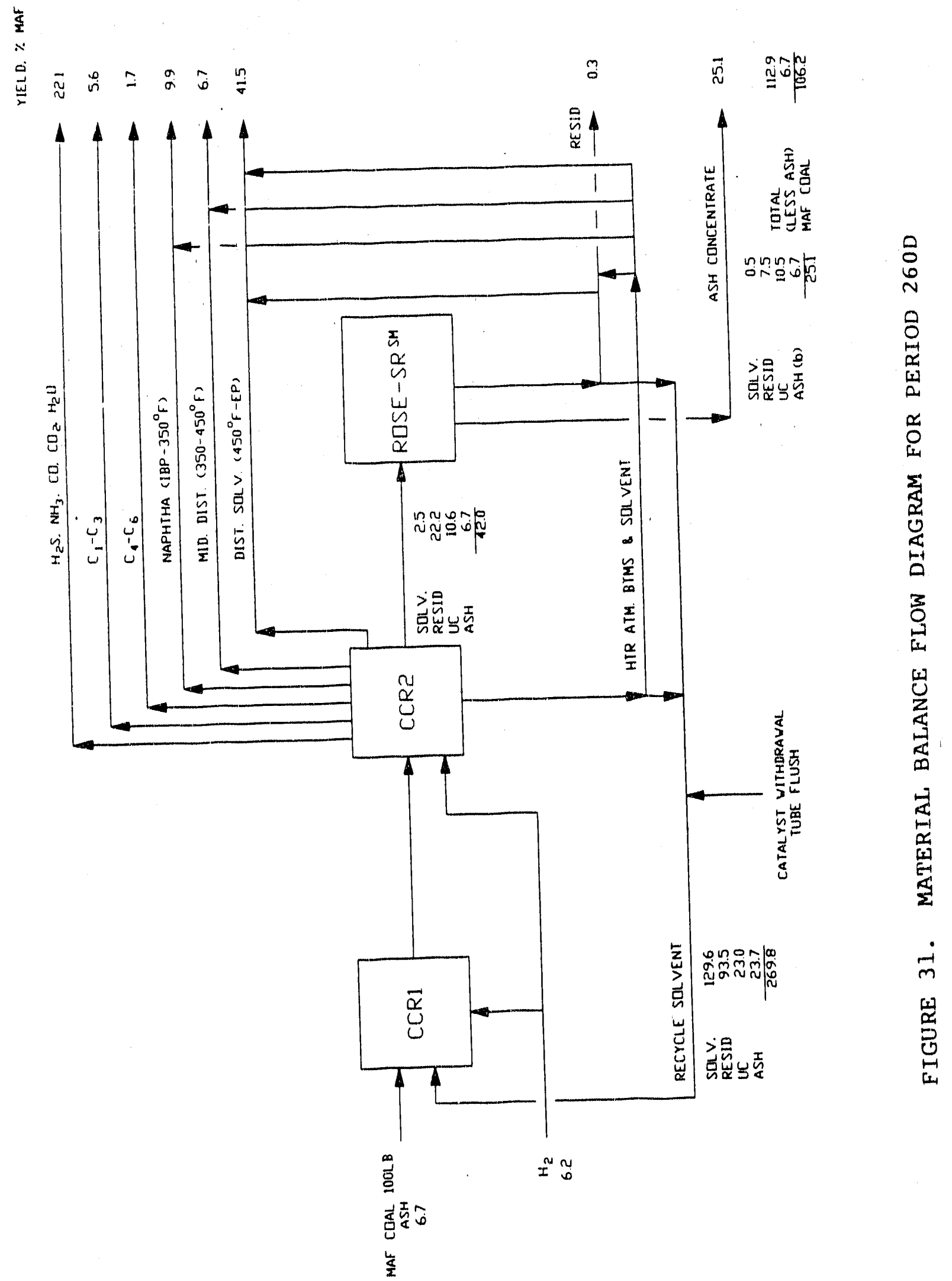


$\frac{n}{\sim}$ บั

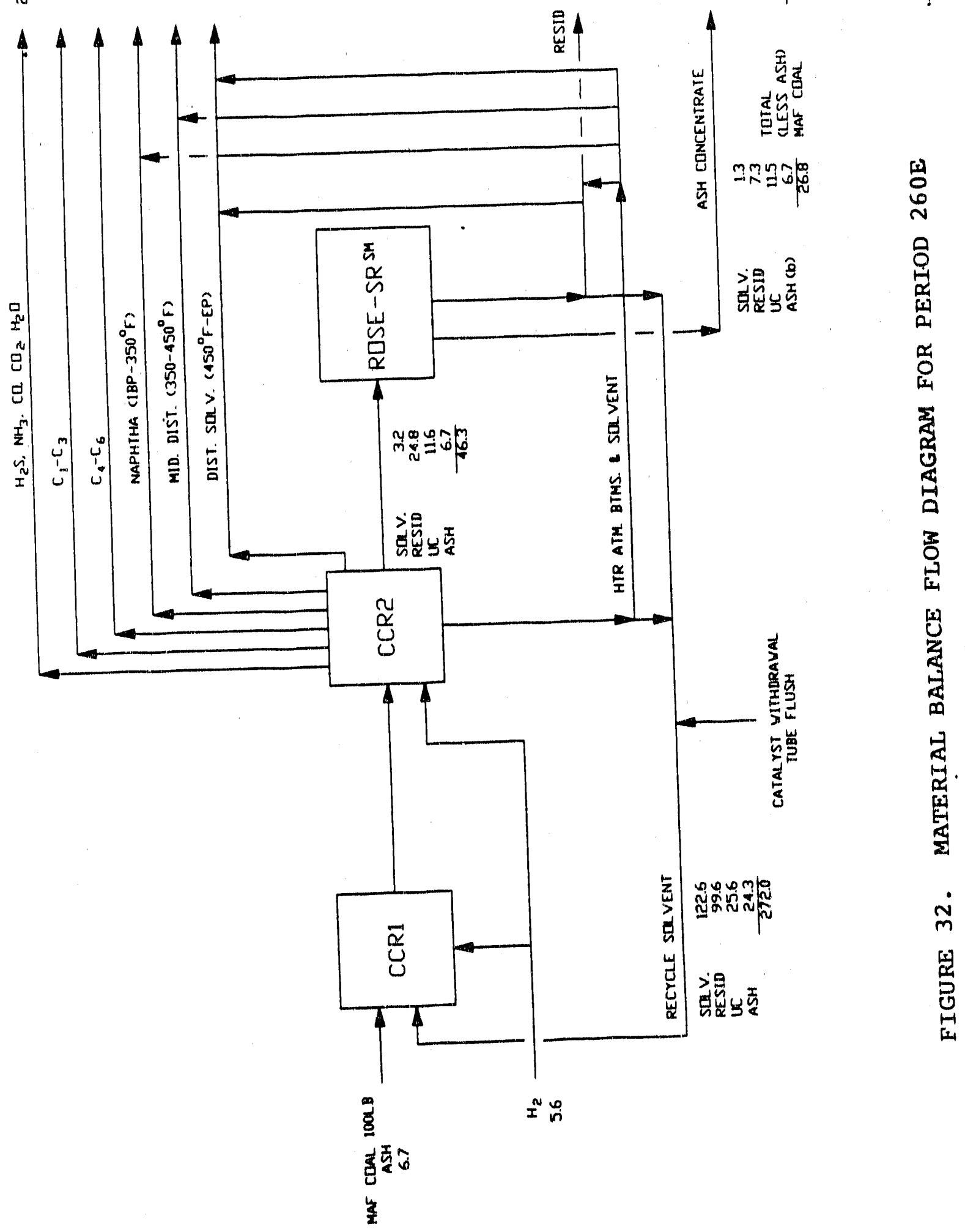




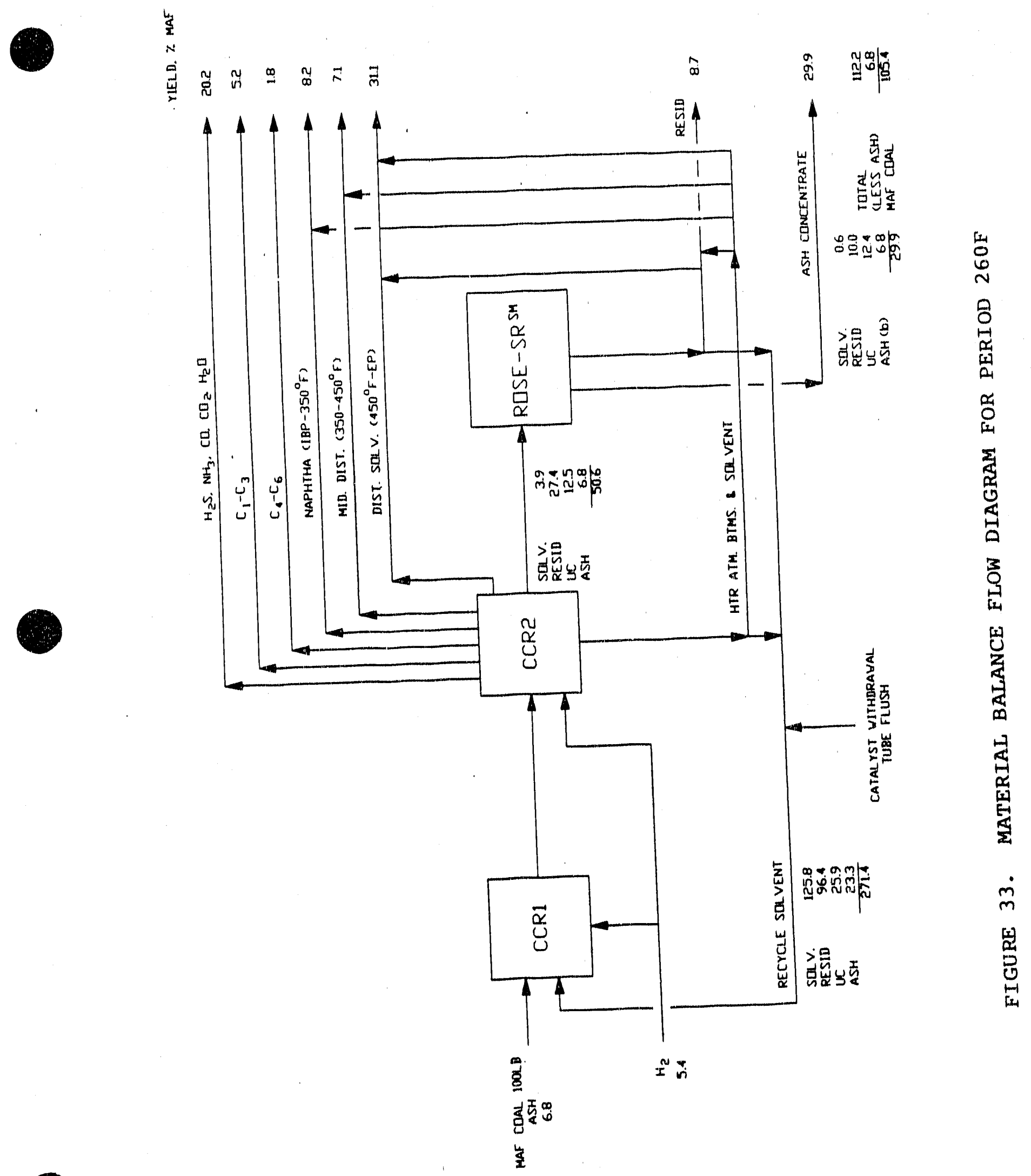




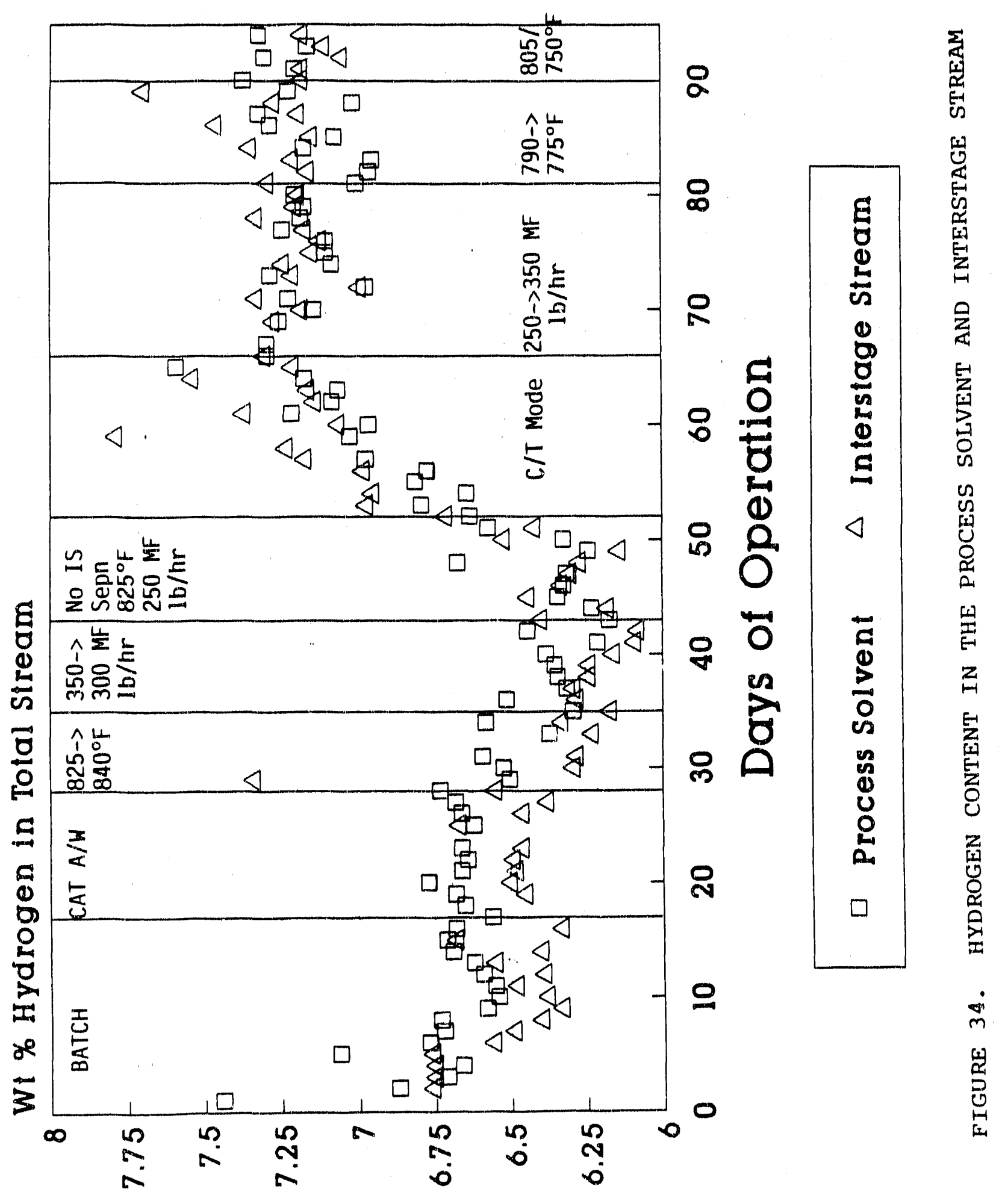




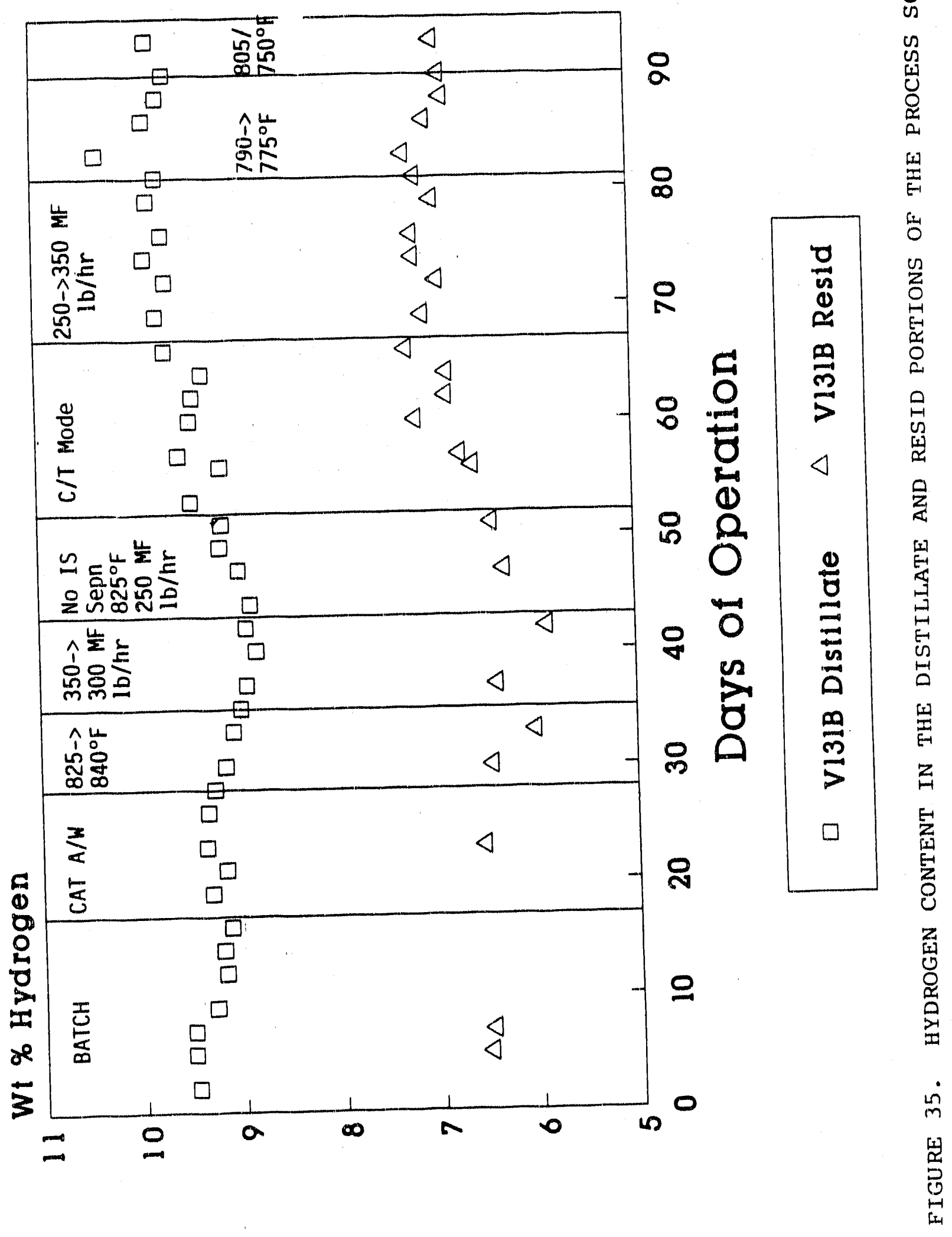




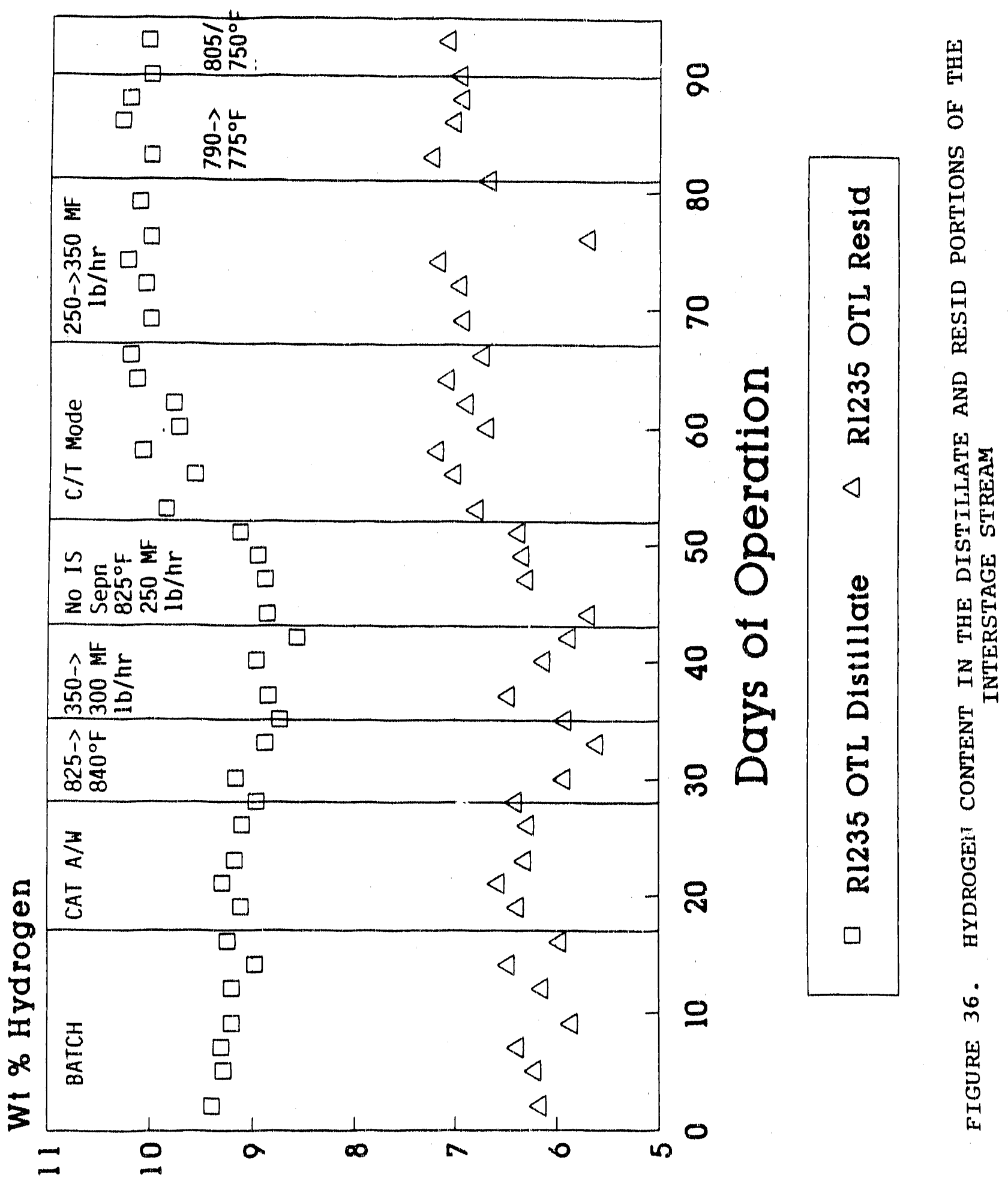




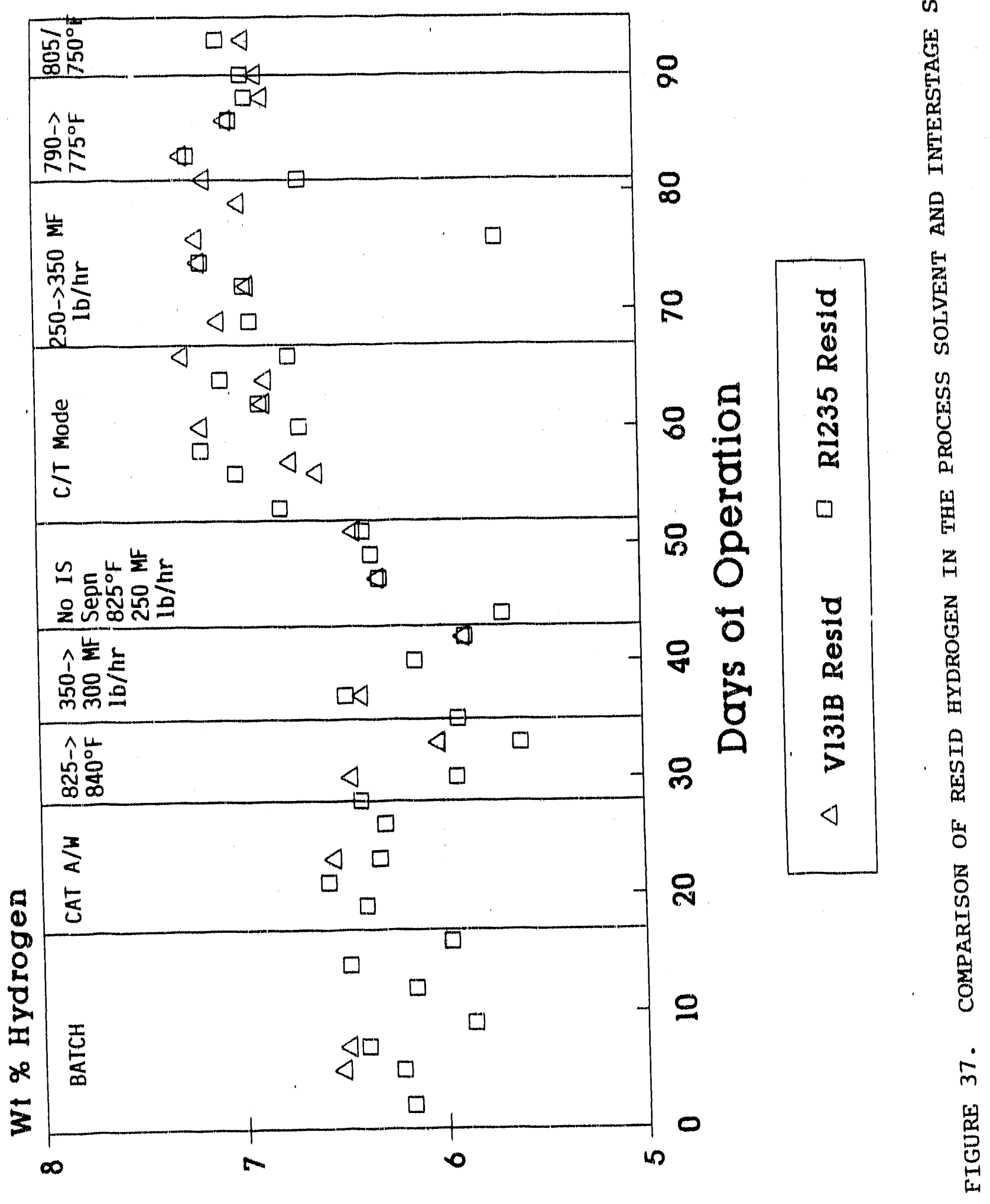



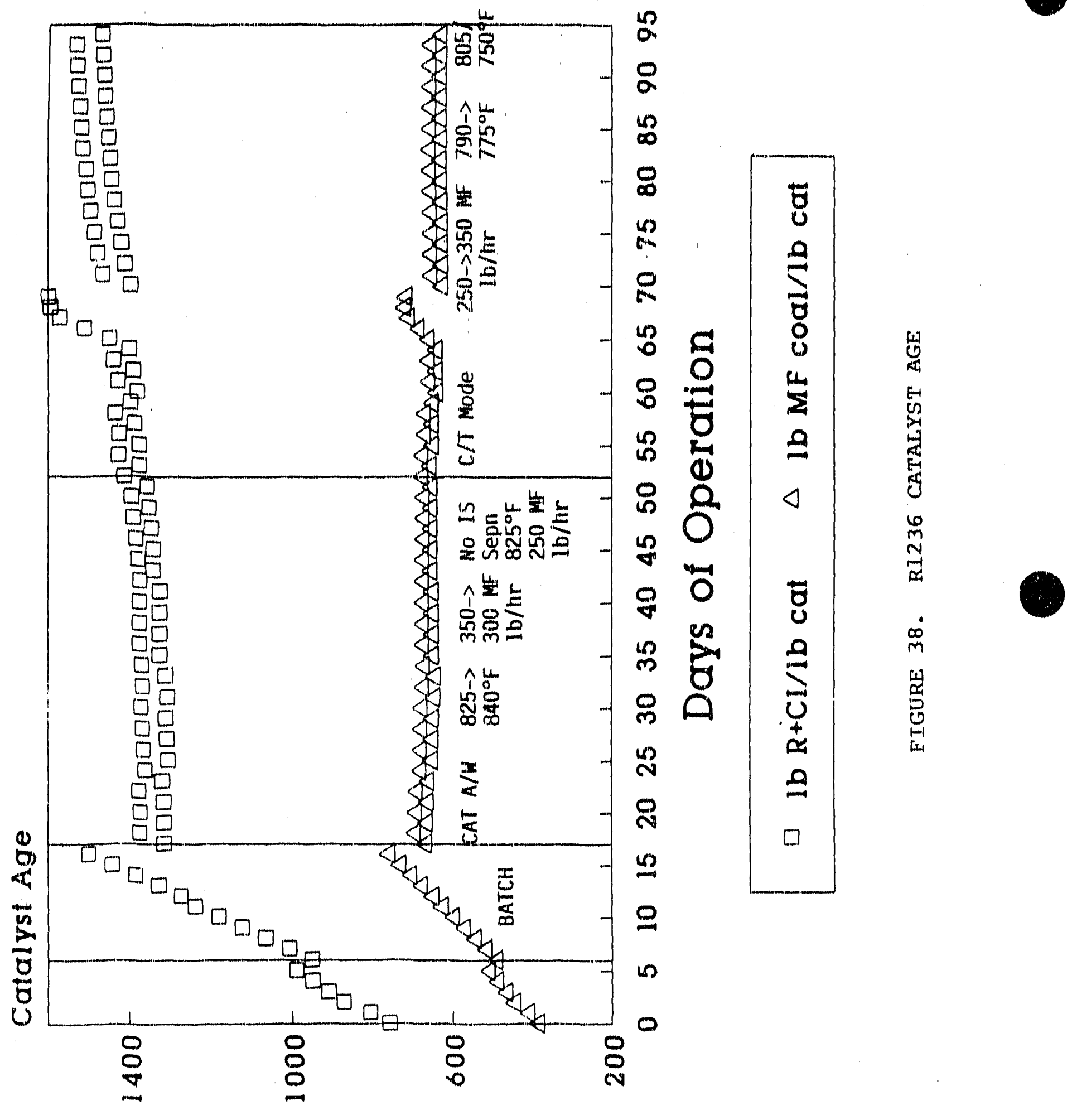


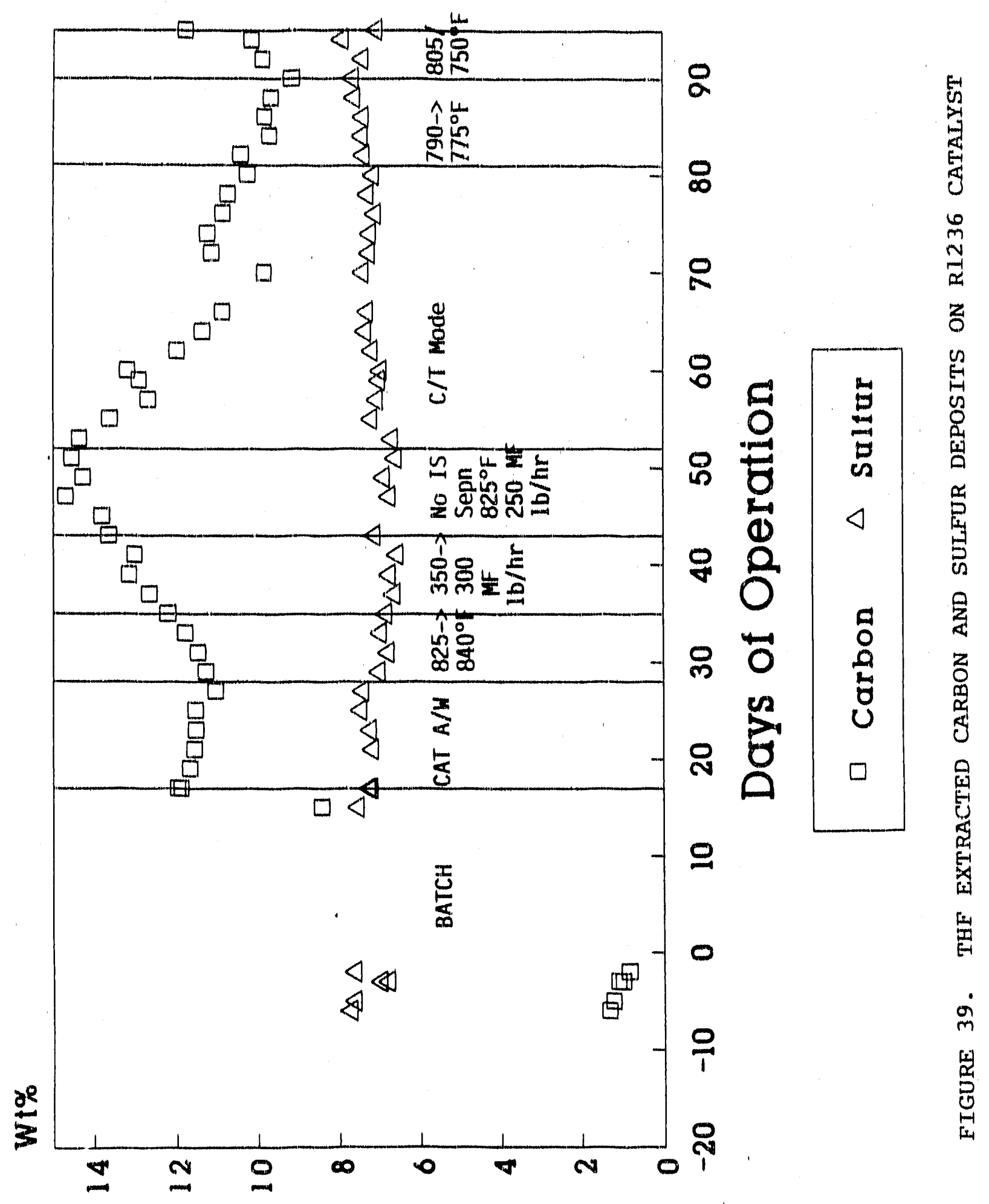




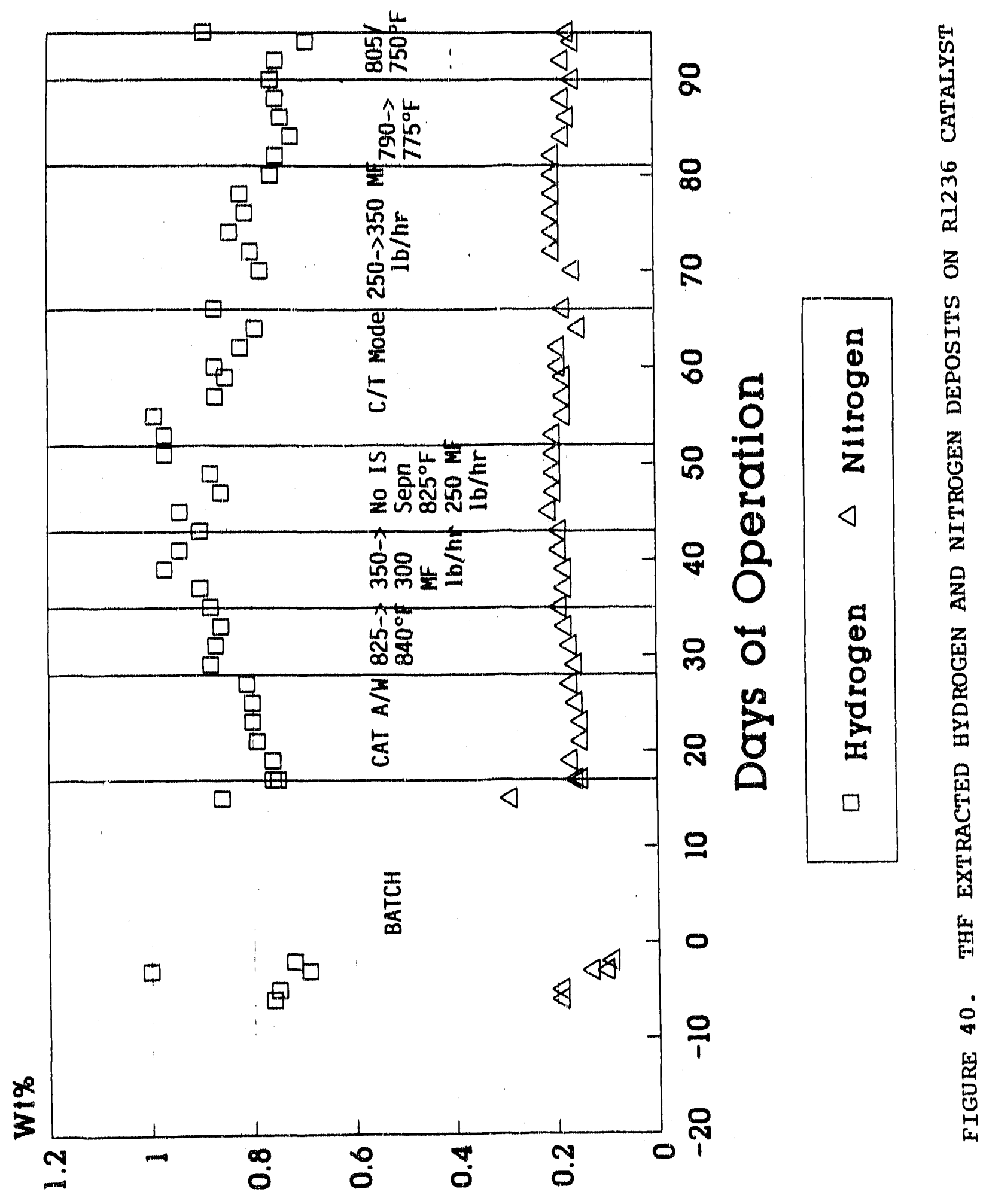




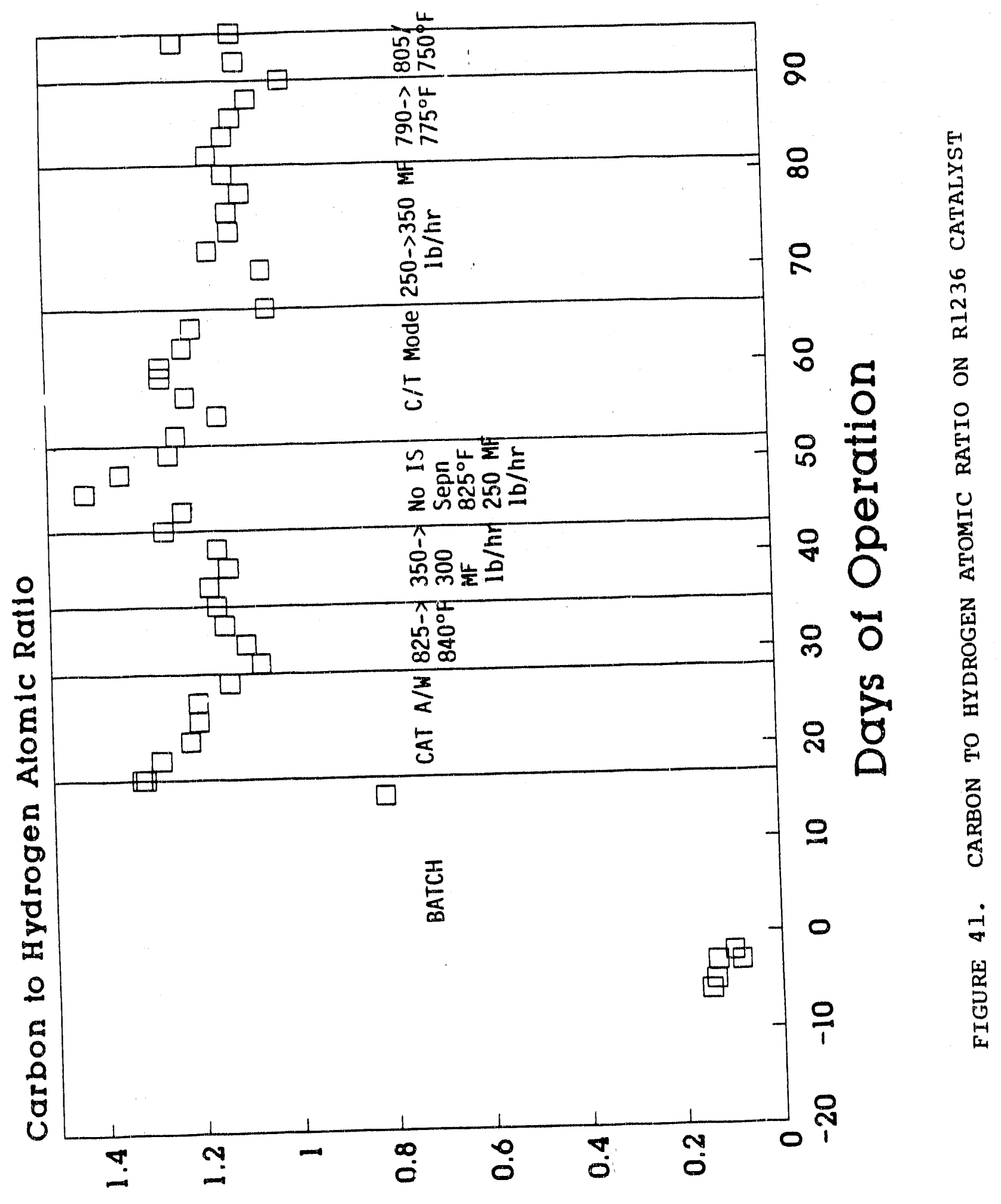




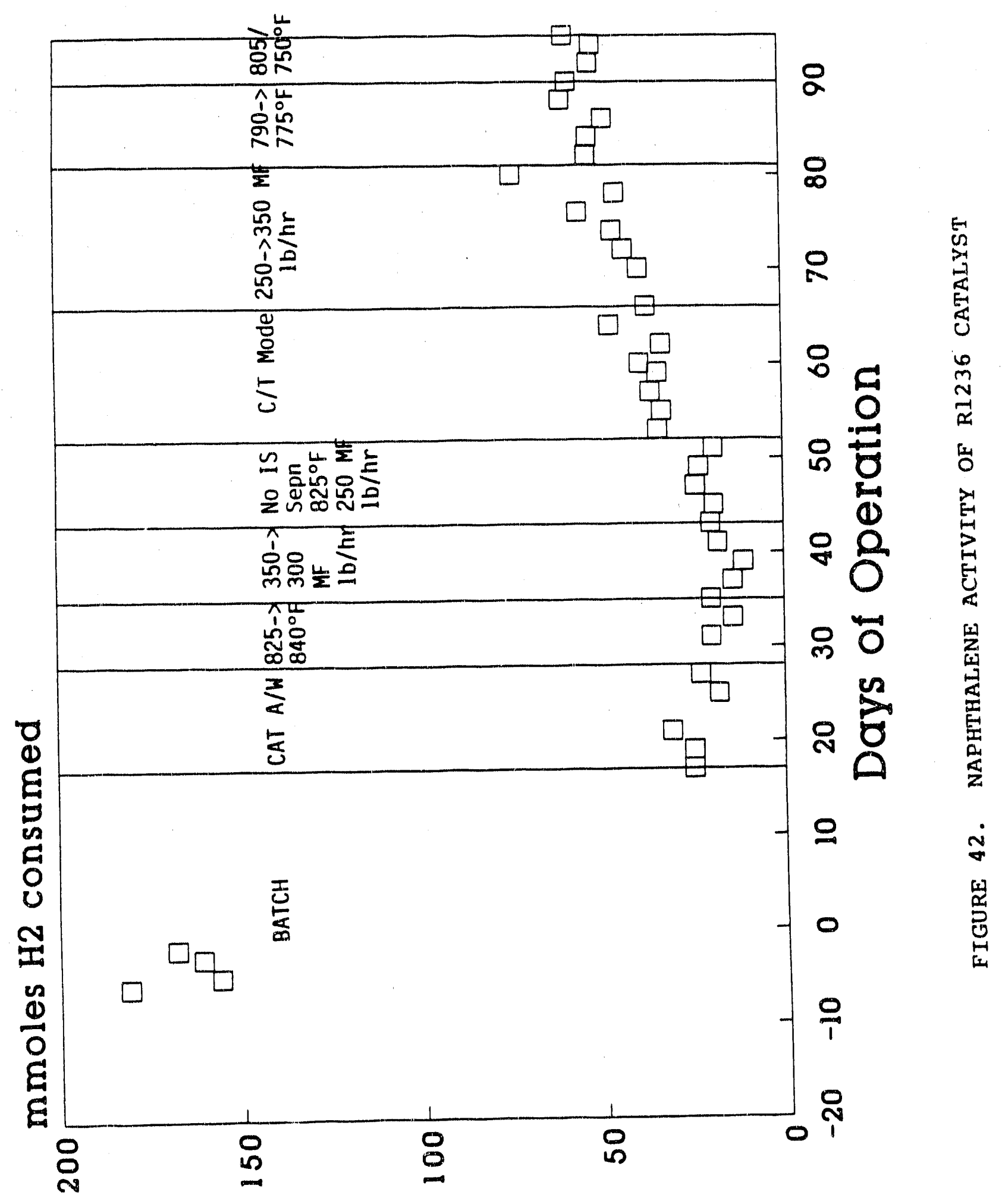




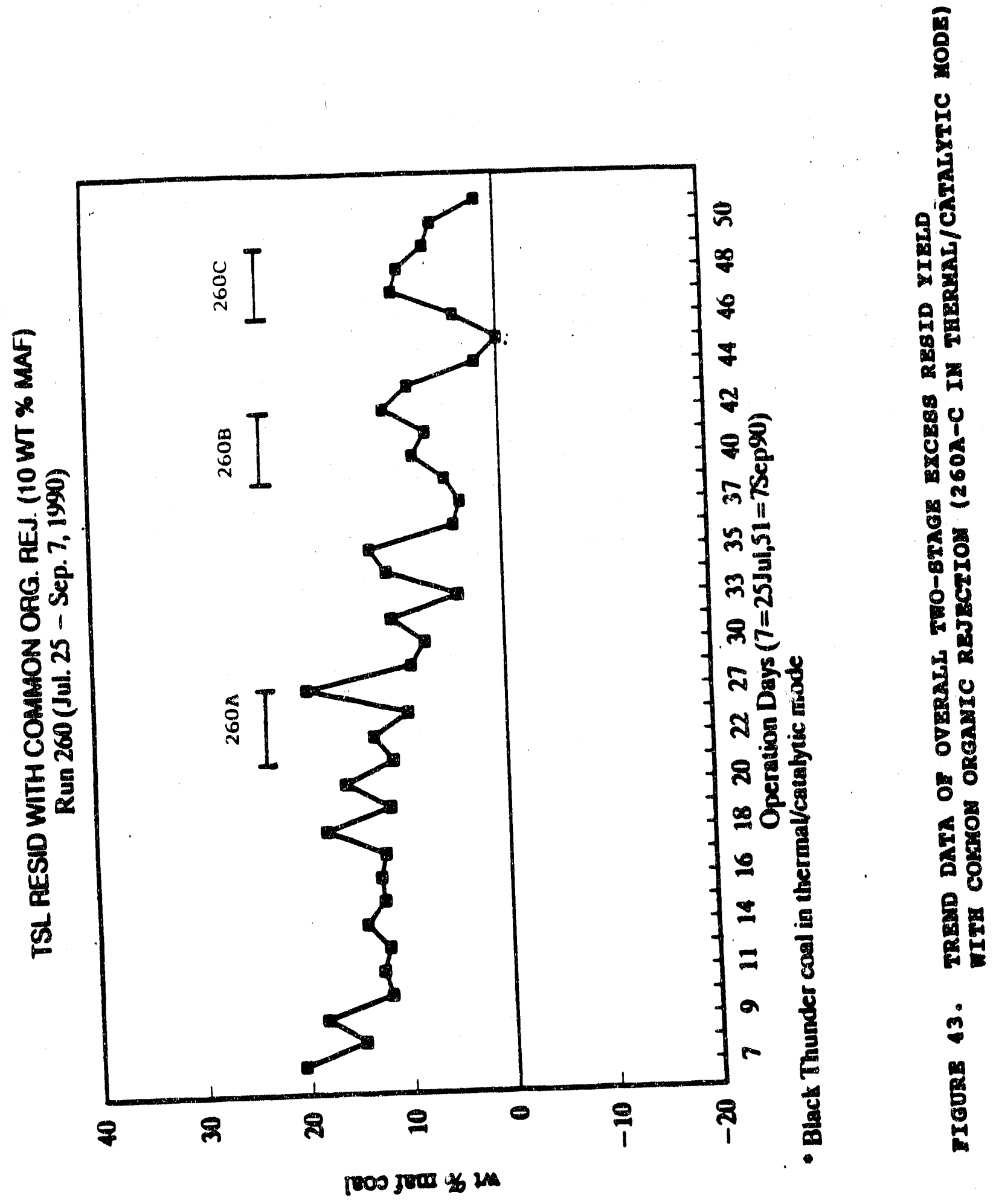




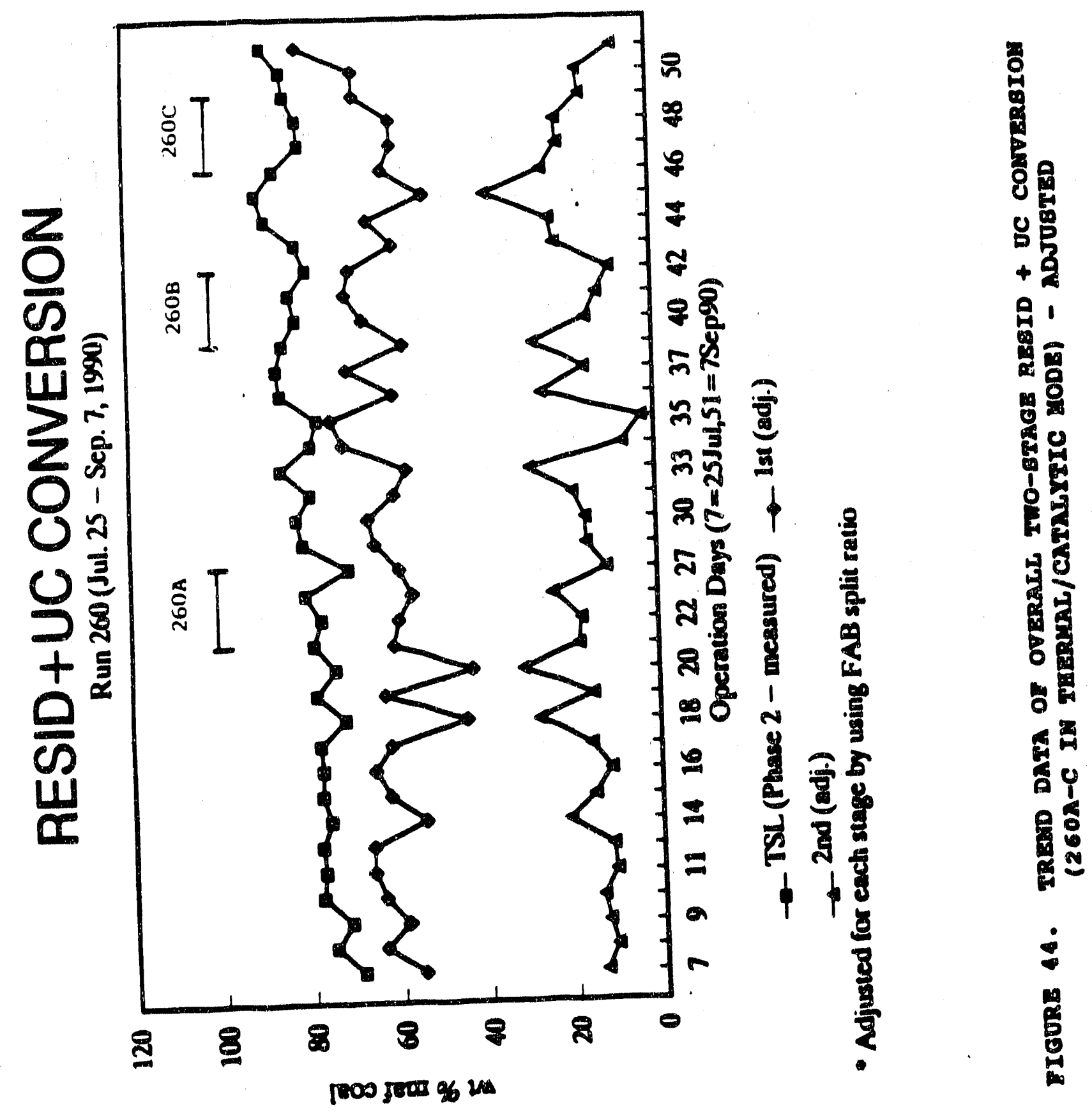




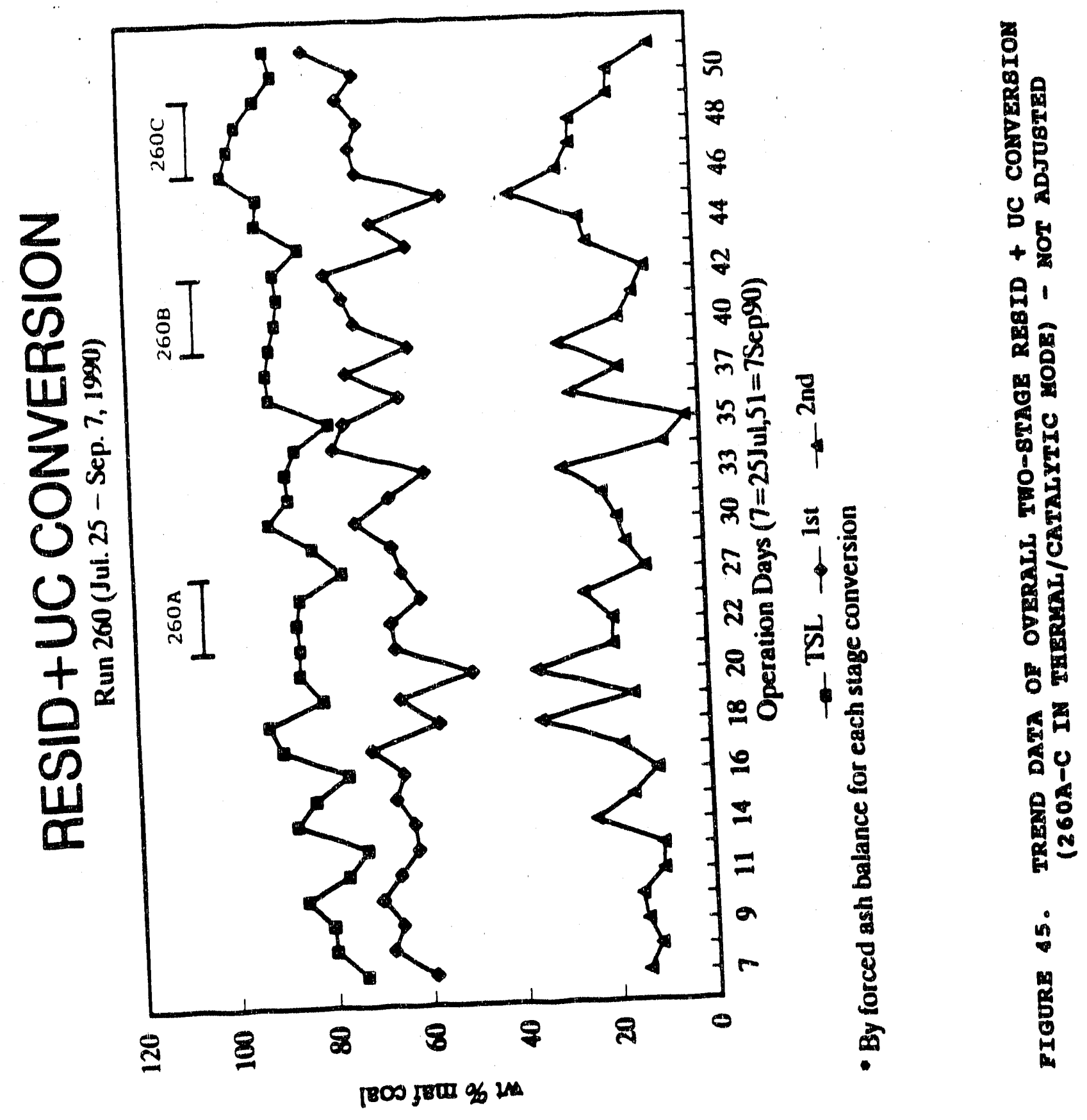




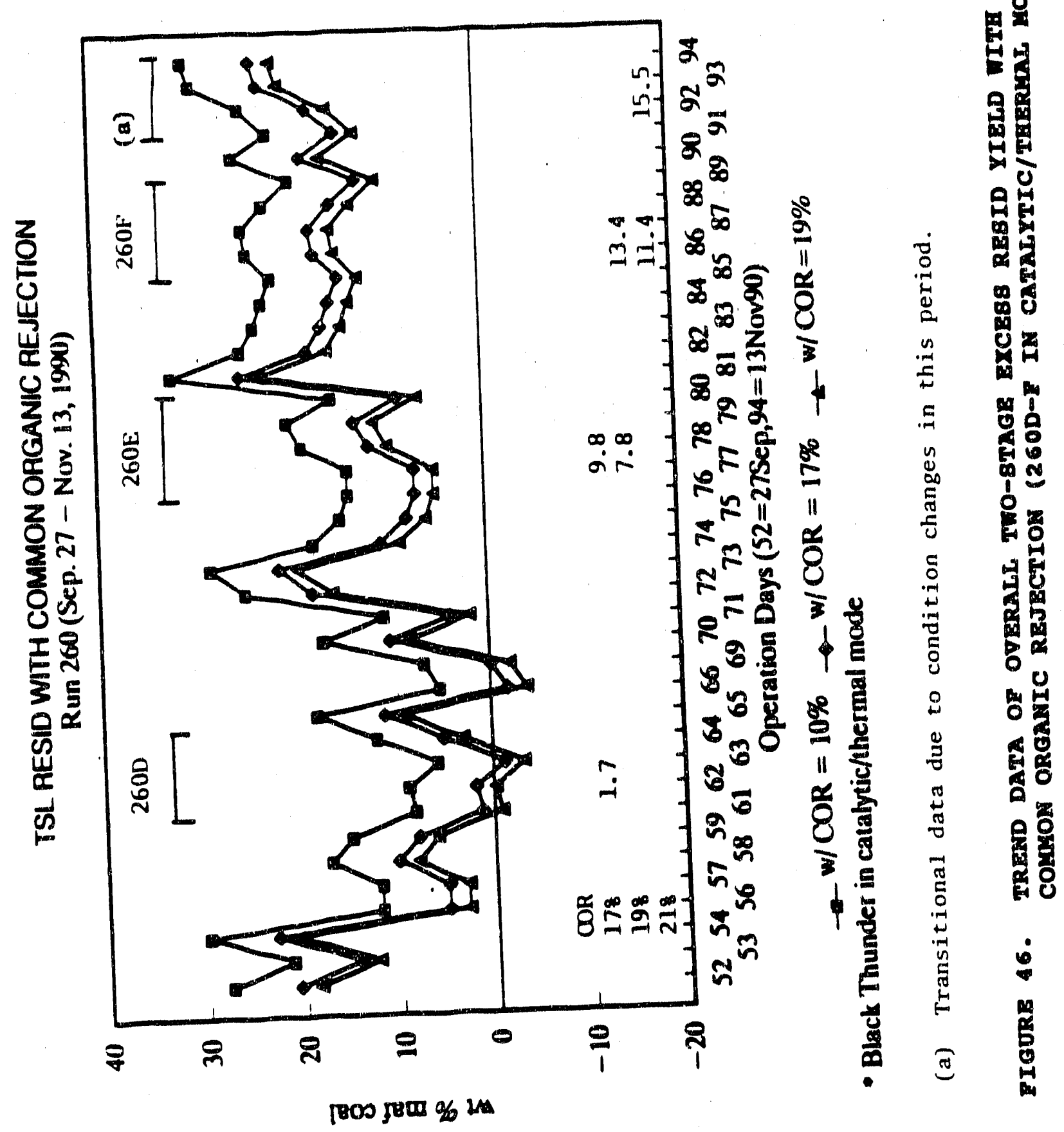

兽

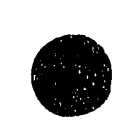




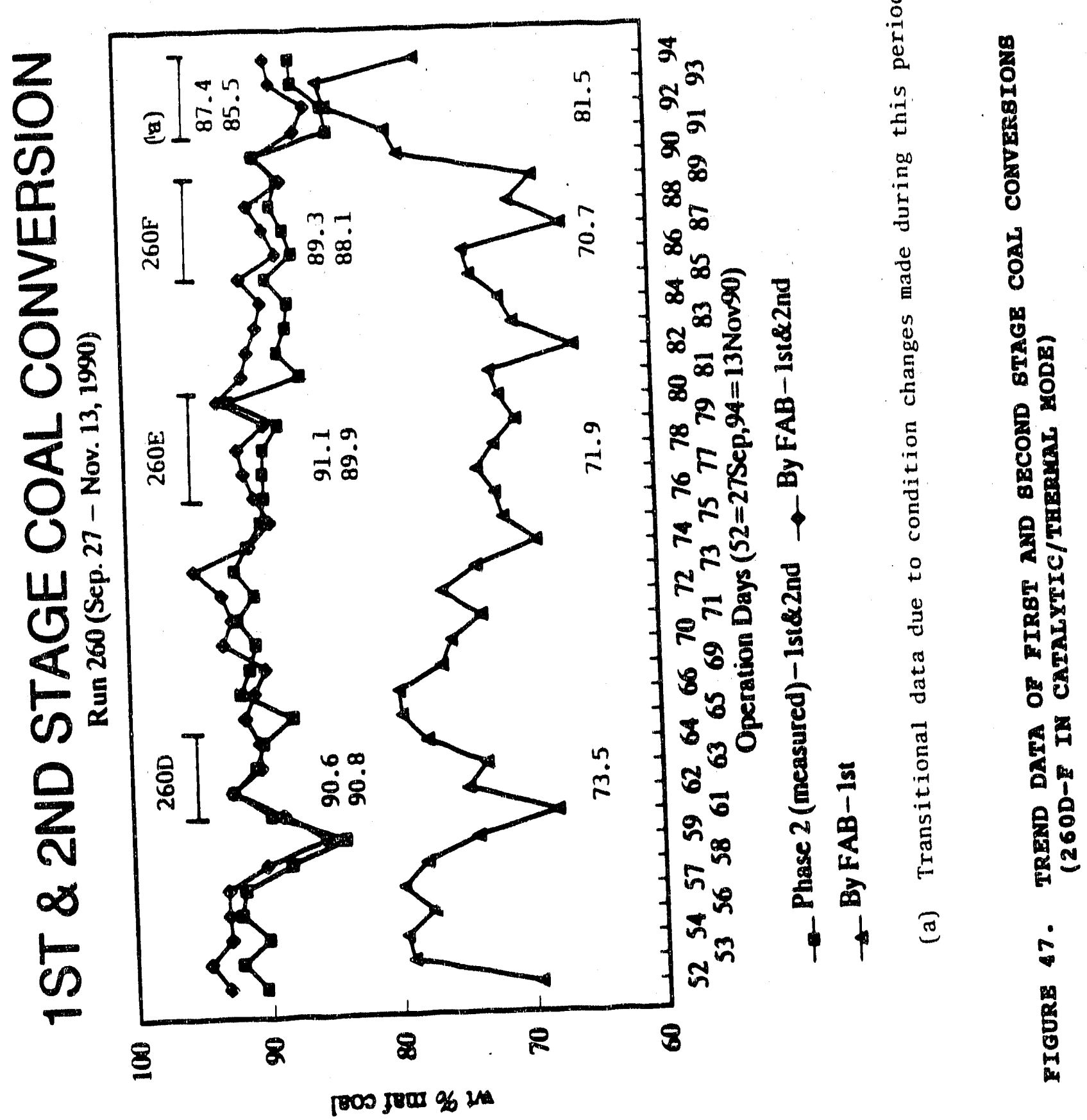




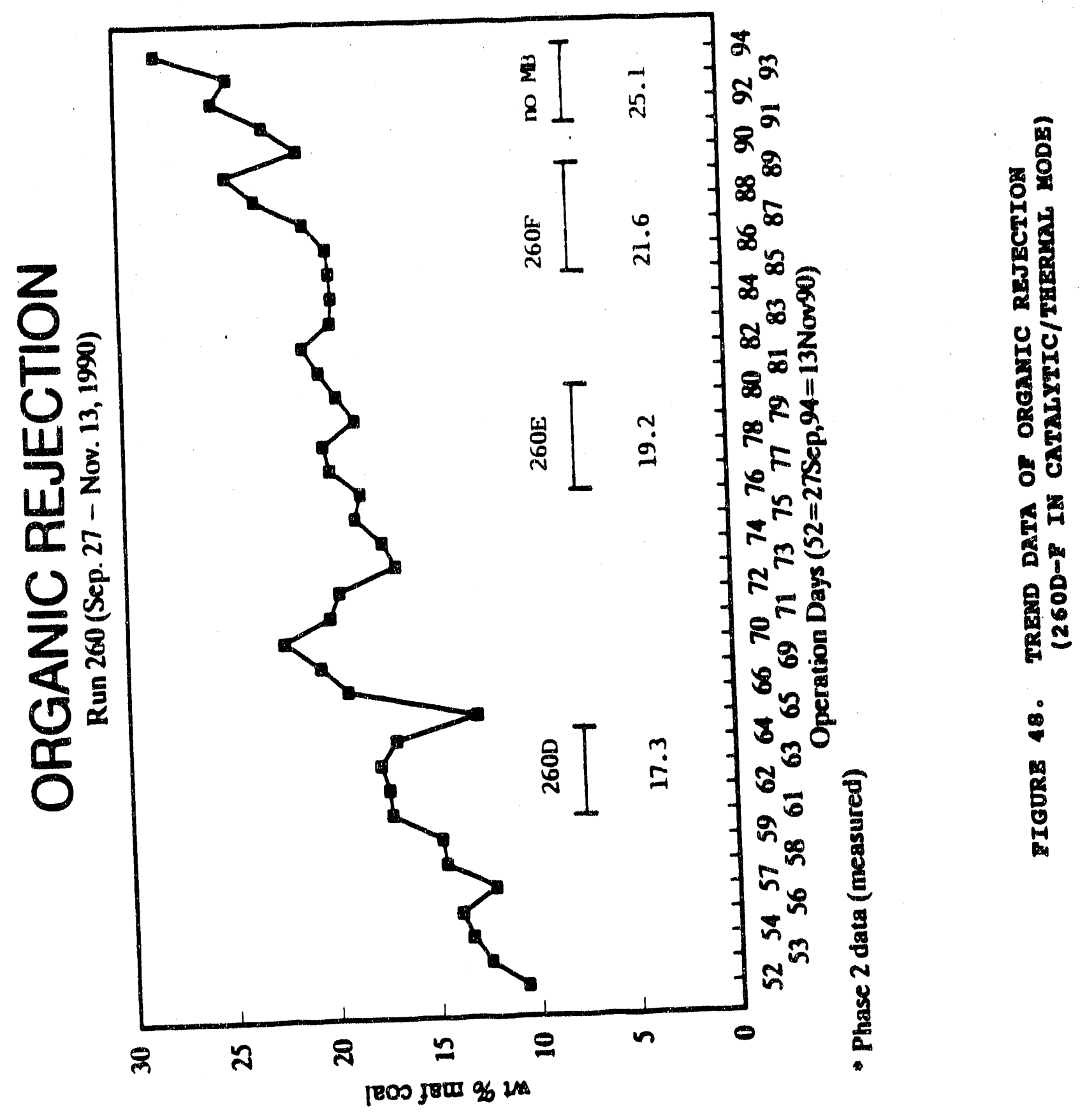




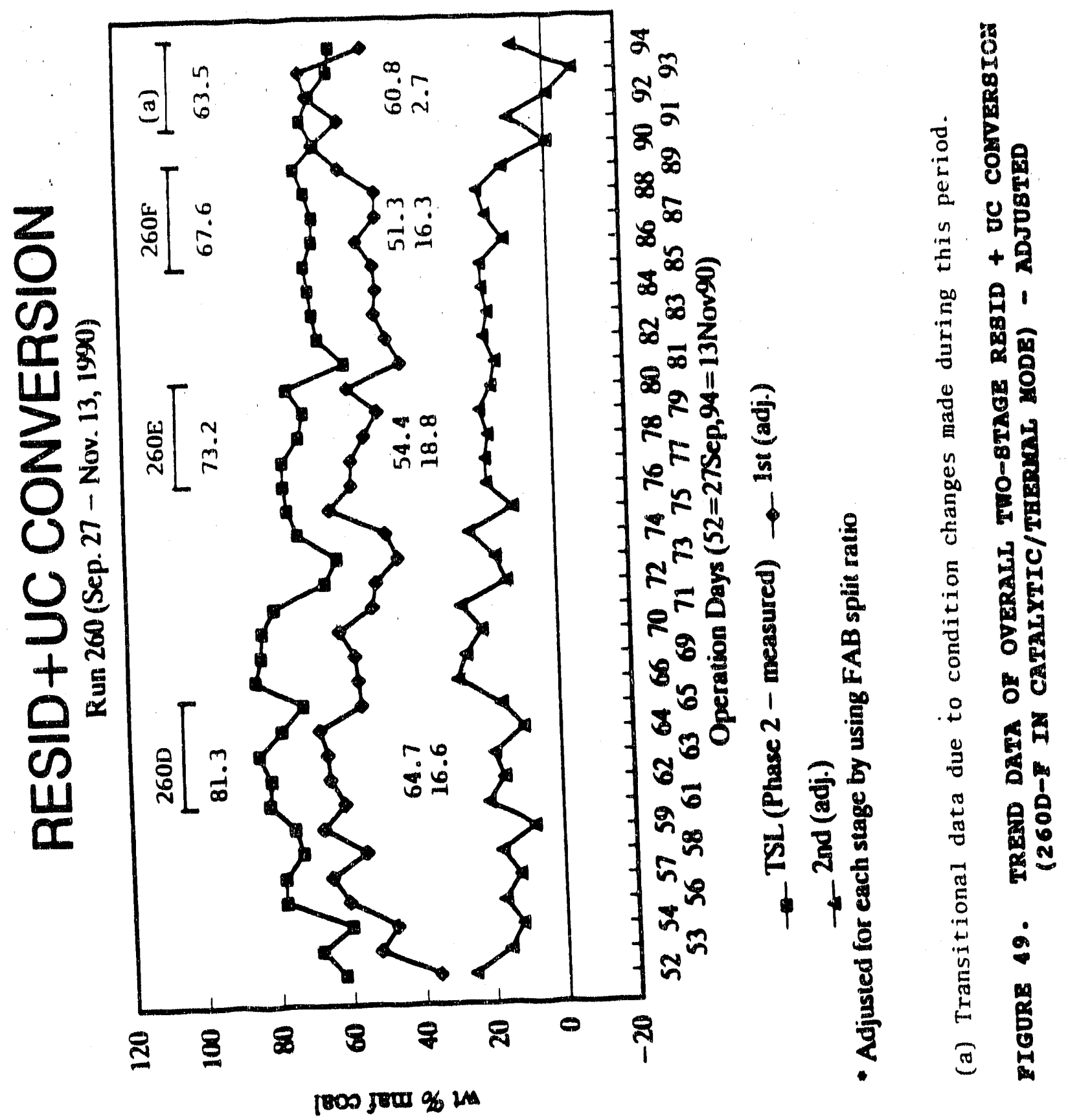




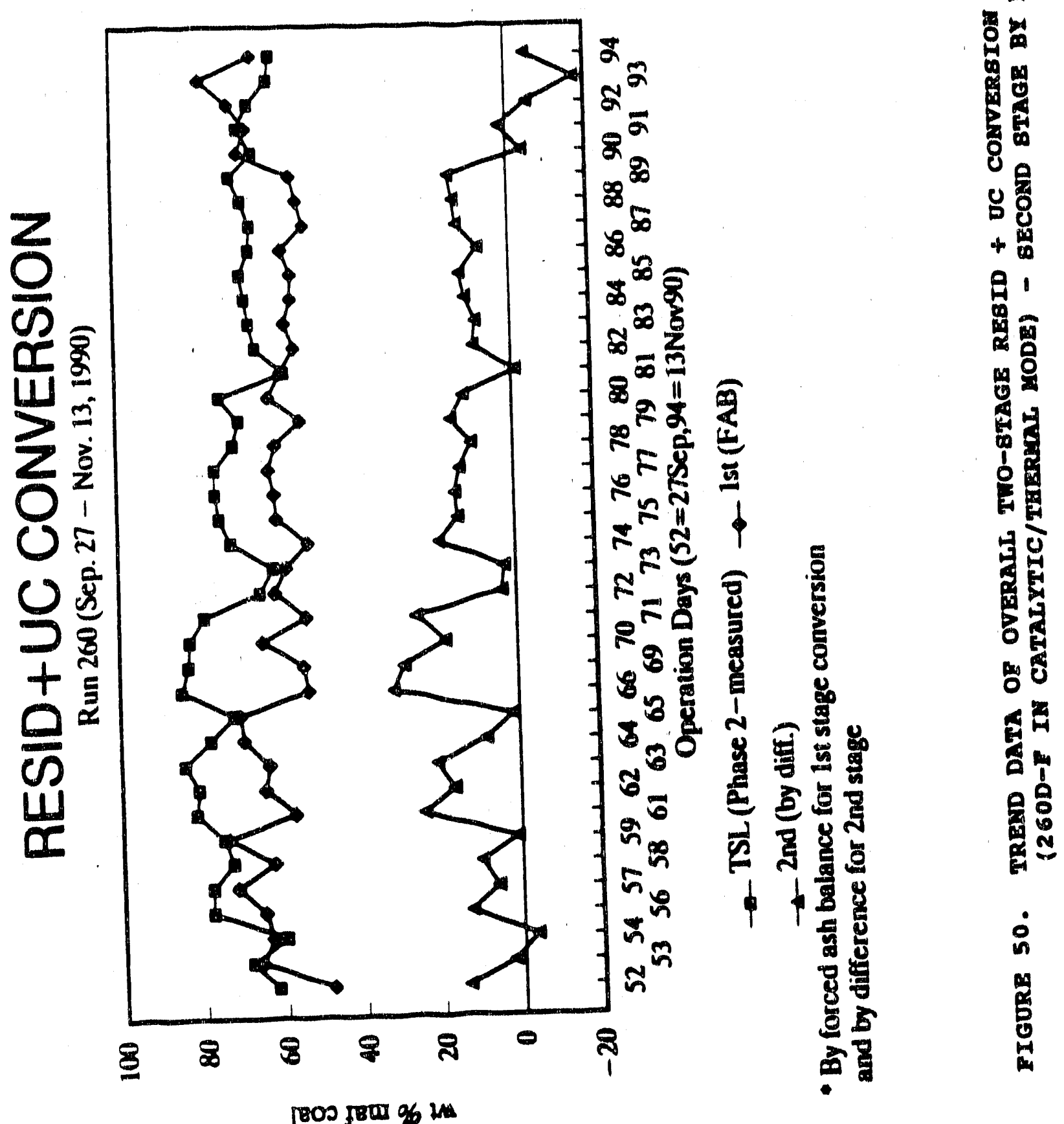

尊

然

政

.

星

$+$

द 1

(1)

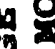

要

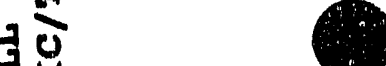

品

[800 58W \% 


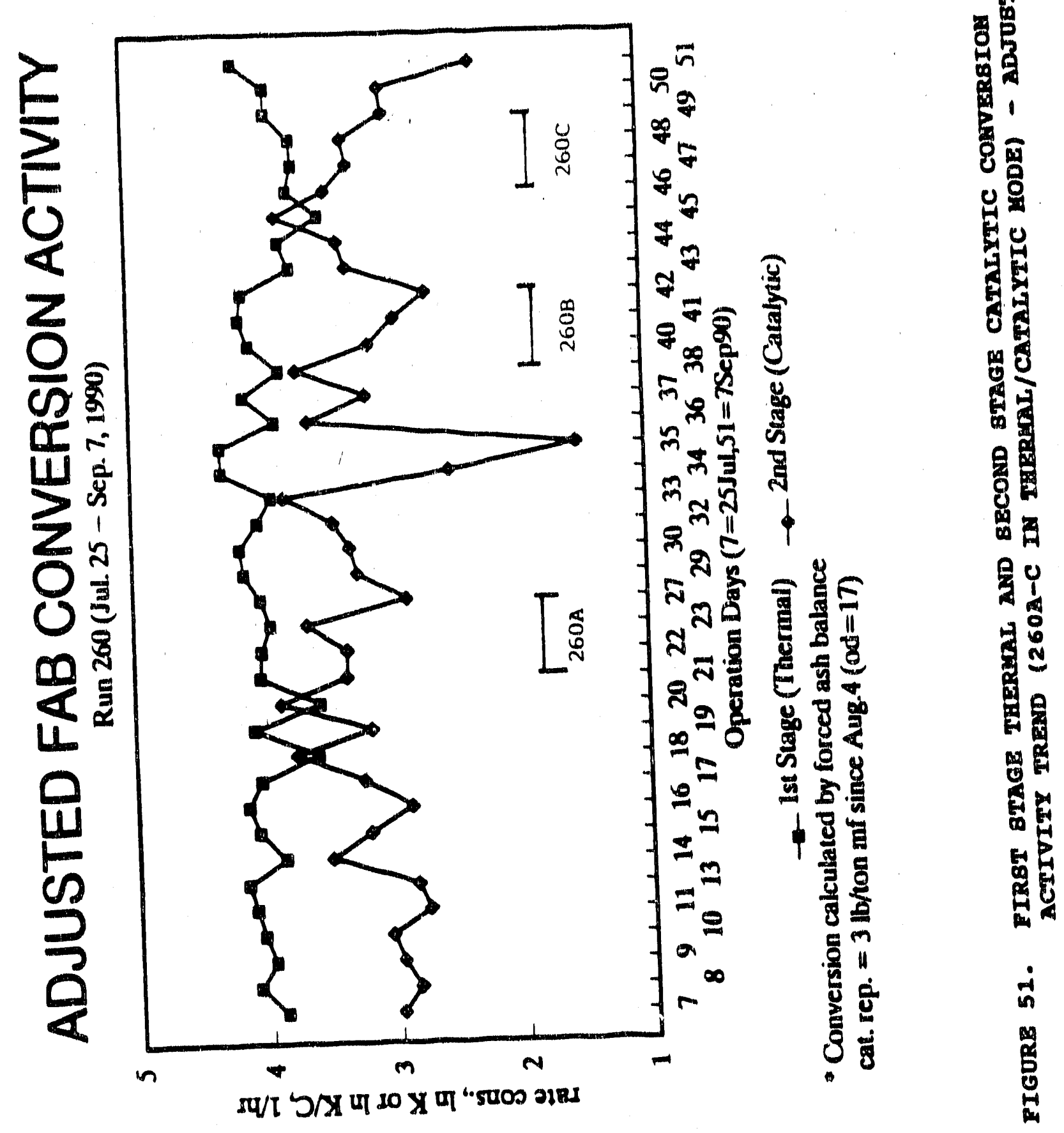




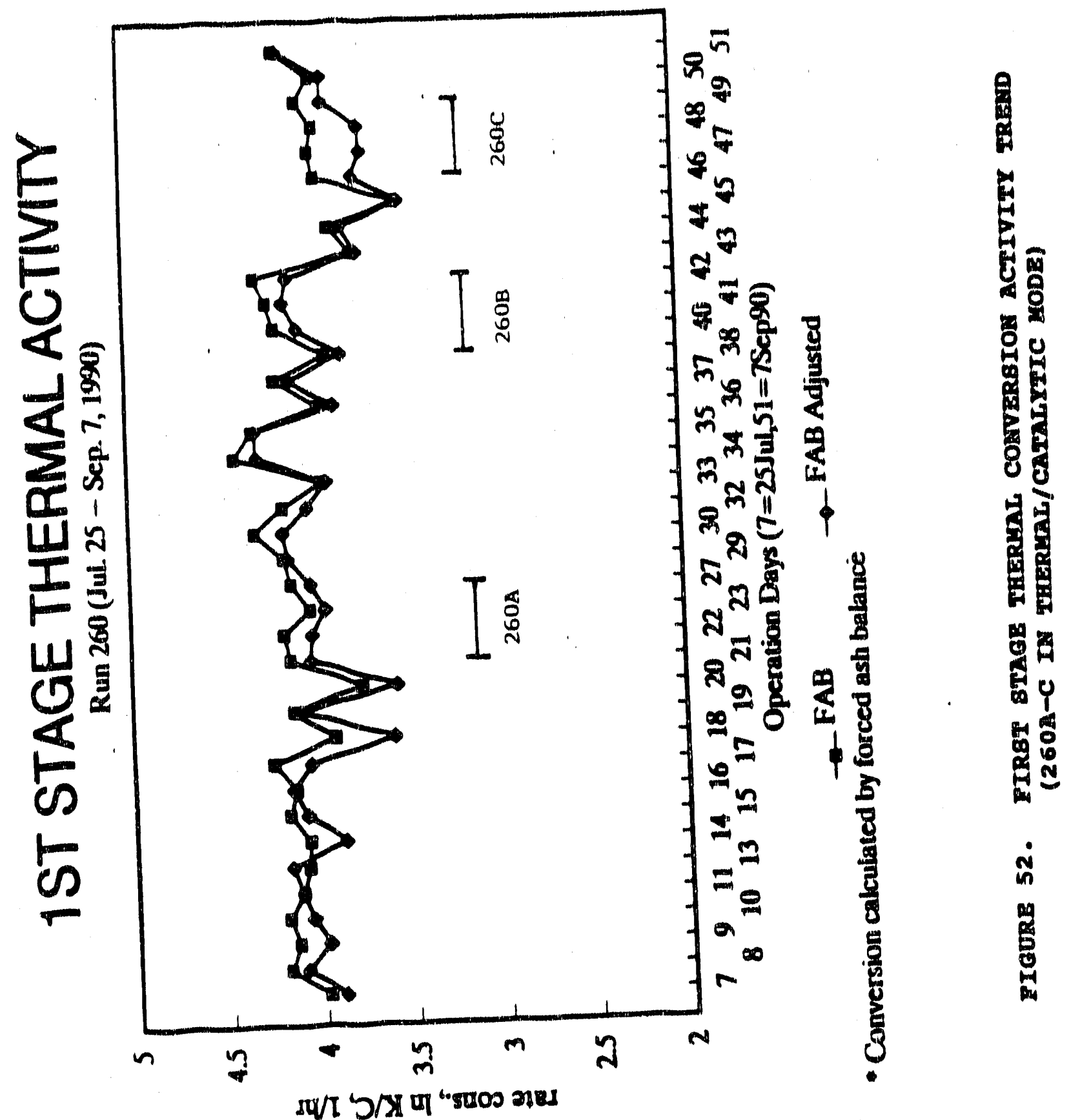




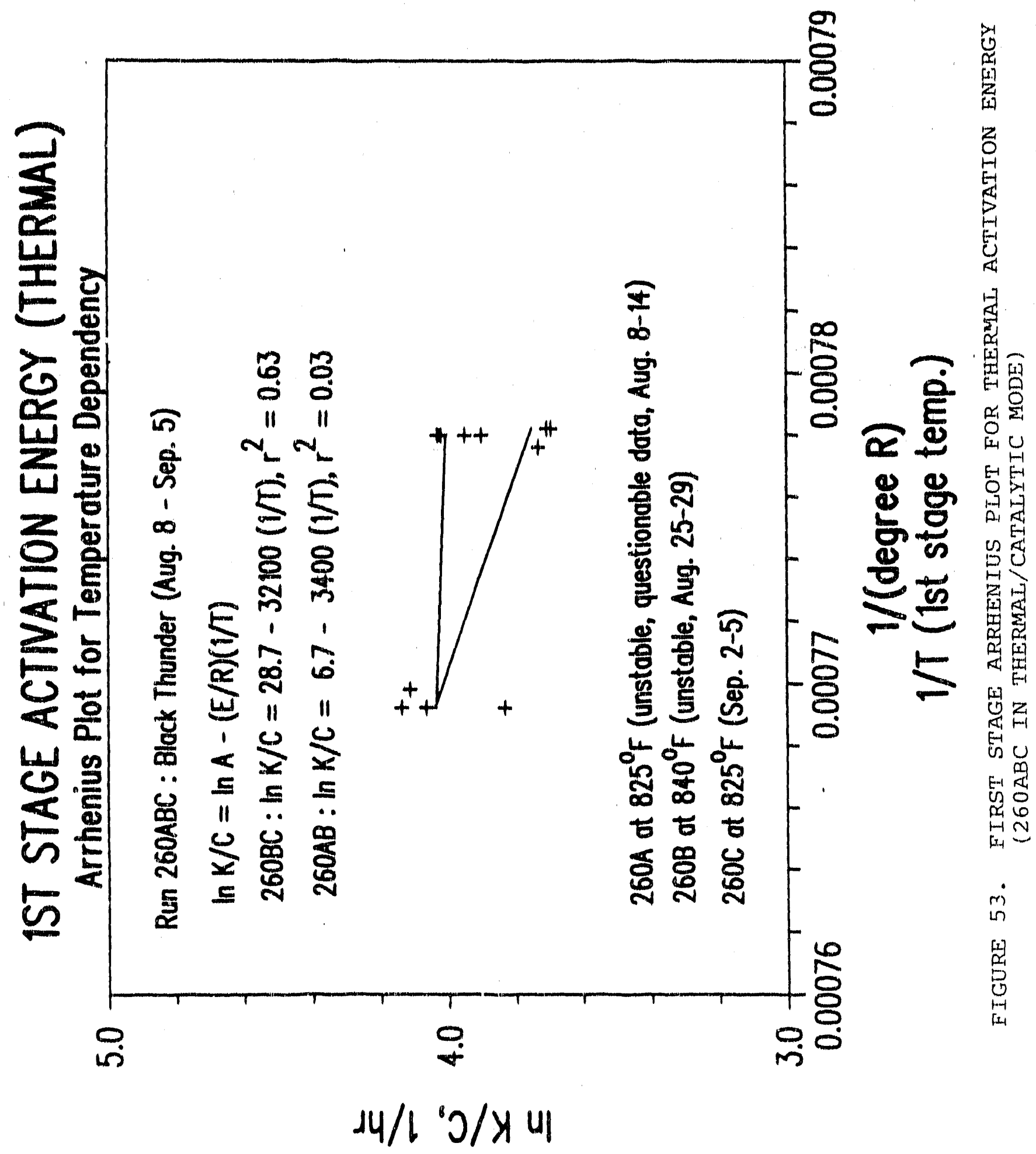




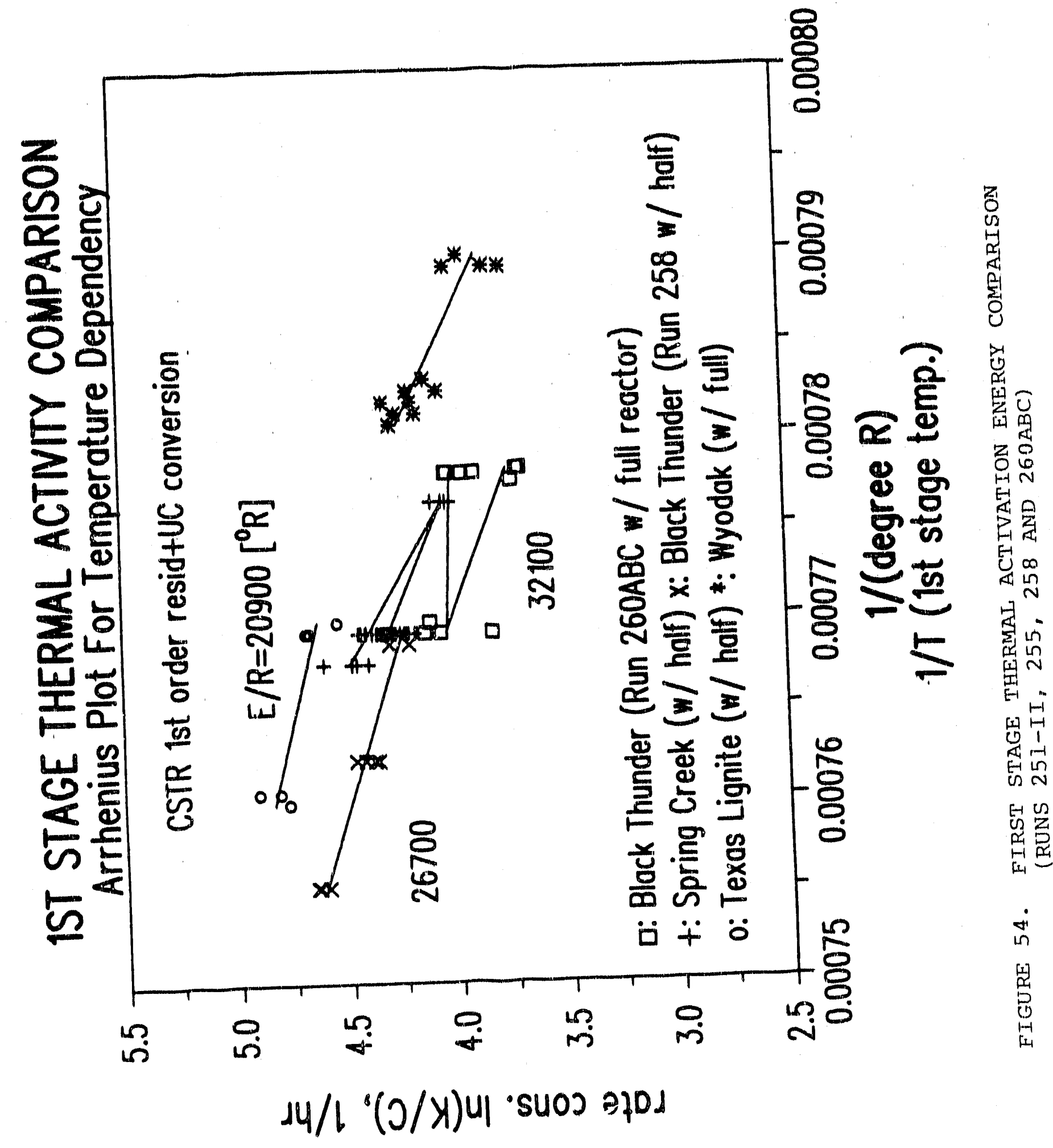




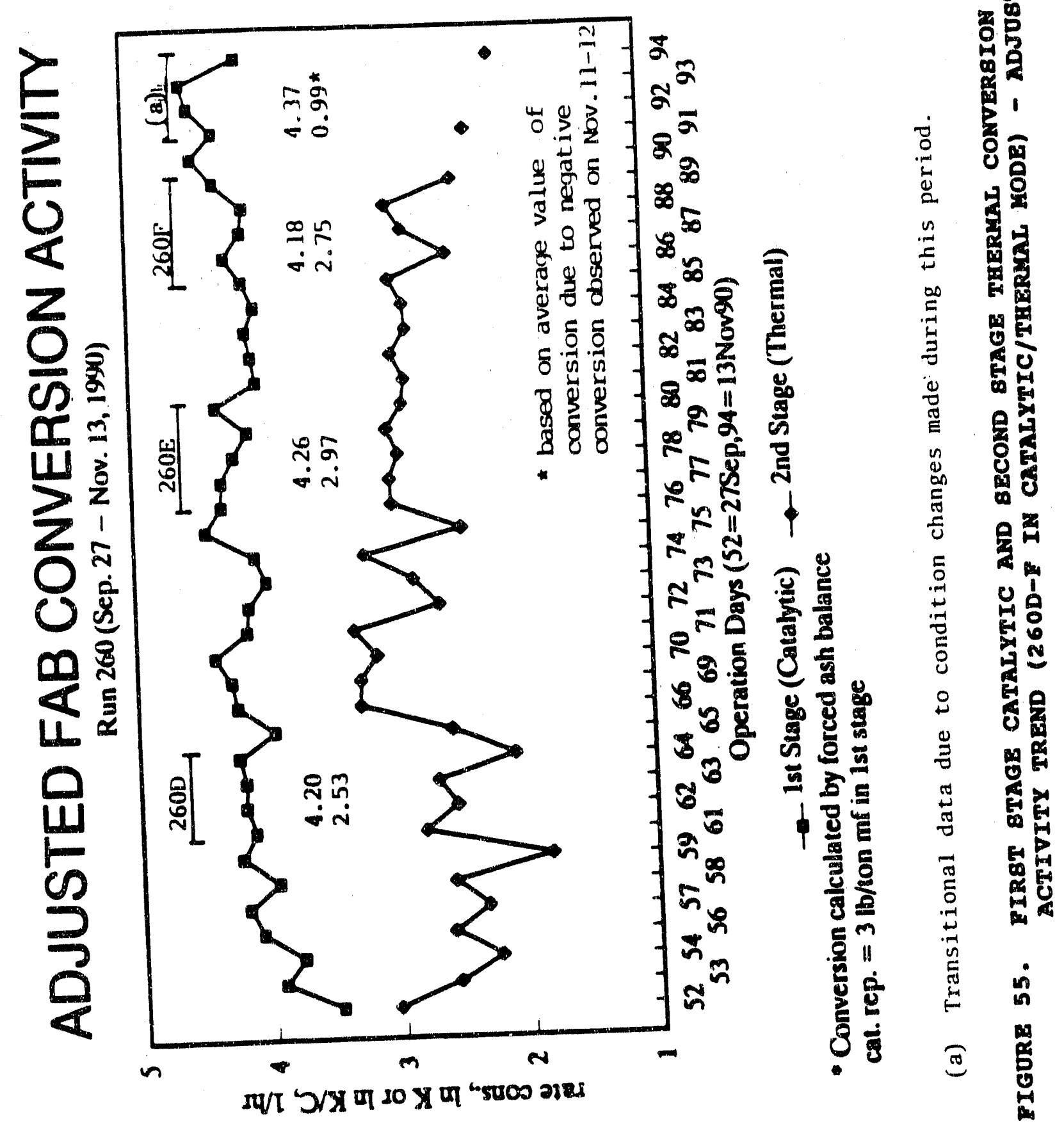




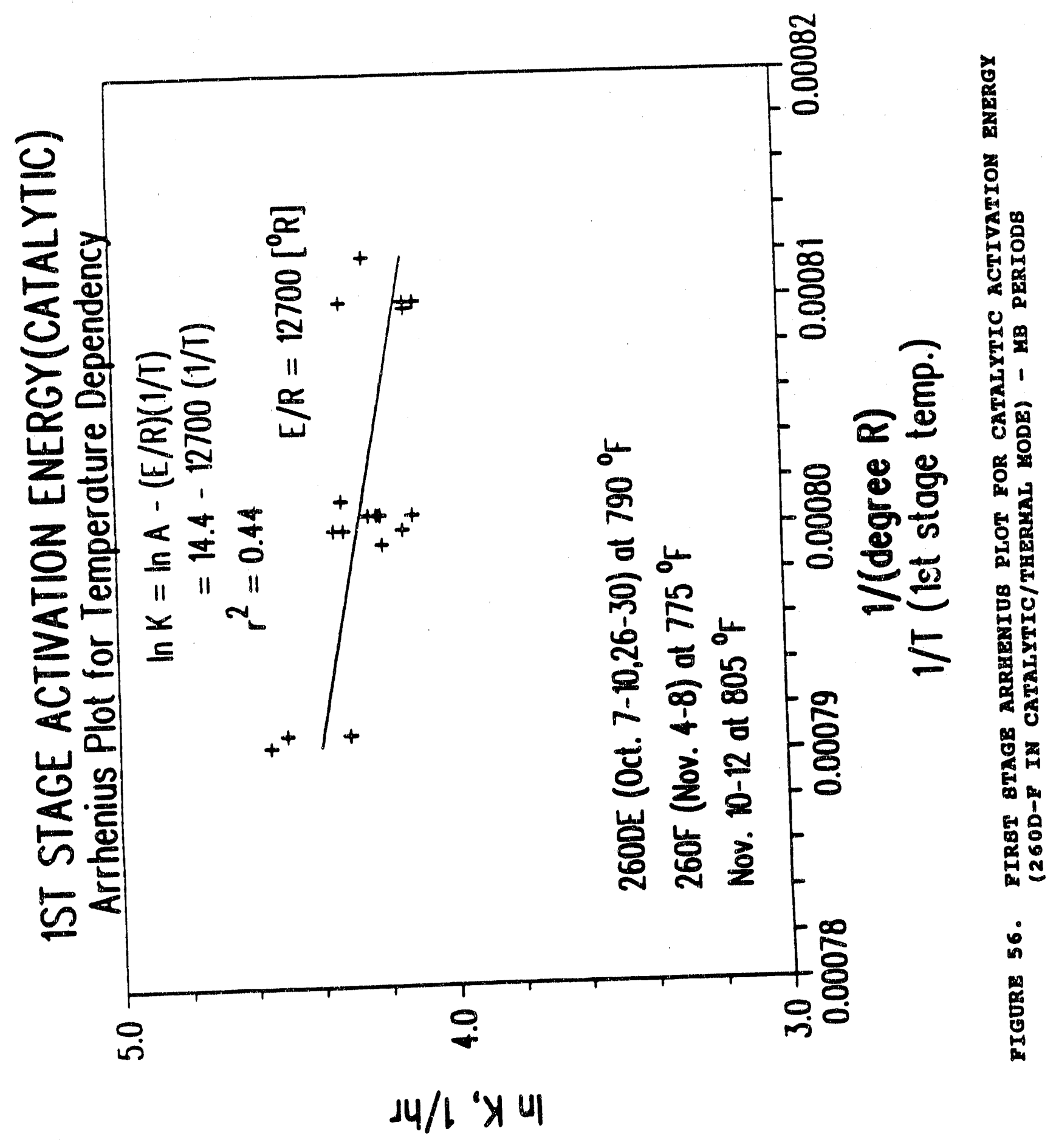




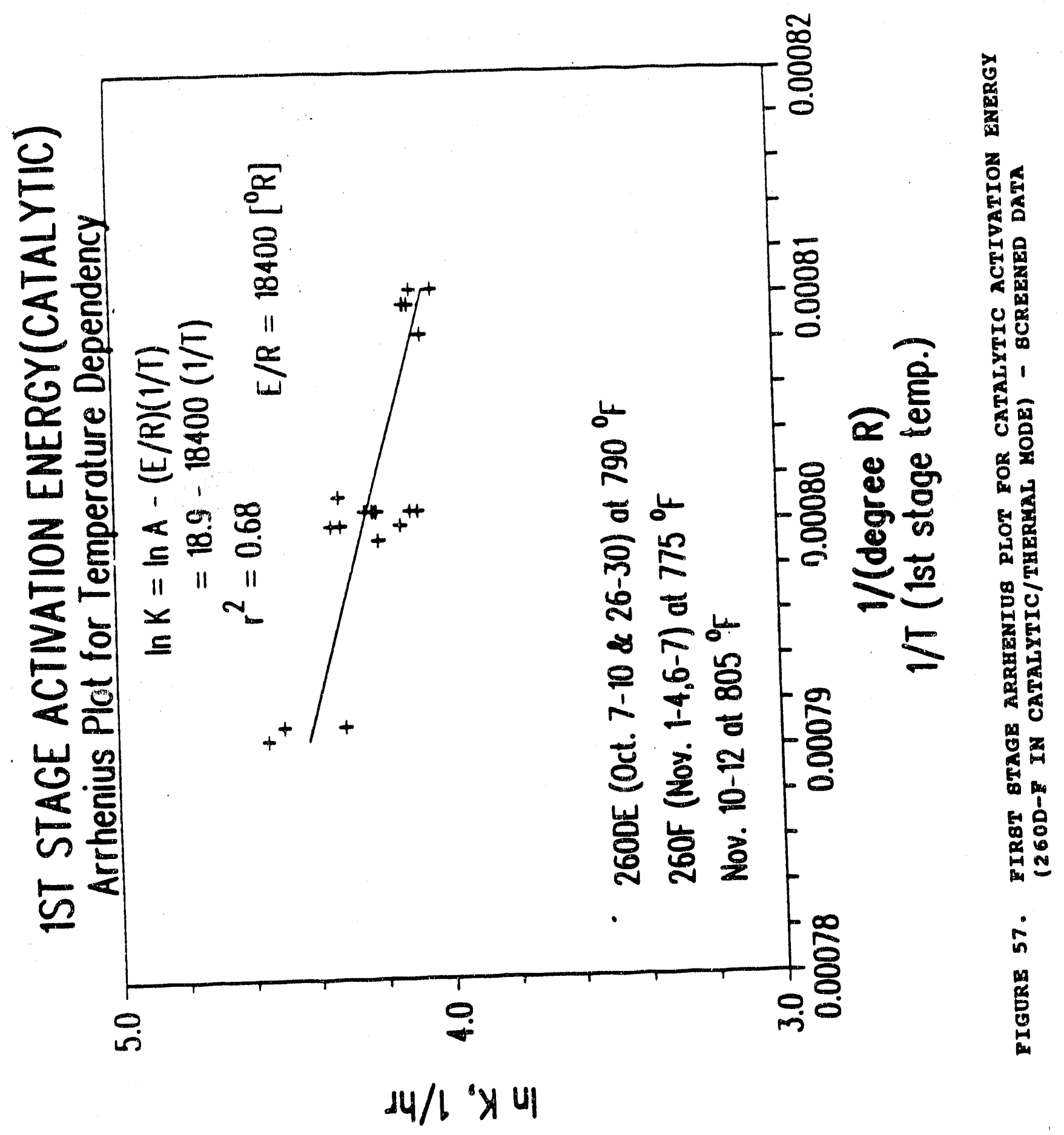




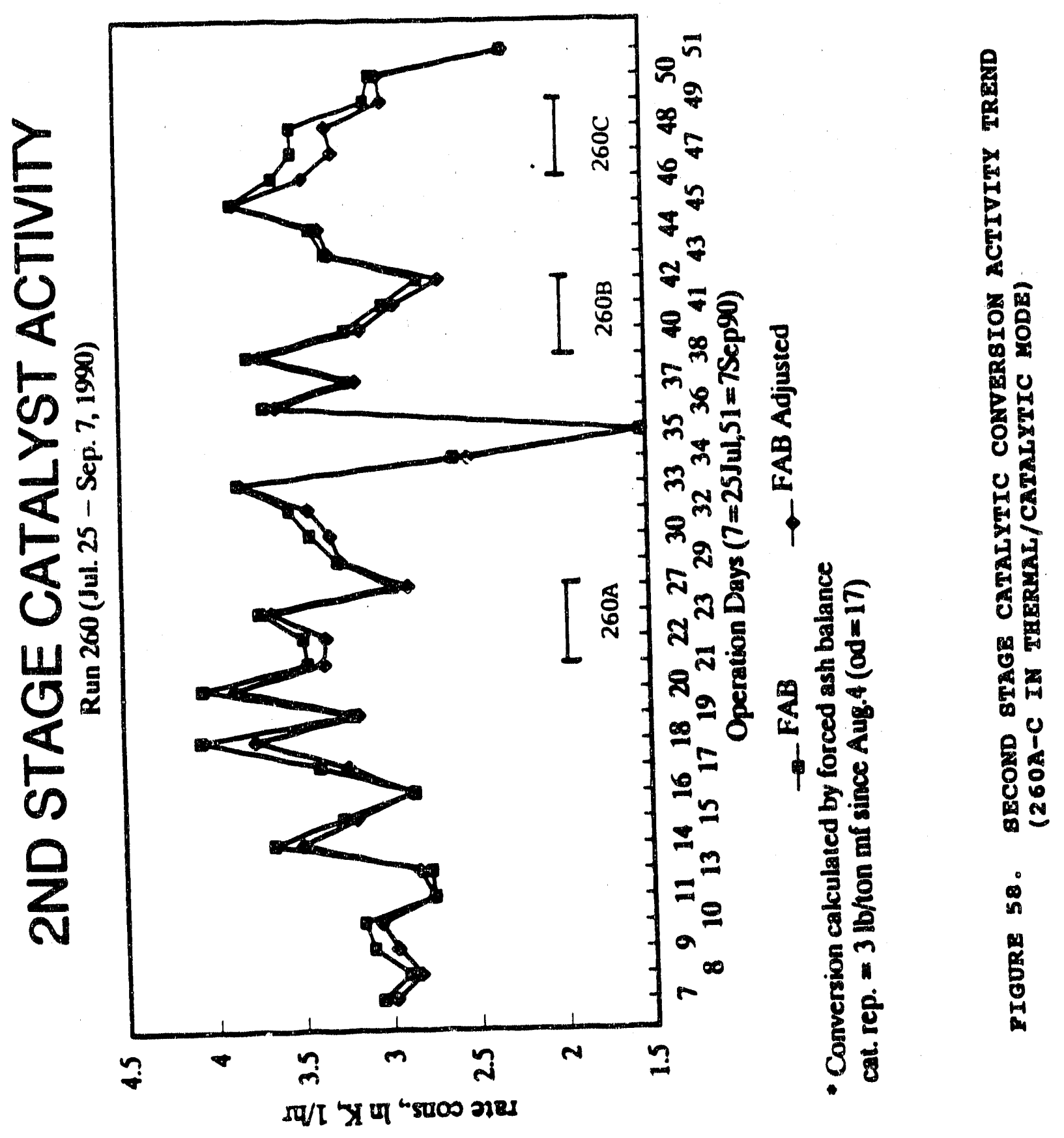




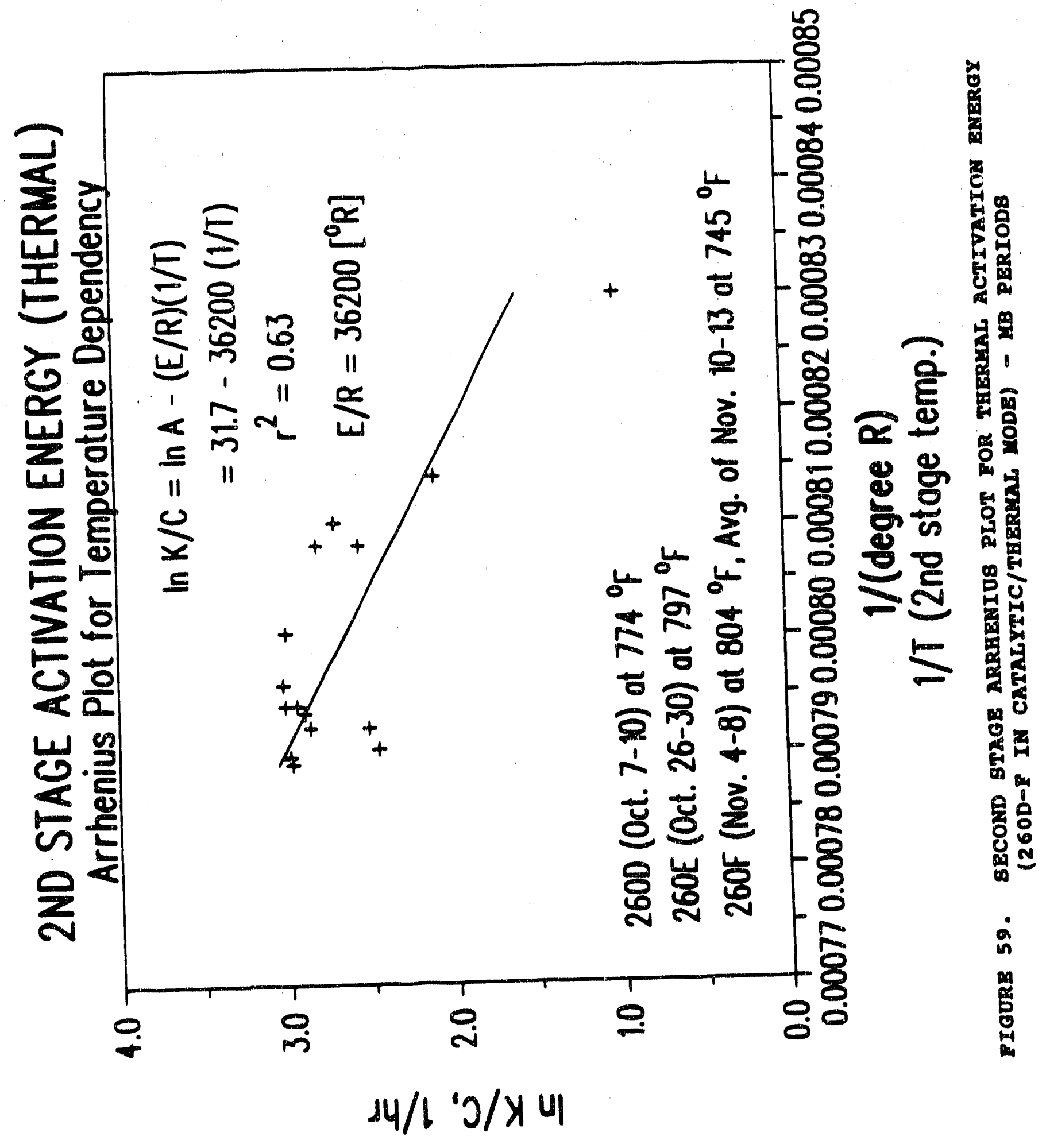




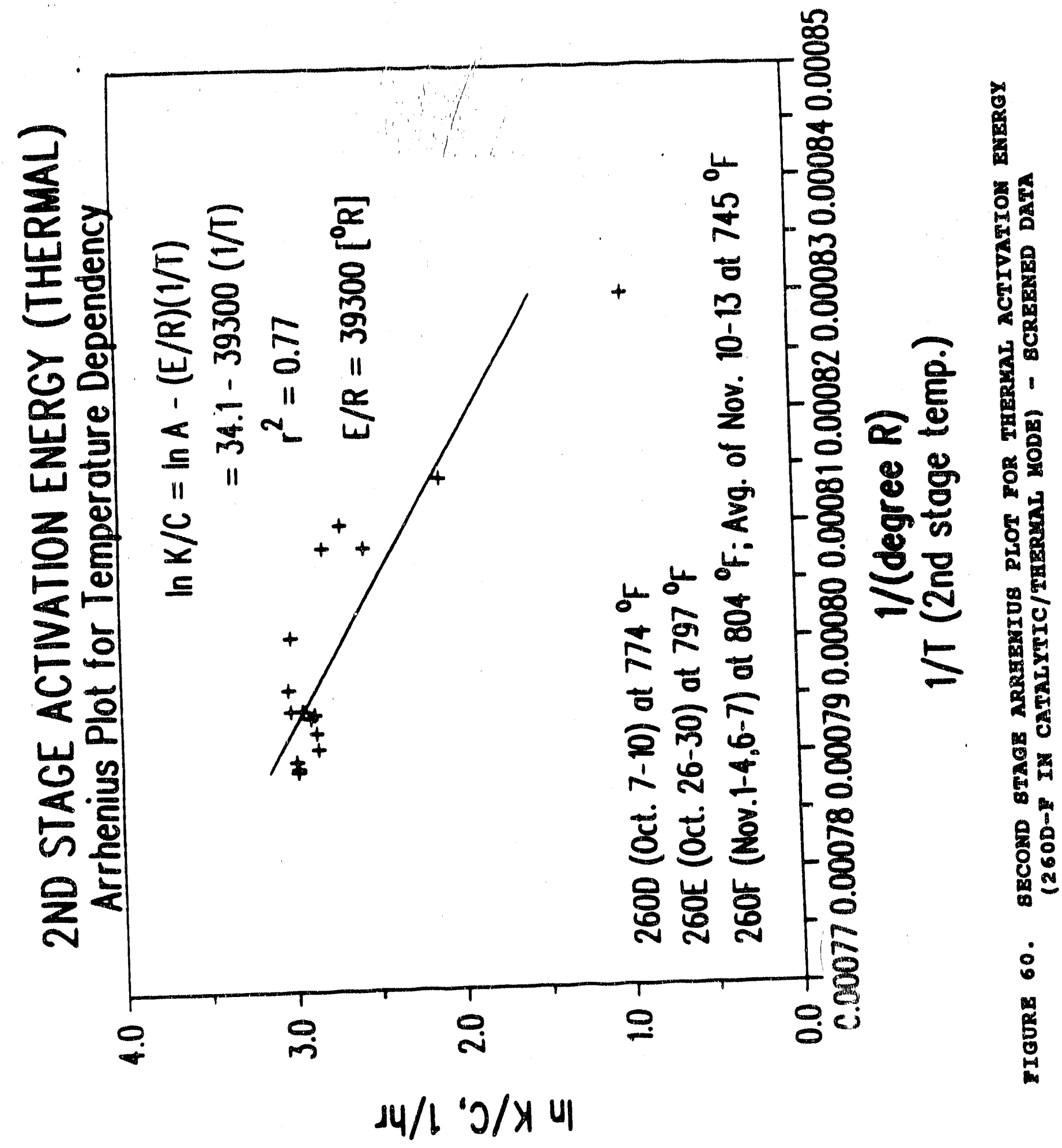




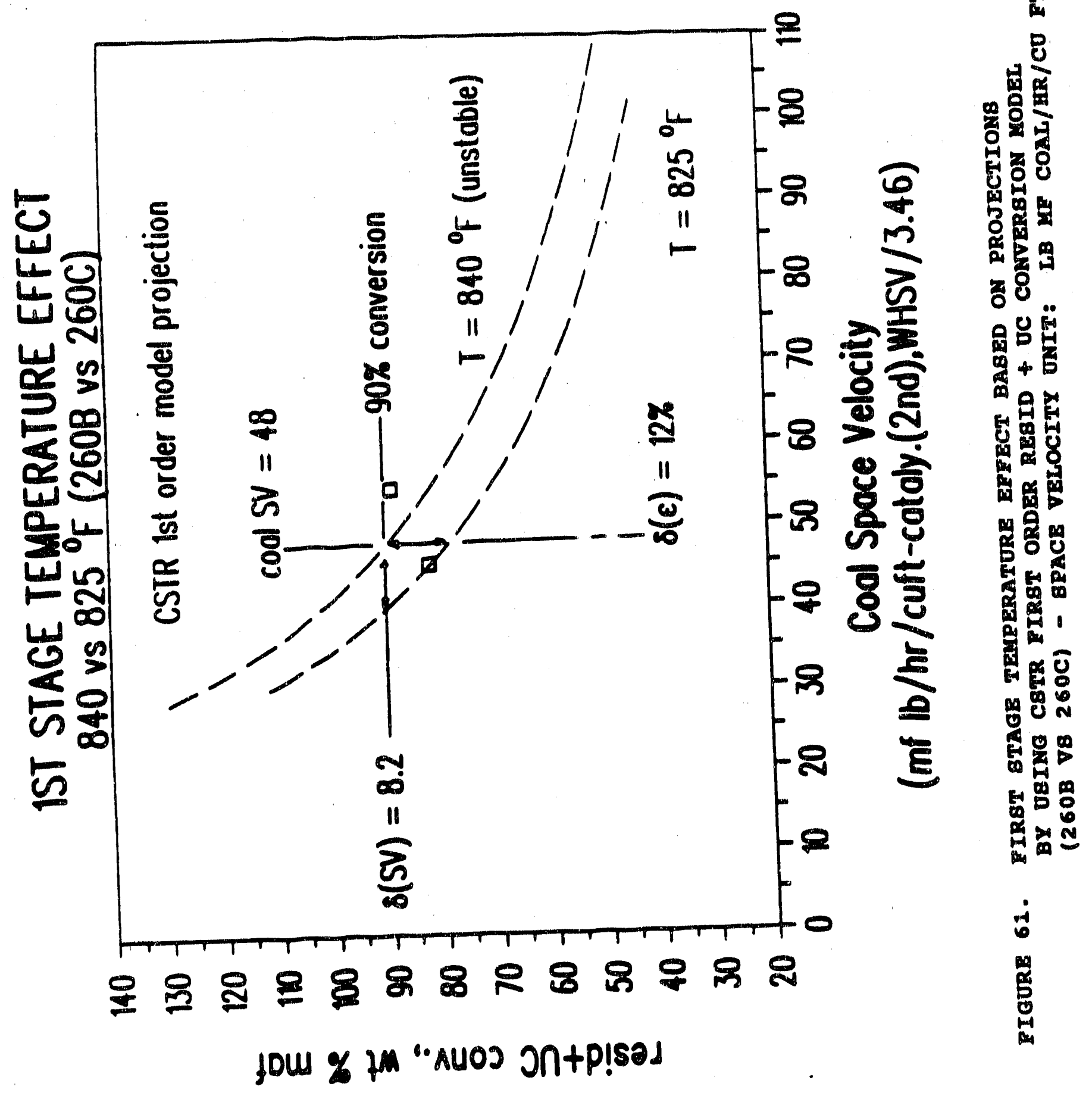




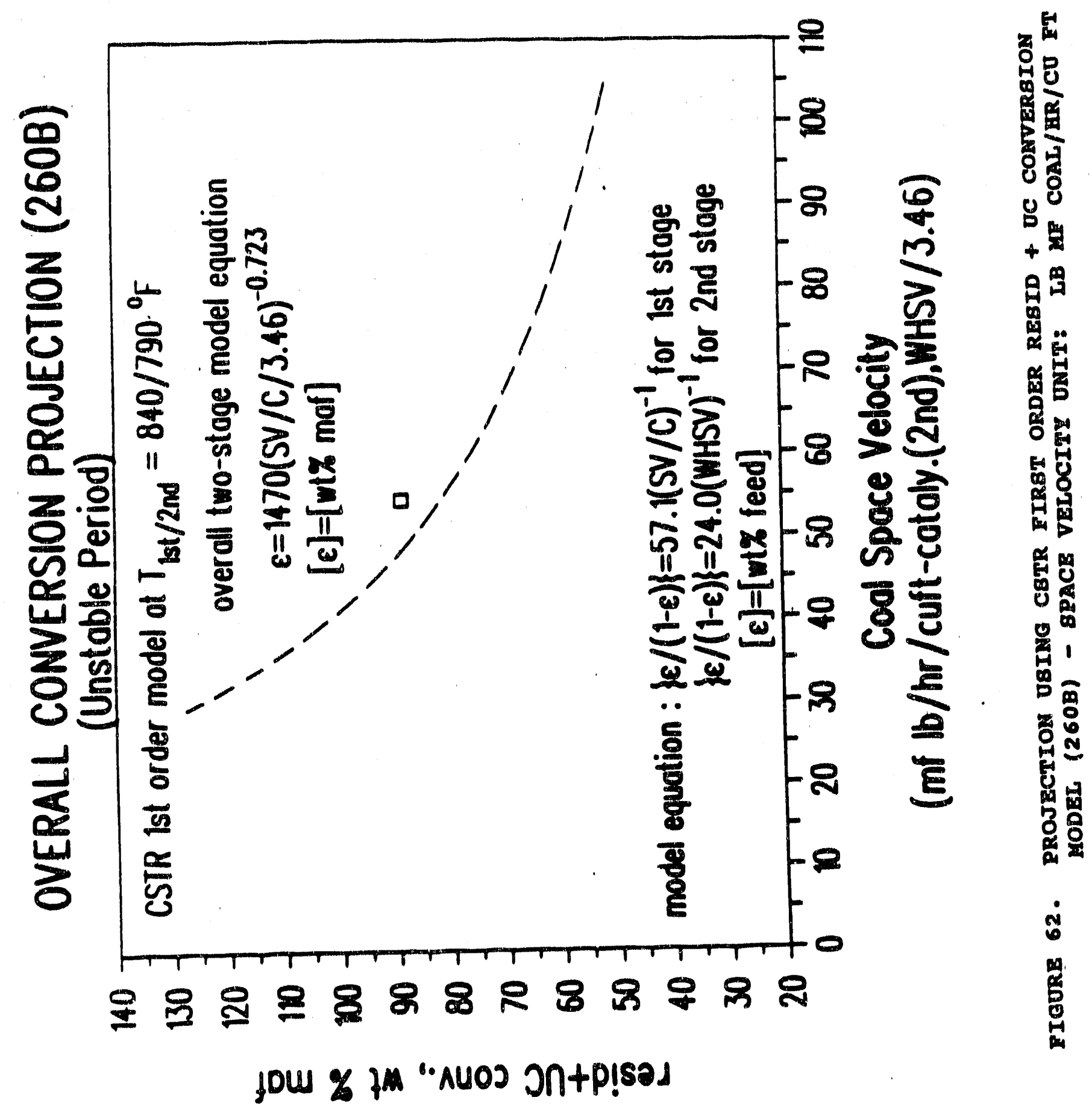




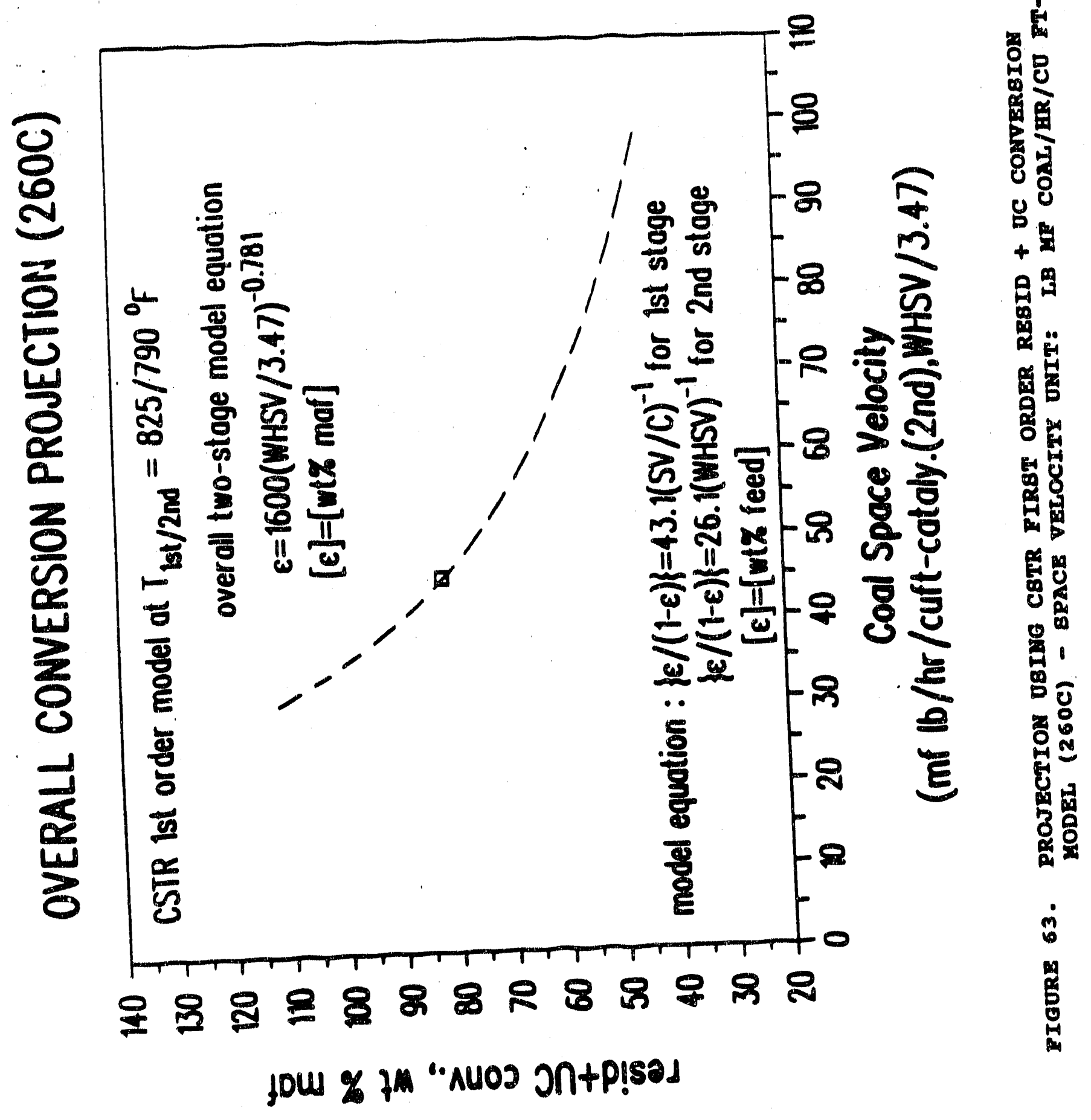




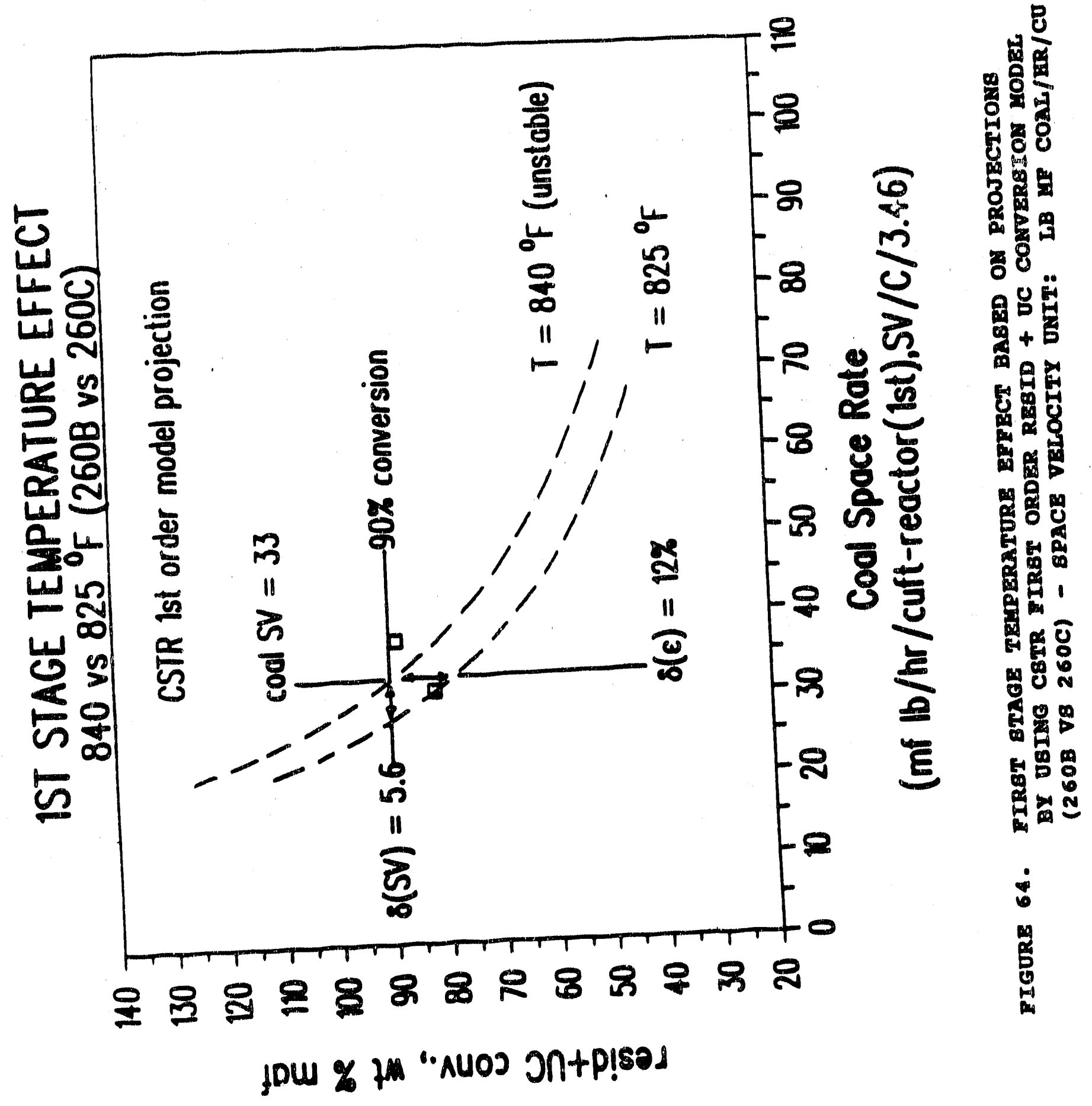




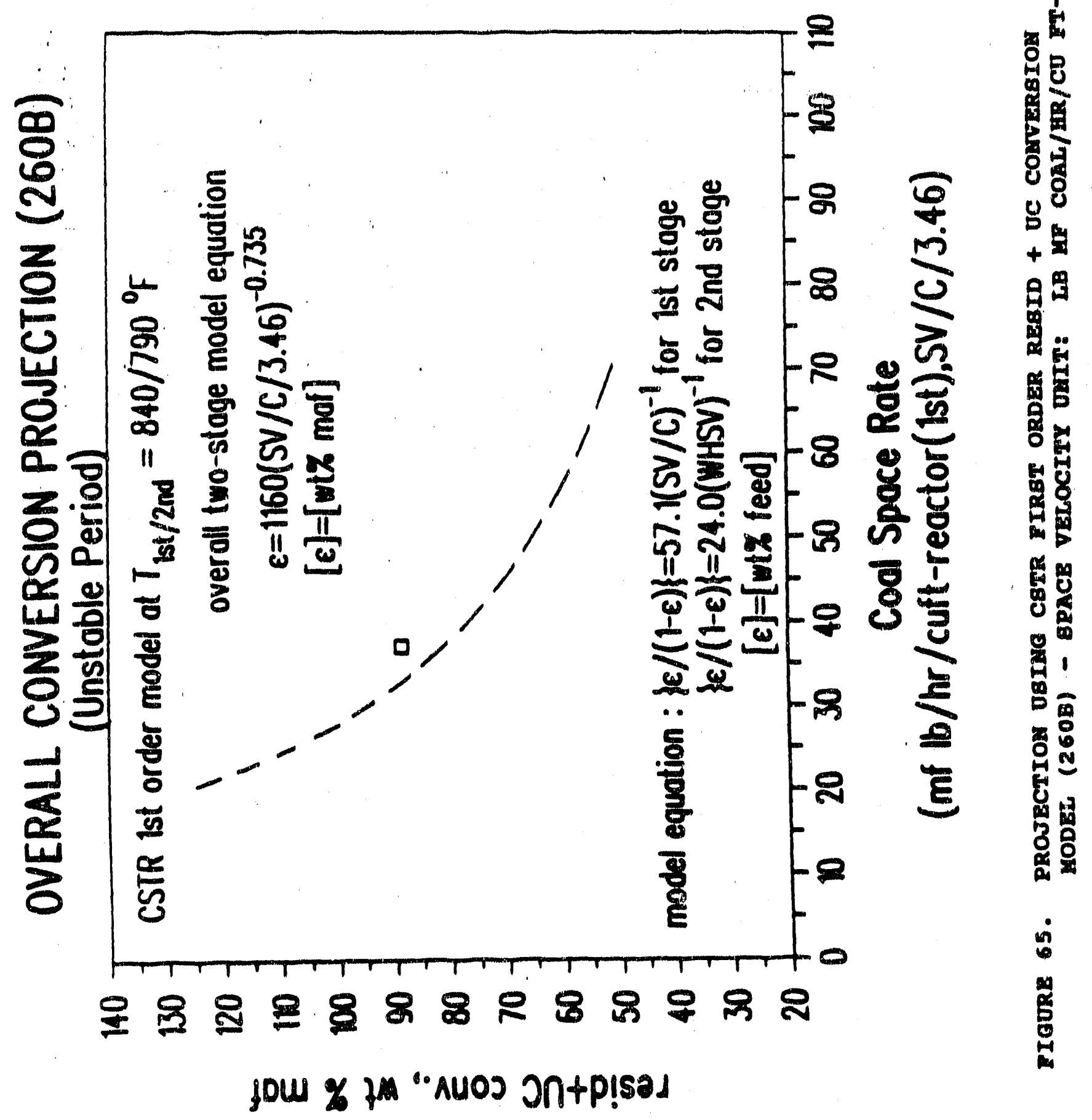




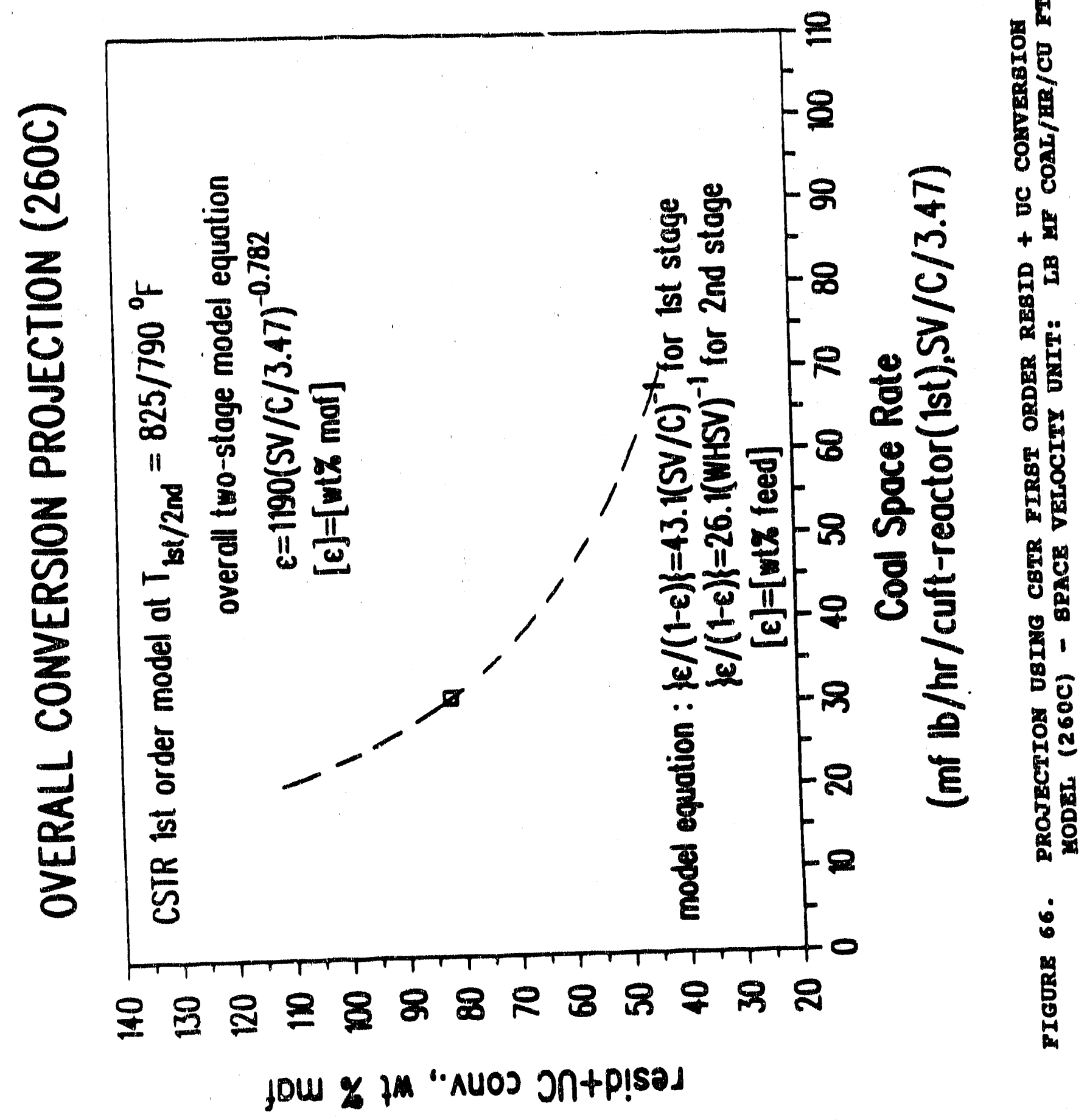




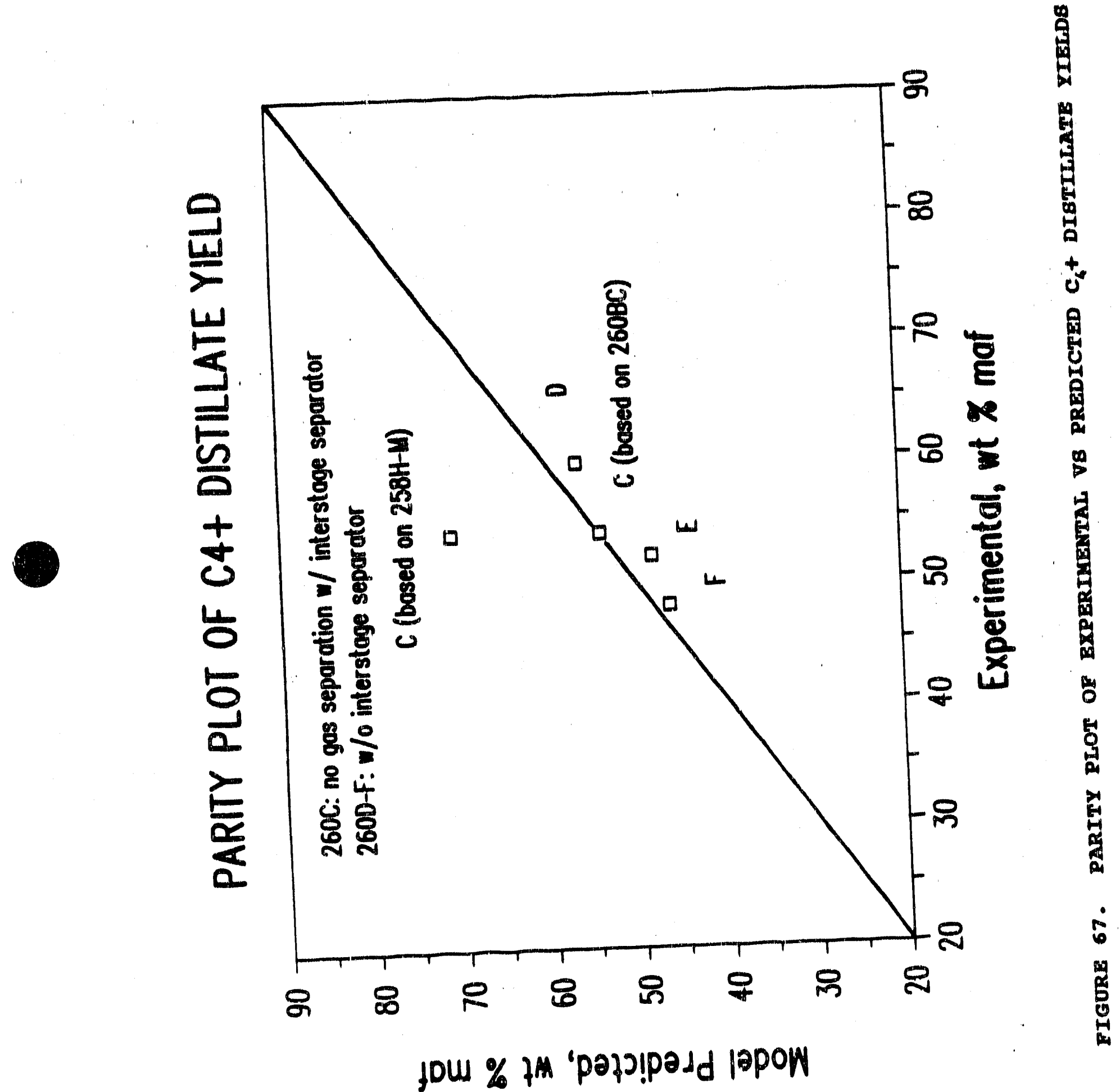




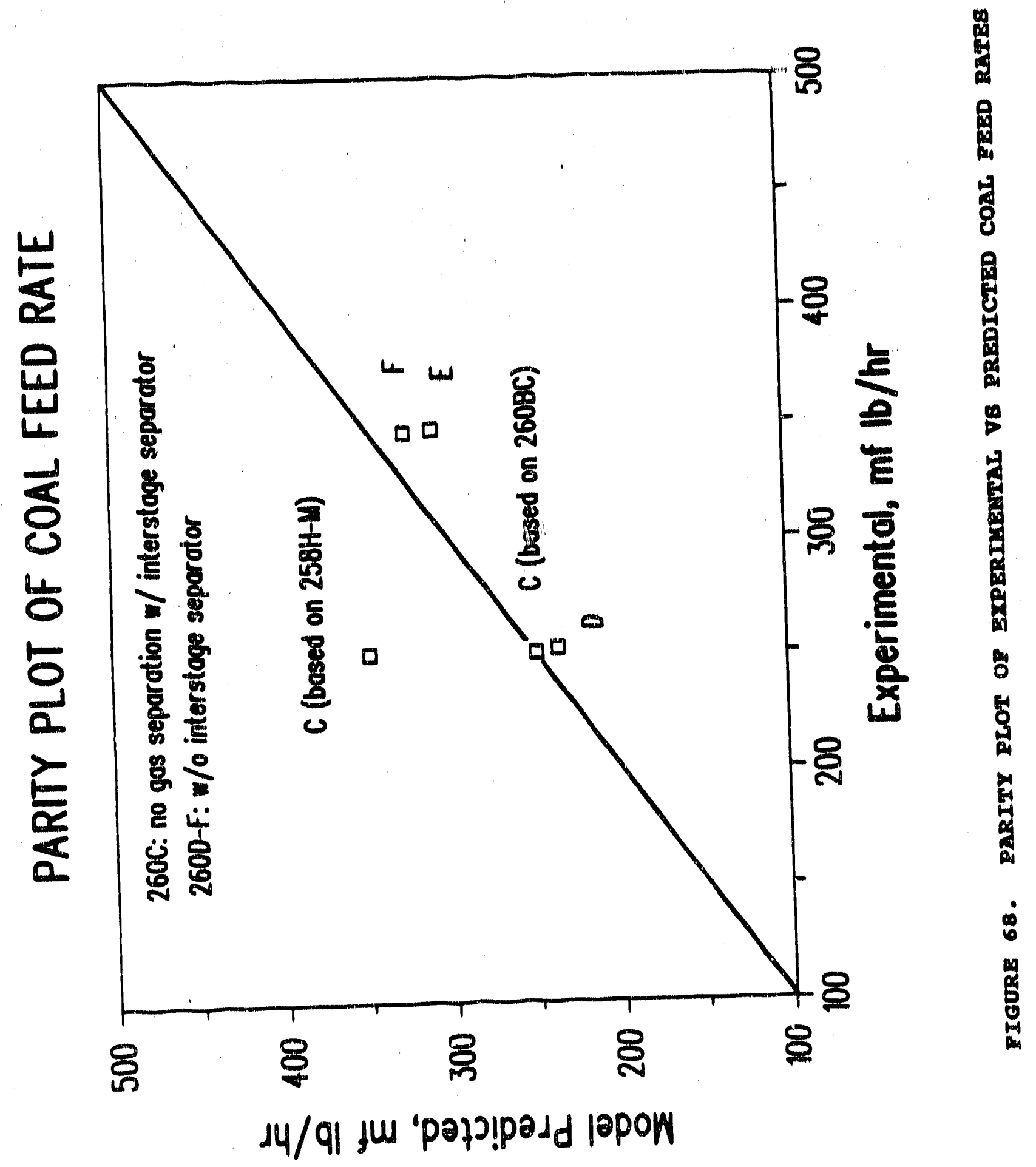




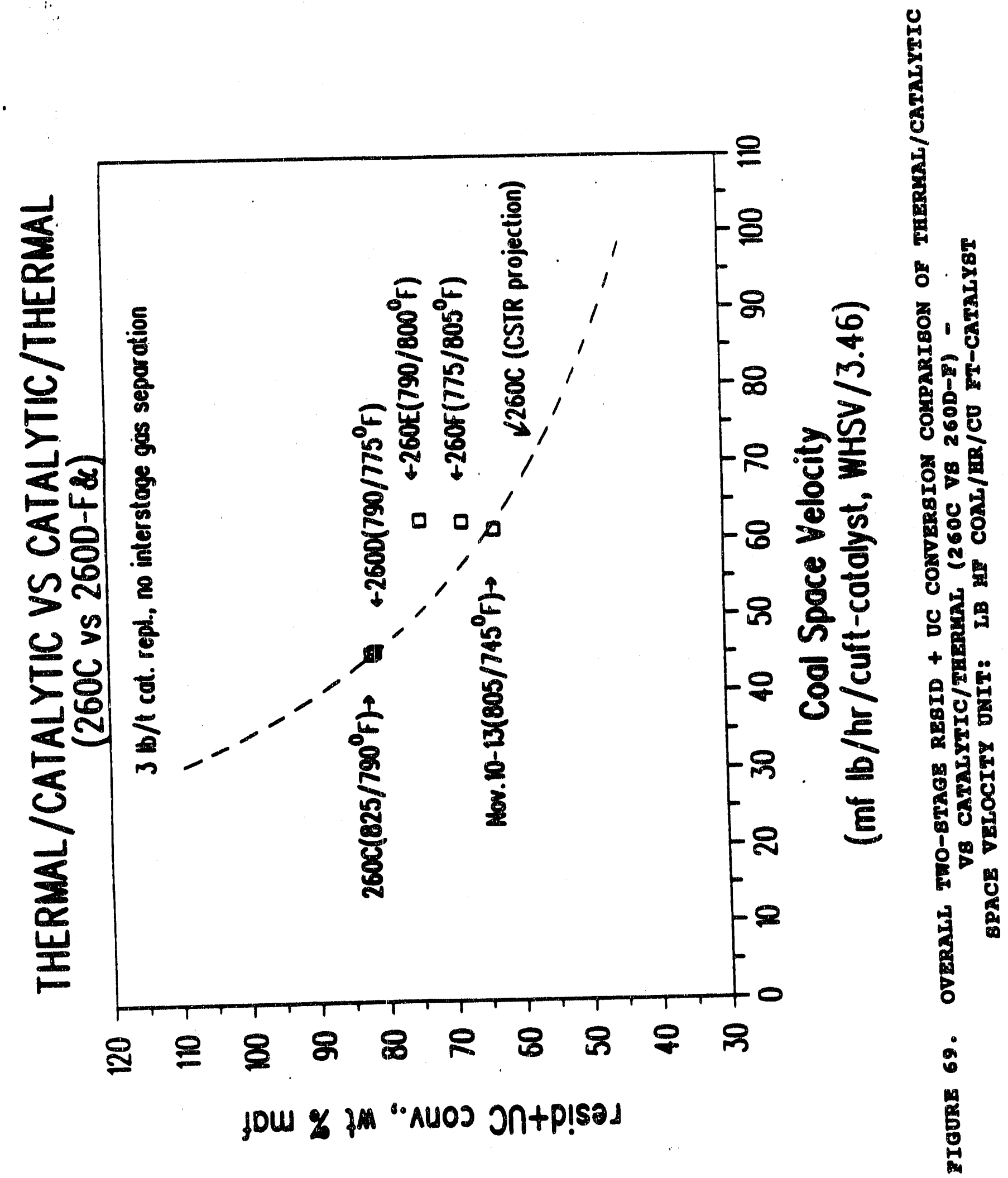

 \%. 둔 a 옹잉 $0 \times$ 80 $\rightarrow-$ $\div 88$

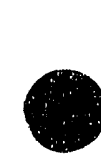




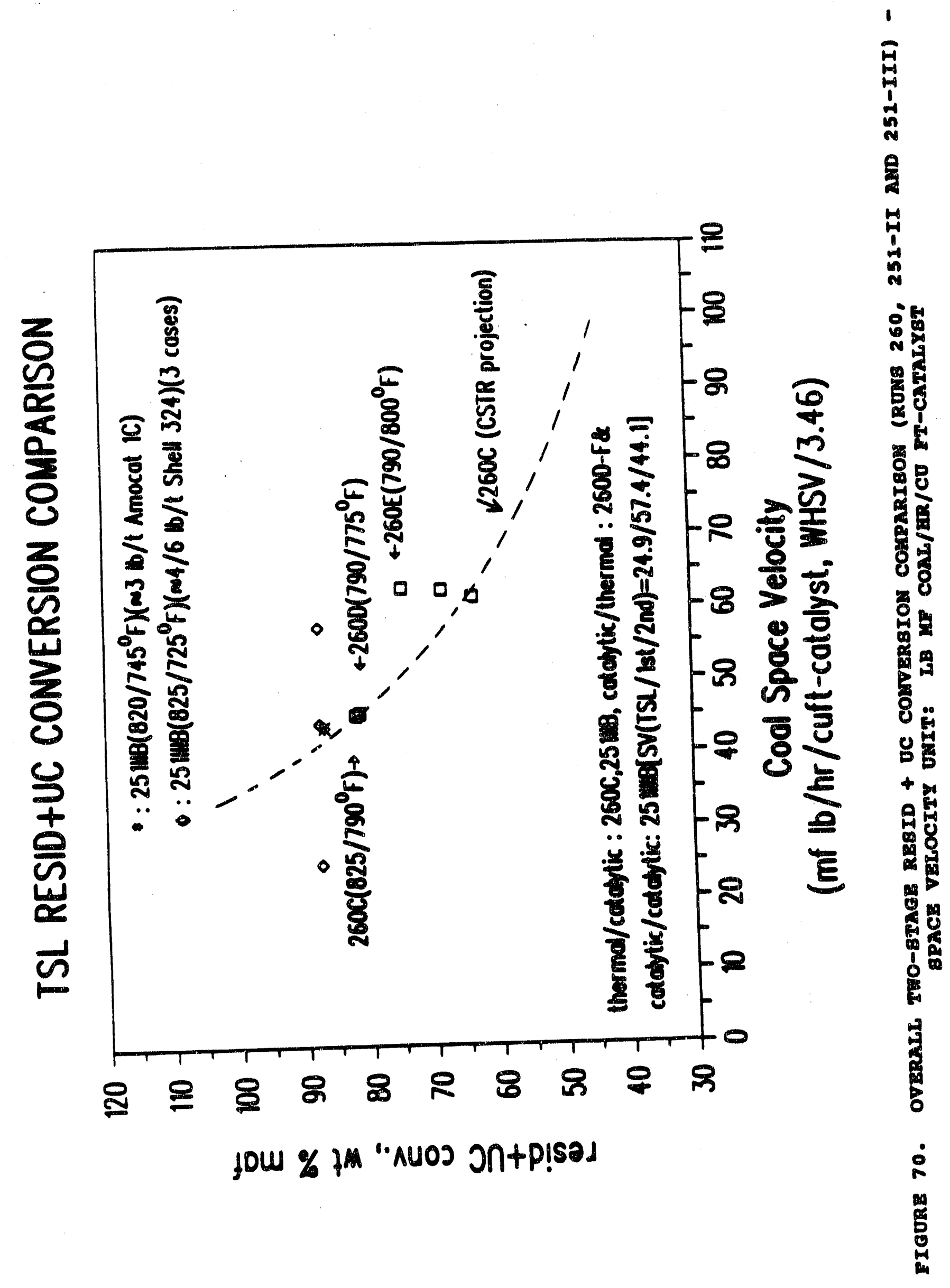




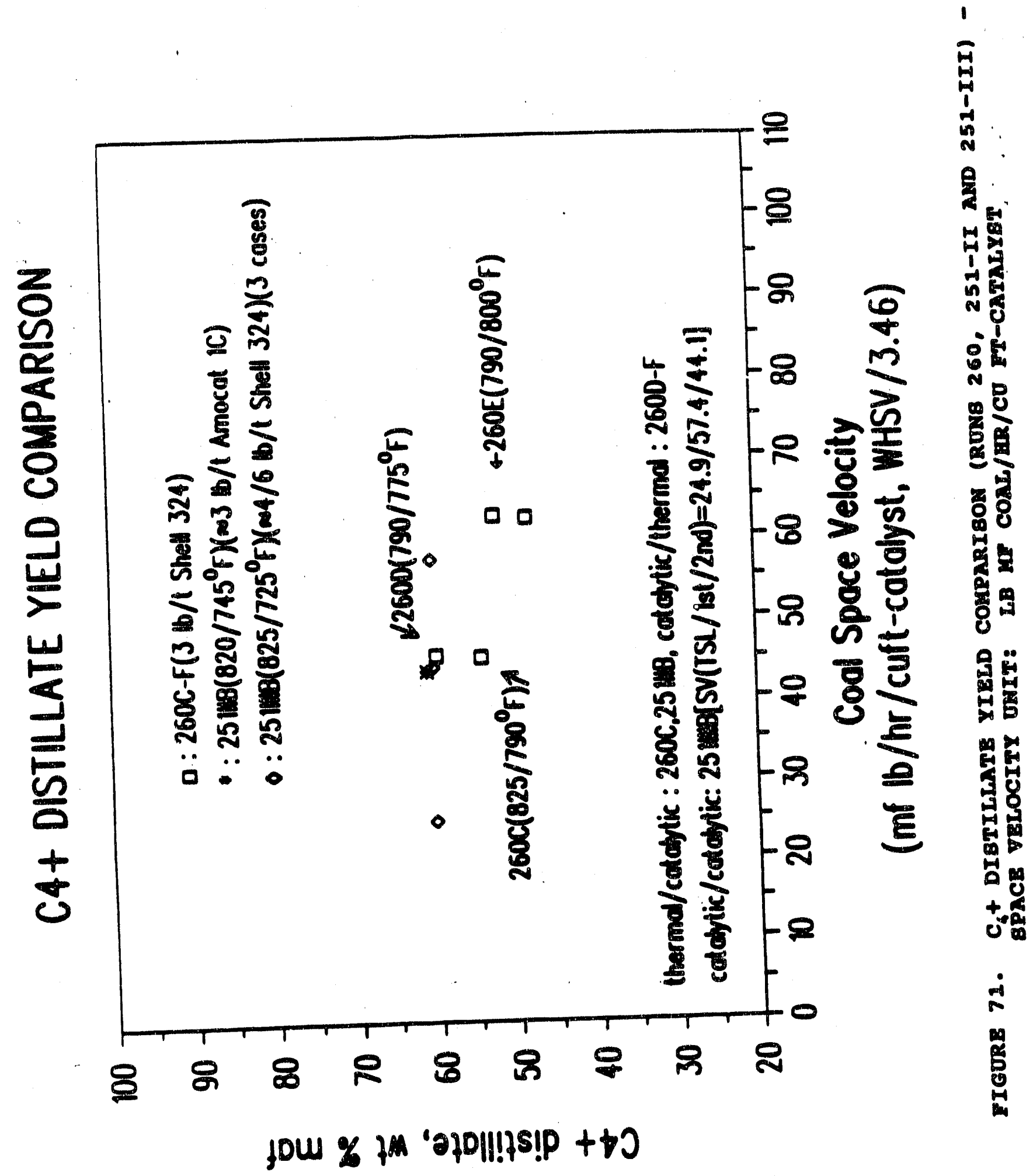




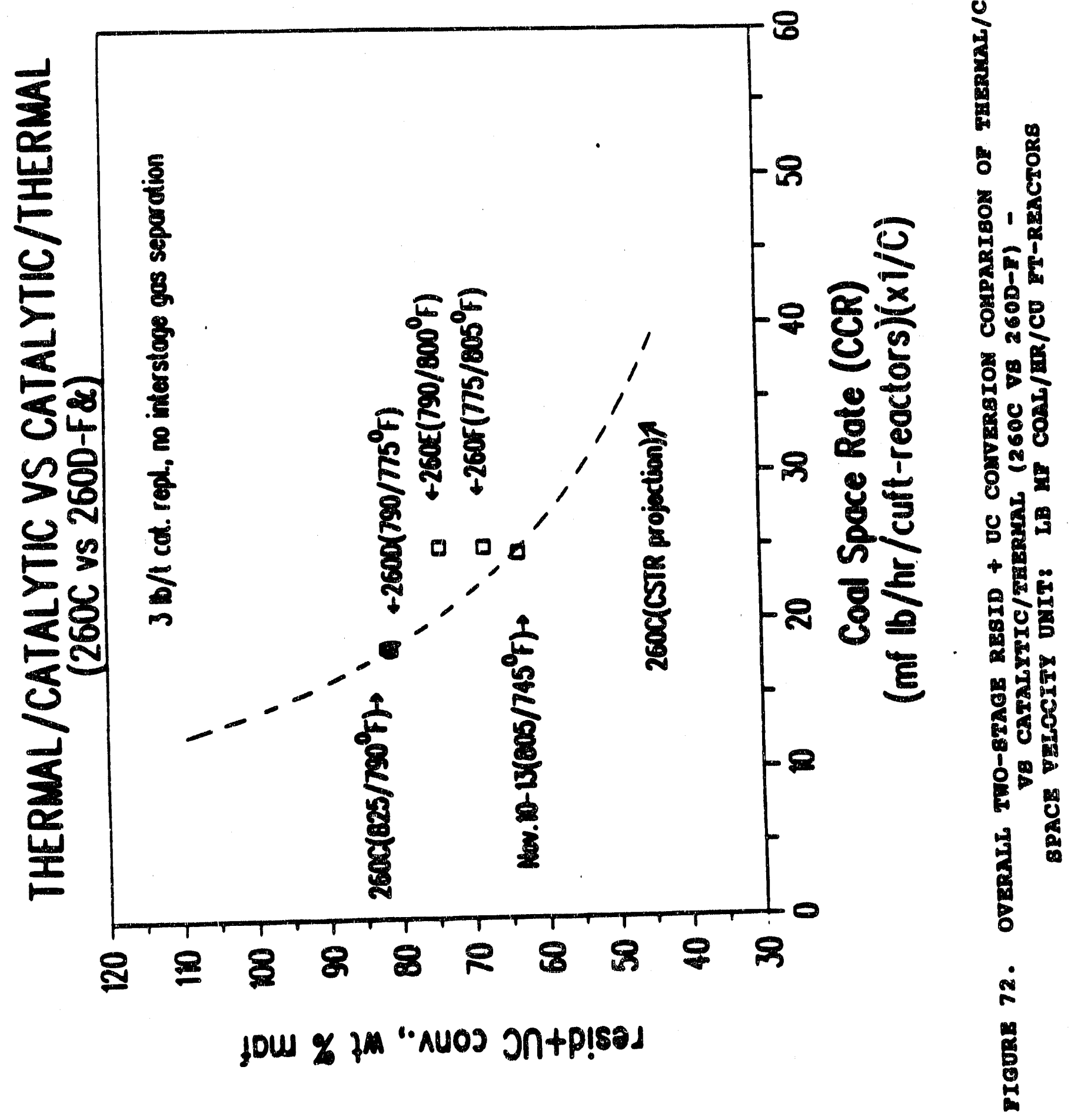




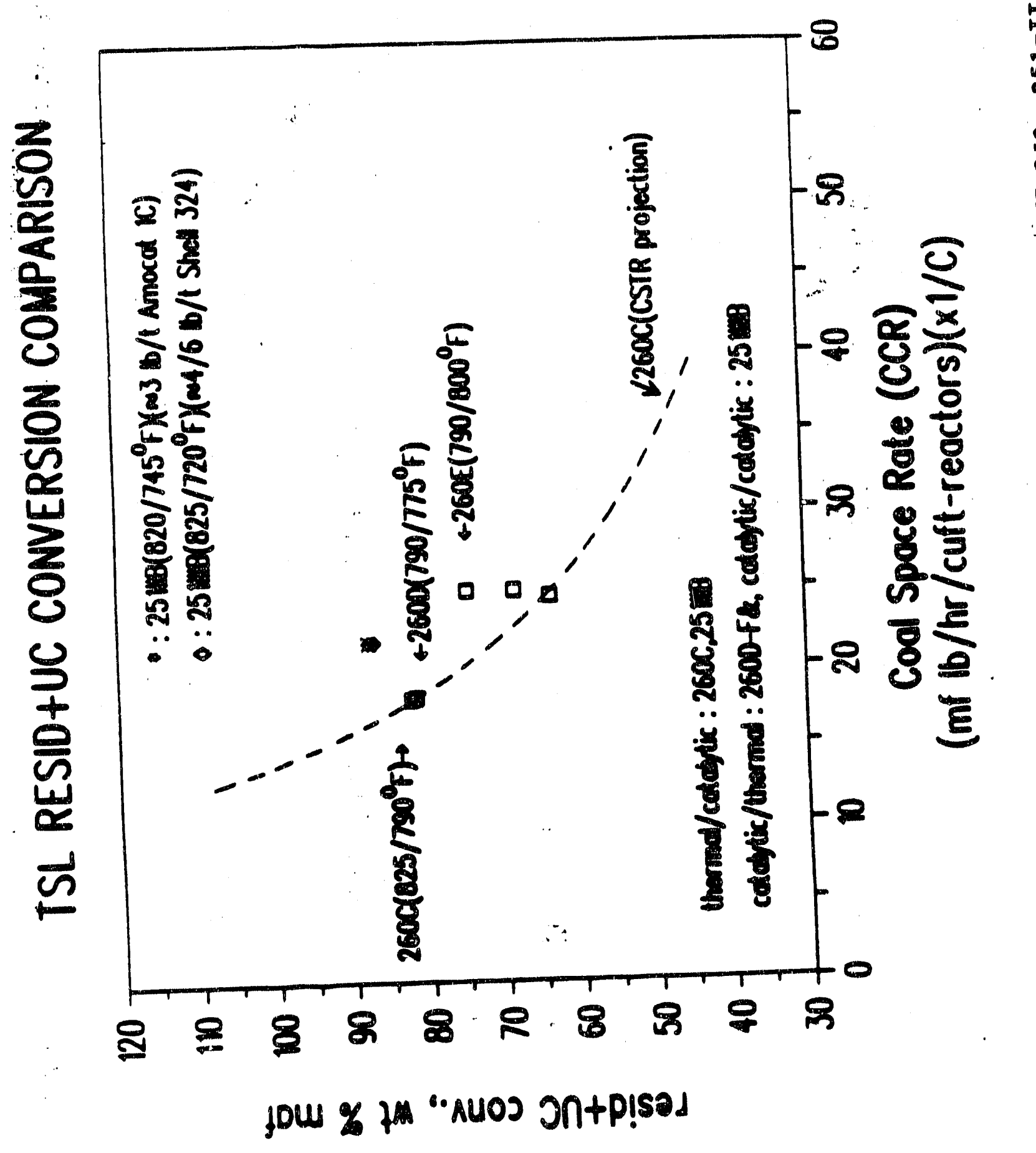




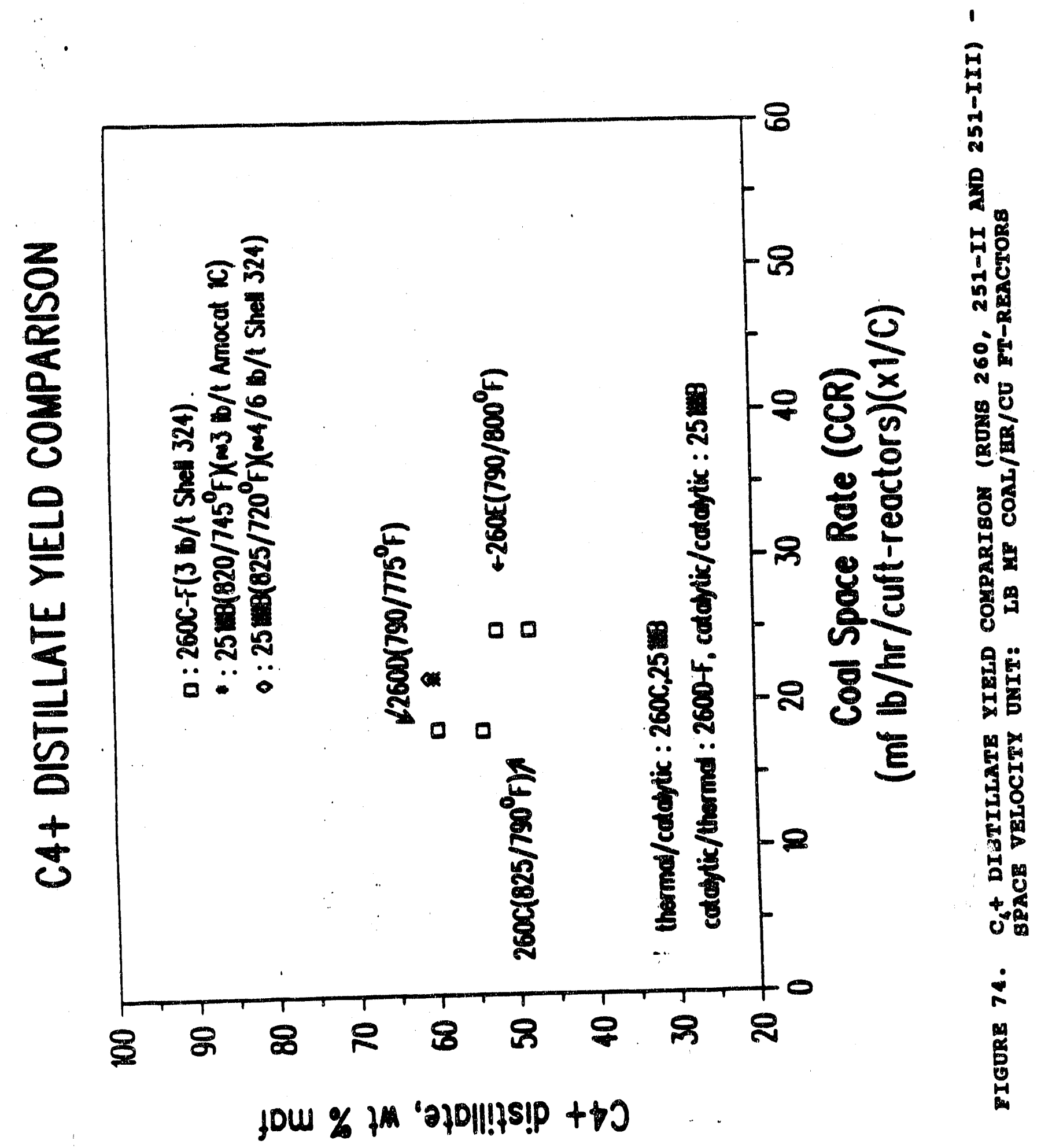




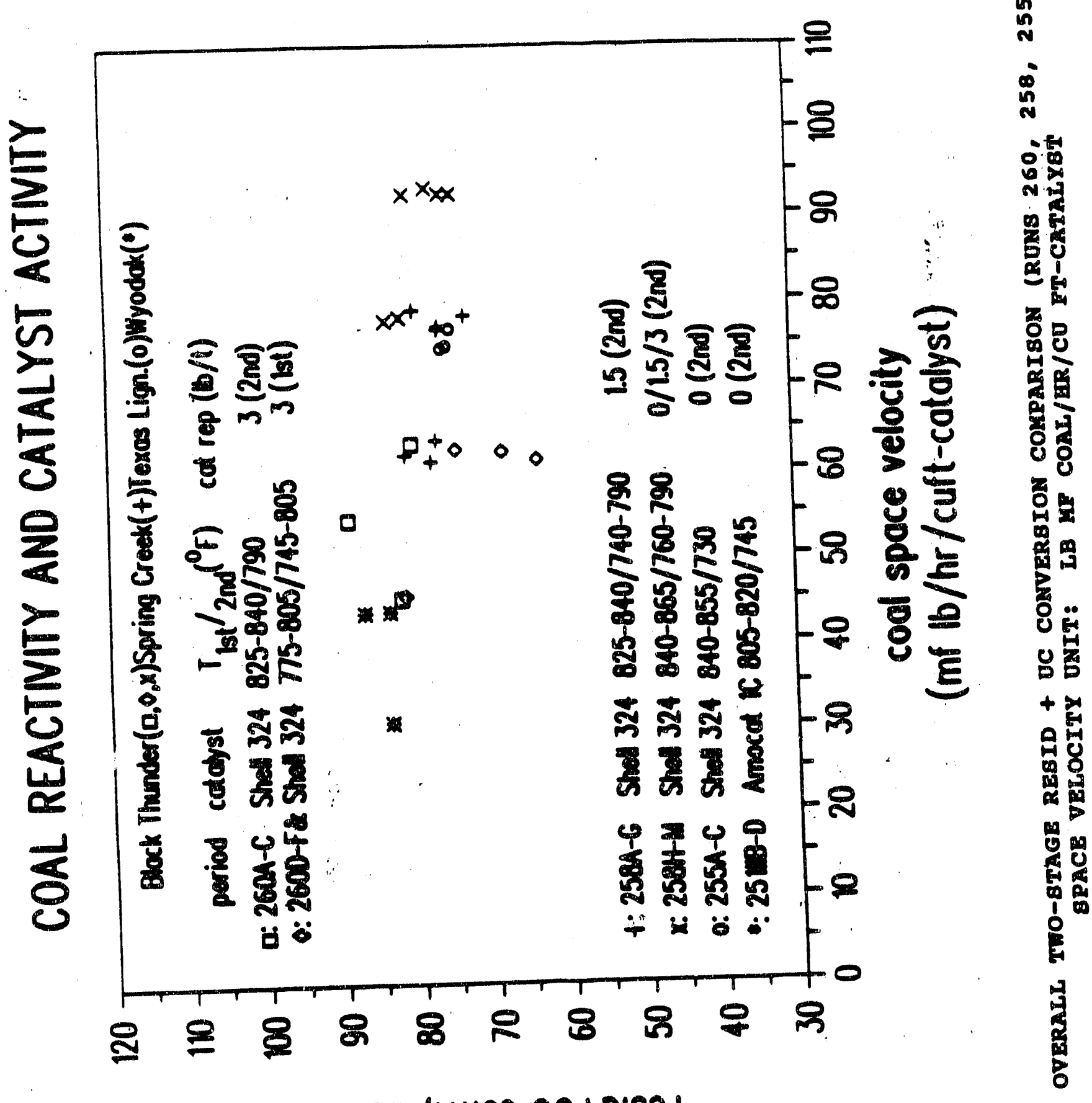

fow \% zm "nuos ontpisos 
8

in
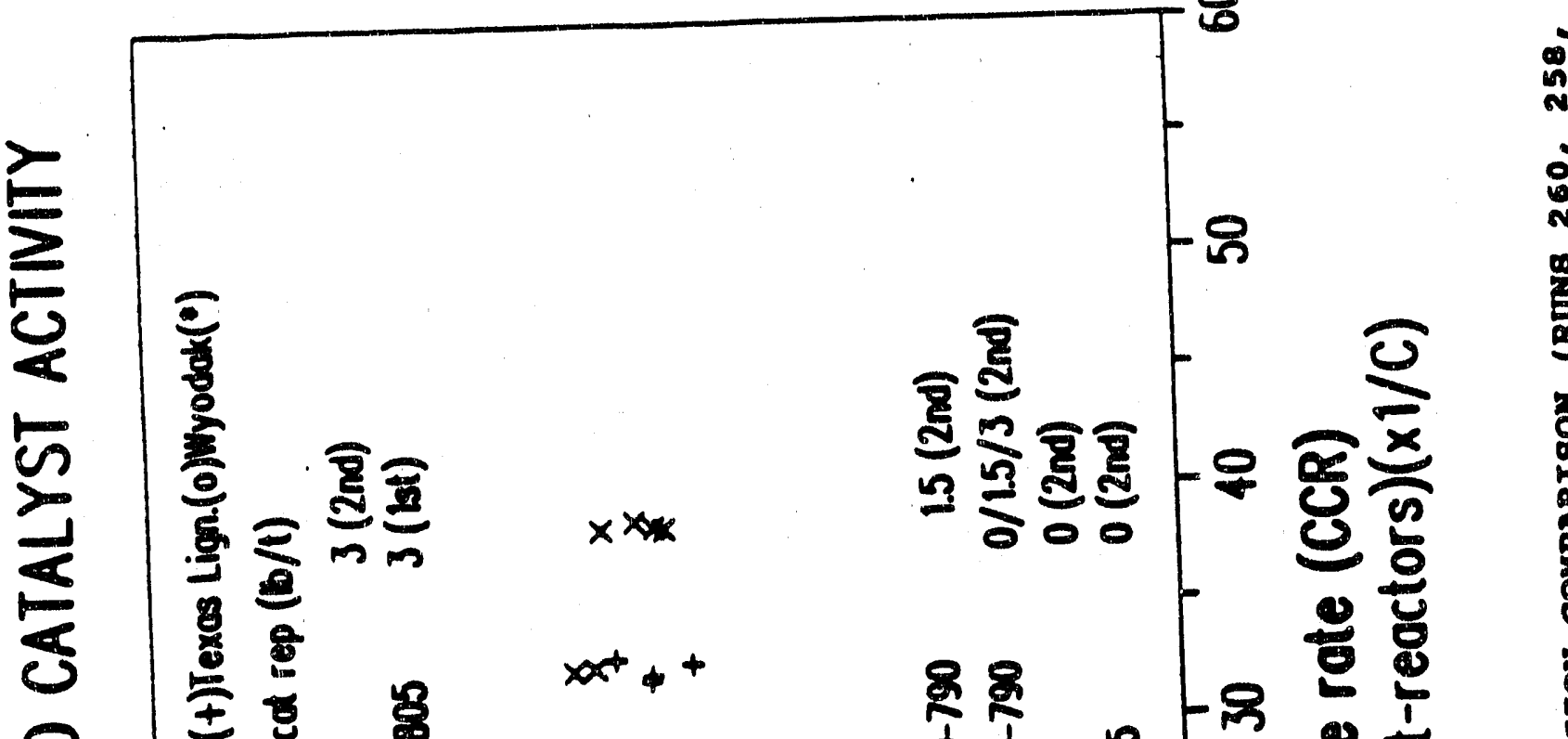

要

s

है

\& 8

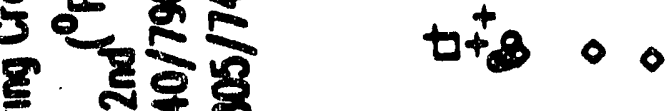

$\sum_{0}^{\infty}$

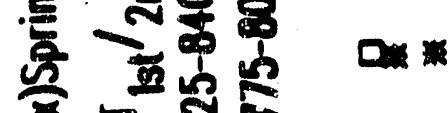

\% $-\mathcal{1}$

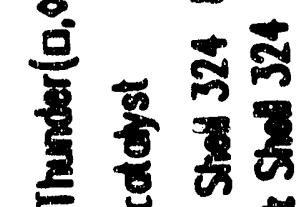

๑

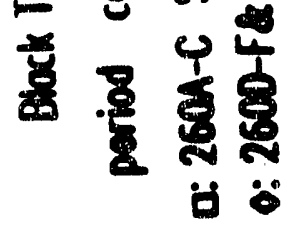

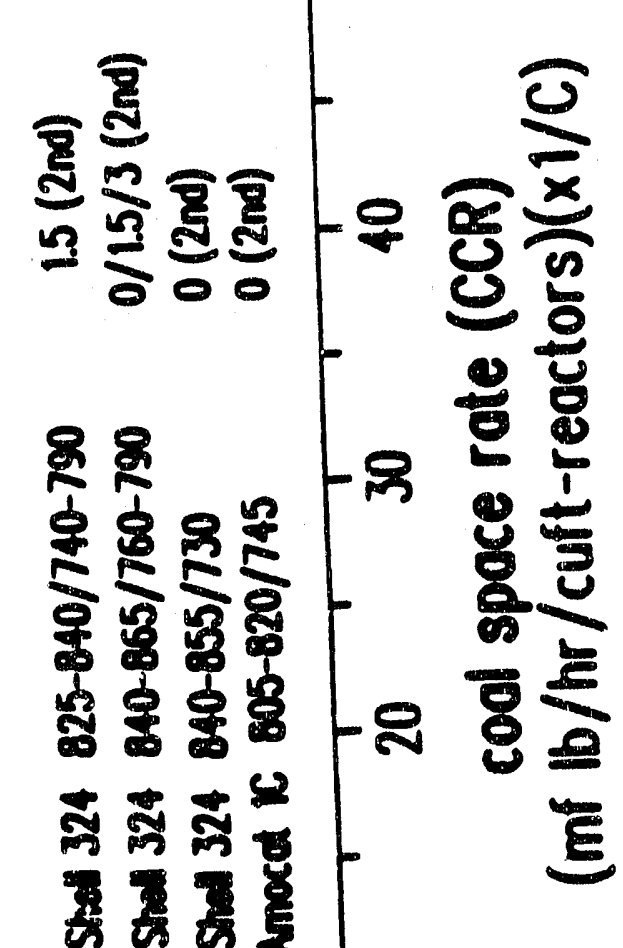

.

蛋

品

总。

울

㫛

8

8

管

点基

照

농

응 \& \& 8 8े \& क क

jow \% in "AUOJ ontp!sad 


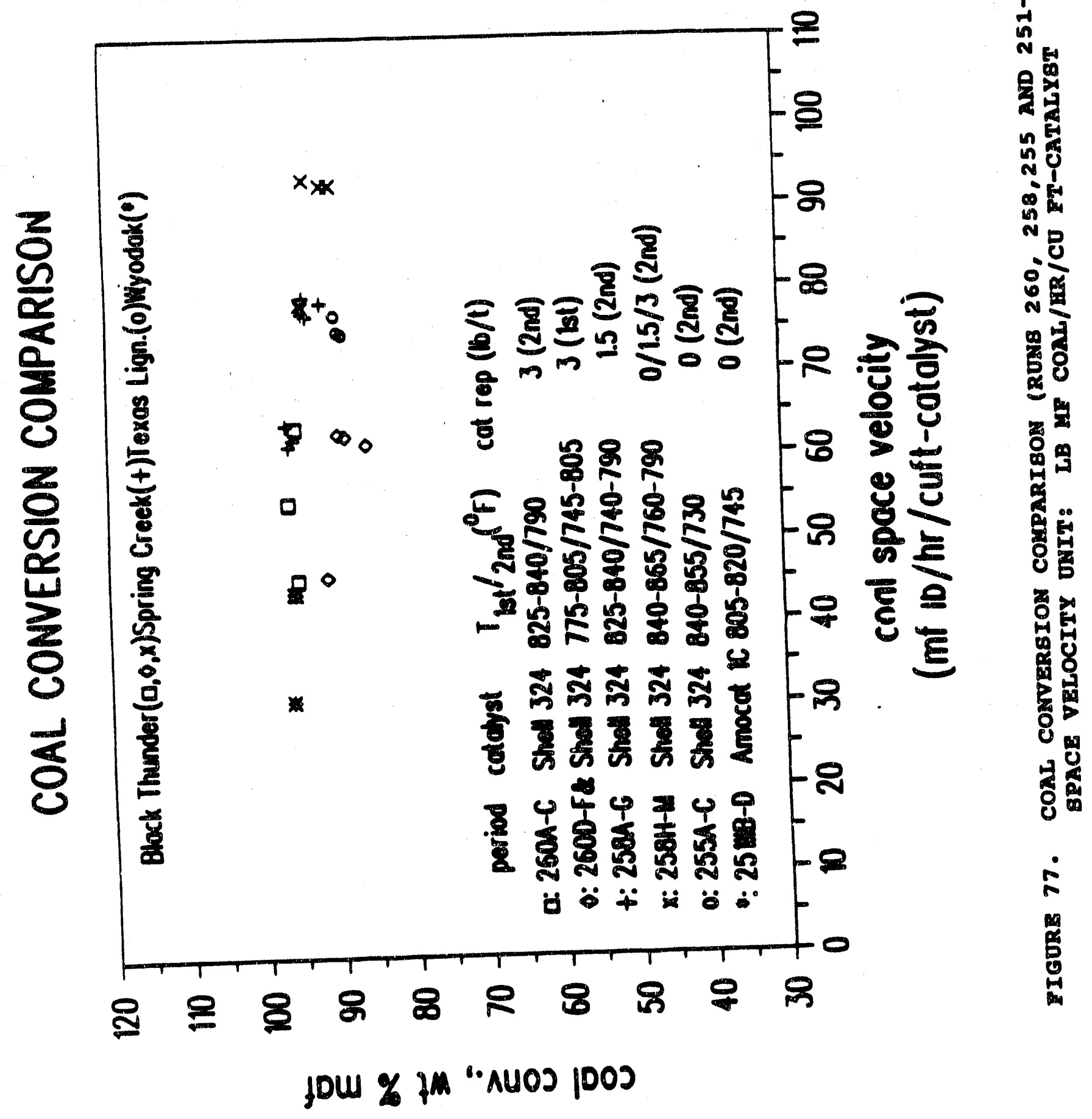




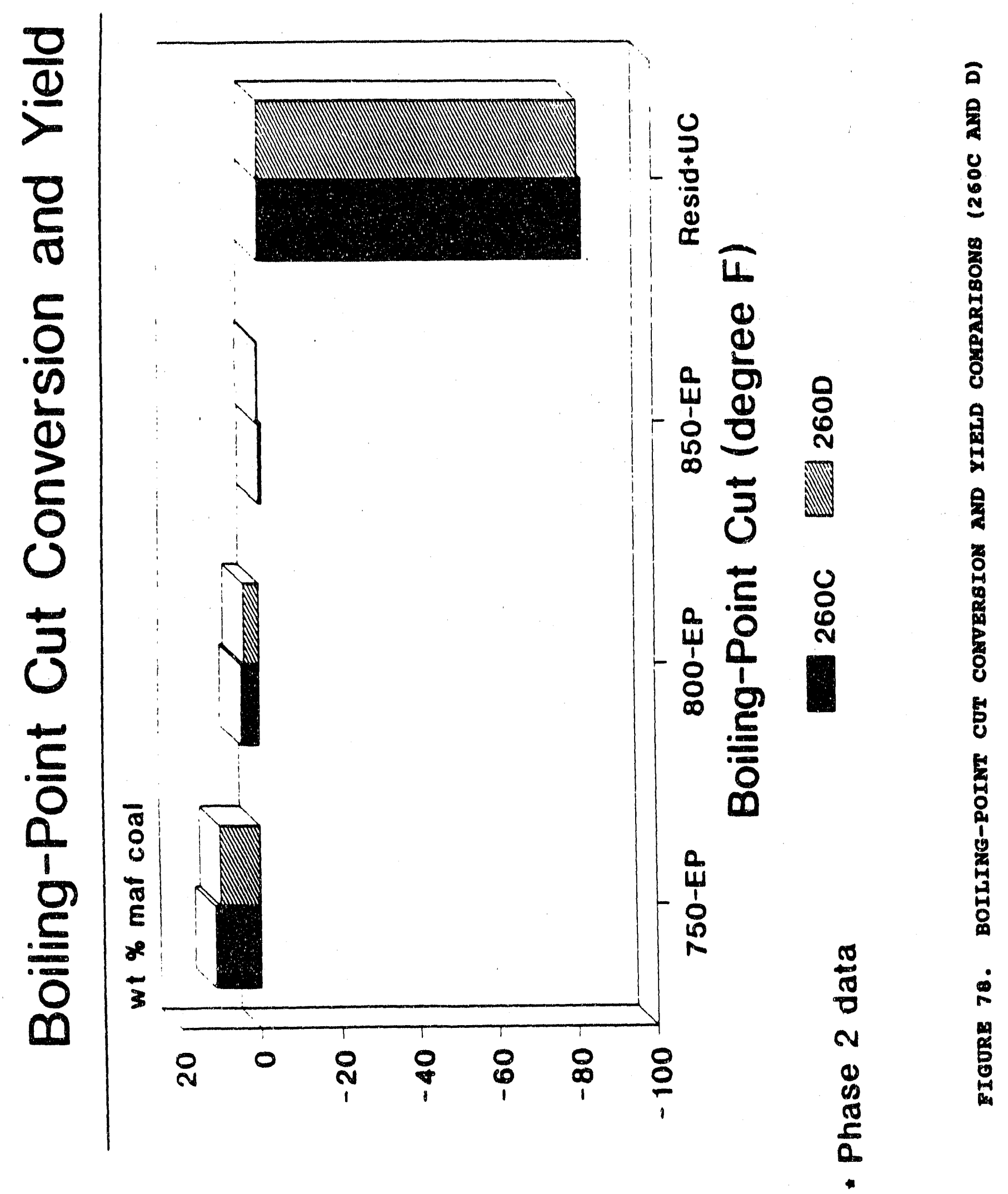




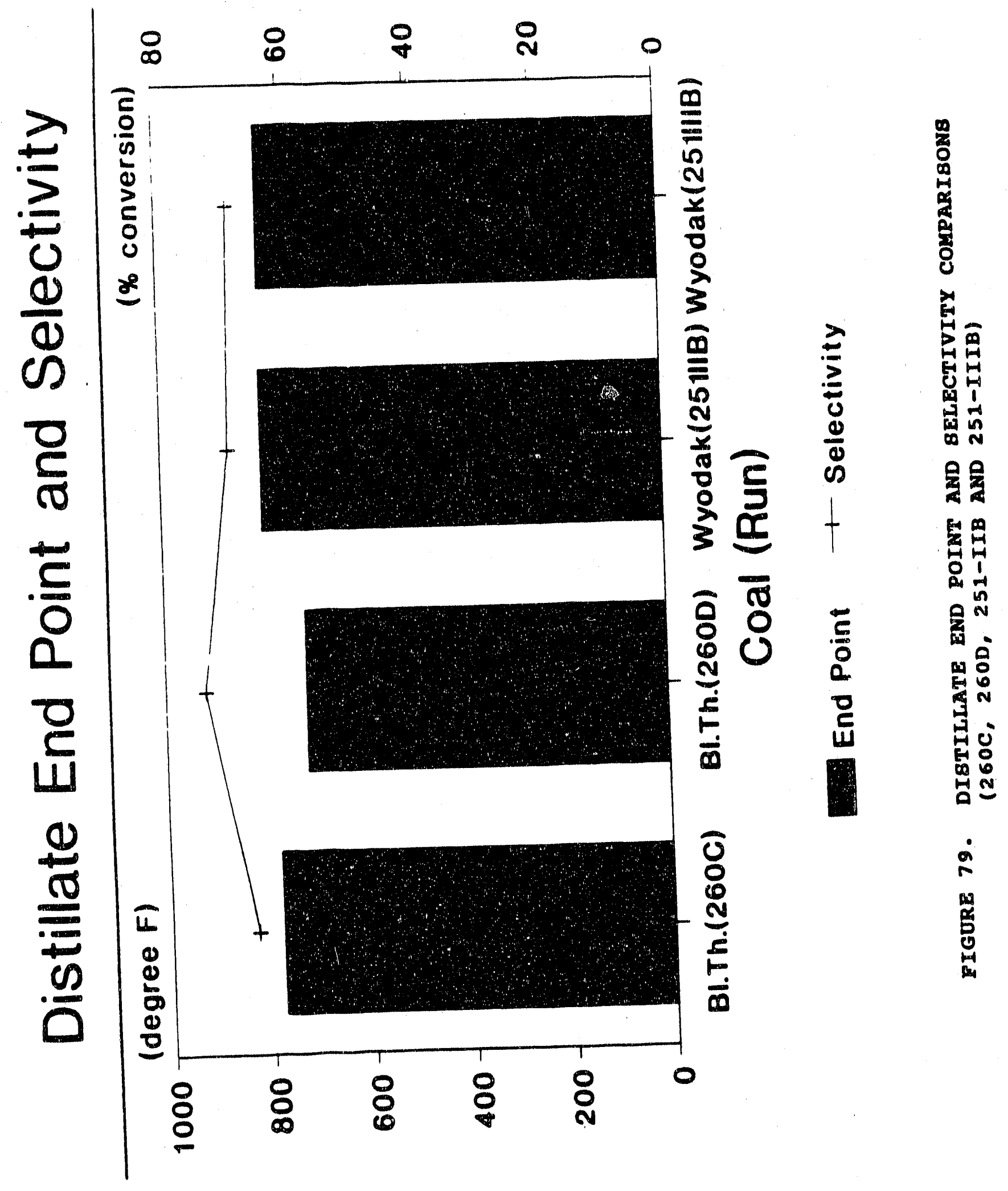




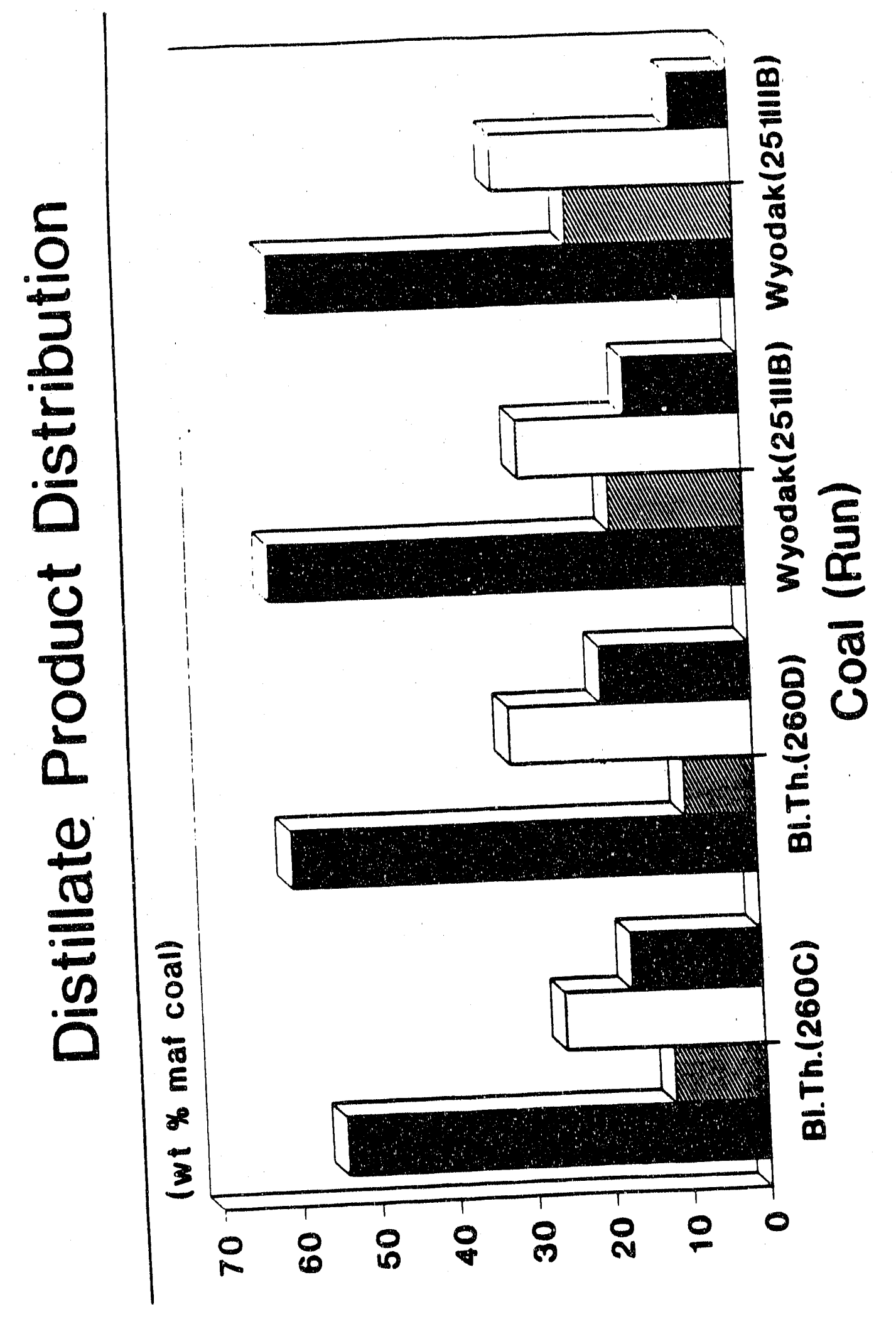

$\overline{\overline{0}}$

क)

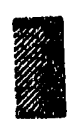

兽

뭉

봉고

号年

O

品.

웅

E.

留

i

48

ง

$\frac{1}{\infty}$

4
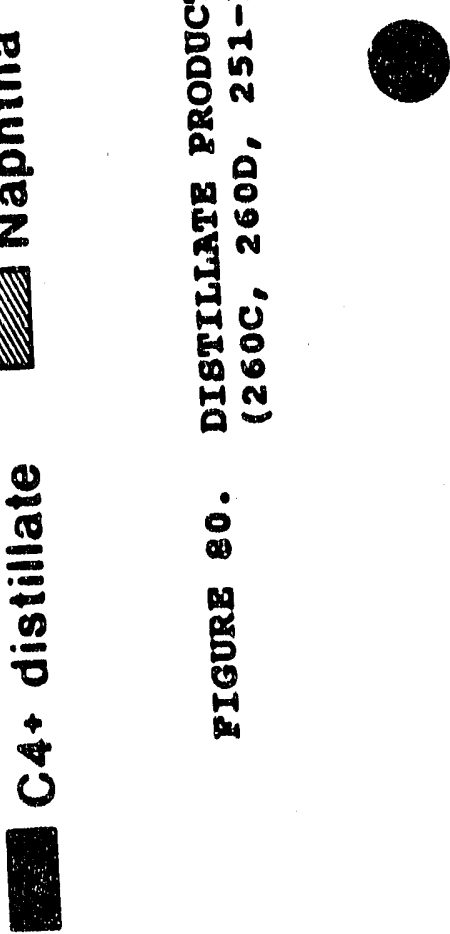


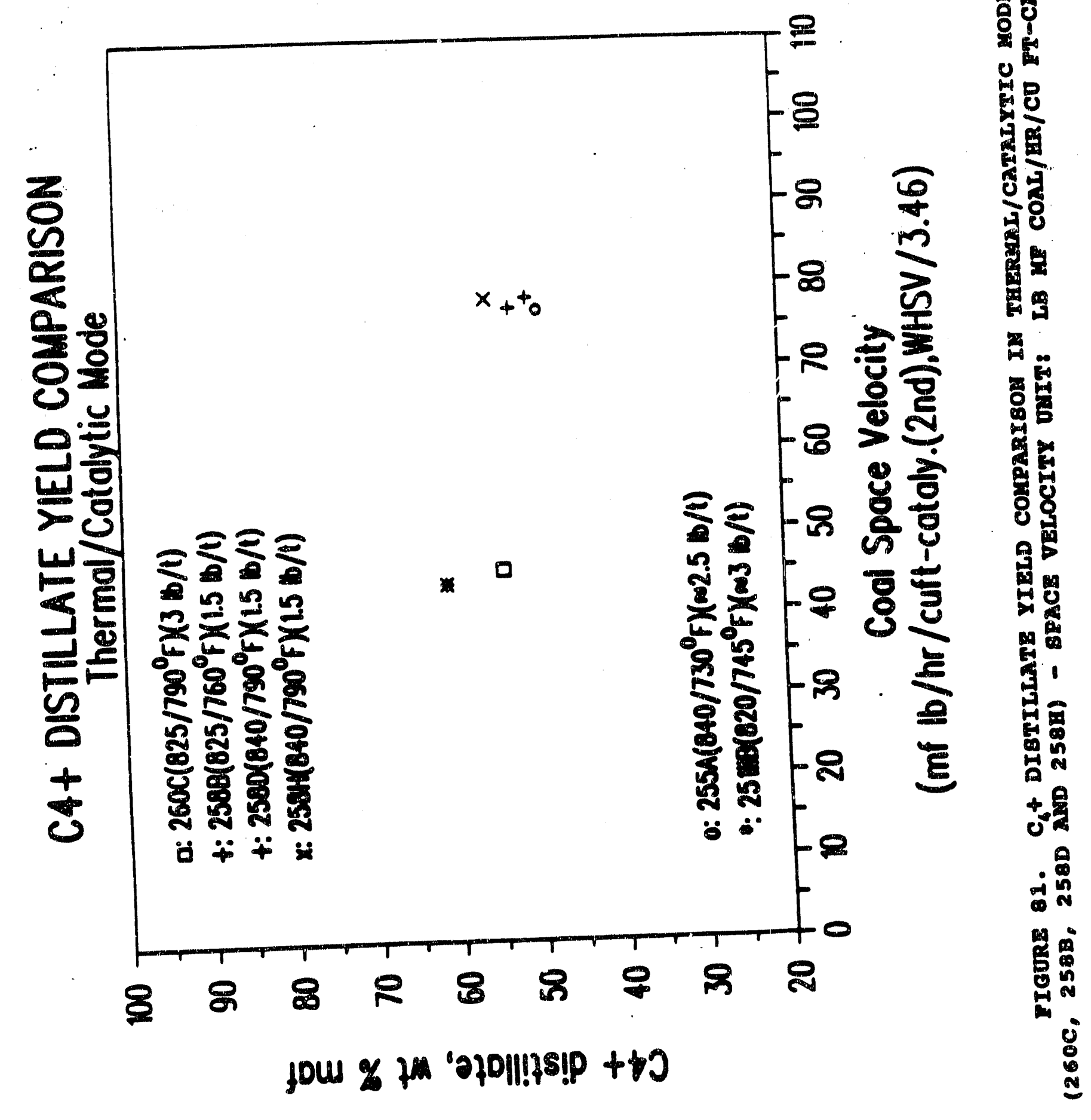




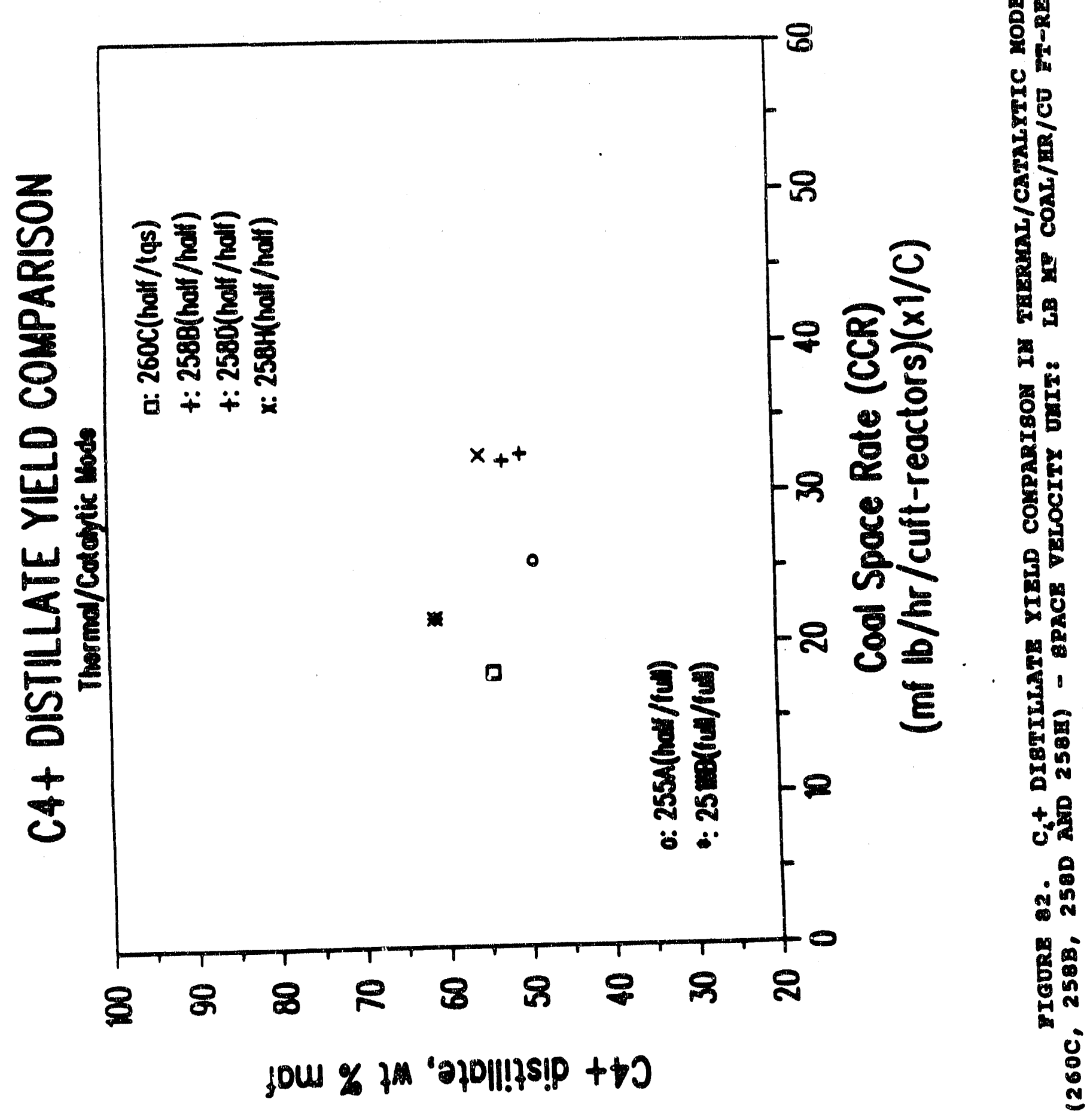




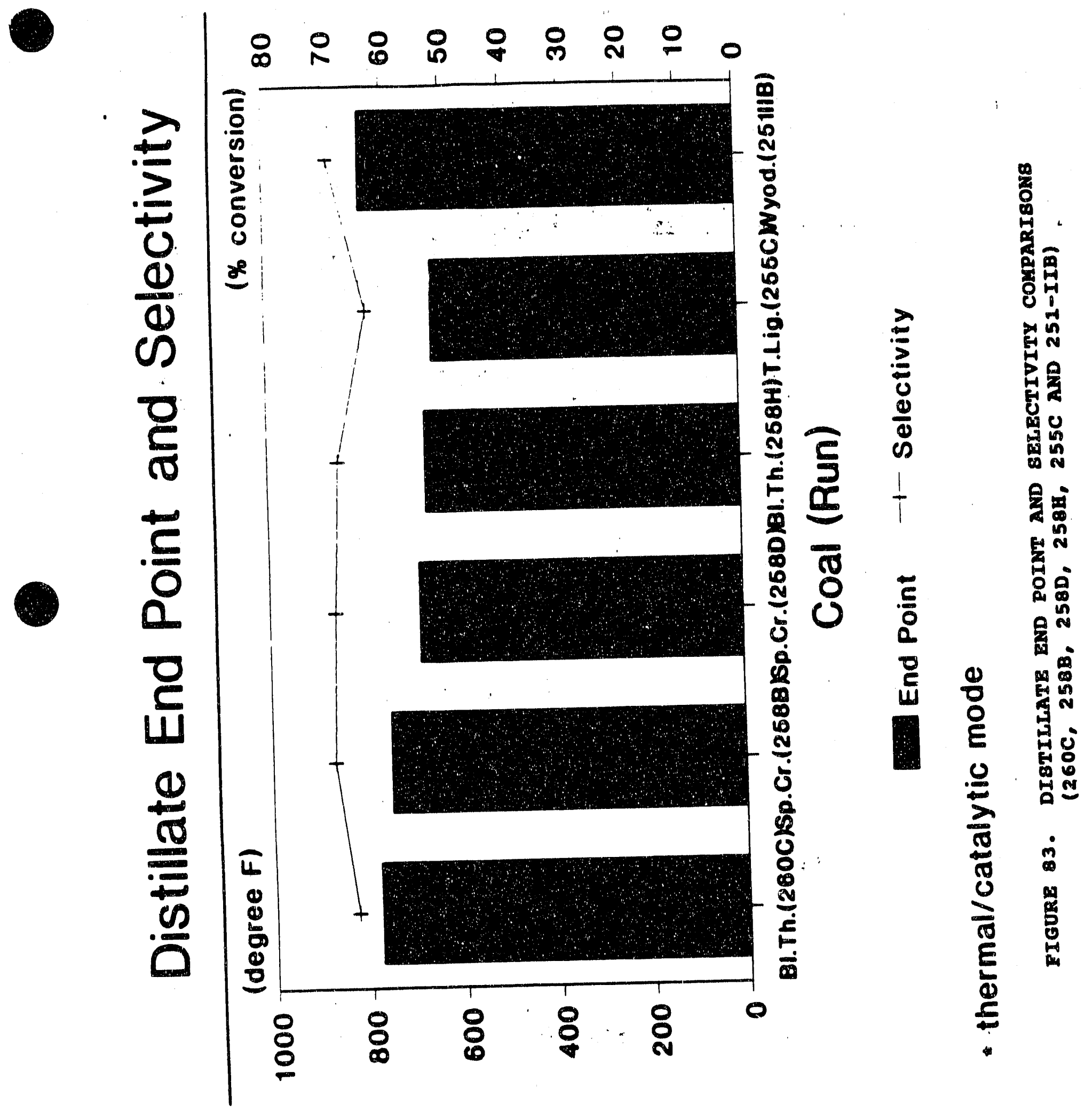




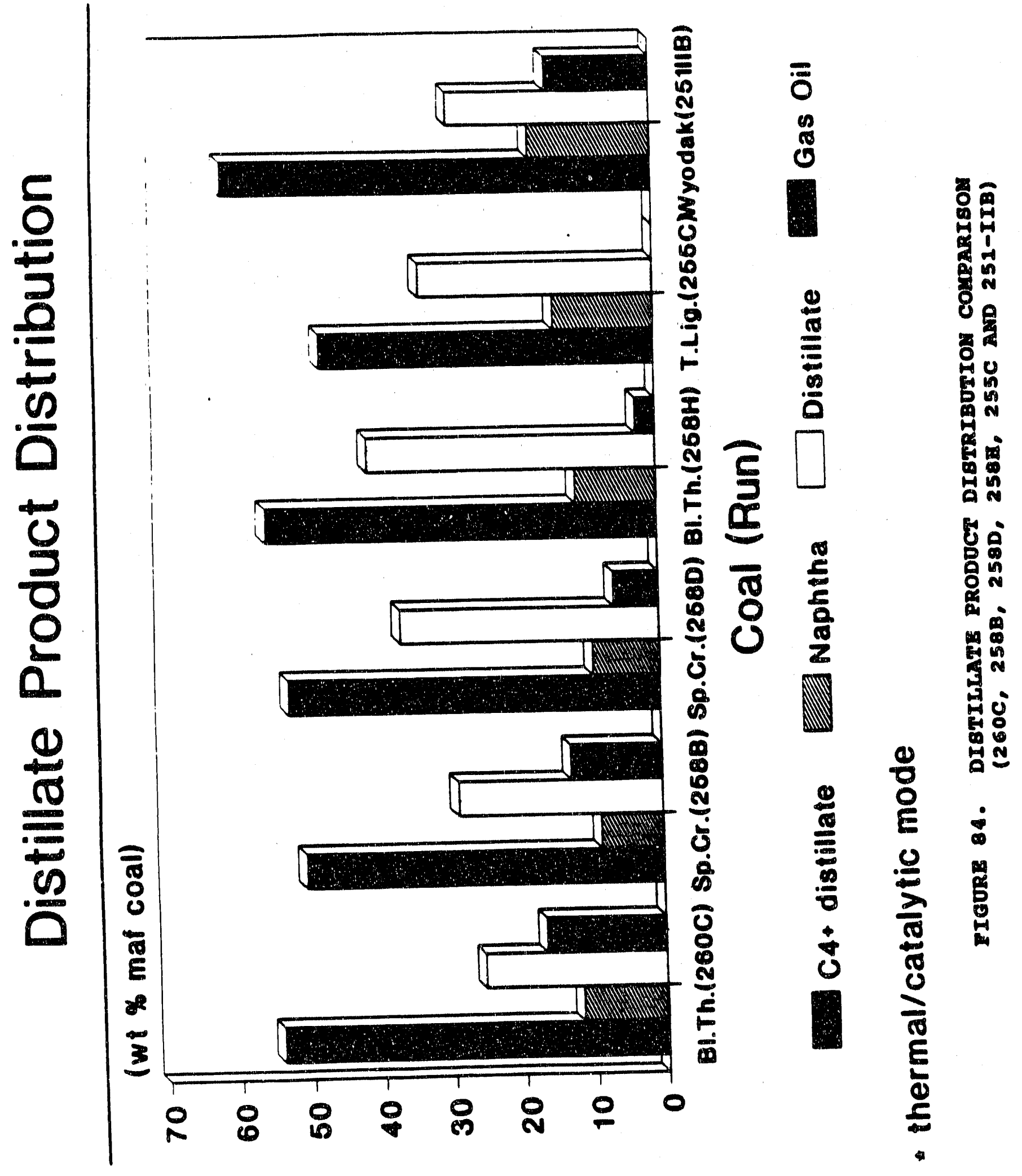



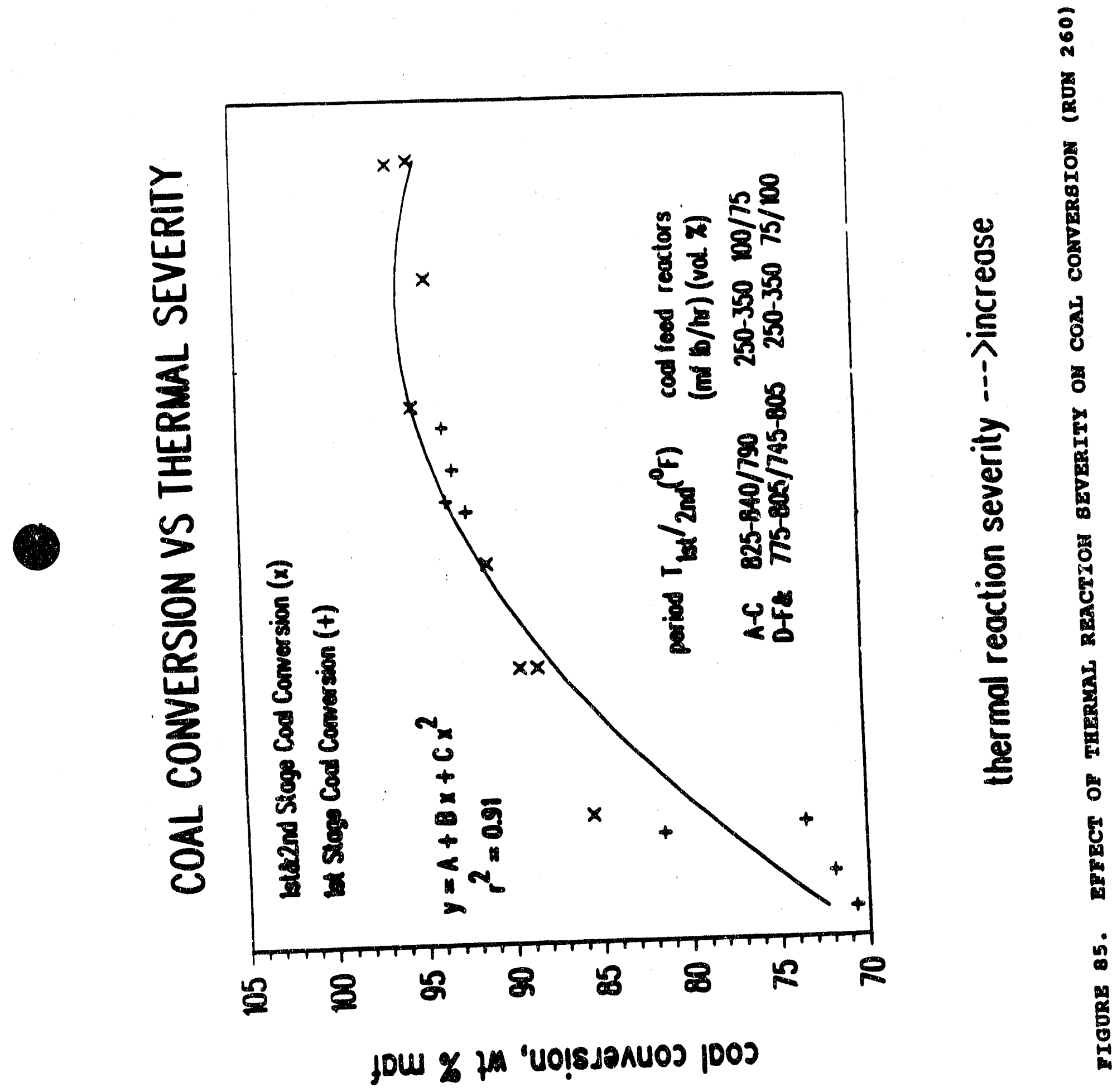


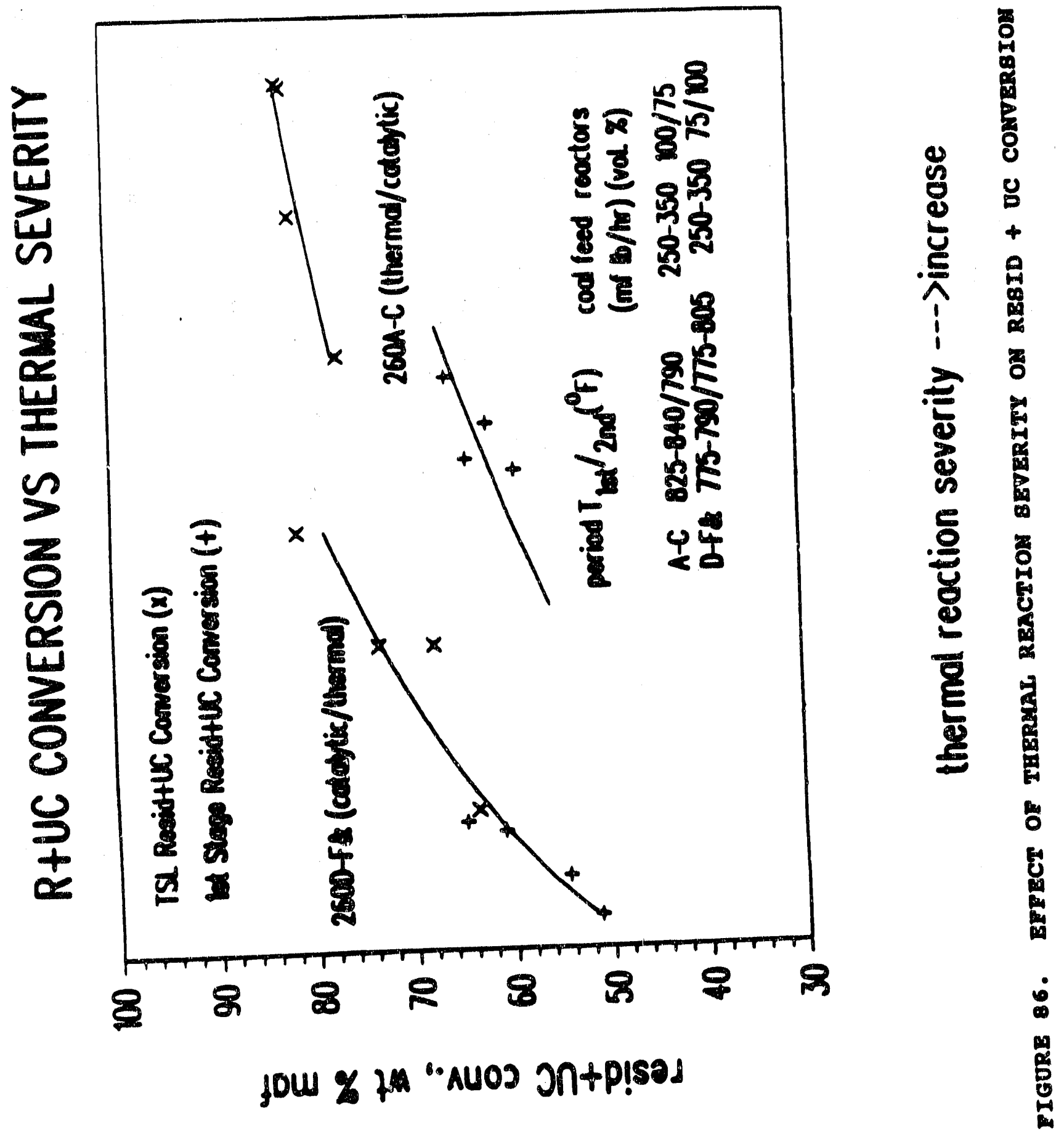



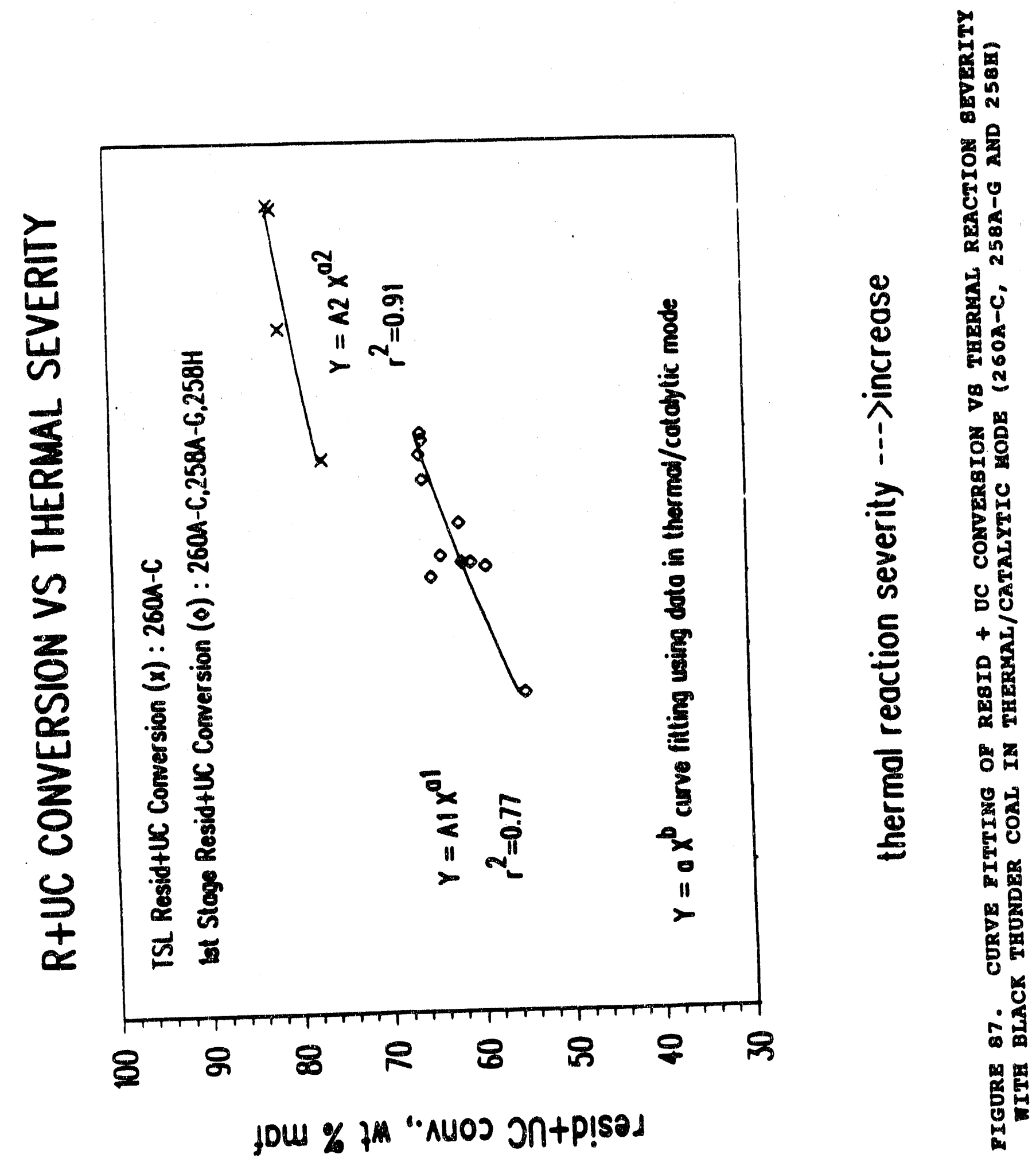
NOTES: Thermal histories during Periods $A$ and $C$ in Run 260 are illustrated by using temperature profile and approximate relative residence time through TSL process system.

These periods operated with an interstage separator. The vent stream of the interstage separator was blocked in 260C. Process times for slurry blend and feed tanks, and process solvent storage tank were significantly reduced for illustration.

$\begin{array}{ccl}\text { Key Equipment } & \text { Location Number } & \text { Description } \\ \text { V101A } & 6-10 & \text { slurry blend tank } \\ \text { V101B } & 10-14 & \text { slurry feed tank } \\ \text { B1200 } & 16-18 & \text { preheater } \\ \text { R1235 } & 19-34 & \text { 1st stage reactor } \\ \text { V1258 } & 36 & \text { interstage separator } \\ \text { B1201 } & 38-40 & \text { interstage heater } \\ \text { R1236 } & 42-57 & \text { 2nd stage reactor } \\ \text { V1247 } & 59 & \text { high press. separator } \\ \text { V1069 } & 61 & \text { atm. flash vessel } \\ \text { V1082 } & 63 & \text { vac. flash vessel } \\ \text { V131B } & 65-69 & \text { process sol. storage }\end{array}$

(For Figures 88 and 89 ) 


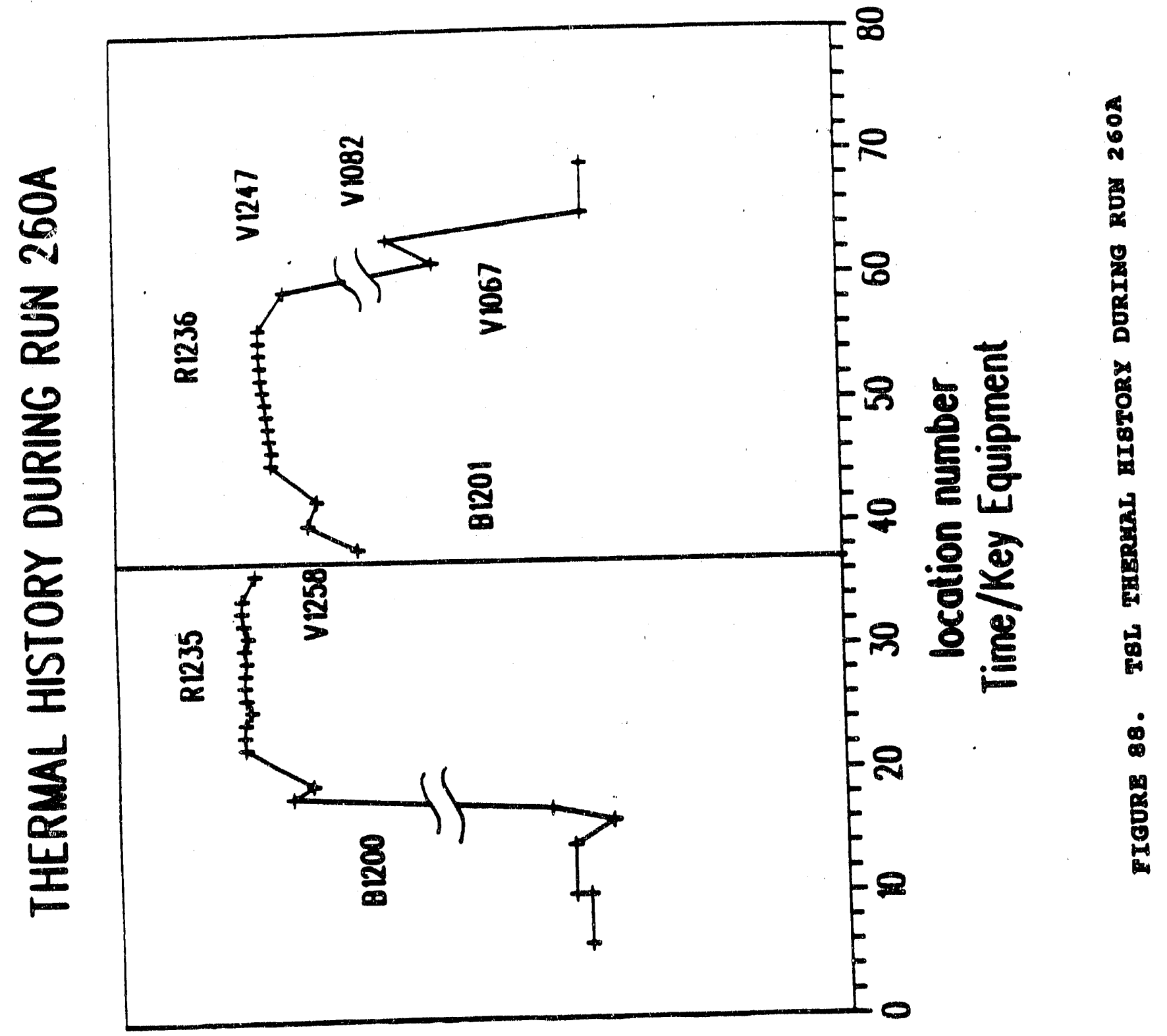

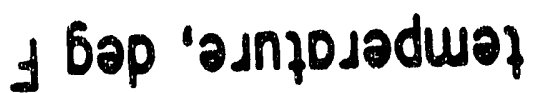




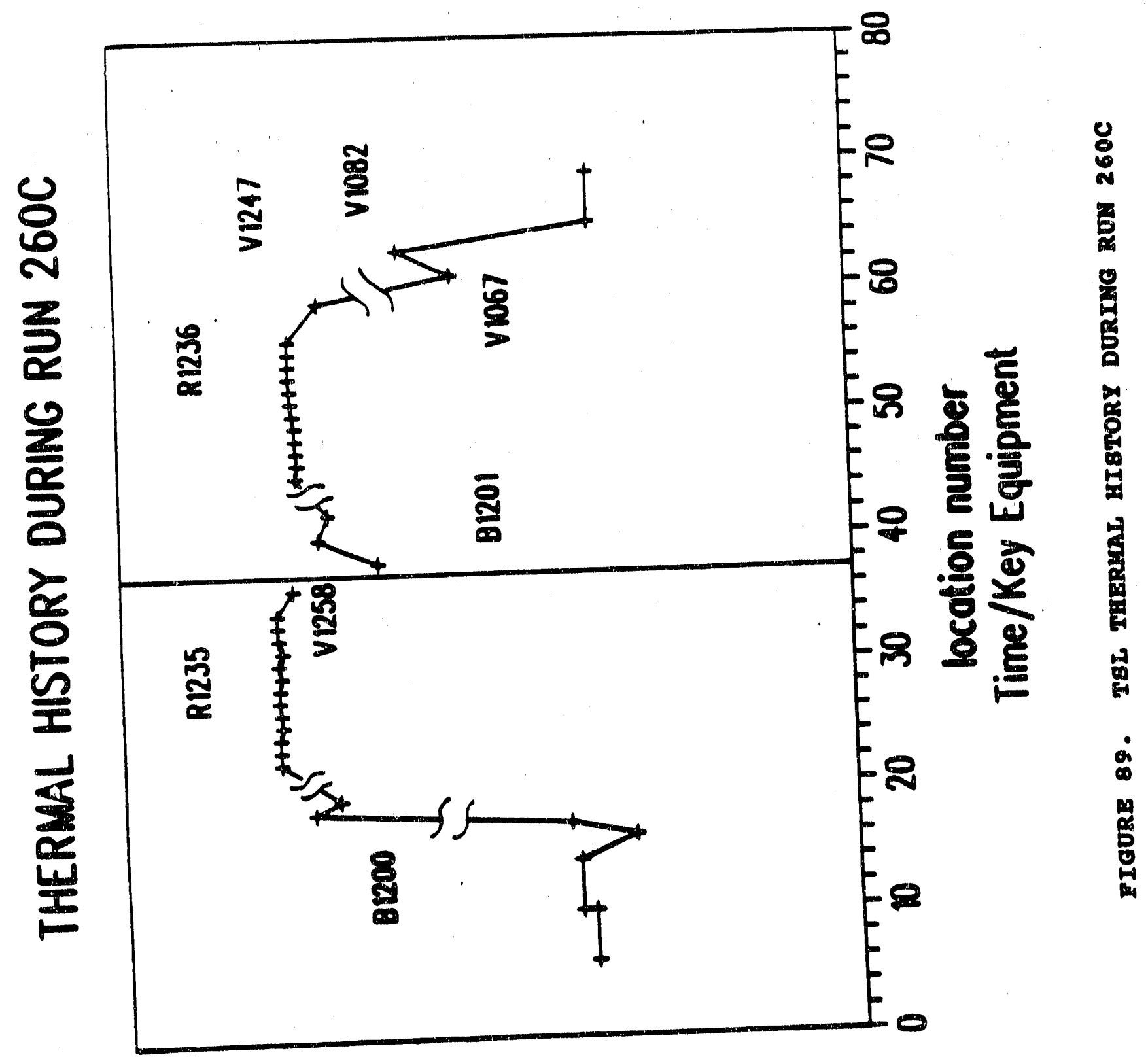

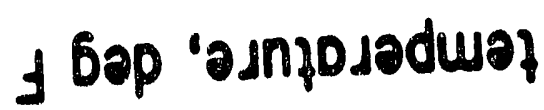


NOTES: Thermal histories during Periods $D-F$ and Novembex 10-13 in Run 260 are illustrated by using temperature profile and approximate relative residence time through TSL process system. These perlods operated without an interstage separator. process times for slurry blend and feed tanks, and process solvent storage tank were significantly reduced for illustration.

Key Equipment

V101A

V101B

B1200

R.1236

B1201

R1235

V1247

V1069

V1082

V131.B
Location Number

$$
\begin{gathered}
6-10 \\
10-14 \\
16-18 \\
19-34 \\
38-40 \\
42-57 \\
59 \\
61 \\
63 \\
65-69
\end{gathered}
$$

Description

slurry blend tank slurry feed tank preheater 1st stage reactor intersiage heater 2nd stage reactor high press. separator atm. flash vessel vac. flash vessel process sol. storage

(For Figures 90, 91 and 92) 


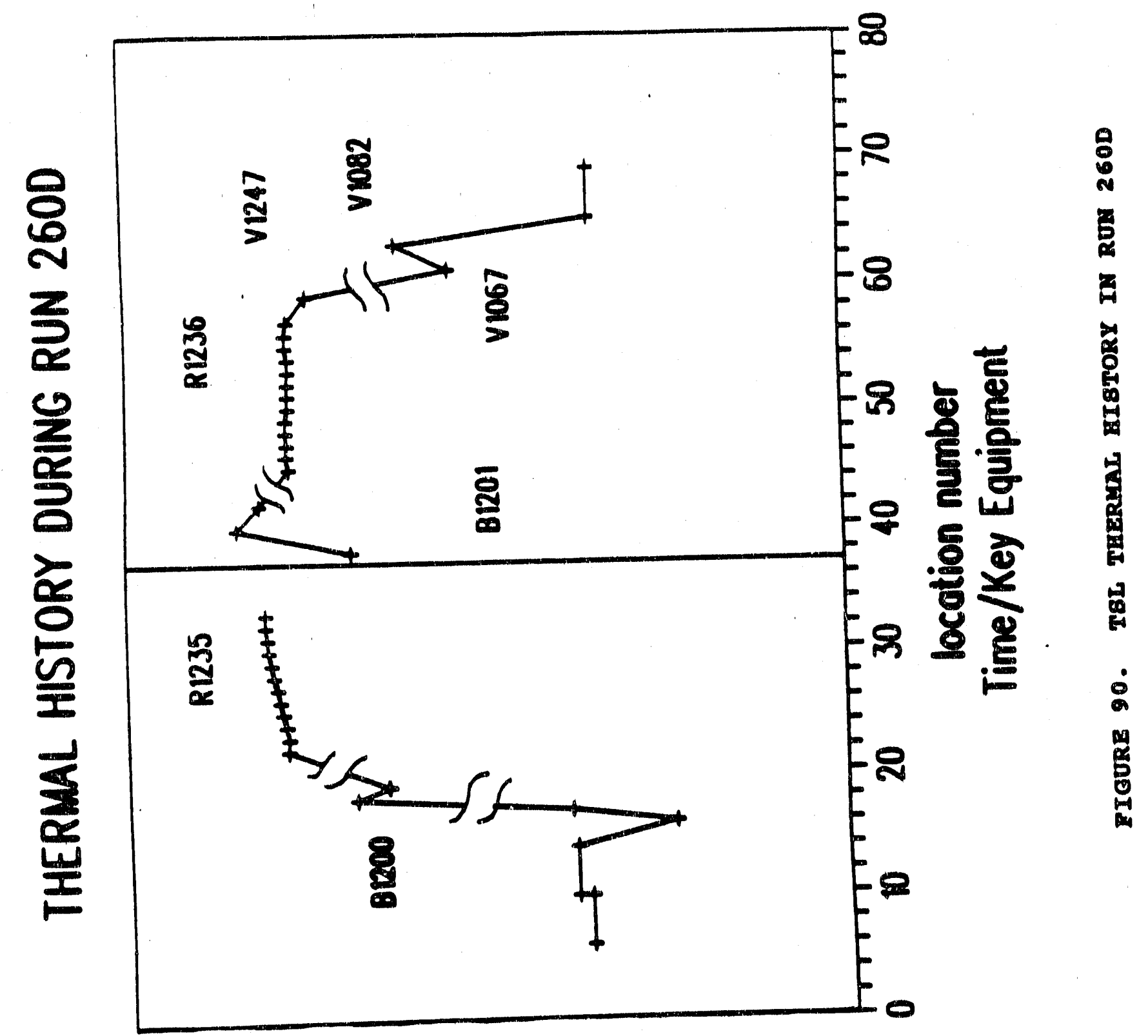

I Gop 'asnjojodwor 


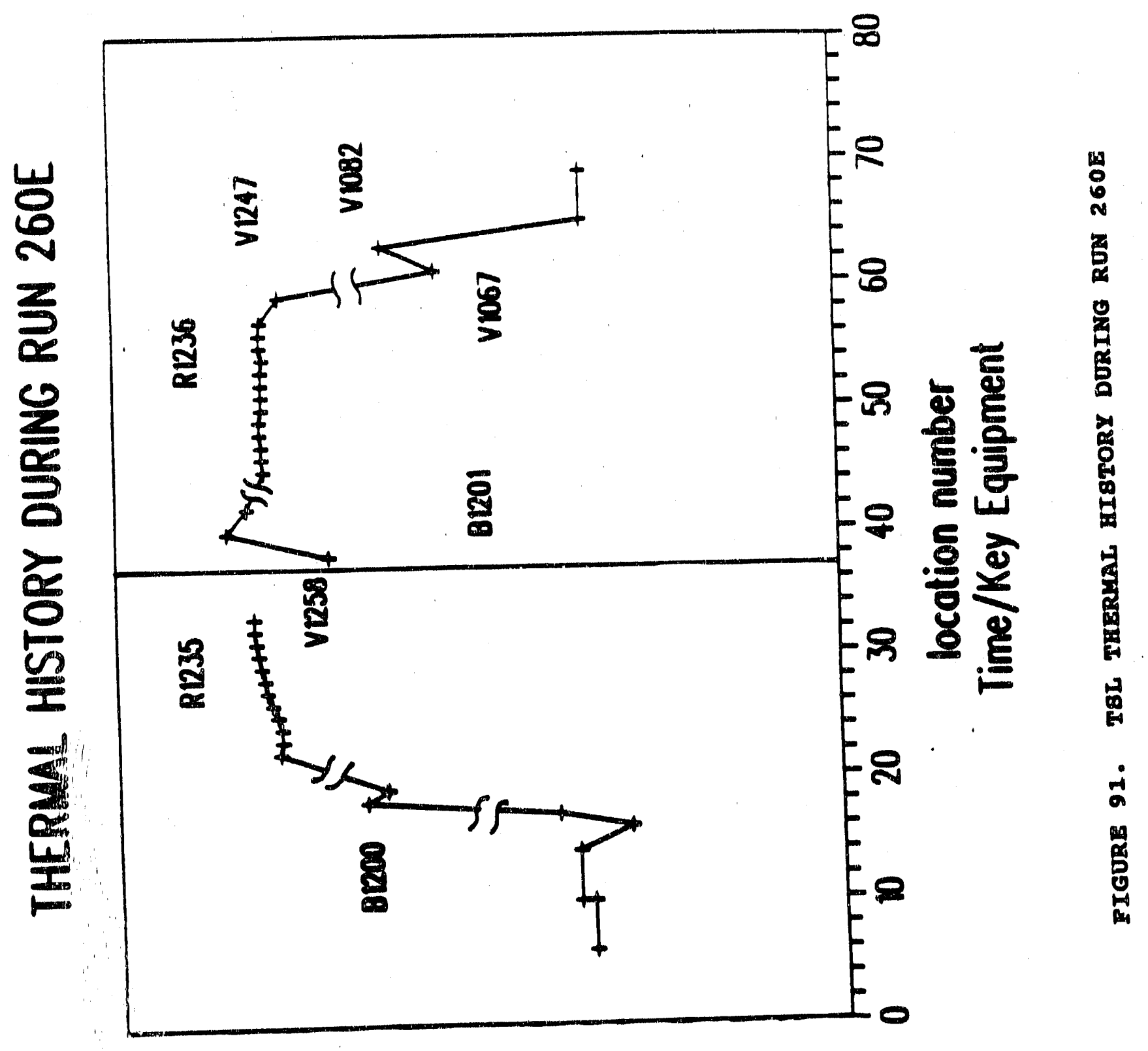

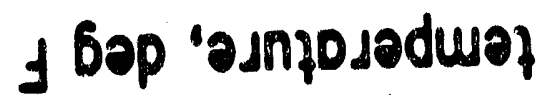




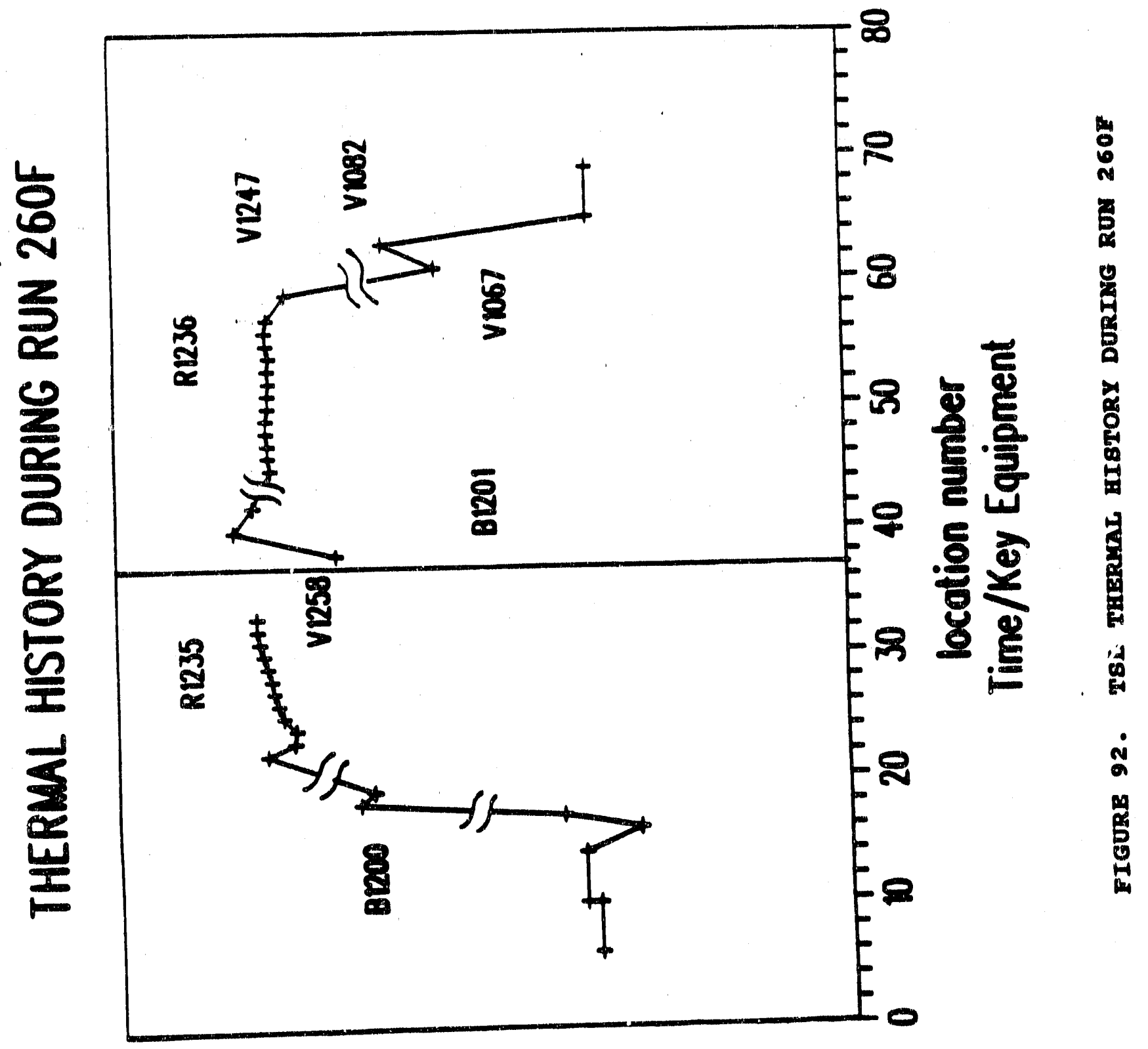

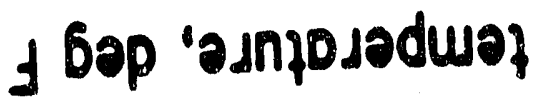




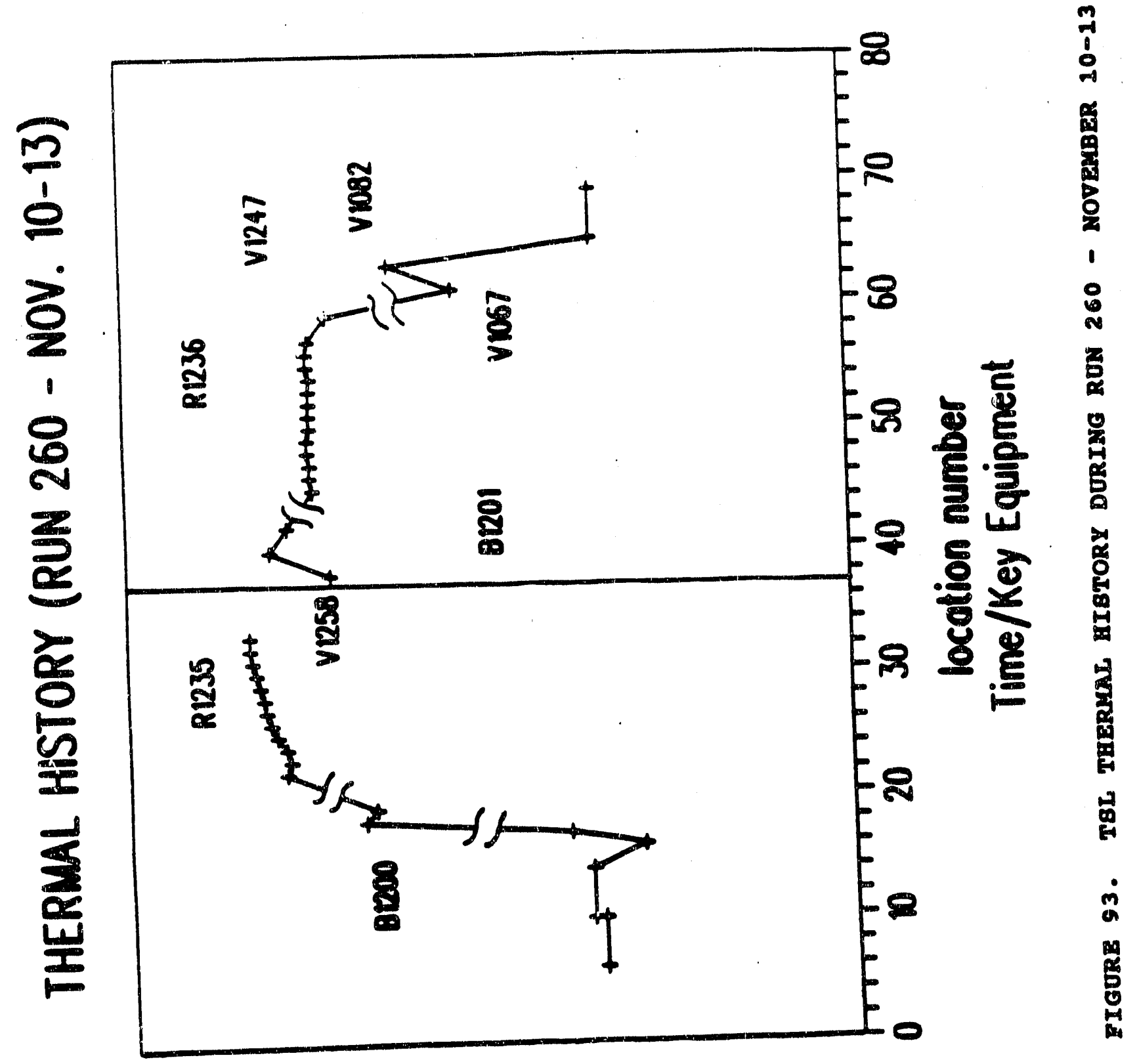

I 6op samp̧ododus? 


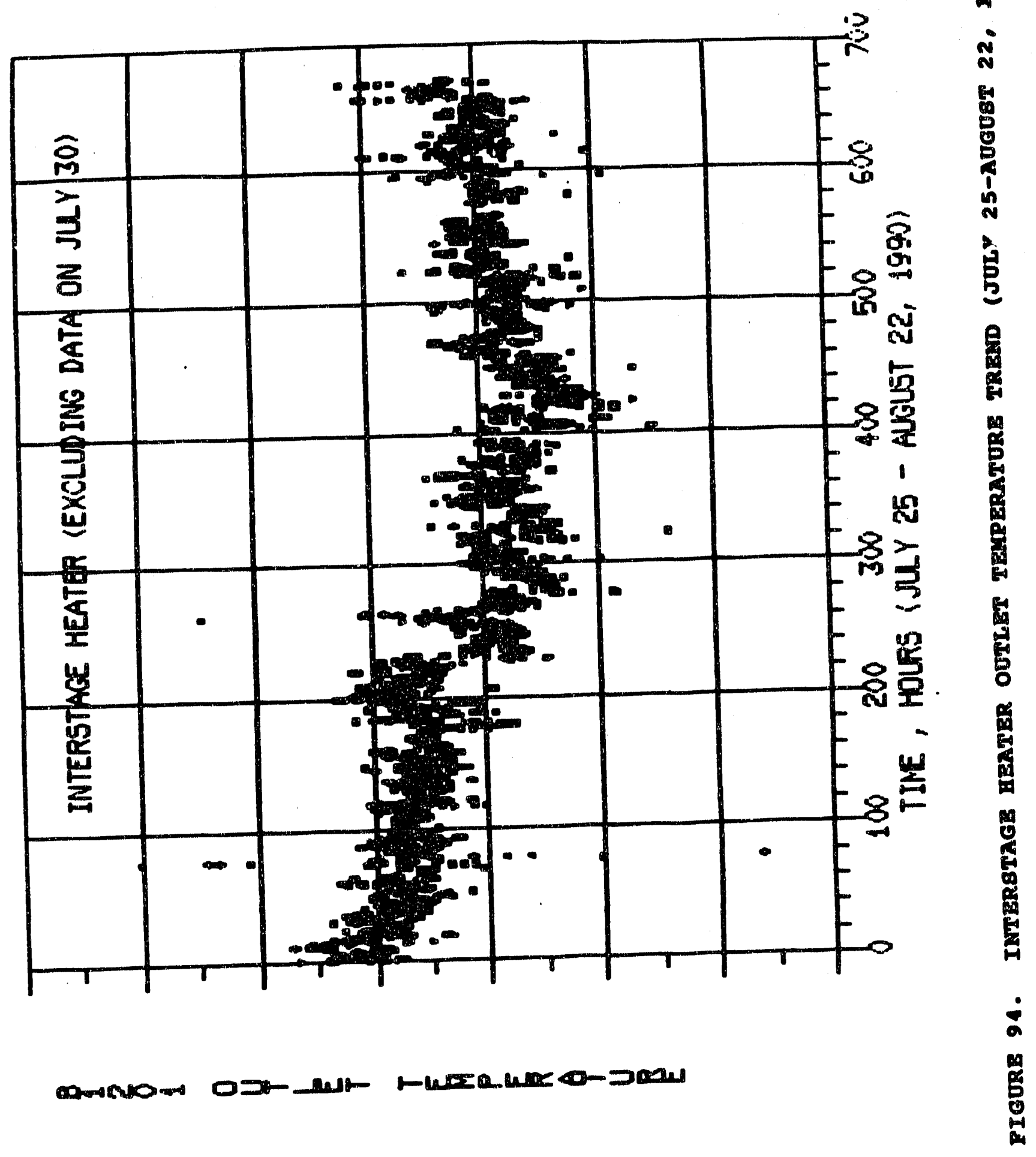




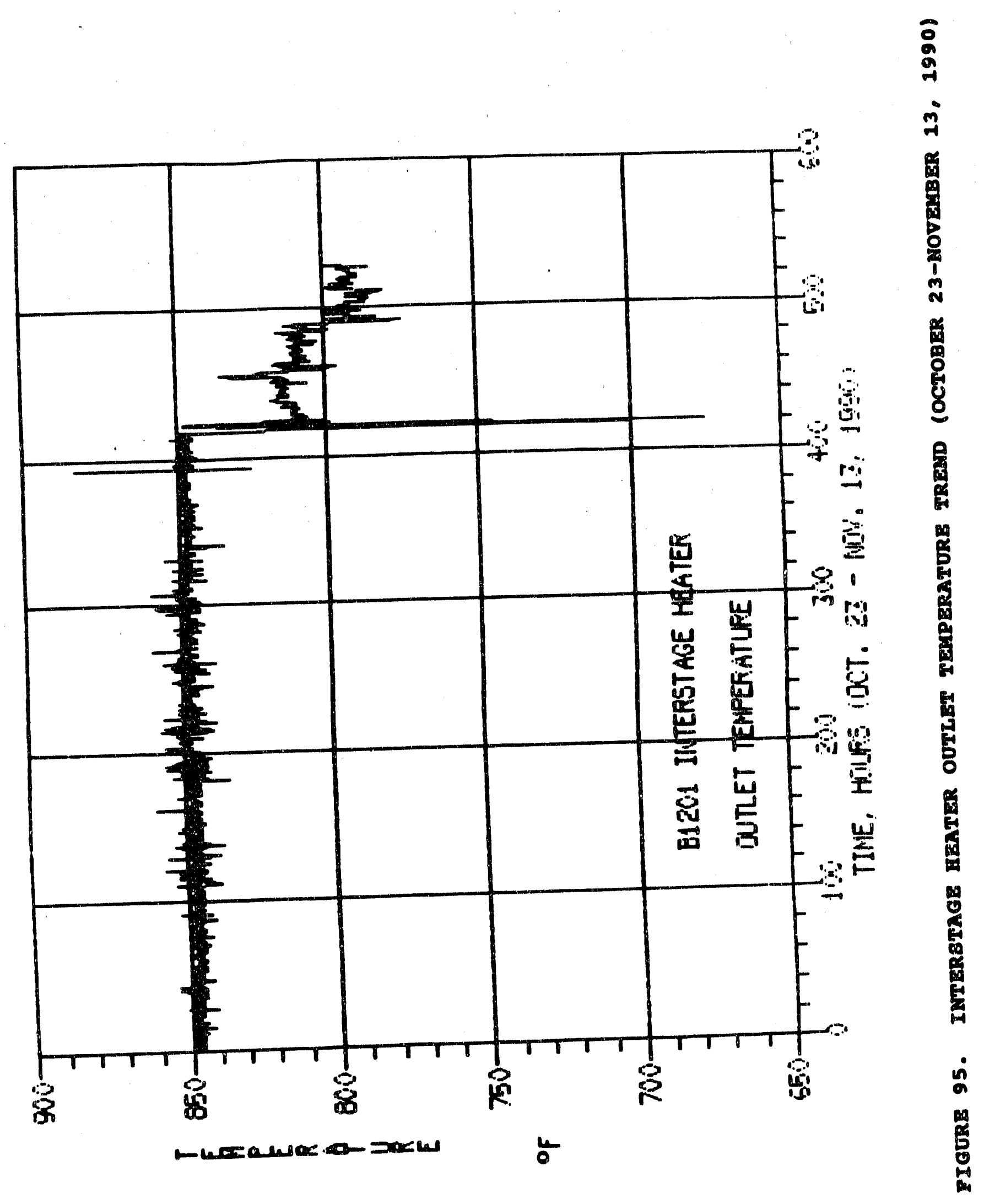




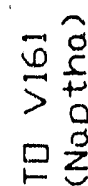

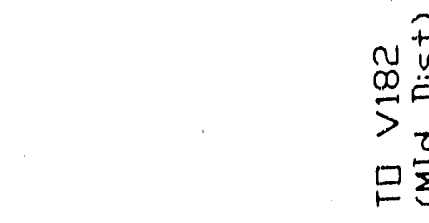

草

豆

章
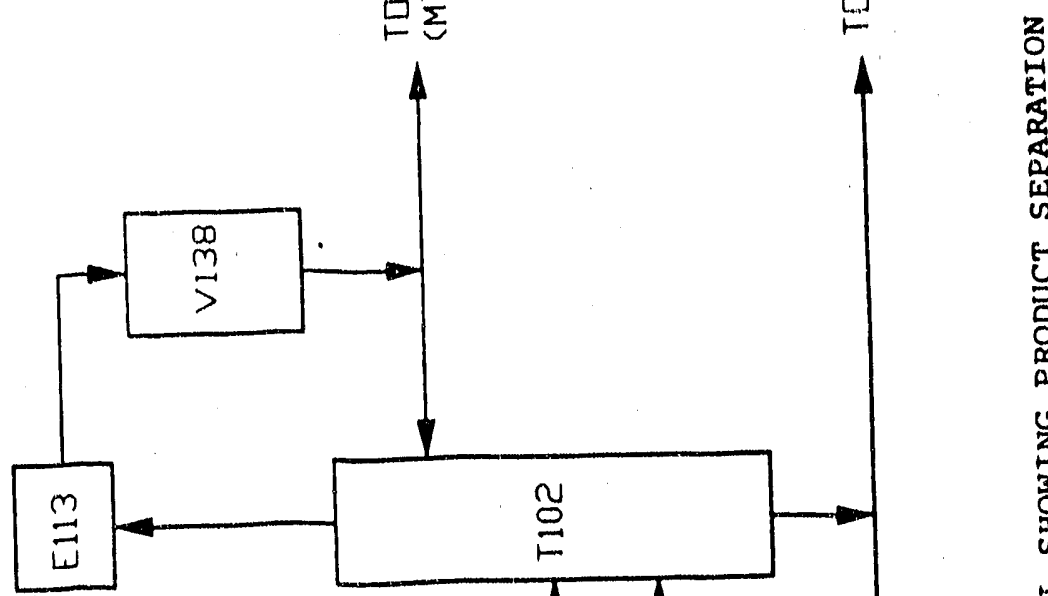

을

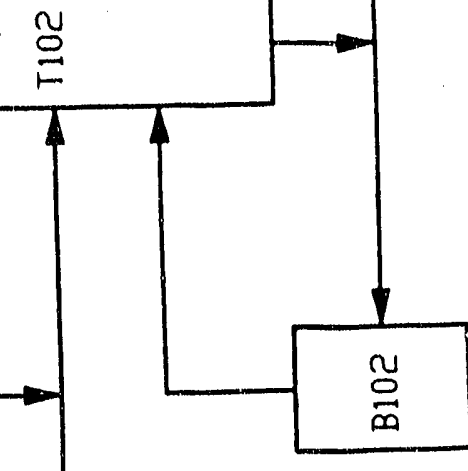

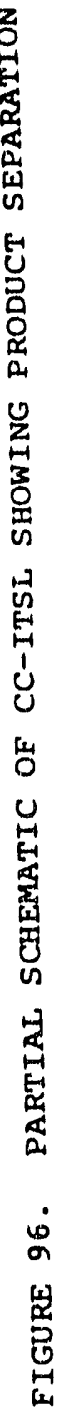



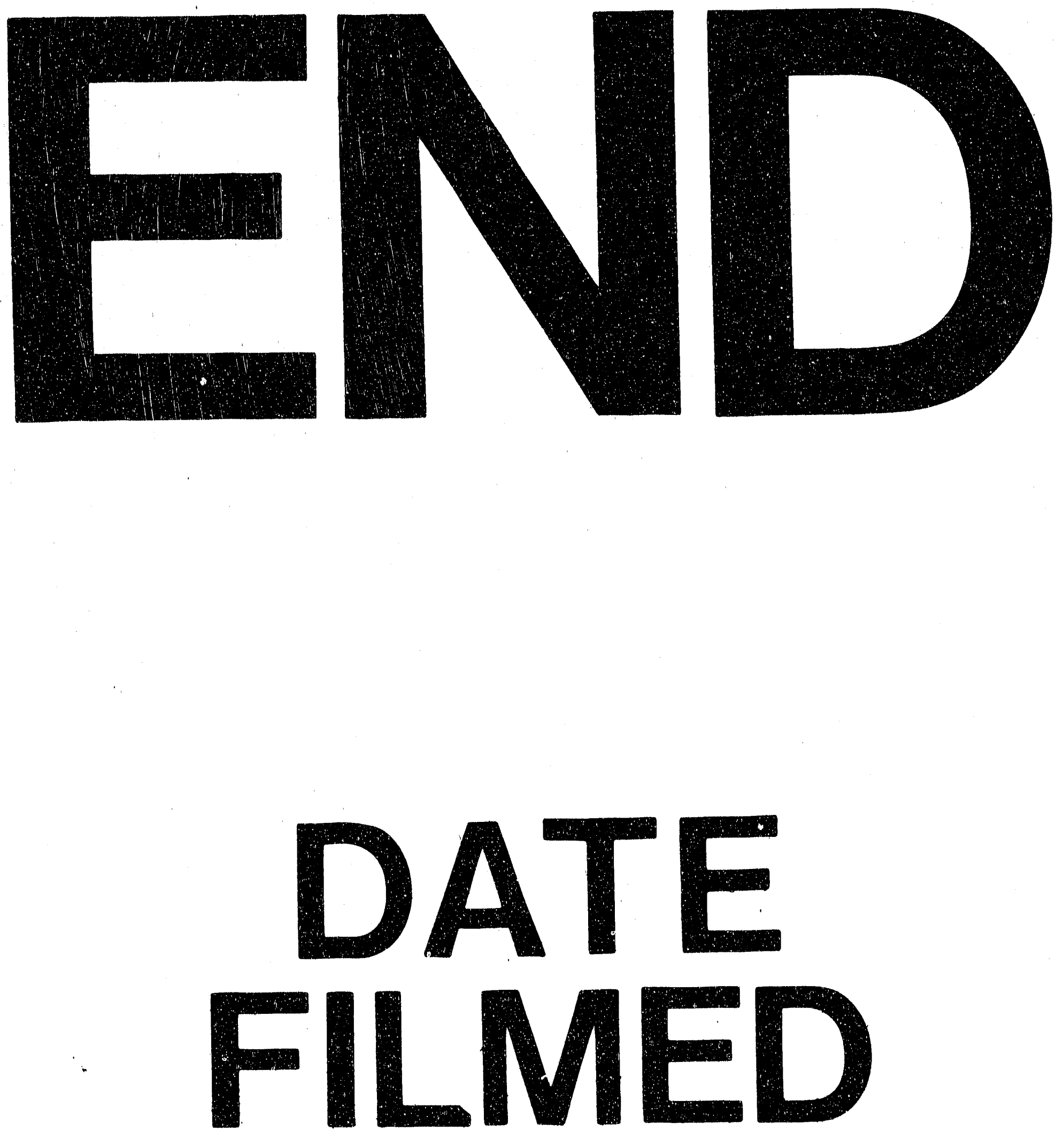

1

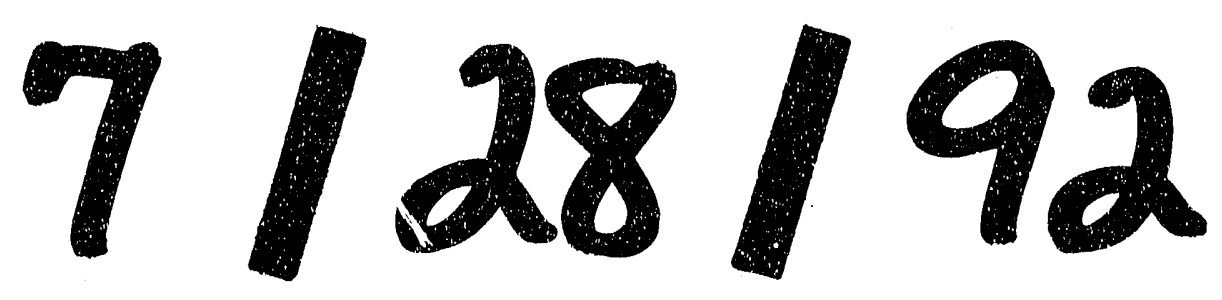


